\title{
PUNÇÃO EM LAJES: EXEMPLOS DE CÁLCULO E ANÁLISE TEÓRICO- EXPERIMENTAL
}

JOSÉ LUIZ PINHEIRO MELGES

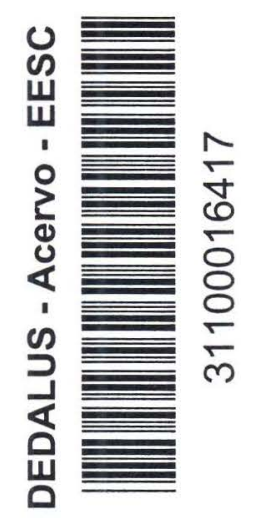

Dissertação apresentada à Escola de Engenharia de São Carlos, da Universidade de São Paulo, como parte dos requisitos para obtenção do Título de Mestre em Engenharia de Estruturas

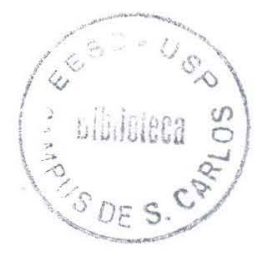


Melges, José Luiz Pinheiro

M469p Punção em lajes: exemplos de cálculo e análise teórico-experimental / José Luiz Pinheiro Melges. --São Carlos, 1995. 217 p.

Dissertação (Mestrado) -- Escola de Engenharia de São CarlosUniversidade de São Paulo, 1995.

Orientador: Prof.Dr. Libânio Miranda Pinheiro

1. Lajes (concreto armado) - Punção. I. Título. 
À minha esposa Ana Célia e ao meu filho Mateus

(estrelas guias da minha existência) 


\section{AGRADECIMENTOS}

A Deus, fonte de todo o amor e sabedoria.

Ao Professor Libânio Miranda Pinheiro, pela zelosa orientação, incentivo e apoio durante a execução deste trabalho.

Ao Professor Samuel Giongo, pela sua dedicação à profissão.

Aos Professores Toshiaki Takeya e Walter Savassi, pelas explicações referentes a ensaios de modelos em laboratório e a alguns dos parâmetros geométricos mencionados pelo texto base, respectivamente.

Ao Professor Ronaldo Gomes, da Universidade Federal de Goiânia, pela gentileza de ter-me enviado sua Tese de Doutorado.

Ao Professor Jasson Rodrigues Figueiredo Filho, pelo empréstimo de material referente aos ensaios experimentais.

À Bibliotecária Maria Nadir Minatel, pela sua dedicação e eficiência e à Desenhista Silvia Helena M. Villani, pela qualidade e presteza na confecção das figuras.

À CAPES, pela bolsa de estudos.

Aos meus familiares, especialmente meus pais e sogros, pelo incentivo e apoio.

Aos professores da Escola de Engenharia de São Carlos, especialmente aos do Departamento de Engenharia de Estruturas, responsáveis pela minha formação profissional.

A todos que direta ou indiretamente contribuíram na realização deste trabalho. 


\section{SUMÁRIO}

LISTA DE FIGURAS....................................................................... i

LISTA DE TABELAS......................................................................... $\mathrm{v}$

LISTA DE SIGLAS ................................................................................. vi

LISTA DE SÍMBOLOS................................................................ vii

RESUMO

xxvi

ABSTRACT.

xxvii

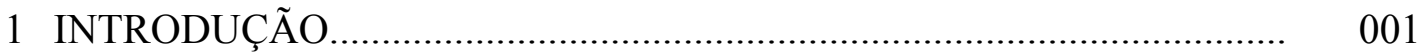

1.1 GENERALIDADES ................................................................. 001

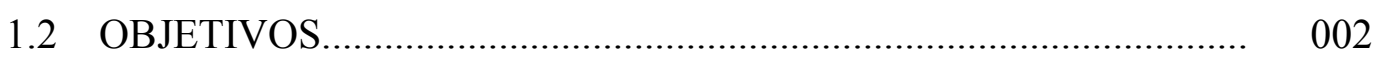

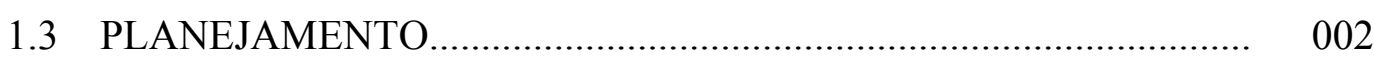

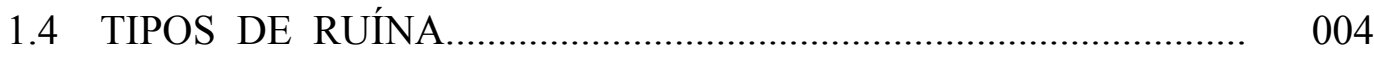

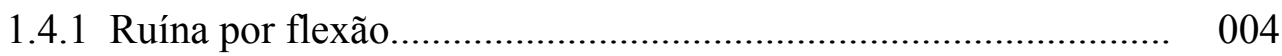

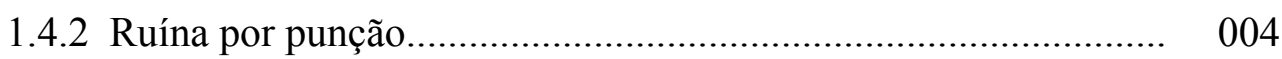

1.4.3 Ruína por flexão associada à punção............................................ 005

1.4.4 Comportamento na punção....................................................... 005

1.5 USO DE CAPITÉIS...................................................................... 006

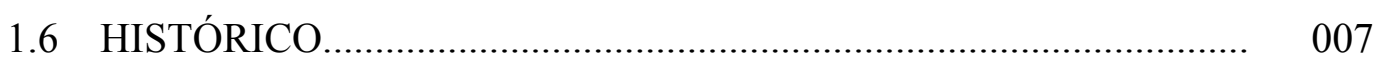

1.7 PESQUISAS EM SÃO CARLOS.................................................. 012

1.8 MÉTODOS NUMÉRICOS........................................................... 014

1.9 VANTAGENS DAS LAJES-COGUMELO........................................ 016

1.10 DESVANTAGENS DAS LAJES-COGUMELO................................. 017

1.11 ASSOCIAÇÃO COM OUTROS SISTEMAS ESTRUTURAIS.............. 018

1.11.1 Lajes-cogumelo aliviadas.......................................................... 018

1.11.2 Lajes-cogumelo protendidas..................................................... 018

1.11.3 Lajes-cogumelo com vigas nas bordas........................................ 019

1.11.4 Associação com sistemas pré-moldados....................................... 020

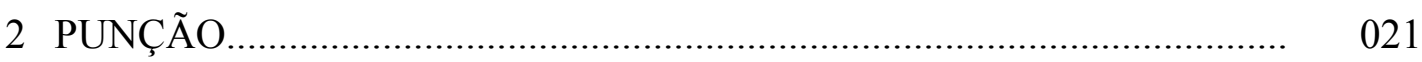

2.1 ANÁLISE DO FENÔMENO DA PUNÇÃO..................................... 021 
2.2 SUPERFÍCIE DE RUÍNA............................................................. 025

2.2.1 Com relação à posição do pilar................................................... 025

2.2.2 Com relação à presença de armadura transversal............................. 027

2.3 PARÂMETROS ENVOLVIDOS.................................................... 028

2.4 ARMADURAS DE COMBATE À PUNÇÃO................................... 029

2.4.1 Placa metálica.......................................................................... 029

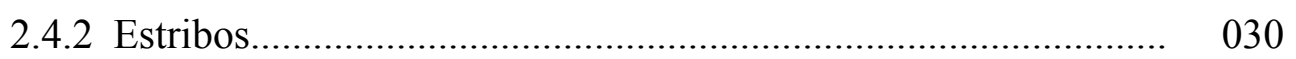

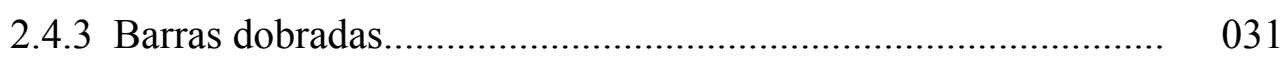

2.4.4 "Shearheads" ....................................................................... 032

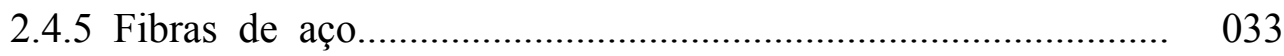

2.4.6 Conectores tipo pino............................................................... 034

2.4.7 Segmentos de perfis metálicos................................................. 035

2.5 MODELOS DE CÁLCULO........................................................ 035

2.5.1 Modelo da superfície de controle............................................. 035

2.5.2 Outros modelos...................................................................... 037

3 TEXTO BASE DA NB-1/94............................................................... 038

3.1 APRESENTAÇÃO E COMENTÁRIOS............................................ 038

3.2 OBSERVAÇÕES GERAIS............................................................. 060

4 EXEMPLOS SEGUNDO O TEXTO BASE DA NB-1/94......................... 061

4.1 PILAR INTERNO SEM ARMADURA DE PUNÇÃO........................ 061

4.1.1 Tensão atuante de cálculo........................................................ 062

4.1.2 Tensão resistente de cálculo....................................................... 063

4.2 PILAR INTERNO COM ARMADURA DE PUNÇÃO....................... 064

4.2.1 Verificação da compressão no concreto...................................... 065

4.2.2 Verificação da região armada..................................................... 066

4.2.3 Verificação além da região armada.............................................. 067

4.3 PILAR DE BORDA SEM ARMADURA DE PUNÇÃO.................... 071

4.3.1 Tensão atuante de cálculo....................................................... 072

4.3.2 Tensão resistente de cálculo....................................................... 073

4.4 PILAR DE BORDA COM ARMADURA DE PUNÇÃO................... 074

4.4.1 Verificação da compressão no concreto..................................... 074

4.4.2 Verificação da região armada.................................................... 075

4.4.3 Verificação além da região armada............................................. 076 
4.5 PILAR DE CANTO SEM ARMADURA DE PUNÇÃO.................... 081

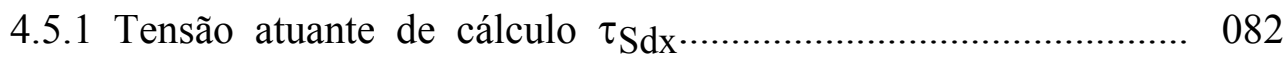

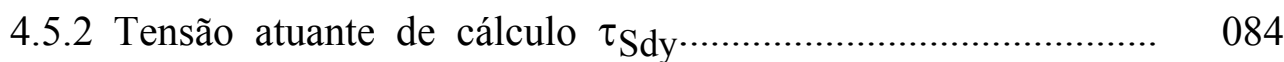

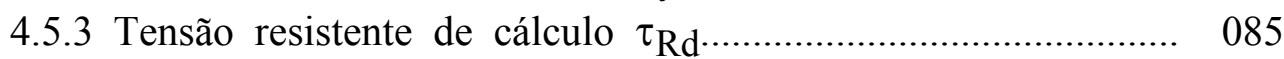

4.6 PILAR DE CANTO COM ARMADURA DE PUNÇÃO.................. 085

4.6.1 Verificação da compressão no concreto....................................... 086

4.6.2 Verificação da região armada................................................... 087

4.6.3 Verificação além da região armada........................................... 087

4.7 COLAPSO PROGRESSIVO....................................................... 091

4.7.1 Pilar interno........................................................................... 092

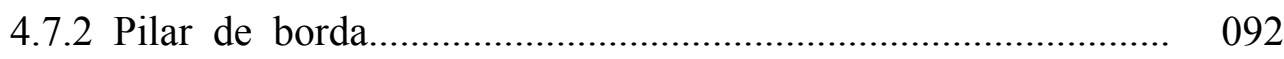

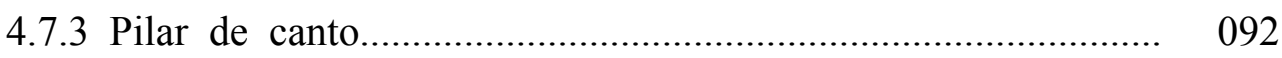

4.8 OBSERVAÇÕES GERAIS............................................................ 092

5 EXEMPLOS SEGUNDO O EUROCODE N.2 (1992).............................. 094

5.1 PILAR INTERNO SEM ARMADURA DE PUNÇÃO........................ 095

5.1.1 Primeira verificação................................................................... 096

5.1.2 Segunda verificação.................................................................. 098

5.2 PILAR INTERNO COM ARMADURA DE PUNÇÃO....................... 098

5.2.1 Primeira verificação................................................................ 099

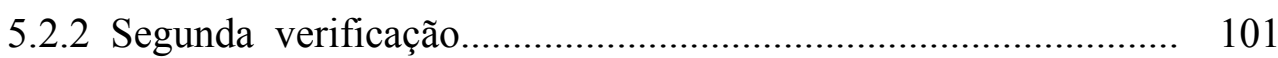

5.2.3 Terceira verificação................................................................... 106

5.3 PILAR DE BORDA SEM ARMADURA DE PUNÇÃO.................... 107

5.3.1 Primeira verificação................................................................. 109

5.3.2 Segunda verificação................................................................. 109

5.4 PILAR DE BORDA COM ARMADURA DE PUNÇÃO................... 109

5.4.1 Primeira verificação................................................................ 110

5.4.2 Segunda verificação.............................................................. 112

5.4.3 Terceira verificação................................................................... 115

5.5 PILAR DE CANTO SEM ARMADURA DE PUNÇÃO.................... 116

5.5.1 Primeira verificação................................................................. 117

5.5.2 Segunda verificação..................................................................... 118

5.6 PILAR DE CANTO COM ARMADURA DE PUNÇÃO.................. 118

5.6.1 Primeira verificação................................................................... 119

5.6.2 Segunda verificação.............................................................. 120

5.6.3 Terceira verificação............................................................... 122 
5.7 OBSERVAÇÕES GERAIS............................................................... 123

6 EXEMPLOS SEGUNDO O CEB/90....................................................... 125

6.1 PILAR INTERNO SEM ARMADURA DE PUNÇÃO........................ 126

6.1.1 Primeira verificação................................................................ 126

6.1.2 Segunda verificação................................................................... 128

6.2 PILAR INTERNO COM ARMADURA DE PUNÇÃO....................... 129

6.2.1 Primeira verificação.................................................................. 129

6.2.2 Segunda verificação................................................................ 130

6.2.3 Terceira verificação............................................................... 131

6.2.4 Verificações adicionais................................................................ 132

6.3 PILAR DE BORDA SEM ARMADURA DE PUNÇÃO.................... 134

6.3.1 Primeira verificação................................................................. 134

6.3.2 Segunda verificação............................................................... 136

6.4 PILAR DE BORDA COM ARMADURA DE PUNÇÃO................... 136

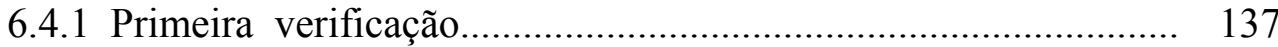

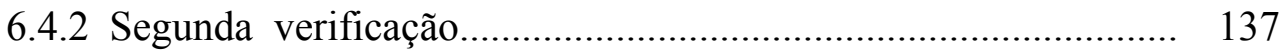

6.4.3 Terceira verificação................................................................ 138

6.4.4 Verificações adicionais.................................................................. 139

6.5 PILAR DE CANTO SEM ARMADURA DE PUNÇÃO.................... 140

6.5.1 Primeira verificação.............................................................. 140

6.5.2 Segunda verificação................................................................. 142

6.6 PILAR DE CANTO COM ARMADURA DE PUNÇÃO.................. 142

6.6.1 Primeira verificação................................................................... 143

6.6.2 Segunda verificação.................................................................... 143

6.6.3 Terceira verificação.................................................................. 144

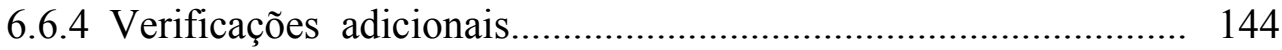

6.7 COLAPSO PROGRESSIVO........................................................... 145

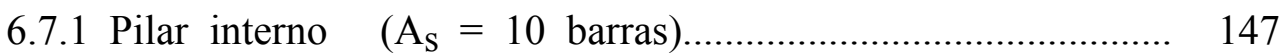

6.7.2 Pilar de borda $\left(\mathrm{A}_{\mathrm{S}}=8\right.$ barras) ............................................ 147

6.7.3 Pilar de canto $\left(\mathrm{A}_{\mathrm{S}}=5\right.$ barras)............................................. 147

6.8 OBSERVAÇÕES GERAIS............................................................ 147

7 EXEMPLOS SEGUNDO O ACI 318/89................................................. 149

7.1 RECOMENDAÇÕES DO ACI 318/89........................................... 149

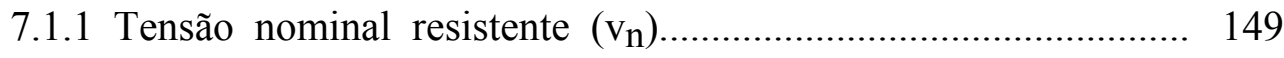

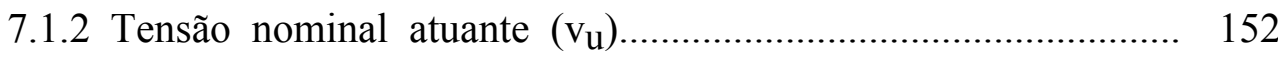


7.2 PILAR INTERNO SEM ARMADURA DE PUNÇÃO........................ 157

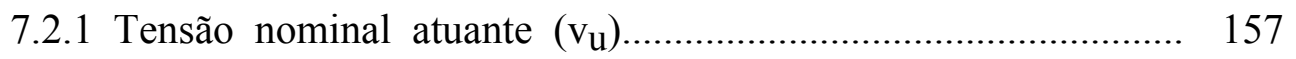

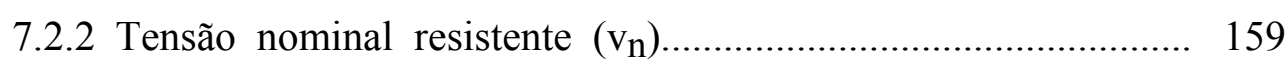

7.2.3 Comparação das tensões............................................................. 160

7.3 PILAR INTERNO COM ARMADURA DE PUNÇÃO....................... 160

7.3.1 Seção crítica a d/2 do pilar..................................................... 161

7.3.2 Seção crítica a d/2 da região armada........................................ 162

7.4 PILAR DE BORDA SEM ARMADURA DE PUNÇÃO.................... 165

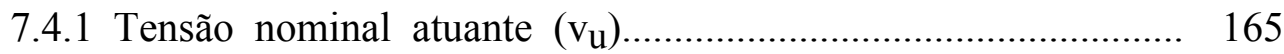

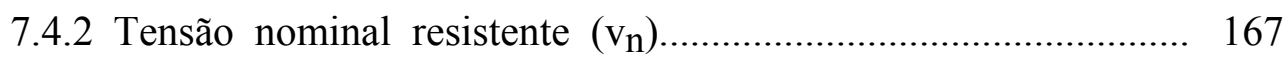

7.4.3 Comparação das tensões............................................................ 168

7.5 PILAR DE BORDA COM ARMADURA DE PUNÇÃO................... 168

7.5.1 Seção crítica a d/2 do pilar....................................................... 168

7.5.2 Seção crítica a d/2 da região armada........................................ 169

7.6 PILAR DE CANTO SEM ARMADURA DE PUNÇÃO.................... 171

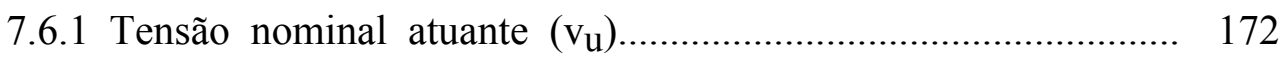

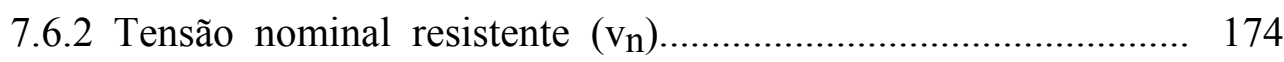

7.6.3 Comparação das tensões........................................................... 174

7.7 PILAR DE CANTO COM ARMADURA DE PUNÇÃO.................. 174

7.7.1 Seção crítica a $\mathrm{d} / 2$ do pilar....................................................... 175

7.7.2 Seção crítica a d/2 da região armada....................................... 176

7.8 OBSERVAÇÕES GERAIS............................................................ 178

8 COMPARAÇÃO COM RESULTADOS EXPERIMENTAIS........................ 180

8.1 ENSAIOS PARA PILARES DE CANTO....................................... 181

8.1.1 Ensaio de MARTINELLI (1974)........................................... 181

8.1.2 Ensaio de STAMENKOVIC; CHAPMAN (1974)..................... 185

8.2 ENSAIOS PARA PILARES DE BORDA........................................ 186

8.2.1 Ensaio de TAKEYA (1981) ................................................... 186

8.2.2 Ensaio de MODOTTE (1986)............................................. 189

8.2.3 Ensaio de STAMENKOVIC; CHAPMAN (1974).................... 192

8.2.4 Ensaio de LIBÓRIO (1985).................................................. 194

8.3 ENSAIOS PARA PILARES INTERNOS.......................................... 197

8.3.1 Ensaio de GOMES et al. (1994)............................................ 197

8.3.2 Ensaio de STAMENKOVIC; CHAPMAN (1974).................... 199

8.3.3 Ensaio de GOMES (1991)..................................................... 201 
9 CONCLUSÕES

9.1 TEXTO BASE DA NB-1/94......................................................... 207

9.2 COMPARAÇÃO COM VALORES EXPERIMENTAIS...................... 209

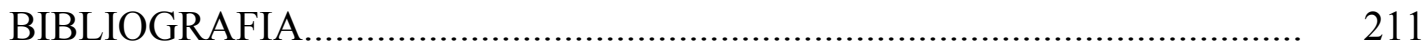




\section{LISTA DE FIGURAS}

Figura 1.1 - Laje-cogumelo........................................................................... 001

Figura 1.2 - Superfície de ruína........................................................................ 005

Figura 1.3 - Capitel................................................................................... 006

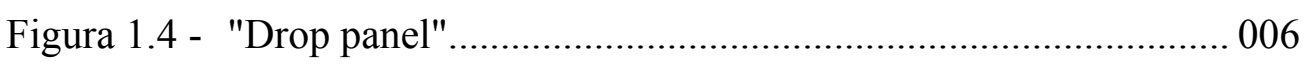

Figura 1.5 - Uso conjugado de "drop panel" e capitel........................................ 006

Figura 1.6 - Modos de ruína observados por Nylander....................................... 010

Figura 1.7 - Variação da relação dos lados do pilar............................................ 013

Figura 1.8 - Método dos Elementos de Contorno x Método dos Elementos

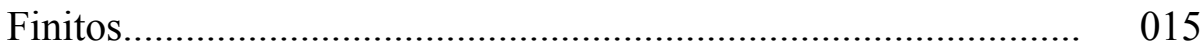

Figura 1.9 - Laje-cogumelo nervurada ("waffle slab")..................................... 018

Figura 1.10 - Efeito da protensão................................................................. 019

Figura 1.11 - Laje-cogumelo com vigas nas bordas........................................... 019

Figura 1.12 - "Lift Slab"........................................................................... 020

Figura 2.1 - Para carga de utilização................................................................ 022

Figura 2.2 - Para carga de ruína...................................................................... 022

Figura 2.3 - Rotação dos segmentos da laje.................................................... 022

Figura 2.4 - "Elementos-de-laje" (TAKEYA, 1981)......................................... 024

Figura 2.5 - Esforços atuantes em um "elemento-de-laje"................................... 024

Figura 2.6 - Variação da força cortante.............................................................. 024

Figura 2.7 - Superfície de ruína para casos simétricos...................................... 025

Figura 2.8 - Superfície de ruína para pilares de canto e borda ........................... 026

Figura 2.9 - Superfícies prováveis de ruína........................................................ 027

Figura 2.10 - Placa metálica......................................................................... 029

Figura 2.11 - Tipos de estribos.................................................................. 030

Figura 2.12 - Inclinação dos estribos............................................................ 030

Figura 2.13 - Detalhe da ancoragem dos ganchos................................................ 031

Figura 2.14 - Ancoragem dos estribos.......................................................... 031

Figura 2.15 - Barras dobradas...................................................................... 032

Figura 2.16 - "Shearheads" ......................................................................... 033

Figura 2.17 - Detalhe dos conectores.............................................................. 034

Figura 2.18 - Ancoragem dos conectores........................................................ 035 
Figura 2.19- Segmentos de perfis metálicos "I" ........................................... 035

Figura 2.20 - Superfície de controle............................................................ 036

Figura 2.21 - Perímetro.......................................................................... 037

Figura 2.22 - Altura......................................................................... 037

Fig. 19.3.1 - Perímetro crítico em pilares internos.......................................... 039

Fig. 19.3.2- Esquema dos esforços na ligação laje-pilar................................... 041

Fig. 19.3.3- Distribuição devida a um momento de transferência da laje ao pilar............................................................................... 041

Fig. 19.3.4- Perímetro crítico em pilares de borda............................................ 043

Figura extra 1 - Excentricidade do perímetro crítico reduzido......................... 044

Fig. 19.3.5- Perímetro crítico em pilares de canto............................................ 045

Figura extra 2 - Esquema para se considerar cada borda livre.......................... 046

Figura extra 3 - Esquema para cálculo de $W_{P 1}$ e de $e^{*}$.................................... 047

Fig. 19.3.6- Definição da altura útil no caso de capitel.................................... 048

Fig. 19.3.7- Perímetro crítico no caso do contorno C apresentar reentrância...... 048

Fig. 19.3.8- Perímetro crítico junto a abertura na laje....................................... 049

Figura extra 4 - Pilares próximos a bordas livres........................................... 049

Figura extra 5 - Definição de $A_{S w}$, referente a uma linha homotética ao pilar.... 053

Fig. 19.3.9- Disposição da armadura de punção em planta............................... 054

Figura extra 6 - Perímetro crítico externo $\mu_{n}$ (disposição em cruz)................. 055

Fig. 19.3.10 - Disposição da armadura de punção em corte................................. 055

Figura extra 7 - Ancoragem......................................................................... 056

Figura extra 8 - Armadura de punção para pilares de borda e de canto........... 057

Fig. 19.3.11 - Detalhe dos conectores................................................................ 057

Fig. 19.3.12 - Efeito favorável dos cabos inclinados....................................... 059

Fig. 19.3.13 - Armadura contra colapso progressivo........................................ 060

Figura 4.1 - Geometria e momentos fletores.................................................. 062

Figura 4.2 - Armadura de flexão (unidades em cm)....................................... 062

Figura 4.3 - Notação (unidades em cm)........................................................ 063

Figura 4.4 - Disposição dos conectores (unidades em $\mathrm{cm}$ )............................... 065

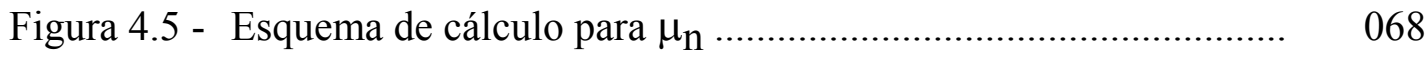

Figura 4.6 - Esquema de cálculo para $\mathrm{W}_{\mathrm{Pn}}$.................................................... 069

Figura 4.7 - Esquema de cálculo para W'Pn …............................................. 070 
Figura 4.8 - Geometria e momentos fletores............................................... 072

Figura 4.9 - Armadura de flexão (unidades em cm)...................................... 072

Figura 4.10 - Disposição dos conectores (unidades em cm)............................. 074

Figura 4.11 - Definição dos novos perímetros crítico e crítico reduzido................ 077

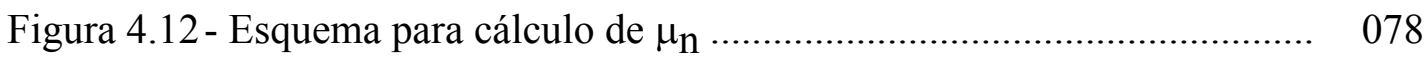

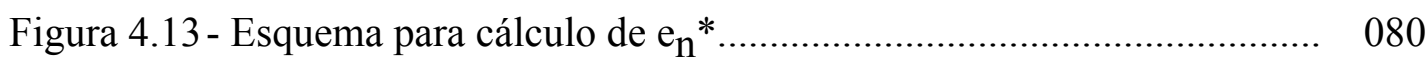

Figura 4.14 - Esquema para cálculo de $\mathrm{W}_{\mathrm{P} 2 \mathrm{n}}$............................................... 080

Figura 4.15 - Geometria e momentos fletores................................................. 082

Figura 4.16 - Armadura de flexão (unidades em cm)..................................... 082

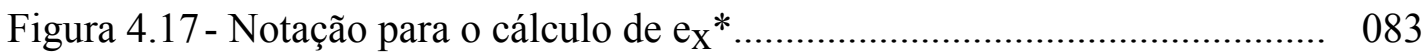

Figura 4.18 - Mudança da notação para o cálculo de $\mathrm{e}_{\mathrm{y}}{ }^{*}$................................. 084

Figura 4.19 - Disposição dos conectores............................................................ 086

Figura 4.20 - Novos perímetros crítico e crítico reduzido adotados (unidades em cm) ............................................................... 088

Figura 4.21 - Segmentos do perímetro crítico reduzido................................... 090

Figura 5.1 - Consideração do perímetro crítico para pilares alongados.............. 095

Figura 5.2 - Perímetro crítico (unidades em cm)............................................. 096

Figura 5.3 - Valores aproximados de $\beta$...................................................... 097

Figura 5.4 - Armadura de punção efetiva....................................................... 099

Figura 5.5 - Momentos fletores mSdx e mSdy.................................................... 102

Figura 5.6 - Detalhamento da armadura para pilares de borda e de canto......... 103

Figura 5.7 - Larguras efetivas das faixas analisadas........................................ 104

Figura 5.8 - Novo perímetro crítico............................................................ 107

Figura 5.9 - Perímetro crítico para pilares de borda (unidades em cm)........... 108

Figura 5.10 - Armadura de punção efetiva...................................................... 110

Figura 5.11 - Faixas de laje efetivas.............................................................. 112

Figura 5.12 - Armadura complementar........................................................ 114

Figura 5.13 - Armadura para borda livre de uma laje...................................... 114

Figura 5.14 - Novo perímetro crítico.............................................................. 116

Figura 5.15 - Perímetro crítico para pilar de canto (unidades em $\mathrm{cm}$ )................ 117

Figura 5.16 - Armadura de punção efetiva.......................................................... 119

Figura 5.17- Detalhamento da armadura necessária para resistir a $\mathrm{m}_{\mathrm{Sdx}}$

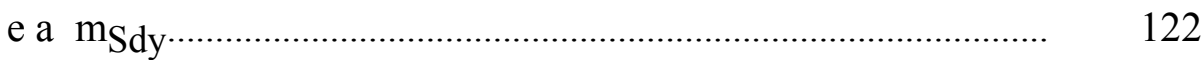

Figura 5.18 - Novo perímetro crítico............................................................. 123

Figura 6.1 - Perímetros crítico e crítico reduzido (unidades em cm)................. 135 
Figura 6.2 - Perímetros críticos para pilares de canto.

Figura 6.3 - Detalhes de ancoragem dados pelo CEB/90

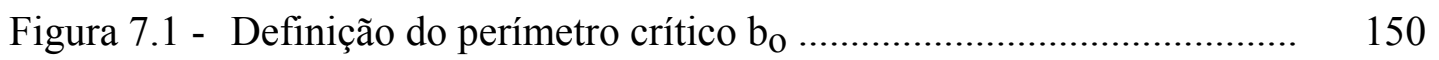

Figura 7.2 - Estribos........................................................................... 152

Figura 7.3 - Distribuição adotada para as tensões de cisalhamento................... 153

Figura 7.4 - Seções críticas externas à região armada (extraídas do ACI 318/89).155

Figura 7.5 - Perímetros críticos recomendados por ANDRADE; GOMES (1994a)............................................... 156

Figura 7.6 - Novo perímetro crítico referente a momentos fletores................... 156

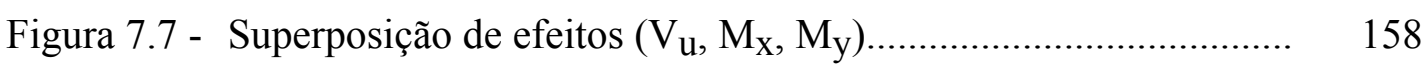

Figura 7.8 - Notação adotada para o cálculo da tensão nominal atuante............ 159

Figura 7.9 - Perímetro crítico U................................................................... 162

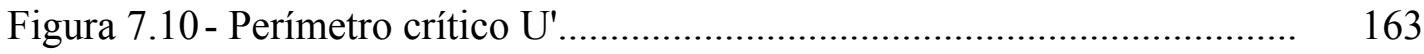

Figura 7.11 - Notação............................................................................... 167

Figura 7.12 - Perímetro crítico U..................................................................... 169

Figura 7.13 - Perímetro crítico $\mathrm{U}^{\prime}$..................................................................... 169

Figura 7.14 - Notação.................................................................................. 172

Figura 7.15 - Perímetro crítico U..................................................................... 176

Figura 7.16 - Perímetro crítico U'............................................................... 176

Figura 8.1 - Esquema do ensaio................................................................ 182

Figura 8.2 - Distribuição da armadura e excentricidade da força resultante........ 187

Figura 8.3 - Resultante no plano diagonal do pilar........................................... 190

Figura 8.4 - Resultante no plano paralelo à borda livre ................................. 190

Figura 8.5 - Representação dos modelos....................................................... 194

Figura 8.6 - Distribuição e tipo dos conectores.............................................. 197 


\section{LISTA DE TABELAS}

TABELA 19.3.1 - Valores de K 040

TABELA 5.1 - Valores de $\tau_{\mathrm{Rd}}$ 097

TABELA 5.2 - Valores de $\rho_{\mathrm{W}}$ 100

TABELA 5.3 - Valores de $\eta$ 103

TABELA 8.1 - MARTINELLI (1974) em valores absolutos. 182

TABELA 8.2 - MARTINELLI (1974) em valores relativos............................. 183

TABELA 8.3 - STAMENKOVIC; CHAPMAN (1974) em valores absolutos.... 185

TABELA 8.4 - STAMENKOVIC; CHAPMAN (1974) em valores relativos...... 185

TABELA 8.5 - TAKEYA (1981) em valores absolutos.................................. 187

TABELA 8.6 - TAKEYA (1981) em valores relativos.................................... 188

TABELA 8.7 - MODOTTE (1986) em valores absolutos............................... 190

TABELA 8.8 - MODOTTE (1986) em valores relativos................................. 191

TABELA 8.9 - STAMENKOVIC; CHAPMAN (1974) em valores absolutos... 193

TABELA 8.10 - STAMENKOVIC; CHAPMAN (1974) em valores relativos..... 193

TABELA 8.11 - LIBÓRIO (1985) em valores absolutos ................................. 194

TABELA 8.12 - LIBÓRIO (1985) em valores relativos..................................... 195

TABELA 8.13 - GOMES et al. (1994) em valores absolutos........................... 197

TABELA 8.14 - GOMES et al. (1994) em valores relativos............................ 198

TABELA 8.15 - STAMENKOVIC; CHAPMAN (1974) em valores absolutos...................................................................... 200

TABELA 8.16 - STAMENKOVIC; CHAPMAN (1974) em valores relativos.......................................................................... 200

TABELA 8.17 - GOMES (1991) em valores absolutos................................... 201

TABELA 8.18 - GOMES (1991) em valores relativos.................................. 202 


\title{
LISTA DE SIGLAS
}

\author{
ACI - American Concrete Institute \\ CEB - Comité Euro-International du Béton \\ EC-2 - EUROCODE N.2 \\ FIP - Fédération Internationale de la Précontrainte \\ LE-EESC - Laboratório de Estruturas da Escola de Engenharia de São Carlos \\ NB - Norma Brasileira \\ NBR - Norma Brasileira Registrada
}




\section{LISTA DE SÍMBOLOS}

A

$\mathrm{A}_{\mathrm{c}}$

$\mathrm{A}_{\mathrm{c}}{ }^{\prime}$

Acrit

Apilar

$\mathrm{A}_{\mathrm{S}}$

$\mathrm{A}_{\mathrm{Sw}}$

Asy

$\mathrm{A}_{\mathbf{V}}$

B

C

$\mathrm{C}^{\prime}$

CR comprimento de um trecho do perímetro crítico $\mathrm{U}$;

área da superfície crítica definida segundo o ACI 318/89;

área da superfície crítica, externa à região armada e calculada pelo produto do perímetro crítico $\mathrm{U}$ pela altura útil d;

área da região definida pelo EUROCODE N.2 e limitada pelo perímetro crítico u;

área do pilar;

armadura de flexão inferior, que atravessa a projeção da área em que se aplica a reação de apoio, definida pelo texto base da NB-1/94 e pelo CEB/90; área de armadura calculada segundo as recomendações do EUROCODE N.2, para dimensionar uma determindada faixa da laje à flexão;

área da armadura de cisalhamento numa linha de armadura homotética a $\mathrm{C}^{\prime}$;

área do pino;

área da armadura de punção dentro da distância s;

comprimento de um trecho do perímetro crítico U;

contorno do pilar ou da área carregada;

contorno do perímetro crítico $\mu$;

centro de rotação; 


\section{LISTA DE SÍMBOLOS}

A

$\mathrm{A}_{\mathrm{c}}$

$\mathrm{A}_{\mathrm{c}}{ }^{\prime}$

$\mathrm{A}_{\text {crit }}$

A pilar

$\mathrm{A}_{\mathrm{S}}$

$\mathrm{A}_{\mathrm{Sw}}$

Asy

$\mathrm{A}_{\mathrm{V}}$

B

C

$\mathrm{C}^{\prime}$

$\mathrm{CR}$ comprimento de um trecho do perímetro crítico $\mathrm{U}$;

área da superfície crítica definida segundo o ACI 318/89;

área da superfície crítica, externa à região armada e calculada pelo produto do perímetro crítico U pela altura útil d;

área da região definida pelo EUROCODE N.2 e limitada pelo perímetro crítico u;

área do pilar;

armadura de flexão inferior, que atravessa a projeção da área em que se aplica a reação de apoio;

área da armadura de cisalhamento numa linha de armadura homotética a $C^{\prime}$;

área do pino;

área da armadura de punção dentro da distância s;

comprimento de um trecho do perímetro crítico $\mathrm{U}$;

contorno do pilar ou da área carregada;

contorno do perímetro crítico $\mu$;

centro de rotação; 
$\mathrm{C}_{1}{ }_{1}, \mathrm{C}_{2}$ contornos das superfícies críticas a serem consideradas no caso da ligação apresentar capitel ou "drop panel" ;

D diâmetro do conector tipo pino;

$\mathrm{D}_{\mathrm{a}} \quad$ comprimento do segmento a , multiplicado pela distância do seu centro de gravidade ao centro do pilar;

$\mathrm{D}_{\mathrm{b}} \quad$ comprimento do segmento $\underline{\mathrm{b}}$, multiplicado pela distância do seu centro de gravidade ao centro do pilar;

$\mathrm{D}_{\mathrm{c}} \quad$ comprimento do segmento $\underline{\mathrm{c}}$, multiplicado pela distância do seu centro de gravidade ao centro do pilar;

$D_{\mathrm{d}} \quad$ comprimento do segmento $\underline{\mathrm{d}}$, multiplicado pela distância do seu centro de gravidade ao centro do pilar;

$\mathrm{D}_{\mathrm{e}} \quad$ comprimento do segmento e , multiplicado pela distância do seu centro de gravidade ao centro do pilar;

FSd carga ou reação concentrada de cálculo, definida pelo texto base da NB-1/94; reação de apoio;

FSd,ef reação de apoio majorada, de forma a se considerarem os efeitos de uma eventual transferência de momentos da laje para o pilar;

$\mathrm{J}_{\mathrm{c}} \quad$ propriedade definida pelo ACI 318/89, análoga ao momento de inércia polar, relativo à seção crítica;

$\mathrm{J}_{\mathrm{X}}, \mathrm{J}_{\mathrm{y}} \quad$ propriedades relacionadas à seção crítica definida pelo ACI 318/89, análogas ao momento de inércia polar e relacionadas a $M_{x}$ e a $M_{y}$, respectivamente;

$\mathrm{J}_{\mathrm{X}}, \mathrm{J}_{\mathrm{y}}$ propriedades relacionadas ao perímetro crítico $\mathrm{U}$, análogas ao momento de inércia polar e relacionadas a $M_{x}$ e a $M_{y}$, respectivamente; 
com relação ao texto base, $\mathrm{K}$ é o coeficiente que fornece a parcela de um momento fletor transmitida a um pilar interno por cisalhamento e que é tabelado em função da relação $c_{1} / c_{2}$; com relação ao $\mathrm{CEB} / 90$, o termo $\mathrm{K}$ foi definido para duas situações diferentes: para pilares internos, ele é análogo ao coeficiente $\mathrm{K}$ definido pelo texto base, enquanto que, para pilares de borda, $\mathrm{K}$ é análogo ao coeficiente $\mathrm{K}_{2}$, também definido pelo texto base, mas com uma diferença: enquanto este depende da relação $c_{2} / 2 c_{1}$, aquele depende da relação $c_{1} / 2 c_{2}$;

$\mathrm{K}^{\prime}$

coeficiente referente a um pilar interno, calculado de forma análoga a K e utilizado para determinar a parcela de um momento fletor M'Sd a ser transmitida por cisalhamento;

$\mathrm{K}_{1} \quad$ coeficiente definido pelo texto base da NB-1/94, para pilares de borda e de canto, em função da relação $\mathrm{c}_{1} / \mathrm{c}_{2}$;

$\mathrm{K}_{2}$ coeficiente definido pelo texto base da NB-1/94, para pilares de borda, dado em função da relação $c_{2} / 2 c_{1}$;

M momento de cálculo aplicado pela laje a um pilar interno, com relação ao texto base e ao CEB/90; momento fletor definido pelo texto base, referente a pilares de borda e de canto, como sendo igual à subtração $\left(\mathrm{MSd}_{\mathrm{S} 1}-\mathrm{MSd}_{\mathrm{Sd}}{ }^{*}\right.$, devendo o resultado assumir um valor maior ou igual a zero; momento fletor referente a pilares de borda e que atua na direção paralela à borda livre, definido conforme a recomendação dada pelo $\mathrm{CEB} / 90$;

M'Sd momento fletor, referente a pilares internos, perpendicular a $\mathrm{M}_{\mathrm{Sd}}$;

$\mathrm{MSd}^{*} \quad$ momento de cálculo resultante da excentricidade do perímetro crítico reduzido $\mu^{*}$ em relação ao centro do pilar;

$\mathrm{M}_{\mathrm{Sdn}} \quad\left(\mathrm{M}_{\mathrm{Sd} 1}-\mathrm{M}_{\mathrm{Sdn}}{ }^{*}\right) \geq 0$ 
MSdn * momento de cálculo resultante da excentricidade do novo perímetro crítico reduzido $\mu_{\mathrm{n}} *$ em relação ao centro do pilar;

MSdx momento fletor utilizado para dimensionar uma determinada faixa da laje, segundo a direção $\mathrm{x}$, conforme recomendação do EUROCODE N.2;

MSdy momento fletor utilizado para dimensionar uma determinada faixa da laje, segundo a direção $\mathrm{y}$, conforme recomendação do EUROCODE N.2;

MSd1 momento de cálculo definido pelo texto base e que atua no plano perpendicular à borda livre de pilares de borda e perpendicular à borda livre adotada para pilares de canto;

MSd2 momento de cálculo referente a pilares de borda, definido pelo texto base e que atua no plano paralelo à borda livre;

$\mathrm{M}_{\mathrm{u}} \quad$ momento fletor desbalanceado, definido pelo ACI 318/89;

$\mathrm{M}_{\mathrm{X}}, \mathrm{M}_{\mathrm{y}}$ momentos fletores que atuam segundo as direções $\mathrm{x} \quad \mathrm{e} y$, respectivamente;

M1d, M2d momentos fletores definidos segundo a Figura 19.3.2, no capítulo 3;

$\mathrm{N}_{1 d}, \mathrm{~N}_{2} \mathrm{~d}$ forças concentradas definidas segundo a Figura 19.3.2, no capítulo 3;

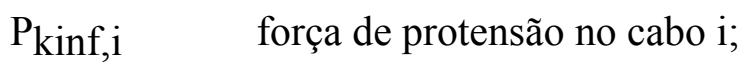

$\mathrm{P}_{\mathrm{r}} \quad$ carga total que atua na laje;

$P_{\text {rd }} \quad$ capacidade de resistência de uma laje sem armadura de punção;

PSd reação de apoio do pilar, definida pelo CEB/90;

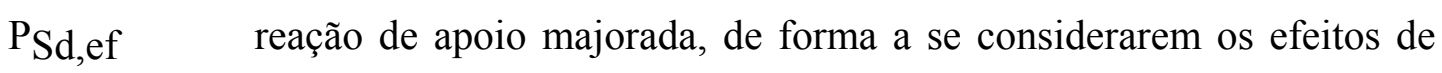
uma eventual transferência de momentos da laje para o pilar, definida pelo CEB/90; 
$\mathrm{R}_{\mathrm{C}} \quad$ força resultante de compressão dada pelo concreto;

$\mathrm{R}_{\mathrm{t}} \quad$ força resultante de tração dada pela armadura;

U, U' perímetros críticos externos à região transversalmente armada, utilizados na aplicação das recomendações dadas pelo ACI 318/89;

força concentrada;

$\mathrm{V}_{\mathrm{Sd}} \quad$ reação de apoio do pilar;

$\mathrm{V}_{\mathrm{U}}, \mathrm{V}_{\mathrm{X}} \quad$ força cortante; reação de apoio no pilar;

$\mathrm{W}_{\mathrm{n} \text {,ef }} \quad$ parâmetro referente ao novo perímetro crítico $\mathrm{u}_{\mathrm{n}, \mathrm{ef}}$, relacionado a MSd;

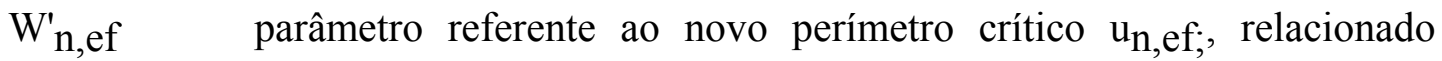
a M'Sd;

WP módulo de resistência plástica do perímetro crítico, definido pelo texto base;

W'P módulo de resistência plástica calculada segundo a direção em que atua $\mathrm{M}^{\prime} \mathrm{Sd}$;

WPC módulo de resistência plástica do perímetro crítico $\mu$, referente a pilares circulares internos;

WPn módulo de resistência plástica calculada segundo a direção em que o momento fletor $\mathrm{M}_{\mathrm{Sd}}$ atua e referente ao novo perímetro crítico $\mu_{\mathrm{n}}$, externo à região armada;

W'Pn módulo de resistência plástica calculada segundo a direção em que o momento fletor M'Sd atua e referente ao novo perímetro crítico $\mu_{\mathrm{n}}$, externo à região armada; 
Wena comprimento do segmento a do novo perímetro crítico, multiplicado pela distância entre o seu centro de gravidade e o eixo que passa pelo centro do pilar e que é perpendicular à direção na qual o momento fletor $\mathrm{M}_{\mathrm{Sd}}$ atua;

W'Pna produto do comprimento do segmento a, referente ao novo perímetro crítico, pela distância entre o centro de gravidade deste segmento e o eixo perpendicular à direção na qual o momento fletor M'Sd atua e que passa pelo centro do pilar;

Wenb comprimento do segmento $\underline{b}$ do novo perímetro crítico, multiplicado pela distância entre o seu centro de gravidade e o eixo que passa pelo centro do pilar e que é perpendicular à direção na qual o momento fletor $\mathrm{M}_{\mathrm{Sd}}$ atua;

W'Pnb produto do comprimento do segmento $\underline{b}$, referente ao novo perímetro crítico, pela distância entre o centro de gravidade deste segmento e o eixo perpendicular à direção na qual o momento fletor M'Sd atua e que passa pelo centro do pilar;

WPnc comprimento do segmento $\underline{\mathrm{c}}$ do novo perímetro crítico, multiplicado pela distância entre o seu centro de gravidade e o eixo que passa pelo centro do pilar e que é perpendicular à direção na qual o momento fletor $\mathrm{MSd}_{\mathrm{Sd}}$ atua;

W'Pnc produto do comprimento do segmento $\underline{\mathrm{c}}$, referente ao novo perímetro crítico, pela distância entre o centro de gravidade deste segmento e o eixo perpendicular à direção na qual o momento fletor M'Sd atua e que passa pelo centro do pilar;

Wend comprimento do segmento d do novo perímetro crítico, multiplicado pela distância entre o seu centro de gravidade e o eixo que passa pelo centro do pilar e que é perpendicular à direção na qual o momento fletor $\mathrm{MSd}_{\mathrm{Sd}}$ atua; 
W'Pnd produto do comprimento do segmento $\underline{\mathrm{d}}$, referente ao novo perímetro crítico, pela distância entre o centro de gravidade deste segmento e o eixo perpendicular à direção na qual o momento fletor M'Sd atua e que passa pelo centro do pilar;

WPn1x módulo de resistência plástica, calculado pelo perímetro $\mu_{\mathrm{n}}$ e referente a um pilar de canto, ignorando-se a borda livre paralela ao eixo $\mathrm{x}$;

WPn1y módulo de resistência plástica, calculado pelo perímetro $\mu_{\mathrm{n}}$ e referente a um pilar de canto, ignorando-se a borda livre paralela ao eixo y;

WP1 módulo de resistência plástica perpendicular à borda livre, calculado pelo perímetro $\mu$, para pilares de borda e de canto;

WP1x módulo de resistência plástica, calculado pelo perímetro $\mu$ e referente a um pilar de canto, ignorando-se a borda livre paralela ao eixo x;

WP1y módulo de resistência plástica, calculado pelo perímetro $\mu$ e referente a um pilar de canto, ignorando-se a borda livre paralela ao eixo y;

WP1n módulo de resistência plástica perpendicular à borda livre, calculado pelo novo perímetro crítico $\mu_{\mathrm{n}}$, referente a pilares de borda;

WP2 módulo de resistência plástica na direção paralela à borda livre, calculado pelo perímetro $\mu$, referente a pilares de borda;

WP2n módulo de resistência plástica paralela à borda livre, calculado pelo novo perímetro crítico $\mu_{\mathrm{n}}$, referente a pilares de borda;

W 2 a produto do comprimento do segmento a do novo perímetro crítico $\mu_{\mathrm{n}}$, pela distância entre o centro de gravidade desse segmento e o eixo perpendicular à borda livre e que passa pelo centro do pilar; 
WP2b produto do comprimento do segmento $\underline{\mathrm{b}}$ do novo perímetro crítico $\mu_{\mathrm{n}}$, pela distância entre o centro de gravidade desse segmento e o eixo perpendicular à borda livre e que passa pelo centro do pilar;

WP2c produto do comprimento do segmento $\underline{\mathrm{c}}$ do novo perímetro crítico $\mu_{\mathrm{n}}$, pela distância entre o centro de gravidade desse segmento e o eixo perpendicular à borda livre e que passa pelo centro do pilar;

WP2d produto do comprimento do segmento $\underline{\mathrm{d}}$ do novo perímetro crítico $\mu_{\mathrm{n}}$, pela distância entre o centro de gravidade desse segmento e o eixo perpendicular à borda livre e que passa pelo centro do pilar;

WP2e produto do comprimento do segmento e do novo perímetro crítico $\mu_{\mathrm{n}}$, pela distância entre o centro de gravidade desse segmento e o eixo perpendicular à borda livre e que passa pelo centro do pilar;

$\mathrm{W}_{1}$ parâmetro do perímetro crítico, definido pelo CEB/90 e calculado em relação a $\mathrm{u}_{1}$, análogos ao módulo de resistência plástica $\mathrm{W}_{\mathrm{P}}$ para o caso de pilares internos e a $\mathrm{W}_{\mathrm{P} 2}$, quando referente a pilares de borda;

W'1 parâmetro calculado em função do perímetro crítico $\mathrm{u}_{1}$, definido pelo $\mathrm{CEB} / 90$, análogo ao módulo de resistência plástico $\mathrm{W}_{\mathrm{P}}^{\mathrm{P}}$;

comprimento de um trecho do perímetro crítico reduzido $\mu^{*}$, referente a um pilar de borda, definido segundo o texto base; maior lado do pilar, definido segundo o EUROCODE N.2;

$a_{1}$ dimensão de um trecho do perímetro crítico reduzido $\mu^{*}$, paralelo a $\mathrm{c}_{1}$ e referente a um pilar de canto; lado de um pilar interno paralelo à direção de um cabo i, conforme Fig. 19.3.12; comprimento efetivo de um trecho do perímetro crítico u, definido pelo EUROCODE N.2, paralelo ao maior lado do pilar;

$\mathrm{a}_{1}$ trecho do novo perímetro crítico reduzido $\mu_{\mathrm{n}}{ }^{*}$, paralelo ao lado $\mathrm{c}_{1}{ }_{1} \mathrm{e}$ referente a pilares de canto; 
a2

$\mathrm{a}^{\prime} 2$

b

$b_{0}$

$\mathrm{b}_{1}$

$b^{\prime} 1$

$\mathrm{b}_{2}$

$b^{\prime} 2$

c

$\mathrm{c}_{\mathrm{AB}}$

$\mathrm{c}_{\mathrm{A}^{\prime} \mathrm{B}^{\prime}}$ dimensão de um trecho do perímetro crítico reduzido $\mu^{*}$, referente a um pilar de canto;

trecho do novo perímetro crítico reduzido $\mu_{\mathrm{n}}{ }^{*}$, paralelo ao lado c'2 e referente a pilares de canto;

lado de um pilar interno, perpendicular à direção de um cabo i, conforme Fig. 19.3.12; menor lado do pilar, definido segundo o EUROCODE N.2;

comprimento do perímetro crítico definido pelo ACI 318/89, localizado a $\mathrm{d} / 2$ do contorno do pilar;

comprimento efetivo de um trecho do perímetro crítico $\mathrm{u}$, definido pelo EUROCODE N.2, paralelo ao menor lado do pilar; comprimento da seção crítica definida pelo ACI 318/89, na direção do vão para o qual o momento fletor foi determinado ou, conforme o caso, paralelo ao eixo $\mathrm{x}$;

dimensão da seção crítica U' externa à região armada e paralela ao eixo $\mathrm{x}$;

comprimento da seção crítica definida pelo ACI 318/89, medida na direção perpendicular $a b_{1}$;

dimensão da seção crítica U' externa à região armada e paralela ao eixo y;

comprimento do lado de um pilar de borda ou canto; comprimento do lado de um pilar interno quadrado;

distância do eixo c-c, paralelo ao eixo y e que passa pelo centróide da seção crítica definida pelo ACI 318/89, até a face AB;

distância do eixo c-c, paralelo ao eixo y e que passa pelo centróide da seção crítica sugerida para a verificação da região além da transversalmente armada, até a face A'B'; 
$\mathrm{c}_{\mathrm{AD}}$ distância do eixo c'-c', paralelo ao eixo $\mathrm{x}$ e que passa pelo centróide da seção crítica definida pelo ACI 318/89, até a face AD;

$\mathrm{c}_{\mathrm{A}^{\prime} \mathrm{D}^{\prime}} \quad$ distância do eixo $\mathrm{c}^{\prime}-\mathrm{c}^{\prime}$, paralelo ao eixo $\mathrm{x}$ e que passa pelo centróide da seção crítica sugerida para a verificação da região além da transversalmente armada, até a face A'D';

$\mathrm{c}_{\mathrm{CB}}$ distância do eixo $\mathrm{c}^{\prime}$-c', paralelo ao eixo $\mathrm{x}$ e que passa pelo centróide da seção crítica definida pelo ACI 318/89, até a face CB;

$\mathrm{c}_{\mathrm{C}^{\prime} \mathrm{B}^{\prime}}$ distância do eixo c'-c', paralelo ao eixo $\mathrm{x}$ e que passa pelo centróide da seção crítica sugerida para a verificação da região além da transversalmente armada, até a face C'B';

$\mathrm{c}_{\mathrm{CD}}$ distância do eixo c-c, paralelo ao eixo y e que passa pelo centróide da seção crítica definida pelo ACI 318/89, até a face CD;

$\mathrm{c}_{\mathrm{C}^{\prime} \mathrm{D}^{\prime}} \quad$ distância do eixo c-c, paralelo ao eixo y e que passa pelo centróide da seção crítica sugerida para a verificação da região além da transversalmente armada, até a face C'D';

$\mathrm{c}_{\mathrm{X}} \quad$ dimensão de um pilar paralela à borda livre;

$\mathrm{c}_{\mathrm{y}} \quad$ dimensão de um pilar perpendicular a $\mathrm{c}_{\mathrm{X}}$;

$\mathrm{c}_{1} \quad$ comprimento do lado de um pilar interno, paralelo à excentricidade da carga ou, conforme o caso, paralelo ao eixo x; comprimento do lado de um pilar de borda perpendicular à borda livre da laje; comprimento do lado de um pilar de canto, perpendicular à borda livre adotada, ou paralelo ao eixo x, conforme o caso;

c'1 lado de um pilar de canto paralelo ao eixo x; 
c'2 lado de um pilar de canto paralelo ao eixo y;

d

$\mathrm{d}_{\mathrm{a}}$

$\mathrm{d}_{\mathrm{c}}$

$d_{\mathrm{X}}, \mathrm{d}_{\mathrm{y}} \quad$ alturas úteis segundo duas direções ortogonais definidas através dos eixos x e y;

$\mathrm{d}$

e

$\mathrm{e}^{*}$

$\mathrm{e}_{\mathrm{n}} *$

$\mathrm{e}_{\mathrm{X}} *$

$\mathrm{e}_{\mathrm{xn}} *$

$\mathrm{e}_{\mathrm{y}}{ }^{*}$

altura útil; altura útil a ser considerada no perímetro definido pelo contorno $\mathrm{C}_{2} 2$, definido pelo texto base;

altura útil da laje a ser considerada no perímetro $\mathrm{C}^{\prime} 1$, definido pelo texto base;

altura útil da laje na face do pilar;

comprimento infinitesimal no perímetro crítico, utilizado na definição de $\mathrm{W}_{1}$;

distância entre d e o eixo sobre o qual atua o momento fletor $\mathrm{M}_{\mathrm{Sd}}$, que, por sua vez, passa pelo centro do pilar;

excentricidade do perímetro crítico reduzido $\mu^{*}$, em relação ao centro do pilar, definido tanto para pilares de borda como para pilares de canto;

excentricidade do novo perímetro crítico reduzido $\mu_{\mathrm{n}}{ }^{*}$, referente a pilares de borda, dada em relação ao centro do pilar;

excentricidade do perímetro crítico reduzido $\mu^{*}$, referente a um pilar de canto, ignorando-se a borda livre paralela ao eixo $\mathrm{x}$;

excentricidade do novo perímetro crítico reduzido $\mu_{\mathrm{n}}$ * em relação ao centro do pilar, para pilar de canto, ignorando-se a borda livre paralela ao eixo $\mathrm{x}$;

excentricidade do perímetro crítico reduzido $\mu^{*}$, para pilar de canto, ignorando-se a borda livre paralela ao eixo y; 
resistência de cálculo do concreto à compressão;

$\mathrm{f}_{\mathrm{cd} 2}$ parâmetro definido pelo $\mathrm{CEB} / 90$, utilizado na verificação da região adjacente ao pilar;

$\mathrm{f}_{\mathrm{ck}} \quad$ resistência característica do concreto à compressão;

fy tensão de escoamento da armadura de punção, definida pelo ACI 318/89;

fyd tensão de escoamento da armadura de flexão, definida pelo texto base e pelo CEB/90; tensão de escoamento da armadura de punção, definida pelo EUROCODE N.2;

fywd resistência de cálculo da armadura de cisalhamento, definida pelo texto base e pelo $\mathrm{CEB} / 90$;

h espessura da laje;

j distância entre a face do pilar e o novo perímetro crítico $\mu_{\mathrm{n}}$;

$\mathrm{k}$ coeficiente definido pelo EUROCODE N.2, dado em função da altura útil;

$\mathrm{k}_{\mathrm{C}}, \mathrm{k}_{\mathrm{S}} \quad$ coeficientes dados em PINHEIRO (1993), utilizados para dimensionar uma determinada faixa da laje à flexão;

l vão dos painéis quadrados adjacentes ao pilar;

$\ell^{\prime} \quad$ comprimento de um segmento do perímetro crítico externo à região armada;

$\ell_{\mathrm{x}} ; \ell_{\mathrm{y}} \quad$ vãos das lajes segundo as direções x e y, respectivamente; 
$\bullet_{\mathrm{x}} ; \quad$ vãos das lajes segundo as direções x e y, respectivamente;

mSdx; mSdy momentos fletores mínimos, dados por unidade de largura e definidos pelo EUROCODE N.2, que precisam ser resistidos de forma a se garantir que os valores referentes à resistência da ligação, definidos pelo EUROCODE N.2 possam ser alcançados;

distância circunferencial entre os conectores mais externos; número total de espaçamentos radiais em uma linha de armadura de punção;

carga uniformemente distribuída;

raio de um pilar circular interno;

$\mathrm{r}_{\mathrm{r}}$

raio da circunferência que representa a linha de inflexão dos momentos fletores negativos nos "elementos-de-laje", que representam a região próxima ao pilar (aproximadamente igual a 0,220 ;

espaçamento da armadura de punção, definida pelo ACI 318/89 e não podendo ser superior a $\mathrm{d} / 2$;

$\mathrm{S}_{\mathrm{O}}$

distância entre a face do pilar e a camada mais interna da armadura de punção;

$\mathrm{S}_{\mathrm{r}}$

espaçamentos radiais entre linhas de armadura de cisalhamento, não maiores que $0,75 \mathrm{~d}$;

$\mathrm{u}$ perímetro crítico localizado a 1,5d do contorno do pilar, definido pelo EUROCODE N.2;

$u^{\prime}$ novo perímetro crítico, externo à região armada e utilizado na verificação baseada nas recomendações do EUROCODE N.2; 
$\mathrm{u}_{\mathrm{o}}$ perímetro definido pelo $\mathrm{CEB} / 90$ e utilizado na verificação da região adjacente ao pilar;

comprimento do perímetro crítico definido pelo CEB/90, análogo a $\mu$;

perímetro crítico reduzido, definido pelo $\mathrm{CEB} / 90$, análogo a $\mu^{*}$;

novo perímetro crítico localizado a $2 \mathrm{~d}$ da região armada, adotado pelo $\mathrm{CEB} / 90$ e análogo a $\mu_{\mathrm{n}}$;

novo perímetro crítico reduzido, definido pelo $\mathrm{CEB} / 90$ e análogo a $\mu_{\mathrm{n}} *$;

tensão nominal atuante, referente ao canto A da superfície crítica definida segundo o ACI 318/89;

tensão nominal atuante, relacionada ao canto $\mathrm{A}^{\prime}$ do perímetro crítico U';

tensão nominal atuante na face $\mathrm{AB}$ da seção crítica, definida, por sua vez, pelo ACI 318/89, referente a pilares internos e de borda;

tensão nominal atuante, referente ao canto B da superfície crítica definida segundo o ACI 318/89;

tensão nominal atuante, relacionada ao canto $\mathrm{B}^{\prime}$ do perímetro crítico U';

resistência obtida através da contribuição do concreto, conforme definição feita pelo ACI 318/89;

tensão nominal atuante na face $\mathrm{CD}$ da seção crítica, definida, por sua vez, pelo ACI 318/89, referente a pilares internos e de borda;

tensão nominal atuante, referente ao canto $\mathrm{D}$ da superfície crítica definida segundo o ACI 318/89; 
V'D tensão nominal atuante, relacionada ao canto $\mathrm{D}^{\prime}$ do perímetro crítico U';

$\mathrm{v}_{\mathrm{n}}$

tensão nominal resistente, definida pelo ACI 318/89;

$\mathrm{V}_{\mathrm{r}}$

força cortante linearmente distribuída;

vRd1

esforço resistente de cálculo, definido pelo EUROCODE N.2 e dado por unidade de comprimento do perímetro crítico u, referente a uma laje sem armadura de punção;

VRd2 resistência de cálculo máxima, definida pelo EUROCODE N.2 e dada por unidade de comprimento do perímetro crítico u;

VRd3 resistência de cálculo definida pelo EUROCODE N.2 e dada por unidade de comprimento do perímetro crítico u, para lajes com armadura de punção;

$\mathrm{v}_{\mathrm{S}} \quad$ contribuição da armadura de punção na resistência da ligação, dada segundo as recomendações do ACI 318/89;

VSd esforço cortante de cálculo, definido pelo EUROCODE N.2, dado por unidade de comprimento de um perímetro crítico $\mathrm{u}$, localizado a $1,5 \mathrm{~d}$ do contorno do pilar;

v'Sd esforço cortante de cálculo que atua ao longo do perímetro crítico u' que, por sua vez, é utilizado na verificação mencionada pelo EUROCODE N.2, referente à região localizada além da região transversalmente armada;

v tensão nominal atuante, definida pelo ACI 318/89;

$\mathrm{v}_{\mathrm{u}}^{\prime} \quad$ tensão nominal atuante, utilizada na verificação da região externa à região transversalmente armada, baseada nas recomendações do ACI 318/89;

$\mathrm{v}_{\mathrm{u}, \max } \quad$ máxima tensão nominal atuante; 
v'u,max máxima tensão nominal atuante, referente à superfície crítica externa à região armada que por sua vez, é definida com base nas recomendações do ACI 318/89;

posição de um ponto, em relação ao eixo de um pilar; distância entre a linha de armadura mais próxima do canto do pilar e este canto; eixo de referência;

distância entre a linha de conectores mais próxima do canto do pilar até o eixo paralelo ao lado $\mathrm{c}_{1}$ e que passa pelo centro do pilar; eixo de referência, perpendicular ao eixo de referência $\mathrm{x}$;

distância entre a linha de conectores mais próxima do canto do pilar até o eixo paralelo ao lado $c_{2}$ e que passa pelo centro do pilar;

braço de alavanca dos momentos internos;

$\alpha$

com base na Figura 2.3, $\alpha$ é a inclinação da fissura diagonal interna; ângulo de inclinação entre o eixo da armadura de cisalhamento e o plano médio da laje, definido segundo o texto base, o CEB/90 e o EUROCODE N.2; ângulo entre duas linhas de conectores, utilizado na definição do perímetro crítico U;

$\alpha_{i} \quad$ inclinação do cabo i em relação ao plano da laje no contorno considerado;

$\alpha_{\mathrm{S}} \quad$ coeficiente utilizado pelo ACI $318 / 89$

coeficiente definido pelo EUROCODE N.2, que leva em conta os efeitos da excentricidade da carga; coeficiente utilizado pelo CEB/90 para definir a distância entre a camada mais interna da armadura e a face do pilar; ângulo utilizado na definição do perímetro crítico U;

$\beta_{\mathrm{c}} \quad$ coeficiente que representa a razão entre os lados mais longo e mais curto do pilar, definido pelo ACI 318/89; 
$\phi$

$\gamma_{\mathrm{c}}$

$\gamma_{\mathrm{V}}$

$\gamma_{x}, \gamma_{y}$

$\gamma_{\mathrm{x}}^{\prime}, \gamma_{\mathrm{y}}^{\prime}$

$\eta$

$\mu$

$\mu^{*}$

$\mu_{\mathrm{n}}$ coeficiente de minoração da resistência da ligação, definido pelo ACI 318/89;

coeficiente de minoração da resistência do concreto;

coeficiente definido segundo o ACI 318/89 que fornece a parcela do momento fletor a ser transferida pela excentricidade da força cortante;

coeficientes dados pelo ACI 318/89 e que definem as parcelas dos momentos fletores $\mathrm{M}_{\mathrm{X}}$ e $\mathrm{M}_{\mathrm{y}}$, respectivamente, a serem transferidas pela excentricidade da força cortante, sendo calculadas em função de $\mathrm{b}_{1}$ e de $\mathrm{b}_{2}$;

coeficientes dados pelo ACI 318/89 e que definem as parcelas dos momentos fletores $\mathrm{M}_{\mathrm{X}}$ e a $\mathrm{M}_{\mathrm{y}}$, respectivamente, a serem transferidas pela excentricidade da força cortante, sendo calculadas em função de $b^{\prime}{ }_{1}$ e de $b_{2}^{\prime}$;

ângulo definido na Figura extra 6, utilizado no cálculo de $\mu_{\mathrm{n}}$, que, por sua vez, refere-se a uma disposição dos conectores em cruz; coeficiente definido pelo EUROCODE N.2;

perímetro crítico definido pelo texto base, localizado a $2 \mathrm{~d}$ da área de aplicação da carga, no plano da laje; perímetro definido pelo texto base, a ser utilizado na verificação da compressão no concreto; perímetro crítico ou perímetro crítico reduzido, referente a pilares de borda ou canto, conforme a formulação definida no item 19.2.5B do texto base;

perímetro crítico reduzido, definido pelo texto base;

perímetro crítico referente a uma disposição dos conectores em cruz, externo à região armada; novo perímetro crítico, localizado a $2 \mathrm{~d}$ além 
da última camada de armadura, definido com base nas recomendações do texto base;

$\mu_{\mathrm{n}} *$

$\theta$

v

$\rho, \rho_{1}$

$\rho_{\mathrm{X}}, \rho_{\mathrm{y}} \quad$ taxas de armadura segundo as direções $\mathrm{x}$ e $\mathrm{y}$;

$\rho_{x}^{\prime}, \rho_{y}^{\prime} \quad$ taxas de armadura obtidas através do dimensionamento de determinadas faixas da laje, utilizadas para resistir a $\mathrm{m}_{\mathrm{Sdx}}$ e $\mathrm{m}_{\mathrm{Sdy}}$, respectivamente;

$\rho_{\mathrm{W}}$

$\tau_{\mathrm{Pd}}$

$\tau_{\mathrm{Rd}}$

$\tau_{\mathrm{Rd} 1}$

$\tau_{\mathrm{Rd} 2}$

$\tau_{\text {Sd,ef }}$

novo perímetro crítico reduzido, definido externamente à região armada, utilizado na verificação baseada nas recomendações do texto base;

ângulo definido na Figura extra 6, utilizado no cálculo de $\mu_{\mathrm{n}}$, que, por sua vez, refere-se a uma disposição dos conectores em cruz;

coeficiente mencionado pelo texto base;

taxa de armadura de flexão;

taxa de armadura transversal mínima, definida pelo EUROCODE N.2;

tensão devida ao efeito dos cabos de protensão inclinados que atravessam o contorno considerado e passam a menos de $\mathrm{d} / 2$ do pilar;

tensão resistente de cálculo definida pelo texto base; tensão nominal resistente definida pelo $\mathrm{CEB} / 90$; coeficiente definido pelo EUROCODE N.2, fornecido através da tabela 5.1;

tensão resistente de cálculo, definida pelo texto base;

parâmetro definido pelo texto base como sendo igual ao produto $v \mathrm{f}_{\mathrm{cd}}$; 
$\tau_{\mathrm{Sd}} \quad$ tensão atuante de cálculo definida pelo texto base; tensão nominal de cisalhamento definida pelo CEB/90;

$\tau_{\mathrm{Sdn}} \quad$ nova tensão atuante de cálculo, referente ao novo perímetro crítico, externo à região armada, utilizada na verificação baseada nas recomendações do texto base;

$\tau_{\mathrm{Sdnx}} \quad$ nova tensão atuante de cálculo, relacionada ao novo perímetro crítico $\mu_{\mathrm{n}}{ }^{*}$, referente a pilares de canto e ignorando-se a borda livre paralela ao eixo $\mathrm{x}$;

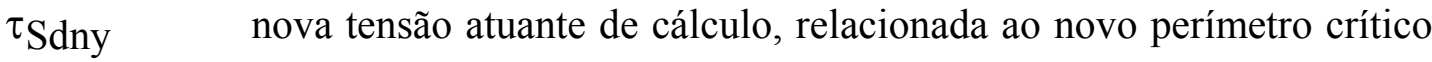
$\mu_{\mathrm{n}}{ }^{*}$, referente a pilares de canto e ignorando-se a borda livre paralela ao eixo y;

$\tau_{\mathrm{Sdx}}, \tau_{\mathrm{Sdy}}$ tensões atuantes de cálculo, relativas a pilares de canto, ignorando-se, respectivamente, as bordas livres paralelas aos eixos x e y;

$\xi \quad$ coeficiente definido pelo CEB/90 e calculado em função da altura útil;

$\psi \quad$ ângulo de rotação;

1/r curvatura da laje;

¿Asw somatória das áreas dos conectores, localizados dentro da região limitada pelo perímetro crítico u que, por sua vez, é definido pelo EUROCODE N.2. 


\section{RESUMO}

MELGES, J.L.P (1995) Punção em lajes: exemplos de cálculo e análise teóricoexperimental. São Carlos, 217p. Dissertação (mestrado) - Escola de Engenharia de São Carlos. Universidade de São Paulo.

Atualmente, alguns códigos como o CEB/90 e o texto base da NB-1/94 (ainda em fase de apreciação pelo meio técnico) têm apresentado inovações com relação à verificação da resistência à punção. Fez-se então, neste trabalho, uma análise do texto base da NB-1/94 referente à punção, comparando suas recomendações com algumas das fornecidas pelo CEB/90. Observou-se uma certa divergência entre os dois códigos com relação a pilares de borda e de canto, fornecendo o CEB/90 um tratamento mais simplificado para essas duas situações. Além disso, observa-se que, ao contrário do $\mathrm{CEB} / 90$, o texto base não menciona as seguintes recomendações: utilização de uma armadura a ser disposta ao longo das bordas livres da laje, destinada a combater esforços de torção, e limitação da resistência do concreto em $50 \mathrm{MPa}$ para essas verificações. Observou-se, ainda, uma omissão desses dois códigos com relação à situação de pilares internos submetidos a momentos fletores atuando em duas direções diferentes. Sugere-se, ainda, ao texto base, a inclusão de expressões que visem a facilitar e agilizar a sua aplicação. Após essa análise, foram apresentados exemplos de cálculo para pilares internos, de borda e de canto, tanto com como sem armadura de punção, verificados segundo as recomendações do texto base da NB-1/94, do EUROCODE N.2, do CEB/90 e do ACI 318/89. Por fim, comparam-se resultados experimentais com valores dados por estes códigos, visando determinar suas respectivas eficiências frente a alguns parâmetros, tais como, por exemplo, a presença de armadura transversal ou a relação entre os lados do pilar. Verifica-se que a utilização de armaduras de combate à punção pode elevar substancialmente o valor da resistência da ligação, além de torná-la mais dúctil. As observações referentes à comparação entre os valores fornecidos através de ensaios e os dados pelos códigos devem ser levadas em consideração apenas como uma indicação de seus respectivos comportamentos, necessitando-se de mais dados para uma afirmação mais conclusiva.

Palavras-chave: Lajes (concreto armado); Punção; Dimensionamento. 


\section{ABSTRACT}

MELGES, J.L.P (1995) Punching shear in slabs: examples of calculation and theoretic-experimental analysis. São Carlos, 217p. Dissertação (mestrado) Escola de Engenharia de São Carlos. Universidade de São Paulo.

Nowadays, some standards like $\mathrm{CEB} / 90$ and the Brazilian code basic text NB-1/94 (not approved yet) have presented some innovations for the punching shear strength. In this work, a comparative analysis is presented about the NB1-94 basic text recommendations and some presented by the CEB/90. Some differences are noted between the NB1-94 basic text and the CEB/90 recommendations relatives to corner and edge columns. The $\mathrm{CEB} / 90$ has a simplified treatment for these situations. It is noted that, in opposition to the CEB/90, the NB1-94 basic text about punching shear strength does not mention an additional reinforcement to be placed at the free edges of the slab, to provide torsion strength, and neither have a limit value of $50 \mathrm{MPa}$ for the concrete compressive strength. It is also noted that the CEB/90 and the NB1-94 basic text do not have a recommendation for internal columns with bending moments acting on two different directions. It is suggested that the NB1-94 basic text includes some expressions that can make its application easier and faster. After this analysis, some examples are presented with internal, edge and corner columns, with and without shear reinforcement, verified by the NB1-94 basic text, the EUROCODEN.2, the CEB/90 and the ACI 318/89 recommendations. Finally, a comparative analysis between some experimental results and those given by the codes is presented. The experimental results were related to some parameters like, for instance, the presence of shear reinforcement or the column sides ratio. It is verified that the shear reinforcement utilization can give more resistance and ductility to the connection. Finally, it is noted that the observations about the comparison between the experimental results and the values given by the codes can just be taken like a behavior indication for the connections. For conclusive affirmations, more experimental analysis are necessary. 


\section{INTRODUÇÃO}

\subsection{GENERALIDADES}

Lajes-cogumelo, pavimentos sem vigas, tabuleiros planos, lajes planas e lajes lisas são alguns nomes que podem ser utilizados para definir um sistema estrutural constituído por lajes de concreto armado, pré-moldadas ou não, protendidas ou não, que estejam diretamente apoiadas e rigidamente ligadas em pilares (Figura 1.1).

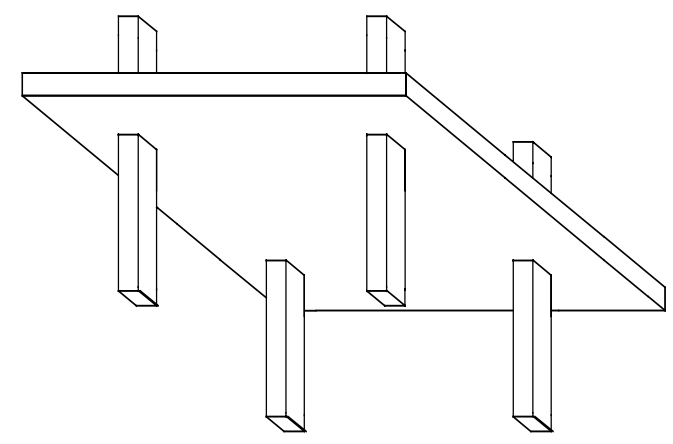

a) Vista em perspectiva

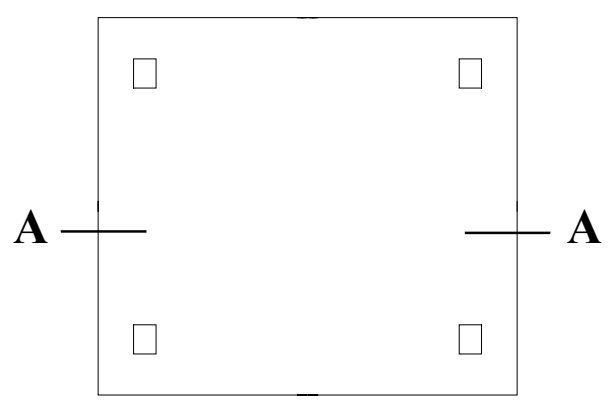

b) Planta

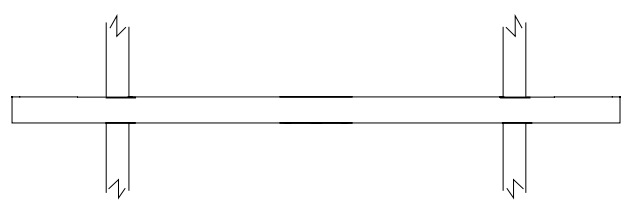

c) Corte A-A

Figura 1.1 - Laje-cogumelo 
Um dos principais problemas que afetam as lajes-cogumelo é a punção. A existência de vários parâmetros envolvidos faz da punção um problema complexo. Apesar de diversos métodos terem sido desenvolvidos, nenhum deles, até agora, obteve uma aceitação completa. É importante frisar que a maioria desses critérios de cálculo se baseia em resultados experimentais.

Atualmente, através de pesquisas recentes sobre o assunto, importantes recomendações têm sido apresentadas. É o caso do CEB/90 e do texto base da NB-1/94, ainda em fase de elaboração.

Portanto, foi observada a necessidade de um trabalho que tratasse da punção, mais voltado para aspectos de projeto e de acordo com as recentes modificações introduzidas nas normas nacionais e internacionais.

\subsection{OBJETIVOS}

Este trabalho apresenta dois objetivos principais. O primeiro é o de comparar resultados de ensaios experimentais com algumas das principais normas e também com alguns métodos de cálculo não normalizados, de forma a se obter informações que permitam uma análise sobre a eficiência dos métodos apresentados.

Já o segundo objetivo é o de analisar uma metodologia para a verificação da resistência da ligação laje-pilar à punção, baseada nas versões do CEB/90 e do texto base da NB-1/94, contando com a apresentação de exemplos e de algumas disposições construtivas mais frequentemente utilizadas.

\subsection{PLANEJAMENTO}

No capítulo 1 faz-se uma breve descrição e apresentação do sistema estrutural denominado laje-cogumelo, explicando-se o porquê desta terminologia e fazendo-se um histórico do desenvolvimento deste sistema. 
Ainda neste capítulo apresentam-se algumas das principais vantagens e desvantagens das lajes-cogumelo e a possibilidade de sua associação com outros sistemas estruturais.

O capítulo 2 apresenta um estudo mais detalhado sobre o fenômeno da punção. Primeiramente é apresentada a sua definição e quais os principais parâmetros envolvidos. A seguir, é mostrado como alguns destes parâmetros podem ser utilizados para aumentar a resistência da ligação laje-pilar. Faz-se também uma breve descrição dos principais fatores que influenciam a superfície de ruína. Por fim, são mencionados modelos de cálculo utilizados para a verificação da punção.

No capítulo 3 é apresentado o texto base da NB-1/94, intercalado com algumas sugestões e observações.

O capítulo 4 contém exemplos de cálculo constituídos por ligações da laje com pilares internos, de borda e de canto, com e sem armadura de punção. As recomendações utilizadas na verificação destes exemplos foram as do texto base.

No capítulo 5 são apresentados os mesmos exemplos dados no capítulo 4, só que agora verificados com base nas recomendações do EUROCODE N.2 (1992).

O capítulo 6 contém os mesmos exemplos mostrados nos capítulos 4 e 5, verificados aqui com base nas recomendações do CEB/90.

No capítulo 7 são apresentados os mesmos exemplos dos capítulos anteriores, só que agora verificados com base nas recomendações do ACI 318/89. 
O capítulo 8 contém comparações de resultados experimentais com valores dados conforme as recomendações do texto base, do CEB/90, do ACI 318/89 e do EUROCODE N.2 (1992).

No capítulo 9 são apresentadas as conclusões e sugestões para o prosseguimento de pesquisas referentes à punção em lajes.

Por fim, é apresentada a bibliografia.

\subsection{TIPOS DE RUÍNA}

Conforme BRANCO (1989), a ruína das lajes-cogumelo pode ocorrer através de três maneiras: flexão, punção e flexão associada à punção.

\subsubsection{RUÍNA POR FLEX̃̃o}

A ruína por flexão pode se dar pelo esmagamento do concreto comprimido ou pela deformação plástica excessiva da armadura de tração. Geralmente, os elementos submetidos à flexão são projetados para que a ruína ocorra com escoamento do aço, caracterizando, desta forma, uma ruína do tipo dúctil.

\subsubsection{RUÍNA POR PUNÇÃO}

$\mathrm{Na}$ ruína por punção, sendo a força cortante predominante, a laje se rompe antes que a capacidade resistente de flexão seja atingida, provocando uma ruína abrupta que, por não fornecer qualquer aviso prévio, é extremamente perigosa. 


\subsubsection{RUÍNA POR FLEXÃO ASSOCIADA À PUNÇÃO}

Para este caso específico, tanto o momento fletor quanto a força cortante têm ação significativa na ruína da ligação que, influenciada pelo momento fletor, apresenta ductilidade, ou seja, capacidade para grandes deformações.

\subsubsection{COMPORTAMENTO NA PUNÇÃO}

A ruína por punção ocorre nas regiões próximas a forças concentradas ou a pequenas áreas carregadas, como é o caso da ligação laje-pilar. Esta forma de ruína se caracteriza pelo deslocamento vertical da laje ao longo de uma superficie tronco-cônica, cujas geratrizes possuem inclinação de aproximadamente $30^{\circ} \mathrm{em}$ relação ao plano médio da laje (Figura 1.2). Outro fator importante é o da armadura de flexão não atingir o seu limite de escoamento, sendo, portanto, uma ruína do tipo frágil. Esta superfície pode ainda ser modificada em função de fatores que serão vistos no capítulo 2.

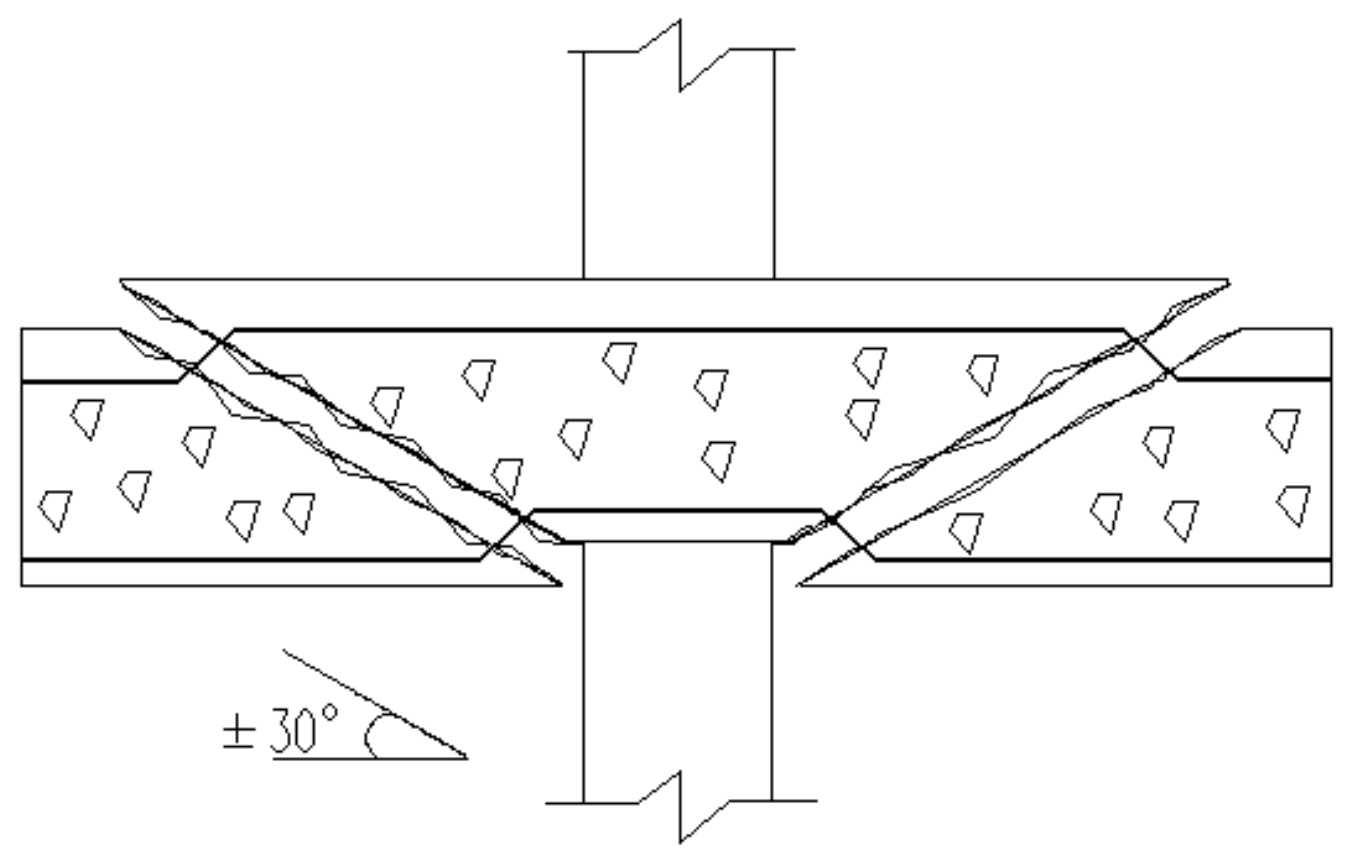

Figura 1.2 - Superfície de ruína 


\subsection{USO DE CAPITÉIS}

Para garantir a segurança e diminuir as tensões de cisalhamento nas ligações, o uso de capitel era comum no início da utilização das lajes-cogumelo.

Capitel é um engrossamento da seção transversal do pilar, próximo à sua ligação com a laje, conforme mostrado na Figura 1.3. Segundo TAKEYA (1981), a inclinação das geratrizes do capitel em relação à horizontal deve estar entre $1: 6\left(9,46^{\circ}\right)$ e $1: 8\left(7,12^{\circ}\right)$.

Pode-se ainda aumentar a espessura da laje na região da ligação. Esse engrossamento geralmente é chamado de ábaco ou pastilha. No entanto, na falta de um consenso, optou-se por utilizar a sua nomenclatura internacional de "drop panel" (Figura 1.4). É comum utilizar-se como espessura do "drop panel" a mesma espessura da laje.

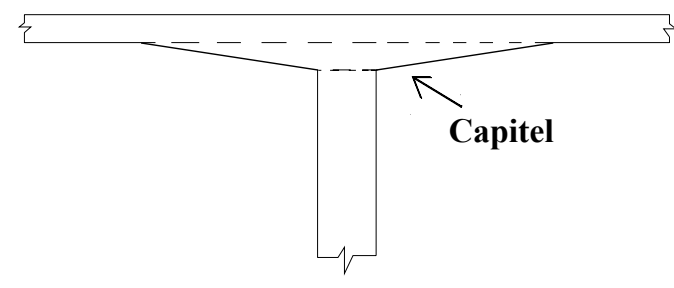

Figura 1.3 - Capitel

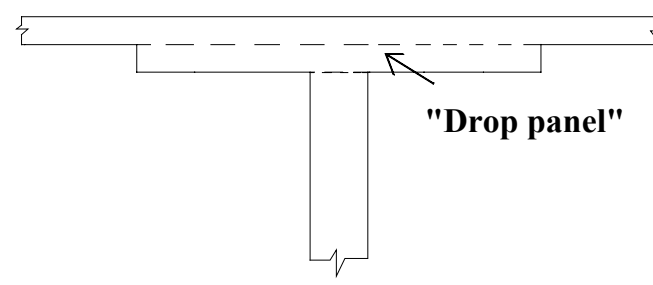

Figura 1.4 - "Drop panel"

Outra opção é a utilização combinada de capitel com "drop panel" (Figura 1.5).

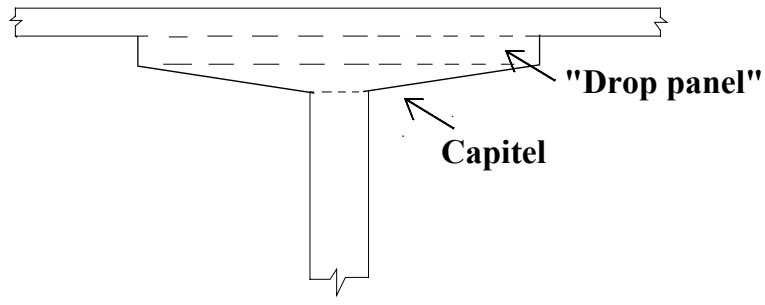

Figura 1.5 - Uso conjugado de "drop panel" e capitel

Do ponto de vista econômico, o uso de pequenos "drop panels" apresenta um menor custo de formas em relação ao uso de capitéis. 
Como o uso de capitéis e de "drop panels" fizesse os edifícios se assemelharem a cogumelos, vem daí a sua denominação. Com a evolução deste sistema estrutural e dos seus métodos de cálculo, os capitéis e os "drop panels" estão sendo cada vez menos utilizados em decorrência das grandes vantagens de se obter tetos planos. Em seu lugar têm sido usadas armaduras específicas de combate à punção que, além de aumentar a resistência da ligação laje-pilar, fornece-lhe maior ductilidade. Os termos armadura de cisalhamento, armaduras transversais e armaduras de combate à punção serão utilizados indistintamente daqui em diante.

Nos Estados Unidos, há uma diferença entre os termos utilizados para definir lajes-cogumelo com capitéis ou "drop panels" e lajes-cogumelo sem capitéis:

* flat plate para lajes com teto plano;

* flat slab para lajes com capitéis ou com "drop panels".

No Brasil, já existe uma tendência a que se denominem de lajescogumelo apenas as lajes que apresentem "drop panels" ou capitéis. Para as outras, a notação a ser utilizada seria a de lajes lisas ou planas. O termo "lisa", no caso, indica que a superfície da laje não apresenta ressaltos. No entanto, como ainda não há um consenso, optou-se, neste trabalho, por se adotar o termo "laje-cogumelo" como sendo a definição de qualquer sistema estrutural onde as lajes estejam diretamente apoiadas em pilares.

\subsection{HISTÓRICO}

As lajes-cogumelo surgiram nos Estados Unidos em 1905, através da iniciativa pioneira de TURNER $^{1}$ apud TAKEYA (1981).

1 TURNER, C. A. P. (1905) Discussion of reinforced concrete warehouse for northwest knitting co. Minneapolis. Engineering News, v.54, n.15, p.383 apud TAKEYA, T. (1981) Estudo experimental da ruína de ligações laje -pilar em bordas de lajes -cogumelo. São Carlos. Dissertação (mestrado), EESC-USP. 
Seu método de cálculo causou uma enorme polêmica entre os especialistas da época, devido ao fato de existirem grandes variações entre as taxas de armadura obtidas por ele e as relativas a outros métodos.

Sendo assim, alguns edifícios construídos por Turner acabaram sendo submetidos a provas de carga e apresentaram um desempenho considerado satisfatório. O fato é que, com a construção de edifícios em Moscou (1908) e em Zurique (1910), a técnica acabou por se difundir ao redor do mundo.

No entanto, em 1911, a utilização indevida deste sistema estrutural provocou um desabamento em Indianápolis, nos Estados Unidos, que resultou na morte de nove pessoas e ferimentos graves em outras vinte. Verificou-se então a necessidade de se conhecer melhor o comportamento deste sistema estrutural, de modo a obter formas de se projetar com segurança e economia.

TALBOT $^{2}$ apud TAKEYA (1981) foi quem iniciou os estudos do fenômeno da punção, tendo ensaiado 197 sapatas sem armadura de cisalhamento e observado a ruína por punção em vinte delas.

Já GRAF ${ }^{3}$ apud TAKEYA (1981) mostrou, através de ensaios de lajes sob cargas concentradas, que o aumento da resistência do concreto influenciava muito pouco a resistência à força cortante, provavelmente devido ao fato dos esforços de flexão provocarem fissuras na seção resistente.

RICHART (1948) através de ensaios de sapatas, observou, assim como Talbot, que o aumento das taxas de armadura eram responsáveis por acréscimos de resistência da peça à punção.

2 TALBOT, A. N. (1913) Reinforced concrete wall footings and column footings. University of Illinois, Engineering Experiment Station. Bull. n.67, 114p. apud TAKEYA, T. (1981) Estudo experimental da ruína de ligações laje -pilar em bordas de lajes -cogumelo. São Carlos. Dissertação (mestrado), EESC-USP.

3 GRAF, O. (1933) Tests of reinforced concrete slabs under concentrated load applied near one support (Versuche über die wiederstandsfähigkeit von eisenbetonplatten unter konzentrierter last nahe einem auflager), Deutscher Ausschuss für Eisenbeton, Berlim, n.73, p.28 apud TAKEYA, T. (1981) Estudo experimental da ruína de ligações laje-pilar em bordas de lajes-cogumelo. São Carlos. Dissertação (mestrado), EESC-USP. 
No entanto, a primeira tentativa de quantificar a influência da resistência à flexão na resistência à força cortante foi feita por HOGNESTAD (1953), ao analisar ensaios de Richart.

Após novos ensaios que confirmaram a influência observada por Talbot e Richart, Hognestad, juntamente com ELSTNER (1956), alterou a sua própria fórmula proposta anteriormente. Também foi deles a primeira proposta para o cálculo da contribuição da armadura de punção na resistência da ligação. Este acréscimo de resistência seria quantificado através da adição de um termo independente na equação utilizada para o cálculo da resistência de ligações laje-pilar sem armadura de punção.

Após ensaios de lajes, MOE (1961) propôs uma formulação semelhante à dada por Hognestad e Elstner com relação à forma de se quantificar o acréscimo de resistência devido à presença de armadura de punção nas ligações. Moe também foi um dos primeiros a analisar os casos assimétricos, caracterizados por pilares de borda, canto e pilares internos com carregamentos assimétricos. Estes casos se caracterizam basicamente pela transferência de momentos da laje para o pilar.

KINNUNEN; NYLANDER ${ }^{4}$, KINNUNEN $^{5}$ e NYLANDER 6 apud TAKEYA (1981), após o ensaio de várias lajes circulares com pilar central, propuseram um modelo mecânico cujo cálculo considera a influência da flexão e da força cortante em conjunto. Neste modelo, que é a base do Regulamento Sueco com respeito à punção, a carga de ruína é determinada através do equilíbrio entre esforços internos e carregamentos externos.

${ }^{4}$ KINNUNEN, S.; NYLANDER, H. (1960) Punching of concrete slabs without shear reinforcement. Estocolmo, Kungl. Tekniska Hoegskolans Handlingar, n.158 apud TAKEYA, T. (1981) Estudo experimental da rúna de ligações laje-pilar em bordas de lajes-cogumelo. São Carlos. Dissertação (mestrado), EESC-USP.

${ }^{5}$ KINNUNEN, S. (1963) Punching of concrete slabs with two-way reinforcement. Estocolmo, Kungl. Tekniska Hoegskolans Handlingar, n.198 apud TAKEYA, T. (1981) Estudo experimental da ruína de ligações laje-pilar em bordas de lajes-cogumelo. São Carlos. Dissertação (mestrado), EESC-USP.

${ }^{6}$ NYLANDER, H. (1964) Punching of concrete slabs. Paris, CEB Bulletin d'information, $n .44$, p.159-183 apud TAKEYA, T. (1981) Estudo experimental da ruína de ligações laje-pilar em bordas de lajes-cogumelo. São Carlos. Dissertação (mestrado), EESC-USP. 
Segundo LIBÓRIO (1985), Nylander observou que:

- estribos verticais mostraram ser mais eficientes que os estribos inclinados;

- a superfície de ruína ocorreu, na maior parte das vezes, fora da região que contém os estribos e abaixo deles, conforme mostrado na Figura 1.6.

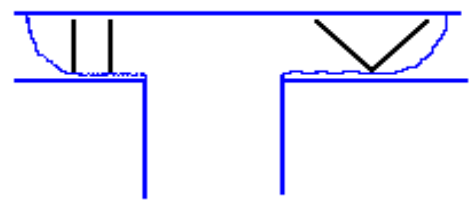

Figura 1.6 - Modos de ruína observados por Nylander

- quando taxas de armadura de flexão eram pequenas, a carga última de ruína foi bem maior nas lajes dotadas de estribos; porém, quando esta taxa era relativamente alta, a carga de ruína era pouco influenciada pela presença da armadura transversal.

Ainda neste ano, FRANZ7 apud LIBÓRIO (1985) chegou a importantes conclusões:

- a utilização de uma armadura destinada a suportar a totalidade do esforço cortante conduz à resistência pouco superior àquela que se obteria se dimensionada para resistir a 2/3 da mesma solicitação;

- a utilização de estribos provocou aumentos de resistência da ordem de $25 \%$ enquanto que a utilização de barras dobradas teve a sua eficiência reduzida pela metade, quando comparada com estribos.

YITZHAKI (1966) propôs uma nova formulação para o problema, baseado em ensaios de lajes circulares com e sem armadura de punção, que, por sua vez, eram constituídas essencialmente de barras dobradas.

7 FRANZ, G. (1964) Remarques préliminaires sur les recherches concernant l'influence de l'armature d'effort tranchant sur la résistances des dalles planes dans la zone des appuis. Paris. CEB Bulletin d'information, n.44, p.219-227 apud LIBÓRIO, J. B. L. (1985) Estudo experimental da ruína de ligações laje-pilar em bordas com pilares de seção retangular. São Carlos. Dissertação (mestrado), EESC-USP 
Também em 1966, LANGENDONCK ${ }^{8}$ apud LIBÓRIO (1985) criticou a complexidade do método sueco (Kinnunen e Nylander) para o uso corrente dos engenheiros. Langendonck concluiu que o método de Moe, para lajes sem armadura de punção, apresentou resultados mais próximos das cargas de ruína observadas em ensaios do que os de outras teorias. Observou, no entanto, uma grande dispersão de resultados para ligações com armadura de punção. Propôs, então, que se usasse a fórmula de Moe para lajes sem armadura de punção, adicionando-se outro termo proposto por ele, que corresponderia a uma melhor avaliação da contribuição deste tipo de armadura.

Em 1968, CORLEY; HAWKINS (1968) realizaram ensaios utilizando perfis metálicos ("shearheads") como armadura de punção para pilares internos.

LONG (1975) propôs um método de cálculo desenvolvido para pilares internos de seção quadrada, para painéis de laje quadrados, que supõe duas maneiras distintas de ruína. A primeira delas supõe que a ruína ocorra com o escoamento da armadura de flexão antes da ruptura do concreto à compressão, enquanto que a outra supõe que a ruptura do concreto se dê antes do escoamento da armadura de flexão. $\mathrm{O}$ valor da resistência da ligação será o menor dos dois valores calculados segundo as duas hipóteses. Desta forma, Long procurou prever qual o mecanismo com que se daria a ruína: por flexão, por cisalhamento ou simultaneamente por flexão e cisalhamento. Long também realizou estudos sobre os casos assimétricos de ligações laje-pilar.

PARK; ISLAM (1976), ao analisar a existência ou não de armadura de punção em lajes assimetricamente carregadas, chegaram a importantes conclusões, como, por exemplo, sobre a eficiência de estribos, de barras dobradas e de "shearheads" como armaduras de punção, sobre o tipo de ruína e também de como o acréscimo de resistência pode ser quantificado devido à presença dessas armaduras.

8 LANGENDONCK, T. (1966) Remarques sur le calcul des dalles au poinçonnement. CEB Bulletin d'information, n.57, p.141-144 apud LIBÓRIO, J. B. L. (1985) Estudo experimental da ruína de ligações laje-pilar em bordas com pilares de seção retangular. São Carlos. Dissertação (mestrado), EESC-USP 
DILGER et al. (1976) e SEIBLE et al. (1980) estudaram tipos especiais de armadura de punção tais como segmentos de perfis metálicos tipo "I", conectores providos com chapas e com "cabeças" em forma de pregos e, por fim, telas soldadas.

Em SHEHATA (1985) é apresentado um modelo racional para o cálculo da punção em pilares internos com carregamento simétrico e sem armadura de punção. As equações fornecidas por este método formam um sistema de equações não lineares, que pode ser resolvido iterativamente até que um dos estados limites definidos pelo autor seja atingido. Desta forma, a carga de ruína não é obtida de forma imediata, sendo necessária a utilização de um microcomputador para se obter a resolução matemática desse sistema de equações. Já em SHEHATA (1990), é apresentado um modelo simplificado composto de bielas comprimidas e tirantes radiais. Conforme relatado em PINTO (1993), este modelo é de fácil aplicação e em geral fornece bons resultados. Porém, para ensaios onde a resistência à compressão do concreto é elevada, o modelo superestimou os valores das cargas de ruína.

Além de ter desenvolvido um novo modelo racional apresentado em GOMES (1991), atualmente, o prof. Ronaldo Gomes está realizando ensaios experimentais para verificar a influência de aberturas na resistência das lajescogumelo. Algumas de suas conclusões a respeito do assunto podem ser encontradas em GOMES (1994).

\subsection{PESQUISAS EM SÃO CARLOS}

Em São Carlos, iniciou-se, em 1972, um amplo projeto de pesquisa sugerido pelo prof. Telemaco van Langendonck, que visava o estudo experimental da resistência de ligações laje-pilar em cantos e em bordas de lajes-cogumelo.

Os ensaios foram realizados no Laboratório de Estruturas da Escola de Engenharia de São Carlos (LE-EESC) e forneceram material para a tese de livre docência do professor MARTINELLI (1974) e também para as dissertações de 
mestrado dos engenheiros FIGUEIREDO $\mathrm{F}^{\mathrm{O}}$ (1981), TAKEYA (1981), LIBÓRIO (1985), GONÇALVES (1986) e MODOTTE (1986).

Além disso, segundo BRANCO (1989), mais de uma dezena de trabalhos já foram publicados com base nestes estudos.

A experimentação teve como principais objetivos caracterizar e determinar, respectivamente, a configuração e a carga de ruína para diversas combinações de parâmetros, como, por exemplo, tipo de ligação (canto ou borda), taxa de armadura de flexão, taxa de armadura transversal, espessura da laje, plano de atuação do momento fletor e dimensões da seção transversal do pilar.

As principais conclusões obtidas foram:

- é recomendável a utilização de uma armadura de torção na região da borda livre;

- à medida que se aumentou a rigidez da ligação, isto é, a relação entre os lados do pilar, foi observada uma diminuição do deslocamento transversal da laje;

- a utilização de armaduras transversais fornece ductilidade à ligação;

- a formulação dada pelo CEB-FIP/78 não é indicada por levar a valores muito conservativos;

- a carga de ruína aumentou com relação próxima da linear, à medida que a razão entre os lados do pilar foi aumentada (Figura 1.7);
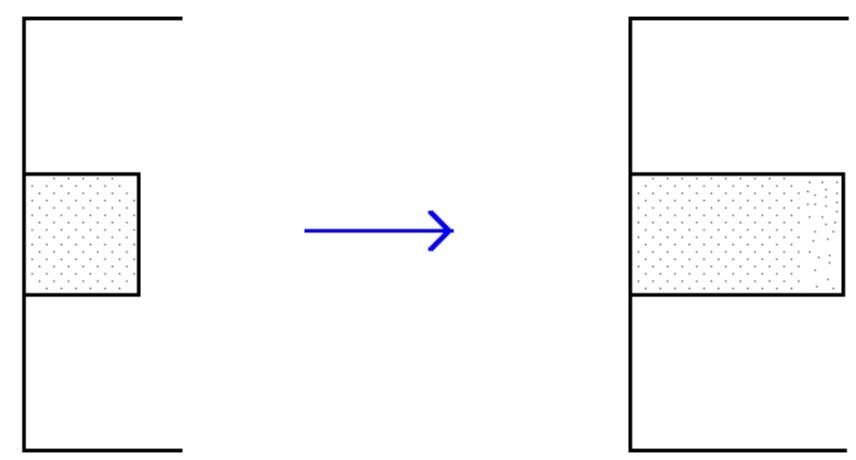
Figura 1.7 - Variação da relação dos lados do pilar

- devida à configuração de ruína observada para ligações com pilares de borda e de canto, observou-se que as armaduras de cisalhamento constituídas por barras dobradas seriam absolutamente inadequadas, podendo ter alguma utilidade apenas nos cantos internos dos pilares;

- o aumento da carga de ruína devido ao uso de armaduras de cisalhamento pode ser considerável. Os estribos devem ser distribuídos uniformemente dentro de uma região considerada crítica e devidamente ancorados em barras horizontais, podendo estas ser a armadura negativa de flexão na face superior da laje e o prolongamento desta armadura através de ganchos na face inferior;

- pode-se recomendar, provisoriamente, uma taxa de armadura transversal (Área estribos / Área crítica) em torno de $2 \%$, onde a área crítica seria a região compreendida dentro de um perímetro considerado crítico, descontando-se a área do pilar;

- as expressões utilizadas para verificar uma laje à punção não podem ser aplicadas caso a ruína se dê por flexão;

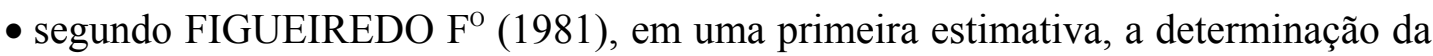
resistência da ligação laje-pilar à flexão, calculada a partir da charneira inferior da laje, acabou por resultar contra a segurança;

- deformações observadas na face inferior parecem confirmar a ação predominante do momento torçor ao longo da borda da laje.

\subsection{MÉTODOS NUMÉRICOS}

CALDERARO (1983), por meio de modelos tridimensionais analíticos e da aplicação do Método dos Elementos Finitos, procurou modelar a resistência de ligações laje-pilar e compará-la com os resultados obtidos através de 
modelos reais ensaiados no LE-EESC. Os resultados provenientes do processo numérico foram praticamente iguais aos observados nos ensaios.

Com o avanço dos microcomputadores e o desenvolvimento de métodos numéricos utilizados para calcular os esforços solicitantes, como, por exemplo, a Analogia de Grelha, o Método dos Elementos Finitos e o Método dos Elementos de Contorno, os resultados teóricos passaram a ser bastante satisfatórios quando comparados com os resultados experimentais.

O Método dos Elementos Finitos tem sido bastante difundido tanto no meio científico, como no meio técnico. Os softwares SAP-90, LUSAS, STRAP e ROBOBAT são exemplos deste fato. Porém, este método apresenta o inconveniente de, no caso de sua utilização para simular lajes-cogumelo, necessitar de uma malha de elementos muito densa na região do apoio, tornando pouco prática a sua utilização.

Já o processo da Analogia de Grelha apresenta, em muitos casos, resultados com precisão superior à do Método dos Elementos Finitos, para malhas com densidade de nós de até oito vezes menor (BRANCO, 1989).

O Método dos Elementos de Contorno, embora não tendo a sua aplicação tão difundida quanto o Método dos Elementos Finitos, apresenta vantagens significativas no que diz respeito à sua entrada de dados, uma vez que, no Método dos Elementos de Contorno, é necessário apenas delinear a estrutura com nós (Figura 1.8).
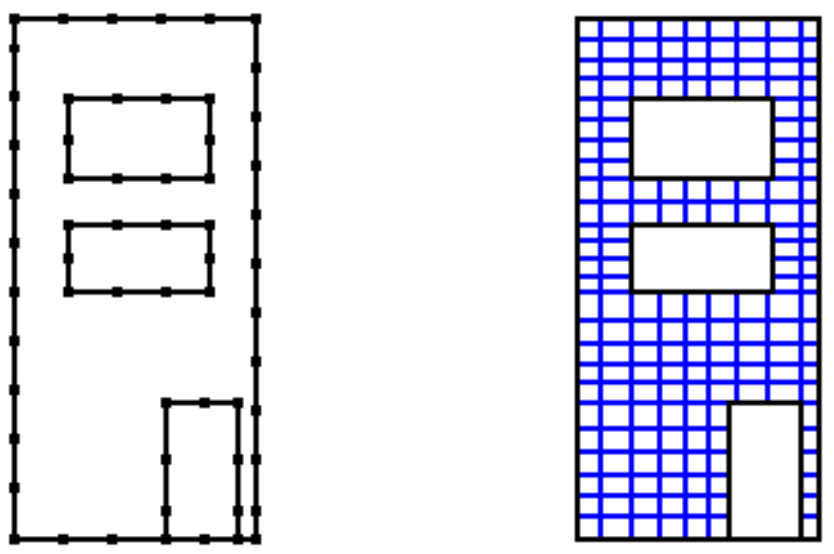


\subsection{VANTAGENS DAS LAJES-COGUMELO}

Algumas das principais vantagens das lajes-cogumelo mencionadas por FIGUEIREDO F (1989) são:

a) maior simplicidade na execução das formas, devido ao fato de existirem recortes apenas na ligação com os pilares, e também na montagem das armaduras, possibilitando o emprego de telas pré-fabricadas;

b) maior facilidade no lançamento, adensamento e desforma do concreto; a não existência de vigas ocasiona um menor número de recortes, diminuindo, assim, o número de regiões onde é comum aparecerem falhas (vazios, ninhos, bicheiras), devidas à dificuldade de acesso do vibrador;

c) redução do tempo nas tarefas de execução de formas, de armaduras e de concretagem;

d) com o teto plano, de altura constante, pode-se obter uma racionalização e uma padronização de cimbramentos; para teto liso, é possível obter estruturas com um bom padrão de acabamento, dispensando a presença de revestimentos, aliviando as ações que atuam nos elementos estruturais e economizando no custo do próprio revestimento; além disso, o teto plano facilita a ventilação e a insolação dos ambientes;

e) redução da altura total do edificio;

f) a inexistência de vigas propicia boas condições de adaptação da obra a diferentes finalidades durante sua vida útil, uma vez que as divisórias não estão mais condicionadas à rígida localização das vigas do piso e das do teto;

g) maior facilidade de limpeza do teto. 
Segundo FLING (1989), para vãos até em torno de 7,5 metros, o sistema estrutural disponível mais simplificado, econômico e rápido é o das lajescogumelo. Também para SOUZA; CUNHA (1994), as lajes-cogumelo podem ser consideradas economicamente competitivas para vãos com cerca de 7 a 8 metros, desde que se utilize capitéis ou "drop panels" .

Observa-se que este sistema é mais vantajoso quando há regularidade de espaçamentos entre os pilares. Esta regularidade facilita o cálculo e, além disso, melhora o comportamento estrutural.

Não basta, no entanto, que as qualidades e as possibilidades de vantagens sejam enumeradas para que elas sejam obtidas. É necessário que projetistas e construtores assimilem a tecnologia de projeto e execução, bem como que haja um certo treinamento no tocante a engenheiros, desenhistas, tecnólogos e, principalmente, no que diz respeito à mão-de-obra, que, atualmente, se encontra tremendamente desqualificada. Conceitos administrativos modernos têm mostrado que controlar a qualidade das fases de fabricação de um produto é mais eficiente que controlar a qualidade do produto final. Sendo assim, o treinamento da mão-de-obra é fundamental, não apenas para a construção de edifícios em lajes-cogumelo, mas para o crescimento das empresas, em geral.

\subsection{DESVANTAGENS DAS LAJES-COGUMELO}

As principais desvantagens das lajes-cogumelo do ponto de vista estrutural são: pequena rigidez das estruturas às ações laterais, quando comparadas com estruturas convencionais; puncionamento das lajes pelos pilares e, por fim, os grandes deslocamentos transversais que ocorrem principalmente nas bordas livres e 
que podem chegar a atingir um estado limite de utilização. Observa-se ainda que o consumo de aço e de concreto referente a esse sistema estrutural é ligeiramente superior ao obtido com a adoção de uma estrutura convencional.

\subsection{ASSOCIAÇÃO COM OUTROS SISTEMAS ESTRUTURAIS}

As lajes-cogumelo podem estar associadas a outros sistemas estruturais, de forma a se buscar ampliar o seu campo de aplicação e/ou diminuir suas restrições. Serão vistos a seguir alguns exemplos destas associações.

\subsubsection{LAJES-COGUMELO ALIVIADAS}

As lajes-cogumelo podem ser aliviadas de modo que o peso próprio seja diminuído, proporcionando um alívio nos esforços solicitantes. Este alívio pode ser feito com o uso de lajes nervuradas ou lajes vazadas, conforme ilustra a Figura 1.9. No entanto, este alívio não deve ser alocado na região dos pilares, uma vez que nesta região ocorrem grandes esforços cisalhantes. Na sua terminologia internacional, este sistema é denominado de "waffle slab".

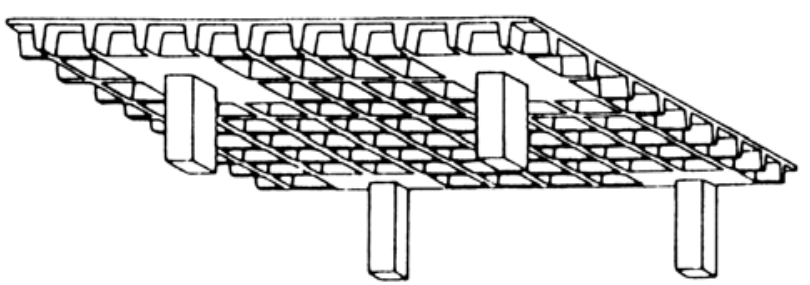

Figura 1.9 - Laje-cogumelo nervurada ("waffle slab")

\subsubsection{LAJES-COGUMELO PROTENDIDAS}


Esta associação permite a utilização de vãos maiores que os usuais nas lajes-cogumelo, possibilitando também uma diminuição na espessura da laje, o que, consequentemente, reduz o valor do peso próprio.

Outro fator importante é que os deslocamentos transversais das lajes, devidos às ações permanentes, podem ser contrabalançados pela curvatura produzida pela protensão, evitando as fissuras e os problemas usuais devidos a esses deslocamentos (Figura 1.10).

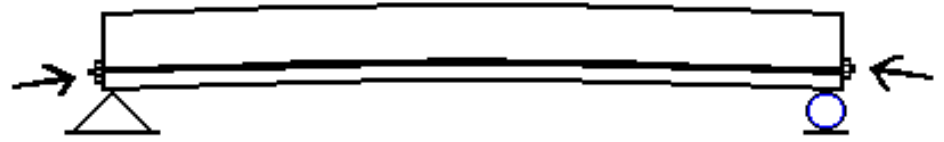

Figura 1.10 - Efeito da protensão

\subsubsection{LAJES-COGUMELO COM VIGAS NAS BORDAS}

Este tipo de associação está mostrado na Figura 1.11. 


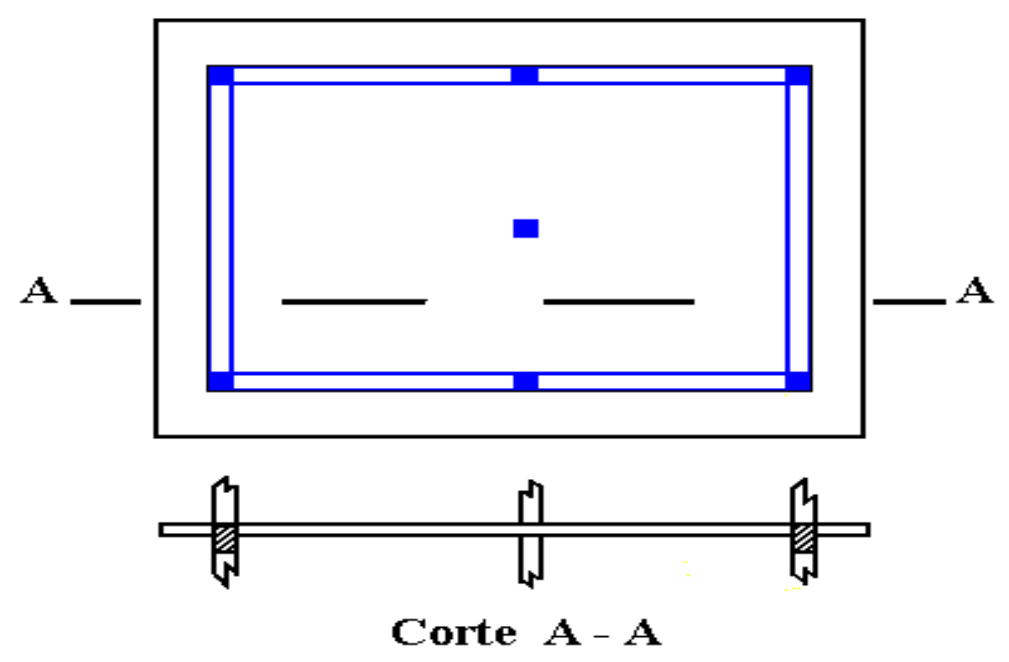

Figura 1.11 - Laje-cogumelo com vigas nas bordas

Embora possa prejudicar algumas das vantagens oferecidas pelas lajes-cogumelo, esta associação melhora o seu desempenho nos seus principais pontos fracos:

a) a presença das vigas elimina o problema do puncionamento da laje na região dos pilares de canto e de extremidade;

b) são nas bordas livres que os deslocamentos transversais são maiores e mais perceptíveis, devida à falta de continuidade da laje; a presença de vigas também elimina este problema;

c) as vigas de borda melhoram o comportamento do edifício quanto à sua estabilidade global.

\subsubsection{ASSOCIAÇÃO COM SISTEMAS PRÉ-MOLDADOS}

As lajes-cogumelo podem estar relacionadas com sistemas prémoldados, de modo que os elementos pré-moldados incluam um segmento de pilar e parte da laje (EL DEBS, 1992). 
Outra forma de associação pode ser feita através do sistema denominado de "lift slabs" ou de "placas ascendentes". Este sistema consiste em se concretar as lajes ao nível do chão, "in loco", uma sobre as outras, com aberturas nas posições dos pilares já previamente colocados e, a seguir, as lajes são levantadas e colocadas nas suas posições de utilização definitivas. A sua fixação se dá através de colares soldados nas lajes e nos pilares (Figura 1.12).
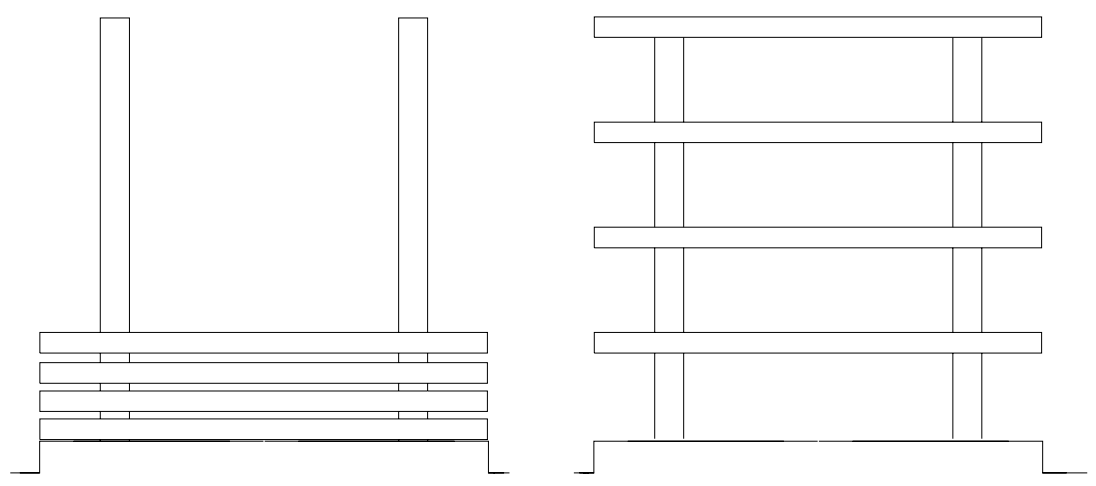

Figura 1.12 - "Lift Slab" 


\section{PUNÇÃO}

\subsection{ANÁLISE DO FENÔMENO DA PUNÇÃO}

O fenômeno da punção de uma placa é basicamente a sua perfuração devida às altas tensões de cisalhamento, provocadas por forças concentradas ou agindo em pequenas áreas. Nos edifícios com lajes-cogumelo, esta forma de ruína pode se dar na ligação da laje com os pilares, onde a reação do pilar pode provocar a perfuração da laje.

Conforme SHEHATA ${ }^{1}$ apud STUCCHI; KNAPP (1993), o comportamento observado em ensaios é descrito a seguir.

" Os danos típicos visíveis nas lajes ensaiadas, anteriormente à ruptura, foram fissurações radiais, as quais começaram quase que no centro das lajes e se estenderam na direção do perímetro das mesmas, dividindo assim as lajes em segmentos radiais " (Figura 2.1).

" Momentos antes da ruptura, algumas fissuras tangenciais na região da punção apareceram, indicando a formação de uma fissuração inclinada interna causada pela tração diagonal " (Figura 2.2).

${ }^{1}$ SHEHATA, I.A.M. (1993) Punção em lajes. In.:COLÓQUIO SOBRE ESTRUTURAS DE CONCRETO, 6. apud STUCCHI, F.R.; KNAPP, L.M. (1993) Punção em lajes. In.: SIMPÓSIO EPUSP SOBRE ESTRUTURAS DE CONCRETO, 3., São Paulo. Anais. p.209-232. 


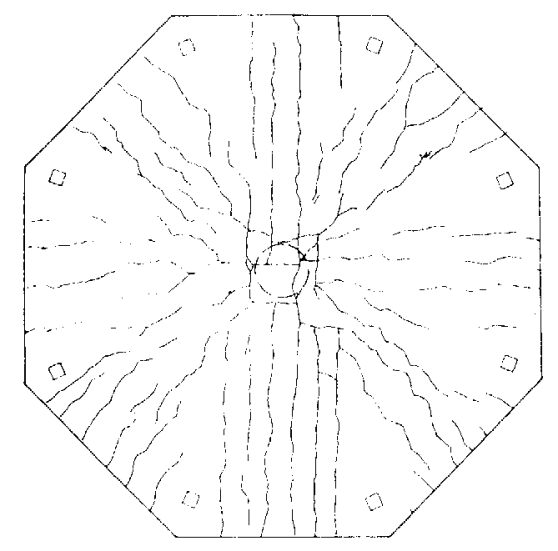

Figura 2.1 - Para carga de utilização

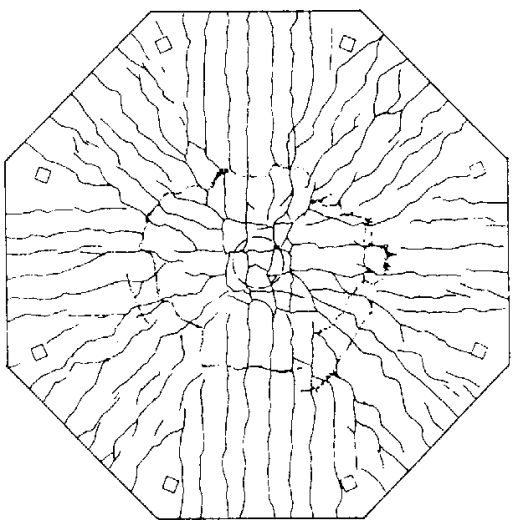

Figura 2.2 - Para carga de ruína

Segundo BRAESTRUP; REGAN (1985), as fissuras inclinadas ocorrem de meio a dois terços da carga de ruína. Após o aparecimento destas fissuras, a condição da laje ainda é estável, podendo ser descarregada e novamente carregada, sem que a sua resistência seja afetada.

" Flechas das lajes ensaiadas, na direção radial, apresentaram perfil quase linear, indicando assim a rotação dos segmentos da laje como corpos rígidos. Este comportamento é também confirmado pelas deformações específicas do aço e do concreto, medidas na direção tangencial ao longo do raio das lajes, as quais foram proporcionais a $1 / \mathrm{r}$ (SHEHATA, 1982, e KINUNNEM; NYLANDER, 1960) " (Figura 2.3).

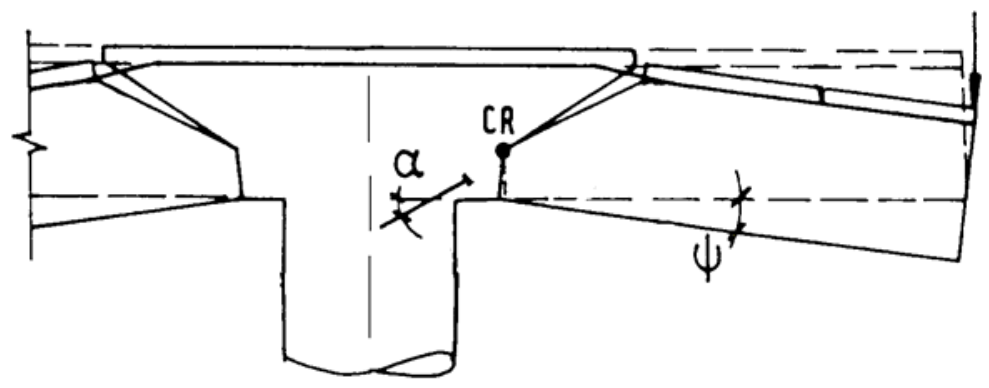

Figura 2.3 - Rotação dos segmentos da laje

" Em todos os casos, a ruptura por punção foi brusca com perda de quase dois terços da carga máxima atingida. Só em algumas lajes houve sinais de esmagamento do concreto perto da coluna nos instantes que precederam a ruptura. A resistência residual é atribuída ao efeito de membrana da malha de aço no lado tracionado da laje e do aço que porventura atravessa a coluna no lado comprimido. " 
Este comportamento referente à fissuração e ao deslocamento de segmentos da laje como corpos rígidos também é observado por LEONHARDT; MÖNIG (1978).

No entanto, segundo BRAESTRUP; REGAN (1985), as configurações de ruína de lajes por punção podem apresentar uma grande variedade nos padrões de fissuração, que dependem da configuração do carregamento e dos apoios.

A maioria dos ensaios tem procurado representar a região de momentos negativos localizada ao redor de pilares ou a região de momentos positivos localizada ao redor de cargas concentradas. Desta forma, os ensaios são feitos com "elementos-de-laje", nos quais é reproduzida apenas parte da laje. Nestes "elementos-de-laje", as bordas procuram representar as linhas de inflexão de momentos fletores em lajes contínuas.

Nos "elementos-de-laje" que representam a região próxima ao pilar, a linha de inflexão dos momentos fletores negativos está posicionada sobre uma circunferência de raio $r_{r} \cong 0,22$, onde é o vão dos painéis quadrados adjacentes ao pilar (Figura 2.4).

Segundo LEONHARDT; MÖNIG (1978), pode-se considerar a seção da laje ao longo desta circunferência como uma borda onde atuam apenas momentos tangenciais pequenos e uma força cortante linearmente distribuída $v_{r}$ (Figura 2.5), definida pela seguinte expressão:

$$
\mathrm{v}_{\mathrm{r}}=\frac{\mathrm{P}_{\mathrm{r}}}{2 \pi \mathrm{r}_{\mathrm{r}}}
$$

onde, de uma maneira simplificada, pode-se supor que $\mathrm{P}_{\mathrm{r}}$ seja o valor da carga total que atua na laje. 

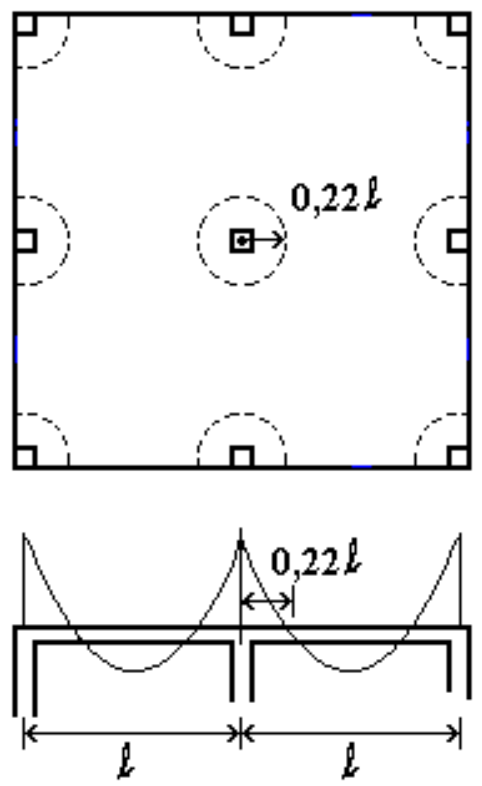

Figura 2.4 - "Elementos-de-laje" (TAKEYA, 1981)

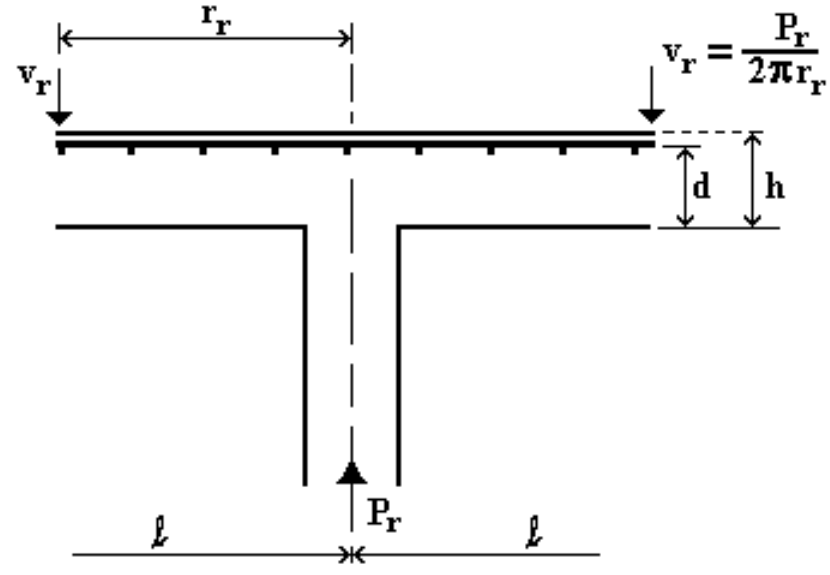

Figura 2.5 - Esforços atuantes em um

"elemento-de-laje"

As principais críticas feitas a respeito deste tipo de ensaio são que este modelo não permite uma completa redistribuição de momentos, além de não levar em conta a restrição lateral oferecida pelas regiões da estrutura adjacentes ao pilar.

Observa-se ainda que o valor da força cortante $\left(\mathrm{V}_{\mathrm{X}}\right)$ aumenta hiperbolicamente em direção ao pilar (Figura 2.6). Desta forma, o valor máximo da força cortante vai ocorrer na região onde os momentos negativos também são máximos, tratando-se, desta forma, de uma região onde o tipo de solicitação é extremamente desfavorável.

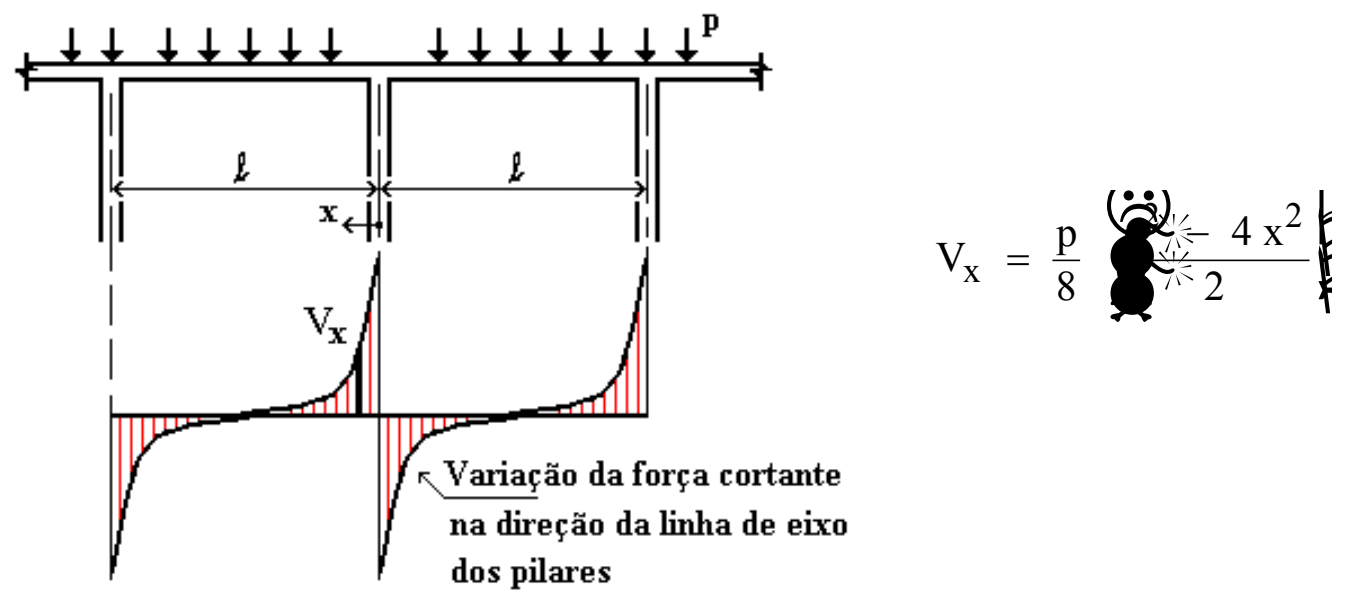

Figura 2.6 - Variação da força cortante 


\subsection{SUPERFÍCIE DE RUÍNA}

A ruína para pilares internos, com lajes e carregamento simétricos (casos simétricos), apresenta uma superfície de ruína tronco-cônica ou troncopiramidal, partindo do contorno da área carregada e se estendendo até a outra face, com uma inclinação entre $30^{\circ}$ a $35^{\circ}$ em relação ao plano médio da laje (Figura 2.7).

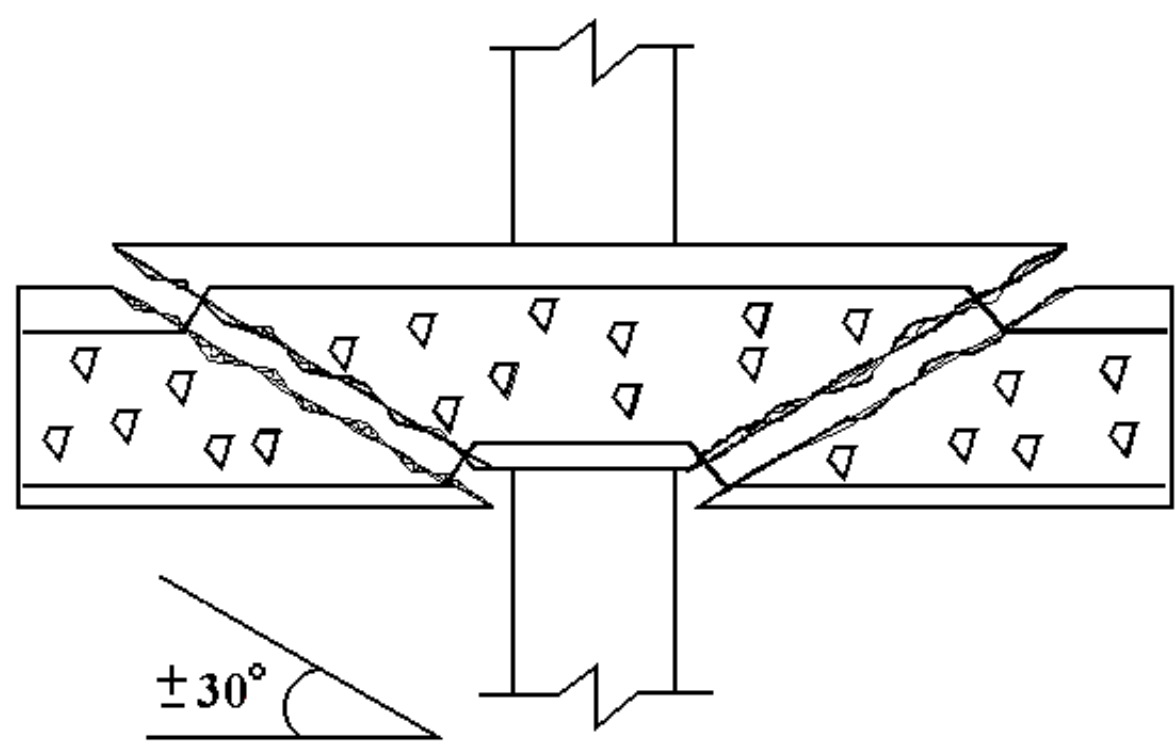

Figura 2.7 - Superfície de ruína para casos simétricos

Porém, esta superfície pode variar em função de dois parâmetros: posição do pilar e presença de armaduras de combate à punção.

\subsubsection{COM RELAÇÃO À POSIÇÃO DO PILAR}

Para os pilares de borda e de canto (casos assimétricos), a superfície de ruína se altera junto às bordas livres, permanecendo, no entanto, com a mesma forma dos casos simétricos junto ao canto interno dos pilares de canto e junto à face interna dos pilares de borda (Figura 2.8). Esta modificação na superfície de ruína se deve, principalmente, à presença de momentos torçores e fletores na ligação. 

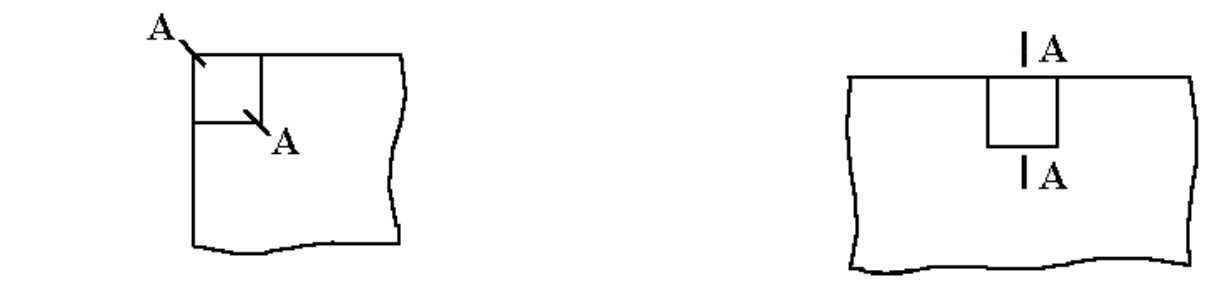

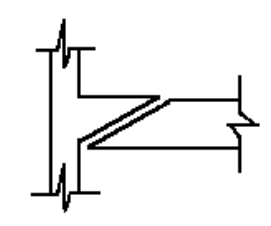

Corte A-A

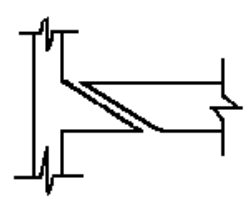

Vista Lateral

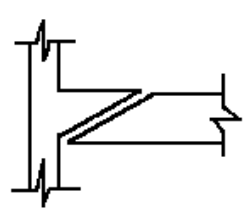

Corte A-A

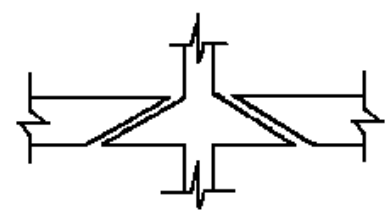

Vista Lateral

a) pilares de canto

b) pilares de borda

Figura 2.8 - Superfície de ruína para pilares de canto e borda

Segundo FIGUEIREDO $\mathrm{F}^{\mathrm{O}}$ (1989), a presença de momentos fletores não balanceados deve-se, principalmente, às seguintes condições:

- esforços laterais causados pela ação do vento e de terremotos;

- espaçamentos desiguais de pilares, produzindo painéis consecutivos de diferentes dimensões;

- existência de diferentes ações variáveis, ou mesmo permanentes, em painéis adjacentes da laje;

- esforços produzidos por recalques diferenciais, variações de temperatura, retração e fluência;

- pilares colocados nas bordas e nos cantos das lajes.

Pesquisas mostram que a transferência destes momentos da laje para os pilares causa uma diminuição no valor da resistência das ligações à força cortante. Esta diminuição é devida à fissuração da laje na região da ligação. O problema é ainda maior para os pilares de borda e canto, devido ao fato da seção de contato entre a laje e o pilar ser menor e também pelo fato de haver torção nas bordas da laje junto à sua ligação com os pilares. Já para o caso de pilares internos, com lajes carregadas simetricamente, estes momentos não causam problemas, quando auto-equilibrados. 


\subsubsection{COM RELAÇÃO À PRESENÇA DE ARMADURA TRANSVERSAL}

Conforme relatado em STUCCHI; KNAPP (1993), as superfícies de ruína mais prováveis numa laje com armadura de cisalhamento, segundo GOMES (1991), são as apresentadas na Figura 2.9 e descritas a seguir:

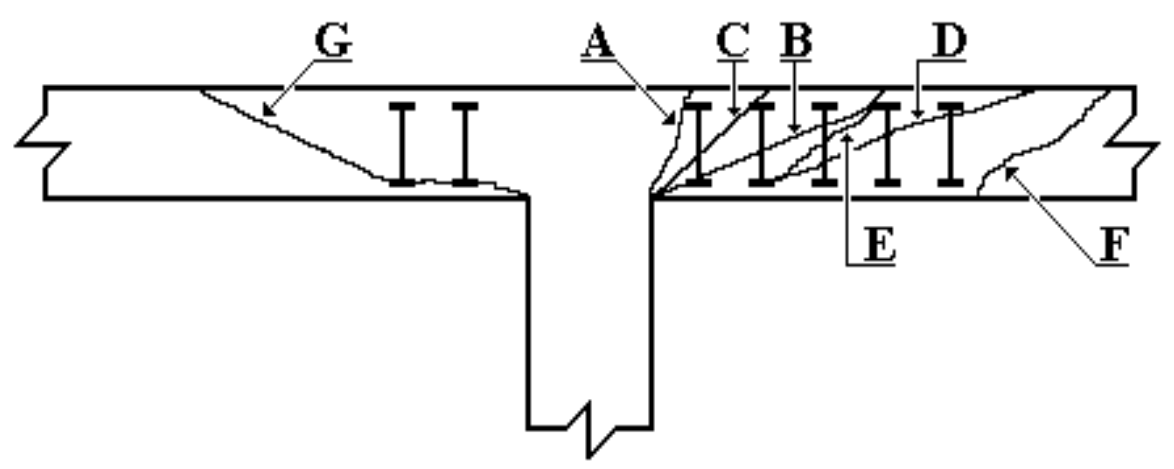

Figura 2.9 - Superfícies prováveis de ruína

"스 - entre o pilar e a linha mais interna da armadura de cisalhamento";

"트 - atravessando a região da armadura de cisalhamento com a mesma inclinação que se obteria em uma laje sem armadura de cisalhamento, partindo do pilar";

"므 - a mesma que em ( $\underline{B})$, porém mais inclinada";

"ㅁ - atravessando a região armada a cisalhamento com a mesma inclinação que ocorreria em uma laje sem armadura de cisalhamento e partindo de um ponto afastado do pilar";

"E - a mesma que em (D)), porém mais inclinada";

"E - além da região armada a cisalhamento";

"G - correndo abaixo dos elementos da armadura de cisalhamento".

"Os resultados dos ensaios mostraram que, quando a armadura de cisalhamento tem ancoragem adequada nos níveis superior e inferior da armadura, é

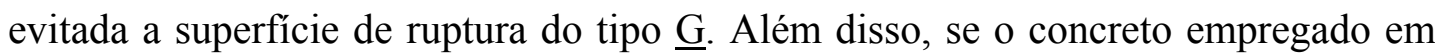
toda a laje tem a mesma resistência, se é adotada a mesma área e resistência da armadura de cisalhamento nas diversas linhas e se o espaçamento entre as mesmas é mantido constante e abaixo de um certo valor, não existe razão para a existência de uma superfície de ruptura atravessando a região armada a cisalhamento que se inicie afastada da face do pilar (tipos $\underline{\mathrm{D}} \mathrm{e} \underline{\mathrm{E}}) "$. 
"Basicamente dois tipos de superfície de ruptura devem ser considerados. As superfícies de ruptura que tem início na face do pilar e aquelas cujo início ocorre além da região da armadura de cisalhamento" ( $\underline{\mathrm{A}}, \underline{\mathrm{B}}, \underline{\mathrm{C}} \mathrm{e} \underline{\mathrm{F}})$.

\subsection{PARAMMETROS ENVOLVIDOS}

Alguns dos principais parâmetros envolvidos neste fenômeno são:
a) espessura da laje;
b) dimensões e forma da seção transversal dos pilares;
c) resistência do concreto;
d) relação momento fletor/força cortante na ligação laje-pilar;
e) taxa de armadura de flexão da laje;
f) presença ou não da armadura transversal de combate à punção.

Estes parâmetros podem variar de acordo com o critério de cálculo a ser adotado. Por exemplo, baseado em resultados experimentais, o CEB/90 admite que a ruína por punção seja uma ruína do tipo frágil e que a resistência ao cisalhamento das lajes depende, principalmente, da resistência à tração diagonal do concreto, do engrenamento dos agregados ao longo das fissuras, do efeito pino da armadura de flexão e do do efeito favorável da compressão na biela inclinada.

Existem basicamente três formas de se aumentar a resistência das ligações laje-pilar à punção: utilizando capitéis e/ou "drop panels", aumentando o valor da resistência do concreto, ou, ainda, utilizando armadura de cisalhamento.

A primeira opção geralmente é indesejável do ponto de vista arquitetônico, econômico e, além disso, ela não fornece ductilidade, ou seja, capacidade de deformação à ligação. DILGER et al. (1978) definem ductilidade como sendo a relação entre a rotação da laje no momento em que a primeira barra de flexão começa escoar e a rotação final na ruptura. Desta forma, quanto maior for a diferença entre estas duas rotações, mais dúctil será a forma com que se dará a ruína. 
Já o aumento da resistência do concreto nem sempre é suficiente para elevar o nível da resistência da ligação aos valores desejados. Sendo assim, o uso de armaduras é o mais indicado, pois, além de elevar o valor da resistência da ligação laje-pilar, fornece-lhe ductilidade.

Ensaios mostram que a utilização de armaduras de punção, mais especificamente os estribos e os conectores tipo pino, faz com que a ruína se dê através do escoamento da armadura longitudinal de flexão que, provocando grandes deformações na ligação, evita o perigo da ruína tipo frágil. Esta opção será vista a seguir com maiores detalhes.

\subsection{ARMADURAS DE COMBATE À PUNÇÃO}

Conforme mostrado em TAKEYA (1981), são diversos os tipos de armaduras e de reforços que podem ser utilizados no combate à punção.

\subsubsection{PLACA METÁLICA}

A utilização de uma placa metálica tem, basicamente, a mesma finalidade que a utilização de um "drop panel" (Figura 2.10);

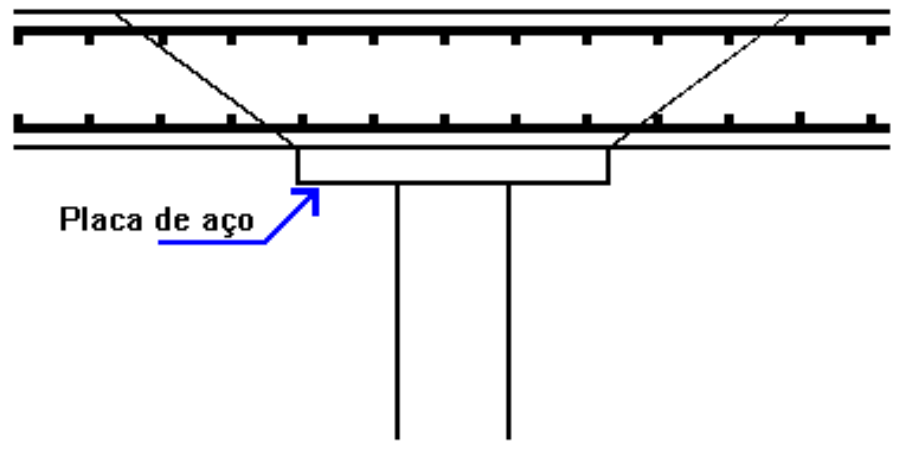

Figura 2.10 - Placa metálica 


\subsubsection{ESTRIBOS}

Os estribos podem ser abertos em forma de ganchos ou fechados em forma de retângulos. Os estribos retangulares podem ainda estar associados entre si (Figura 2.11).
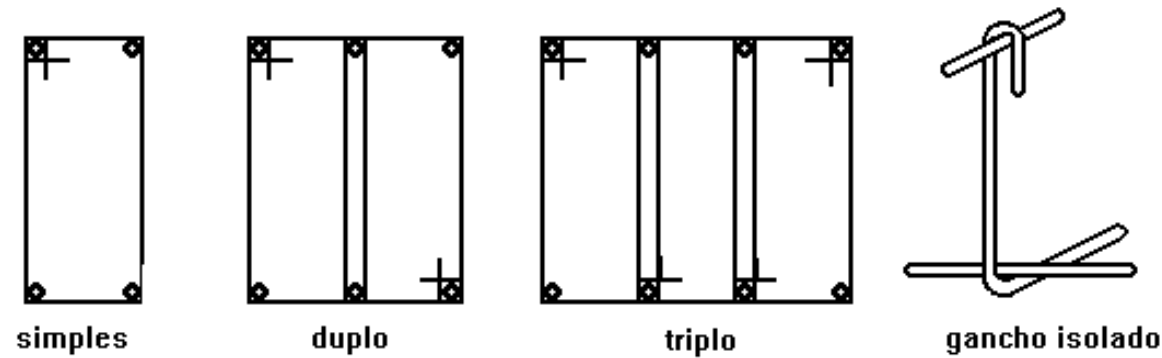

Figura 2.11 - Tipos de estribos

Os estribos podem ainda estar inclinados ou não (Figura 2.12).

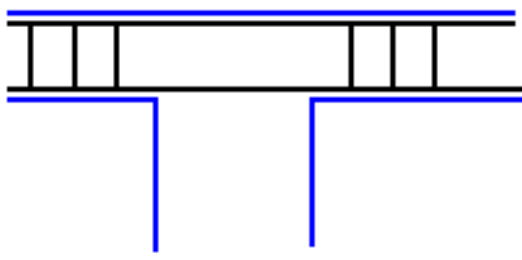

estribos verticais

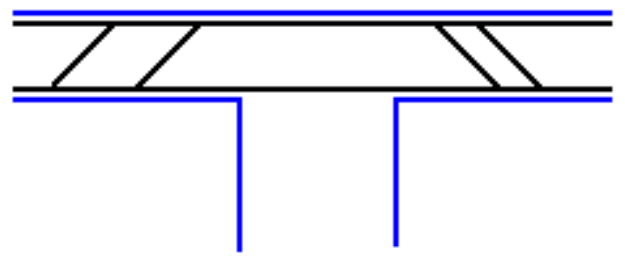

estribos inclinados

Figura 2.12 - Inclinação dos estribos

O desempenho dos ganchos foi considerado satisfatório em ensaios realizados por TAKEYA (1981) e MARTINELLI (1974). Os ganchos possuem a vantagem de não interferir nas armaduras de flexão da laje e nem na dos pilares, sendo de fácil montagem e execução. No entanto, os ensaios confirmaram que para este tipo de armadura de punção, deve-se garantir que não haja folga entre o gancho e as faces superiores da armadura de flexão (Figura 2.13), que estão lhe servindo de apoio, para a sua devida ancoragem; caso contrário, toda a sua eficácia estará comprometida, bem como a segurança da ligação. 
<smiles>c1ccccc1</smiles>

ancoragem correta<smiles>c1ccc2ccccc2c1</smiles>

ancoragem incorreta

Figura 2.13 - Detalhe da ancoragem dos ganchos

Outra dificuldade que aparece com o uso destas armaduras é onde ancorá-las, principalmente em lajes com pequenas espessuras. Este problema pode ser resolvido através da ancoragem desses estribos nas armaduras longitudinais de flexão superiores e inferiores. Nos modelos ensaiados por MARTINELLI (1974) e TAKEYA (1981), como não existia uma armadura inferior, os estribos foram ancorados no prolongamento da armadura negativa (Figura 2.14).

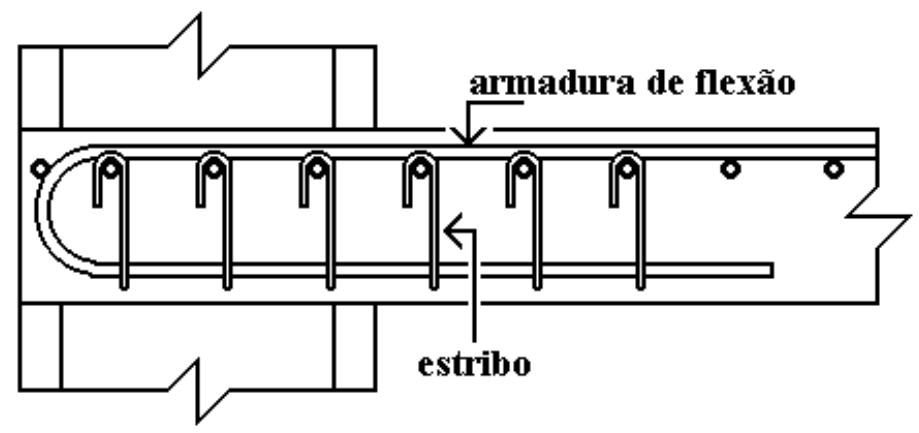

Figura 2.14 - Ancoragem dos estribos

\subsubsection{BARRAS DOBRADAS}

Estas barras seriam o prolongamento da armadura negativa de flexão e estariam sendo ancoradas na face inferior da laje (Figura 2.15). Além da ancoragem dessas barras ser um problema para o caso de lajes com pouca espessura, o seu uso é inadequado para ligações da laje com pilares de borda e de canto. Estudos realizados por MARTINELLI (1974) e TAKEYA (1981) comprovam que, nessas regiões, a disposição das barras dobradas é paralela à superfície de ruína observada nas bordas da laje. 


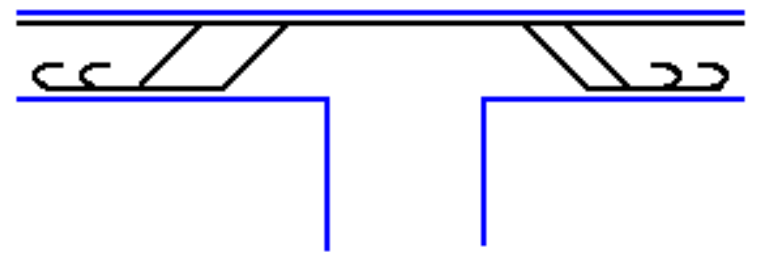

Figura 2.15 - Barras dobradas

Segundo TAKEYA (1981), PARK; ISLAM (1976), através da análise de lajes carregadas simetricamente, com e sem armadura de punção, chegaram às seguintes conclusões: o uso de barras dobradas aumenta a resistência da laje, não aumentando, no entanto, a sua ductilidade; já o uso de estribos fechados ancorados nas barras de flexão proporciona, além de um aumento na resistência da ligação, um considerável aumento na sua ductilidade.

\subsection{4 "SHEARHEADS"}

Na realidade, "shearheads" são perfis metálicos embutidos na laje e posicionados na cabeça do pilar (Figura 2.16). PARK; ISLAM (1976) ressaltam que o uso deste tipo de reforço aumenta a resistência da ligação laje-pilar e também, dentro de certos limites, a sua ductilidade.

Ensaios feitos por CORLEY; HAWKINS (1968) constataram que corpos-de-prova com "shearhead" tiveram um aumento na resistência da ligação da ordem de $75 \%$ em relação a corpos-de-prova sem este tipo de reforço. A situação por eles analisada foi a de ligações da laje com pilares internos, com carregamento simétrico.

GODYCKI; KOZICKI² apud LIBÓRIO (1985) observaram que houve um acréscimo de $40 \%$ a $70 \%$ na capacidade resistente das ligações laje-pilar internas, excentricamente carregadas, devido à presença de "shearheads".

${ }^{2}$ GODYCKI, T.; KOZICKI, J. (1984) Eccentrically loaded interior slab column conections with shearhead reinforcement. Materiaux et Constructions, v.17, n.98, p.145-148 apud LIBÓRIO, J. B. L. (1985) Estudo experimental da ruína de ligações laje-pilar em bordas com pilares de seção retangular. São Carlos. Dissertação (mestrado), EESC-USP. 
No entanto, GONÇALVES ${ }^{3}$ apud FIGUEIREDO F ${ }^{\circ}$ (1989) constatou, através de ensaios, que a carga de ruína observada para pilares de borda com "shearheads" foi menor que a dos modelos sem qualquer tipo de armadura transversal. Foi observado que, além de interferir na armadura do pilar e nas armaduras de flexão em lajes de pouca espessura, o uso de "shearheads" apresenta um custo elevado, sendo indicado apenas para pilares internos.

Convém destacar que o uso de "shearheads" é muito comum nos Estados Unidos.

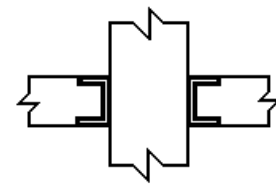

Corte A-A

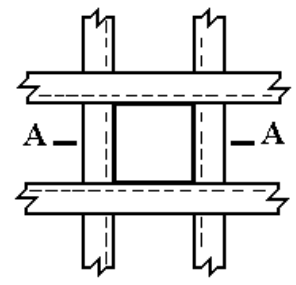

Planta

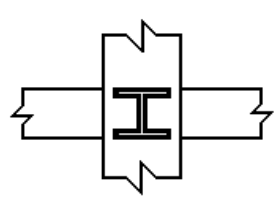

Corte A-A

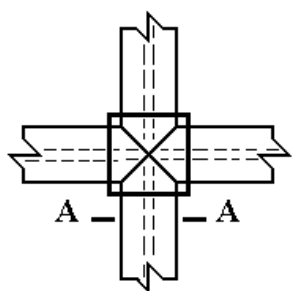

Planta
a) perfis metálicos tipo "U"
b) perfis metálicos tipo "I"

Figura 2.16 - "Shearheads"

\subsubsection{FIBRAS DE AÇO}

Podem ser utilizadas fibras de aço misturadas à massa de concreto. Estas fibras podem ser retas, em forma de gancho ou ainda plissadas, sendo que suas dimensões variam em torno de $50 \mathrm{~mm}$ de comprimento e de $0,5 \mathrm{~mm}$ de espessura. Com base em ensaios, SWAMY; ALI (1982) chegaram à conclusão de que, apesar do uso de armaduras de cisalhamento ser mais eficiente que o uso de fibras, o tempo para realizar a montagem e execução da armadura na laje é significativamente maior que o tempo para preparar o concreto com fibras. Além disto, a presença de fibras proporciona uma maior ductilidade à ligação.

3 GONÇALVES, R.M. (1986) Estudo experimental da ruína de ligações laje-pilar em bordas de lajes-cogumelo com reforço transversal constituído de perfis metálicos. São Carlos. Dissertação (mestrado), EESC-USP apud FIGUEIREDO Fo, J.R. (1989) Sistemas estruturais de lajes sem vigas: subsídios para o projeto e execução. São Carlos. Tese (doutorado), EESC-USP. 
O aumento da resistência de ligações com fibras em relação a ligações sem armadura de cisalhamento e sem fibras pode chegar até a ordem de $40 \%$. É importante frisar que os ensaios realizados foram feitos apenas para a situação de pilares internos, submetidos a carregamentos simétricos.

\subsubsection{CONECTORES TIPO PINO}

O uso de conectores tipo pino, com extremidades alargadas (Figura 2.17), é recomendado pelo texto base da NB1-94, em fase de projeto, e apresenta as seguintes vantagens, mencionadas em FIGUEIREDO $F^{\circ}$ (1989) e aqui transcritas:

- são fáceis de instalar, mesmo em lajes relativamente finas;

- não interferem na colocação e posicionamento das armaduras dos pilares e de flexão das lajes;

- possibilitam ancoragem satisfatória nas duas extremidades, de modo que a armadura atinja toda a sua capacidade resistente antes da ruptura;

- aumentam a resistência e ductilidade da ligação.
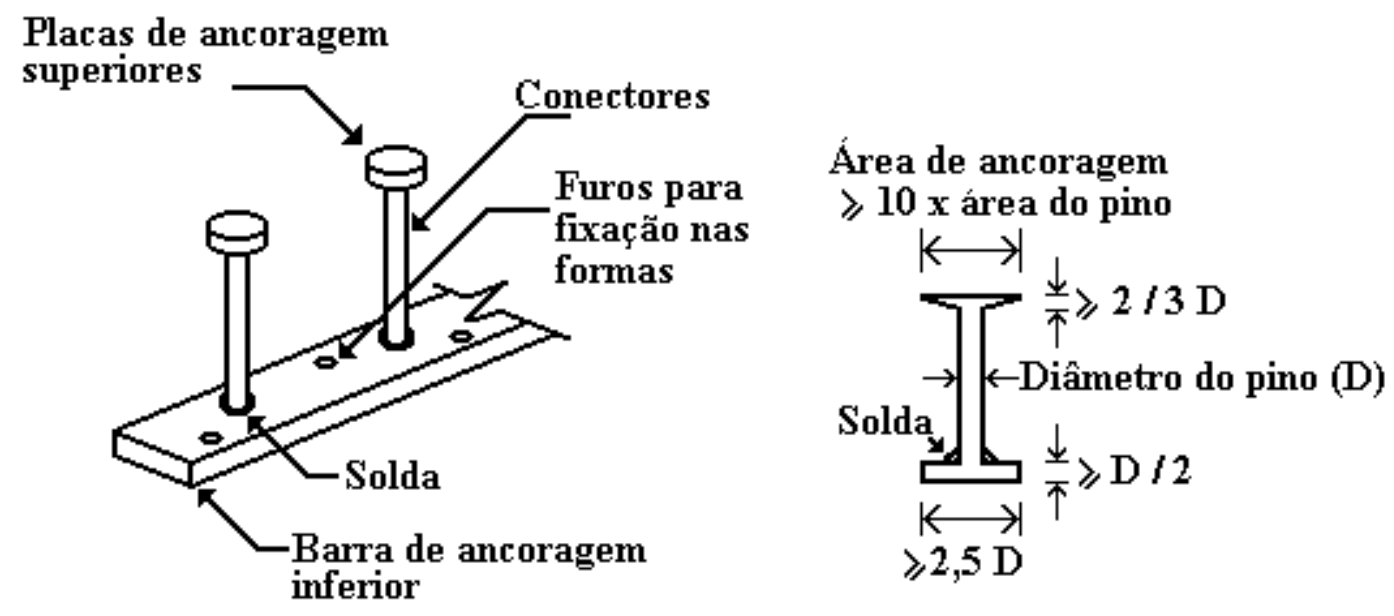

Figura 2.17 - Detalhe dos conectores

Para que a ancoragem seja efetiva, deve-se garantir que a armadura de flexão negativa esteja abaixo da chapa de ancoragem superior do conector (Figura 2.18). 


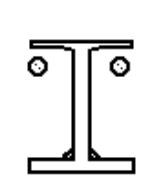

(certo)

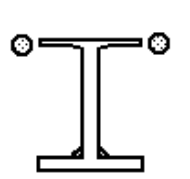

(errado)

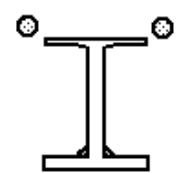

(errado)

Figura 2.18 - Ancoragem dos conectores

\subsubsection{SEGMENTOS DE PERFIS METÁlICOS}

Podem ser utilizados, ao invés de conectores tipo pino, pequenos segmentos de perfis metálicos de seção transversal tipo "I", conforme mostrado em FIGUEIREDO $\mathrm{F}^{\circ}$ (1989). Este tipo de armadura, apesar de ser adequado segundo o ponto de vista da ancoragem do elemento na laje, não é recomendado segundo o ponto de vista de produção e de economia (Figura 2.19).

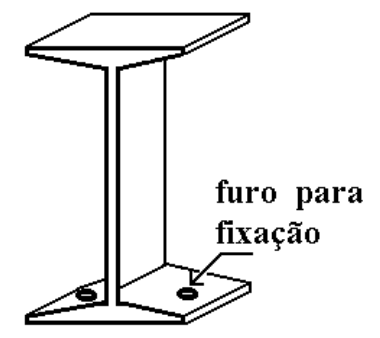

Figura 2.19 - Segmentos de perfis metálicos "I"

\subsection{MODELOS DE CÁLCULO}

\subsubsection{MODELO DA SUPERFÍCIE DE CONTROLE}

O mais antigo modelo de cálculo e também o mais utilizado é aquele em que se calcula uma tensão nominal de cisalhamento em uma determinada superfície de controle e, a seguir, compara-se o seu valor com um determinado parâmetro de resistência do concreto. Este modelo é denominado de Modelo da Superfície de Controle. 
Embora este método de cálculo pouco ou nada tenha a haver com a realidade do fenômeno físico, ele é bastante simples e, quando bem calibrado, conduz a consistentes e razoáveis predições. Além disso, ele é a base da maioria dos regulamentos que, por sua vez, diferem basicamente na definição da superfície de controle e na escolha do parâmetro de resistência. Entre alguns dos regulamentos que utilizam este modelo estão o Código Modelo CEB-FIP (1978), a NBR 6118/82, o ACI 318/89, o EUROCODE $\mathrm{N}^{\mathrm{O}} 2$ (1992), a nova versão do código-modelo CEB-FIP (1990) e o texto-base da NB-1/94.

Define-se, portanto, a tensão nominal de cisalhamento como sendo a razão entre a força cortante e a área da superfície de controle. Esta superfície possui forma cilíndrica ou prismática, dependendo do critério de cálculo a ser utilizado (Figura 2.20).

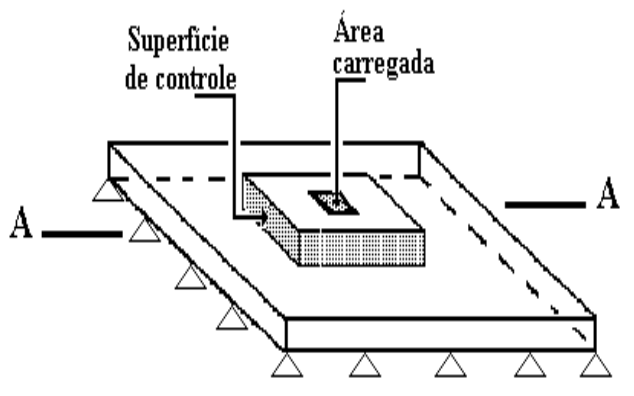

a) Esquema

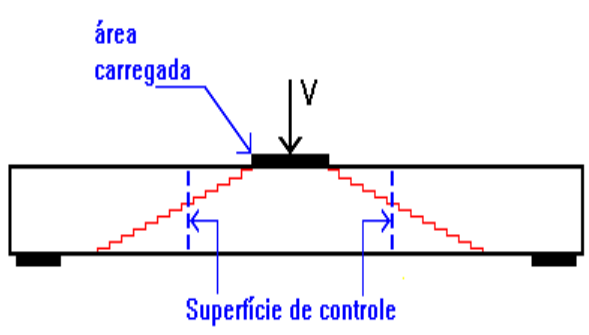

b) Corte A-A

Figura 2.20 - Superfície de controle

A área desta superfície é dada pela multiplicação do perímetro da superfície de controle pela respectiva altura.

O perímetro é definido por uma linha situada no plano da laje, a uma certa distância da área carregada, sendo que esta distância varia conforme o regulamento utilizado. Se o contorno da área carregada for côncavo, a seção da superfície de controle, paralela ao plano médio da laje, terá a forma de um polígono convexo, circunscrito à área carregada, com os cantos podendo ou não ser arredondados, de acordo com cada regulamento (Figura 2.21). 
A altura da superfície de controle pode ser dada pela espessura da laje (h), altura útil (d) ou braço de alavanca dos momentos internos (z), dependendo também de qual o regulamento a ser adotado (Figura 2.22).

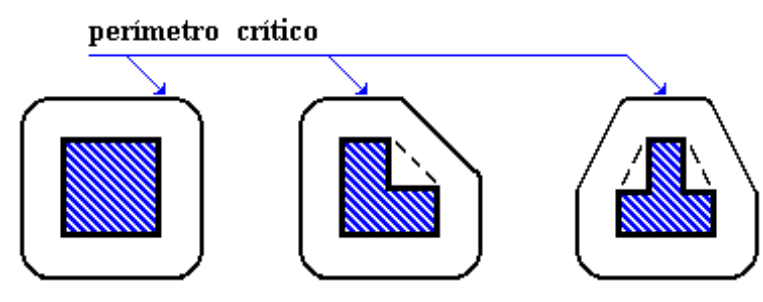

Figura 2.21 - Perímetro

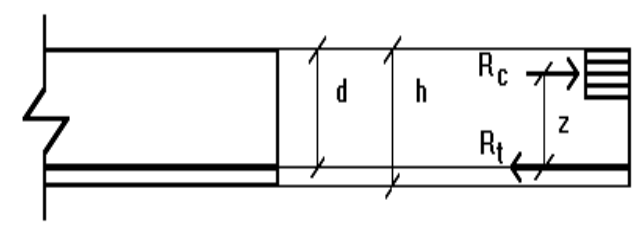

Figura 2.22 - Altura

O valor desta tensão nominal de cisalhamento é então comparado com um parâmetro de resistência do concreto ao cisalhamento que, por sua vez, pode ser dado em função da resistência característica do concreto à compressão, o $\mathrm{f}_{\mathrm{ck}}$.

\subsubsection{OUTROS MODELOS}

Existem ainda outros modelos denominados "racionais" e que são fundamentados pelos modelos constitutivos do concreto e do aço. Têm-se, como exemplos, o "Modelo Mecânico", desenvolvido por Kinnunen e Nylander, a "Teoria de Nölting", a Teoria Plástica e o "Modelo de Andra". Além disso, atualmente, SHEHATA (1985) e GOMES (1991) também propuseram novos modelos de cálculo. No entanto, nenhum dos modelos mencionados obteve uma aceitação mais geral. 


\section{TEXTO BASE DA NB-1/94}

\subsection{APRESENTAÇÃO E COMENTÁRIOS}

Uma vez que serão feitos comentários a respeito do texto base da NB-1/94 sobre punção, julgou-se necessária sua transcrição, intercalada com diversas observações e sugestões. Estes comentários foram baseados no texto base apresentado por STUCCHI; KNAPP (1993).

De forma a se diferenciar o texto base das sugestões feitas, essas sugestões foram impressas em caracteres itálicos. Além disso, também foram incluídas "Figuras extras".

Trata-se, portanto, do item 19.3 do texto base, que tem como título:

\section{" Dimensionamento de Lajes à Punção ".}

" Punção é o Estado Limite Último determinado por cisalhamento no entorno de cargas concentradas. Ela é diferente do Estado Limite Último determinado por cisalhamento em seções planas solicitadas à força cortante (ver item 19.2).

\subsubsection{Modelo de cálculo}

O modelo de cálculo é essencialmente empírico, correspondendo à verificação do cisalhamento numa superfície crítica. "

" A - Nos casos de carregamento simétrico: 


$$
\tau_{\mathrm{Sd}}=\frac{\mathrm{FSd}_{\mathrm{Sd}}}{\mu \mathrm{d}} \leq \tau_{\mathrm{Rd}}
$$

onde:

$\mathrm{d}=$ altura útil da laje ao longo do contorno crítico $\mathrm{C}^{\prime}$ externo ao contorno $\mathrm{C}$ da área de aplicação da carga e deste distante $2 \mathrm{~d}$ no plano da laje

$\mathrm{d}=\left(\mathrm{d}_{\mathrm{x}}+\mathrm{d}_{\mathrm{y}}\right) / 2$, sendo $\mathrm{d}_{\mathrm{x}}$ e $\mathrm{d}_{\mathrm{y}}$ as alturas úteis nas duas direções ortogonais

$\mu \quad=$ perímetro do contorno crítico $\mathrm{C}^{\prime}$

$\mu \mathrm{d}=$ superfície crítica

$\mathrm{F}_{\mathrm{Sd}}=$ carga ou reação concentrada de cálculo

A carga de punção $\mathrm{F}_{\mathrm{S} d}$ pode ser reduzida da carga distribuída aplicada na face oposta da laje, dentro do perímetro considerado na verificação, $\mathrm{C}$ ou $\mathrm{C}^{\prime}$."

Observação: Faltou apenas definir $\tau_{\mathrm{Sd}} e \tau_{\mathrm{Rd}}$ como sendo tensão atuante de cálculo e tensão resistente de cálculo, respectivamente.
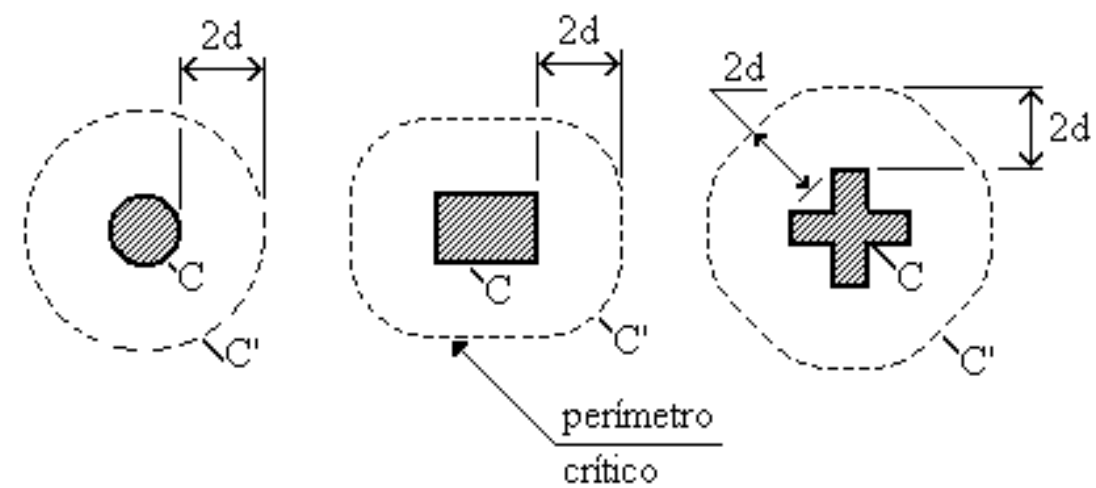

Fig. 19.3.1 - Perímetro crítico em pilares internos

" B - Nos casos em que além da carga vertical, existe transferência de momento da laje ao pilar, seu efeito deve ser considerado. Assim:

$$
\tau_{\mathrm{Sd}}=\frac{\mathrm{F}_{\mathrm{Sd}}}{\mu \mathrm{d}}+\frac{\mathrm{KM}_{\mathrm{Sd}}}{\mathrm{W}_{\mathrm{Pd}}} \leq \tau_{\mathrm{Rd}}
$$


" sendo:

$\mathrm{K}=$ coeficiente que fornece a parcela do $\mathrm{MSd}_{\mathrm{Sd}}$ transmitida ao pilar por cisalhamento, que depende da relação $\mathrm{c}_{1} / \mathrm{c}_{2}$

$\mathrm{c}_{1}=$ dimensão do pilar paralela à excentricidade da carga

$c_{2}=$ dimensão do pilar perpendicular à excentricidade

O coeficiente $\mathrm{K}$ assume os seguintes valores:

TABELA 19.3.1 - VALORES DE K

\begin{tabular}{c||c|c|c|c}
\hline $\mathrm{c}_{1} / \mathrm{c}_{2}$ & 0,5 & 1,0 & 2,0 & 3,0 \\
\hline $\mathrm{K}$ & 0,45 & 0,60 & 0,70 & 0,80 \\
\hline
\end{tabular}

$\mathrm{M}_{\mathrm{Sd}}=$ momento de cálculo aplicado pela laje ao pilar

$\mathrm{W}_{\mathrm{P}}=$ módulo de resistência plástica do perímetro crítico. Pode ser calculado desprezando a curvatura dos cantos do perímetro crítico "

Apesar dos termos $W_{P}$ (dado pela NB-1/94) e $W_{1}$ (dado pelo $C E B / 90)$ serem análogos, eles possuem definições diferentes. A definição dada pelo $C E B / 90$ fornece condições para que se possa calcular este parâmetro, que é relativo ao perímetro crítico $\mu$, de uma forma mais generalizada, através da seguinte expressão:

$$
\mathrm{W}_{1}=\int_{0}^{\mathrm{u}_{1}}|\mathrm{e}| \mathrm{d} \lambda
$$

onde:

$u_{1}=$ comprimento do perímetro crítico $\mu$;

$\mathrm{d} \mathbf{-}$ comprimento infinitesimal no perímetro;

$e=$ distância de $\mathrm{d}$ ao eixo sobre o qual o momento fletor $M_{S d}$ atua.

Em vista da maior abrangência, sugere-se que o texto base da NB-1/94 também apresente a expressão (3.1) como parte da definição de $W_{P}$. 

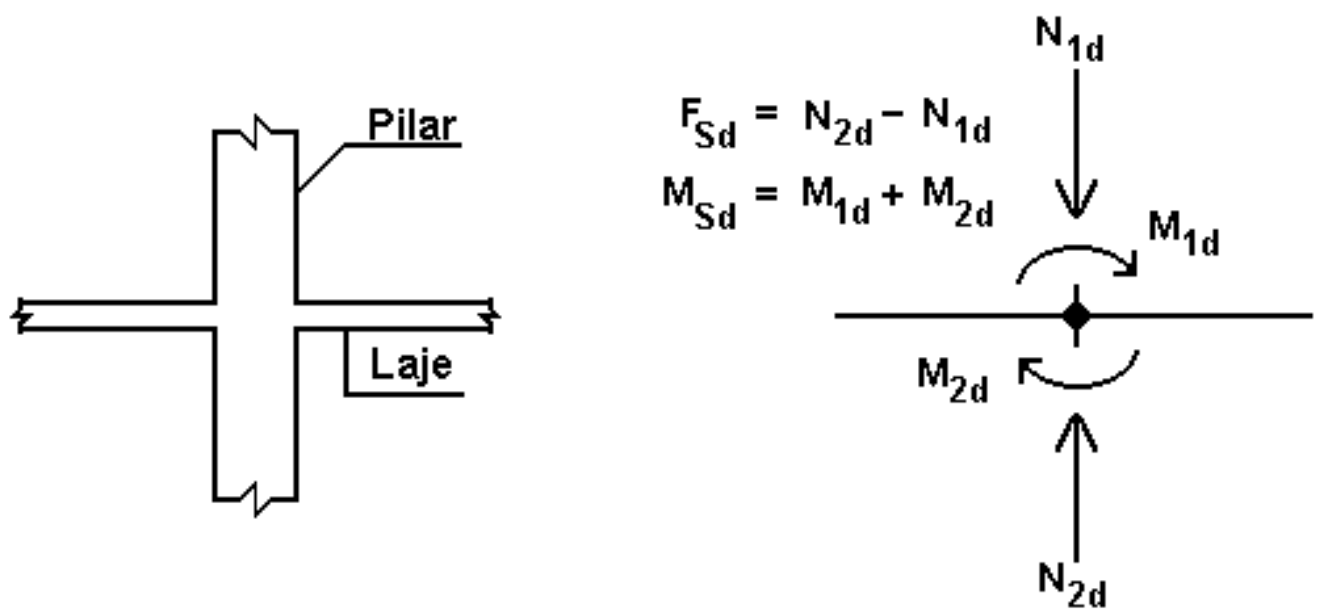

Fig. 19.3.2 - Esquema dos esforços na ligação laje-pilar

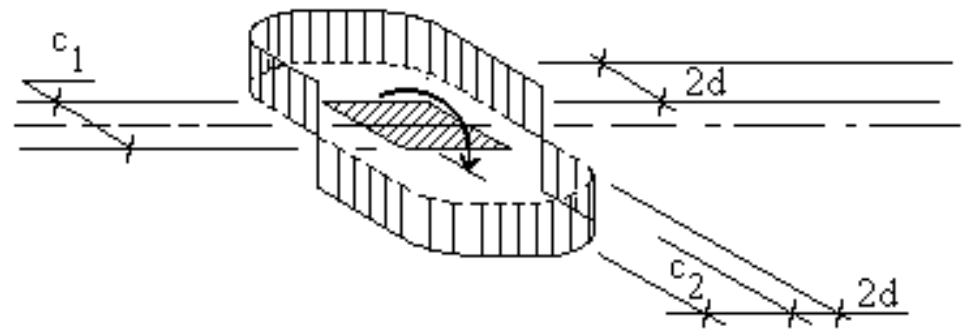

Fig. 19.3.3 - Distribuição devida a um momento de transferência da laje ao pilar

" Para um pilar retangular:

$$
\mathrm{W}_{\mathrm{P}}=\frac{\mathrm{c}_{1}^{2}}{2}+\mathrm{c}_{1} \mathrm{c}_{2}+4 \mathrm{c}_{2} \mathrm{~d}+16 \mathrm{~d}^{2}+2 \pi \mathrm{dc}_{1}
$$

Por se julgar útil, apresenta-se aqui a expressão de $W_{P}$ para pilares circulares internos, não fornecida pelo texto base da NB-1/94 e nem pelo CEB/90:

$$
\mathrm{W}_{\mathrm{PC}}=4 \mathrm{r}^{2}+16 \mathrm{rd}+16 \mathrm{~d}^{2}
$$

onde:

$\mathrm{r}=$ raio do pilar. 
" Comentário: Estuda-se, como solução alternativa, a liberação da verificação $\tau_{\mathrm{sd}}\left(\mathrm{F}_{\mathrm{Sd}}, \mathrm{M}_{\mathrm{Sd}}\right) \leq \tau_{\mathrm{Rd}}$ com $\tau_{\mathrm{sd}}$ calculado elasticamente, usando, por exemplo, o Método dos Elementos Finitos. "

Observa-se que o texto base não menciona a situação de um pilar interno submetido a momentos fletores atuando segundo duas direções diferentes. Neste caso, sugere-se a inclusão de mais um termo na expressão fornecida no item 19.3.1B, a ser calculado de forma análoga à segunda parcela da soma presente nesta mesma expressão. Este será o procedimento adotado para a verificação do exemplo a ser apresentado no capítulo 4, referente a esta situação.

" C - Nos pilares de borda:

- quando não agir momento no plano paralelo à borda livre:

$$
\tau_{\mathrm{Sd}}=\frac{\mathrm{F}_{\mathrm{Sd}}}{\mu^{*} \mathrm{~d}}+\frac{\mathrm{K}_{1} \mathrm{M}_{\mathrm{Sd}}}{\mathrm{W}_{\mathrm{P} 1} \mathrm{~d}} \leq \tau_{\mathrm{Rd}}
$$

onde:

$\mathrm{FSd}=$ reação de apoio

$\mu^{*} \quad=$ perímetro crítico reduzido

$\mathrm{M}_{\mathrm{Sd}}=\left(\mathrm{M}_{\mathrm{Sd} 1}-\mathrm{M}_{\mathrm{Sd}}{ }^{*}\right) \geq 0$

$\mathrm{M}_{\mathrm{Sd} 1}=$ momento de cálculo no plano perpendicular à borda livre

$\mathrm{MSd}^{*}=$ momento de cálculo resultante da excentricidade do perímetro crítico reduzido $\mu^{*}$ em relação ao centro do pilar

$\mathrm{W}_{\mathrm{P} 1}=$ módulo de resistência plástica perpendicular à borda livre, calculado pelo perímetro $\mu$

$\mathrm{K}_{1}=$ conforme tabela 19.3.1 com $\mathrm{c}_{1}$ e $\mathrm{c}_{2}$ de acordo com a figura 19.3.4." 
o menor entre
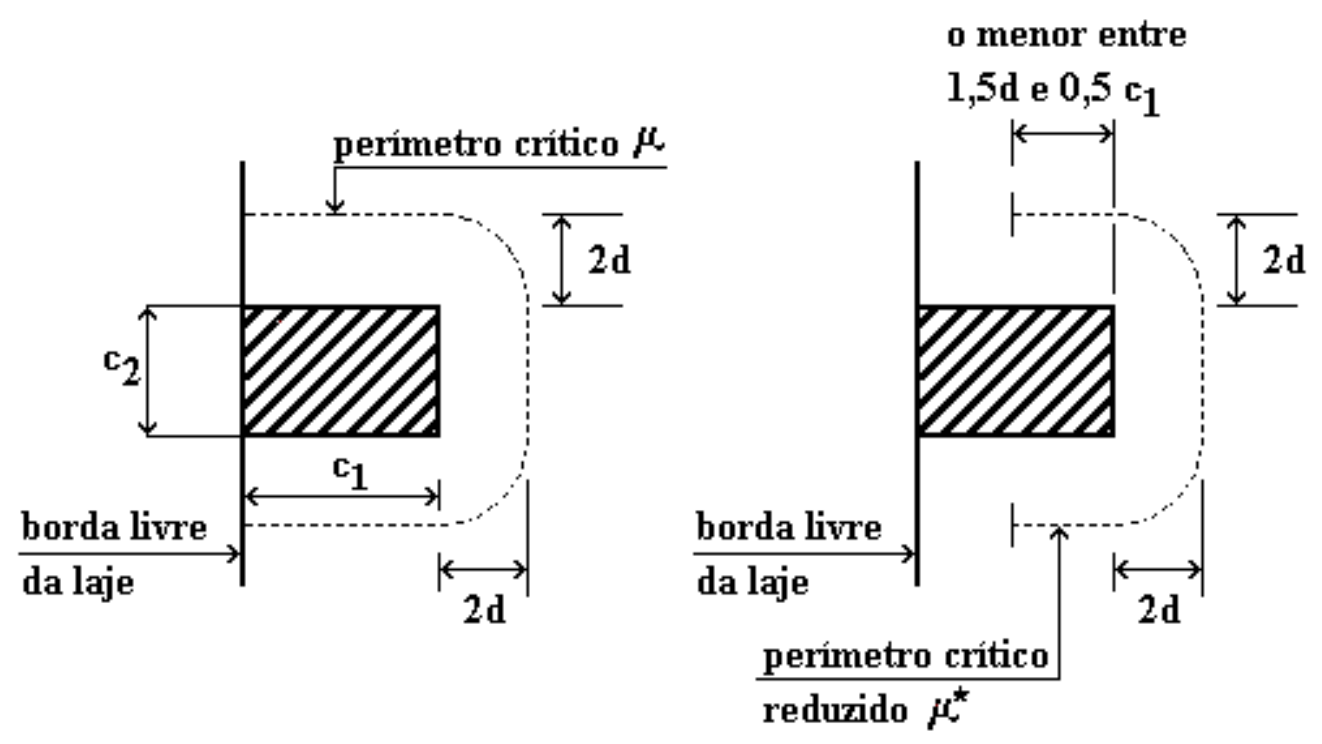

Fig. 19.3.4 - Perímetro crítico em pilares de borda

Observa-se que não foram fornecidas as expressões para a determinação do $M_{S d}{ }^{*}$ e nem do $W_{P 1}$. Com base na Figura 19.3 .4 e na expressão (3.1), tem-se que:

$$
\mathrm{W}_{\mathrm{P} 1}=\frac{\mathrm{c}_{1}^{2}}{2}+\frac{\mathrm{c}_{1} \mathrm{c}_{2}}{2}+2 \mathrm{c}_{2} \mathrm{~d}+8 \mathrm{~d}^{2}+\pi \mathrm{dc}_{1}
$$

Com relação a $\mathrm{MSd}_{\mathrm{S}}$, tem-se que:

$$
M_{S d^{*}}=F_{S d} \cdot e^{*}
$$

onde:

$e^{*}=$ excentricidade do perímetro crítico reduzido $\mu^{*}$, em relação ao centro do pilar (Figura extra 1). 
Esta excentricidade pode ser definida através da seguinte expressão:

$\mathrm{e}^{*}=\frac{\int_{0}^{\mu^{*}}|\mathrm{e}| \mathrm{d} \lambda}{\int_{0}^{\mu^{*}} \mathrm{~d} \lambda}=\frac{\mathrm{c}_{1} \mathrm{a}-\mathrm{a}^{2}+\frac{\mathrm{c}_{1} \mathrm{c}_{2}}{2}+2 \mathrm{dc}_{2}+\pi d \mathrm{c}_{1}+8 \mathrm{~d}^{2}}{2 \mathrm{a}+\mathrm{c}_{2}+2 \pi \mathrm{d}}$

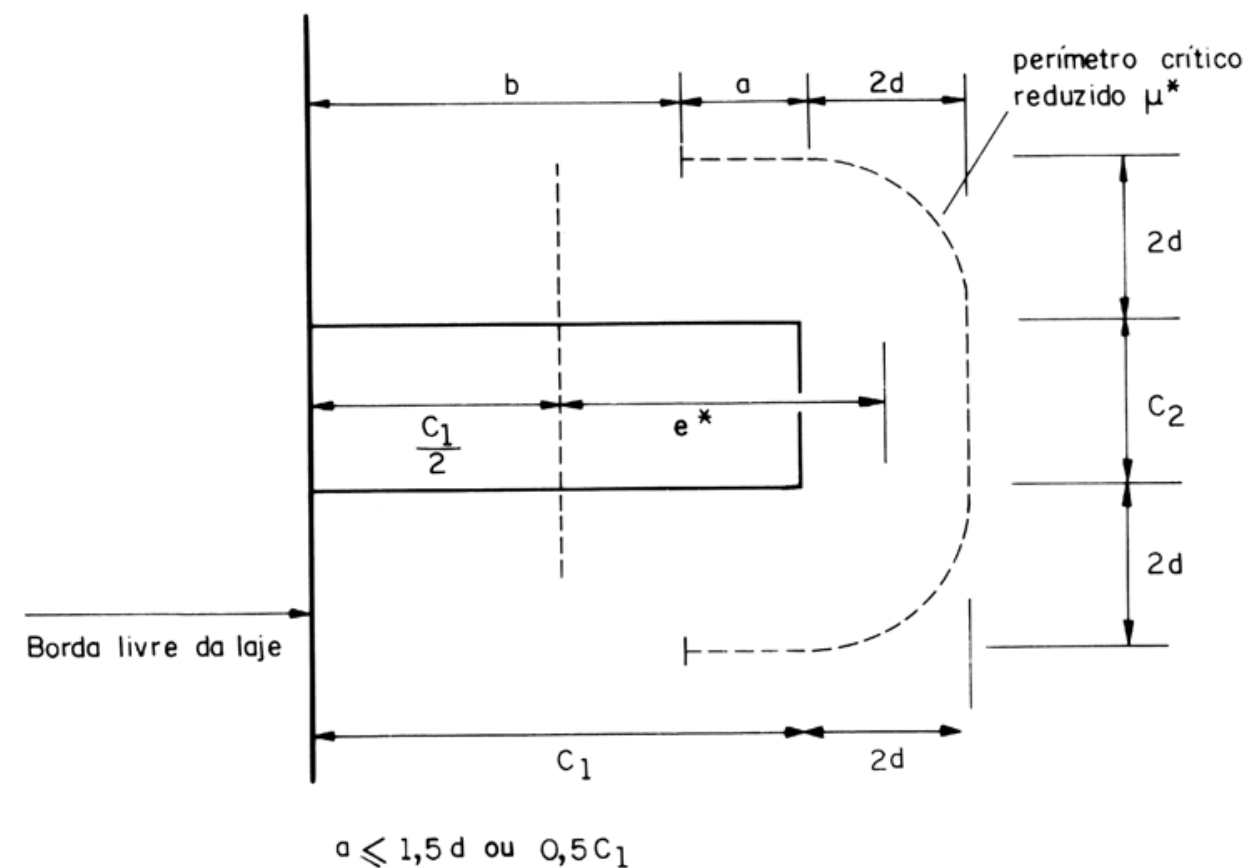

Figura extra 1 - Excentricidade do perímetro crítico reduzido

"- quando agir momento no plano paralelo à borda livre:

$$
\tau_{\mathrm{Sd}}=\frac{\mathrm{F}_{\mathrm{Sd}}}{\mu^{*} \mathrm{~d}}+\frac{\mathrm{K}_{1} \mathrm{M}_{\mathrm{Sd}}}{\mathrm{W}_{\mathrm{P} 1} \mathrm{~d}}+\frac{\mathrm{K}_{2} \mathrm{M}_{\mathrm{Sd} 2}}{\mathrm{~W}_{\mathrm{P} 2} \mathrm{~d}} \leq \tau_{\mathrm{Rd}}
$$

sendo:

$\mathrm{M}_{\mathrm{Sd} 2}=$ momento de cálculo no plano paralelo à borda livre

$\mathrm{W}_{\mathrm{P} 2}=$ módulo de resistência plástico na direção paralela à borda livre, calculado pelo perímetro $\mu$

$\mathrm{K}_{2}=$ conforme tabela 19.3.1, substituindo-se $\mathrm{c}_{1} / \mathrm{c}_{2}$ por $\mathrm{c}_{2} / 2 \mathrm{c}_{1} \quad\left(\mathrm{c}_{1}\right.$ e $\mathrm{c}_{2}$ conforme a figura 19.3.4)" 
Sugere-se que a expressão de $W_{P 2}$ seja incluida no texto base:

$$
\mathrm{W}_{\mathrm{P} 2}=\frac{\mathrm{c}_{2}^{2}}{4}+\mathrm{c}_{1} \mathrm{c}_{2}+4 \mathrm{c}_{1} \mathrm{~d}+8 \mathrm{~d}^{2}+\pi \mathrm{dc} \mathrm{c}_{2}
$$

Observou-se que, enquanto $K_{2}$ é obtido através da relação $c_{2} / 2 c_{1}$, o seu termo análogo $K$, dado pelo $C E B / 90$, é obtido através da relação c $1 / 2 c_{2}$. Para pilares internos, o texto base recomenda que, quanto maior a relação $c_{1} / c_{2}$, sendo c1 lado do pilar paralelo à direção em que o momento fletor atua, maior deve ser a parcela do momento fletor transmitido por esforços de cisalhamento. Seguindo o mesmo procedimento, era de se esperar, para pilares de borda com momento fletor atuando segundo a direção paralela à borda livre, que quanto maior a relação $c_{2} / c_{1}$, maior deveria ser a parcela do momento fletor a ser transmitida à ligação por esforços de cisalhamento. Neste aspecto, o texto base parece estar mais coerente que o $C E B / 90$.

" D - Nos pilares de canto:

Aplica-se o disposto para o pilar de borda quando não age momento no plano paralelo à borda. Nesse caso não se deve fazer correção na proporção $c_{1} / c_{2}$ para cálculo de K."

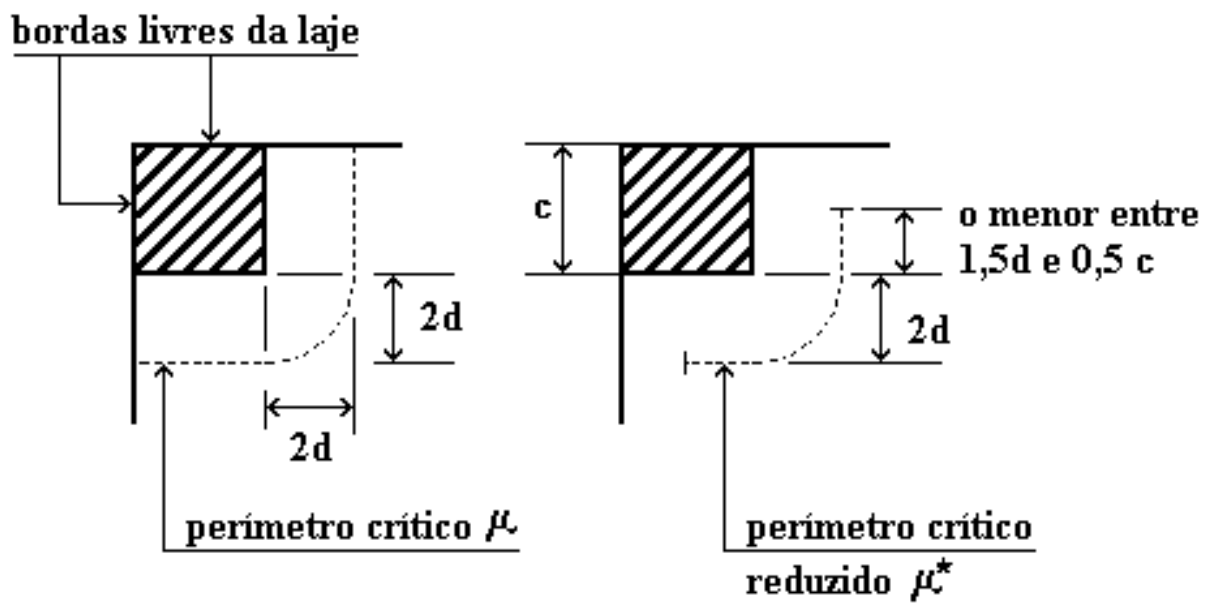

Fig. 19.3.5 - Perímetro crítico em pilares de canto

Segundo o texto, o pilar de canto deve ser tratado como um pilar de borda sem momentos atuando paralelamente à sua borda livre. 
Como o pilar de canto apresenta duas bordas livres, ignora-se alternadamente cada uma delas, projetando-se o momento fletor na direção perpendicular à borda livre adotada (Figura extra 2).
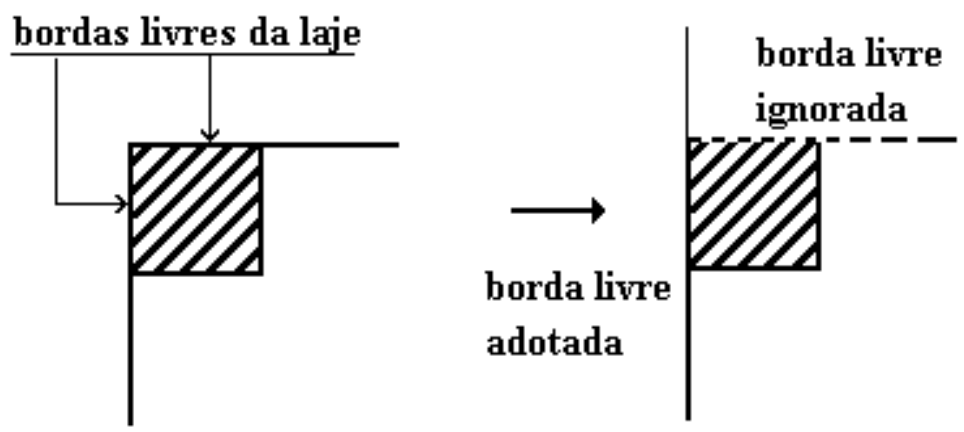

Figura extra 2 - Esquema para se considerar cada borda livre.

O texto menciona ainda que não se deve fazer qualquer correção na proporção $c_{1} / c_{2}$, utilizada na obtenção do valor de $K$, que, por sua vez, é dado pela tabela 19.3.1. Ou seja, a proporção $c_{1} / c_{2}$ não deve ser alterada pelo fato de se estar calculando um pilar de canto.

No entanto, quando o texto menciona que, para o pilar de canto, o cálculo deva ser feito como se fosse um pilar de borda sem momentos atuando paralelamente à borda, já está implícito que se use a relação $c_{1} / c_{2}$ na obtenção de K. Sendo assim, sugere-se a exclusão da última sentença do item 19.3.1D, que passaria a ter a seguinte forma:

"Aplica-se o disposto para o pilar de borda quando não age momento no plano paralelo à borda."

Na Figura extra 3 é mostrada a notação através da qual $e^{*}$ e $W_{P 1}$ foram calculados. A sugestão é que se inclua no texto base tanto as expressões como a notação utilizada: 


$$
\mathrm{e}^{*}=\frac{\mathrm{c}_{1} \mathrm{a}_{1}-\mathrm{a}_{1}{ }^{2}+\mathrm{c}_{1} \mathrm{a}_{2}+4 \mathrm{a}_{2} \mathrm{~d}+\pi \mathrm{c}_{1} \mathrm{~d}+8 \mathrm{~d}^{2}}{2\left(\mathrm{a}_{1}+\mathrm{a}_{2}+\pi \mathrm{d}\right)}
$$

$$
\mathrm{W}_{\mathrm{P} 1}=\frac{\mathrm{c}_{1}{ }^{2}}{4}+\frac{\mathrm{c}_{1} \mathrm{c}_{2}}{2}+2 \mathrm{c}_{2} \mathrm{~d}+4 \mathrm{~d}^{2}+\frac{\mathrm{c}_{1} \pi \mathrm{d}}{2}
$$

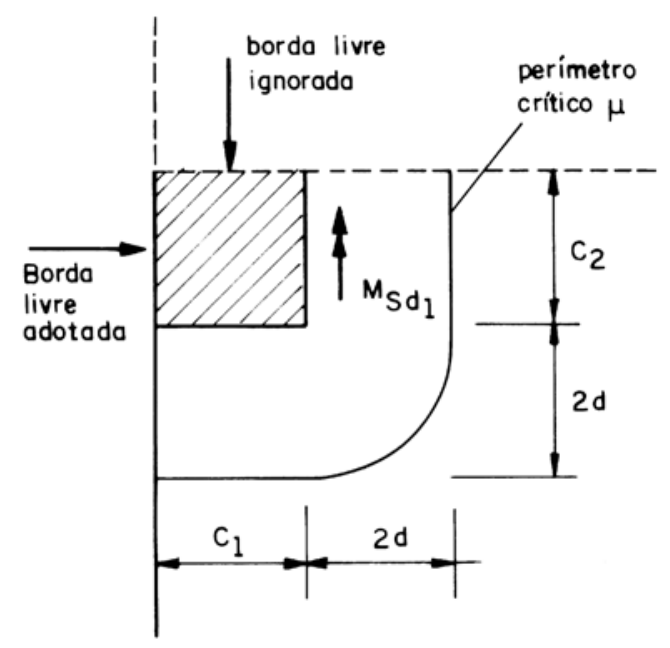

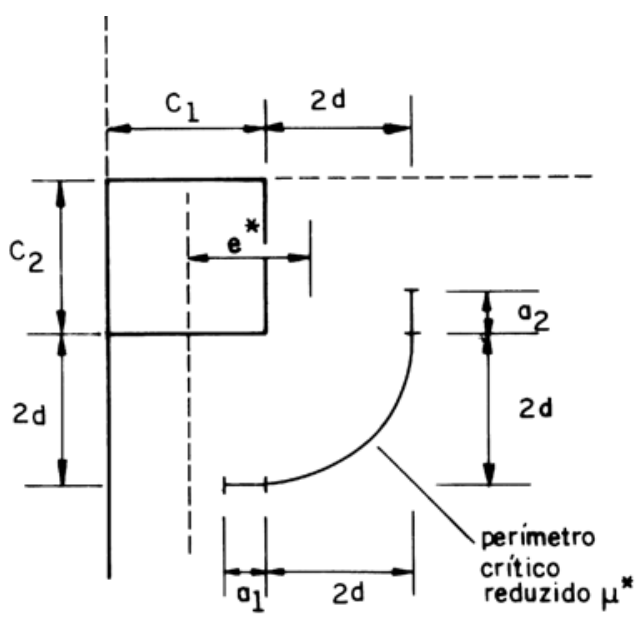

$a_{1} \leqslant 1,5 \mathrm{~d}$ ou $0,5 \mathrm{C}_{1}$

$a_{2} \leqslant 1,5 \mathrm{~d}$ ou $0,5 \mathrm{C}_{2}$

Figura extra 3 - Esquema para cálculo de $W_{P 1}$ e de $e^{*}$

Segundo esse esquema, $c_{1}$ e $c_{2}$ devem ser definidos como sendo os lados do pilar, perpendicular e paralelo à borda livre adotada, respectivamente.

" E - No caso em que existir capitel:

Devem ser feitas duas verificações nos perímetros críticos $C_{1}^{\prime}$ e $C_{2}^{\prime}$, conforme indica a figura 19.3.6, onde:

$\mathrm{d}=$ altura útil da laje fora do capitel a considerar no perímetro $\mathrm{C}_{2}$

$\mathrm{d}_{\mathrm{c}}=$ altura útil da laje na face do pilar

$\mathrm{d}_{\mathrm{a}}=$ altura útil da laje a ser considerada no perímetro $\mathrm{C}_{1}^{\prime}{ }^{\prime \prime}$ 


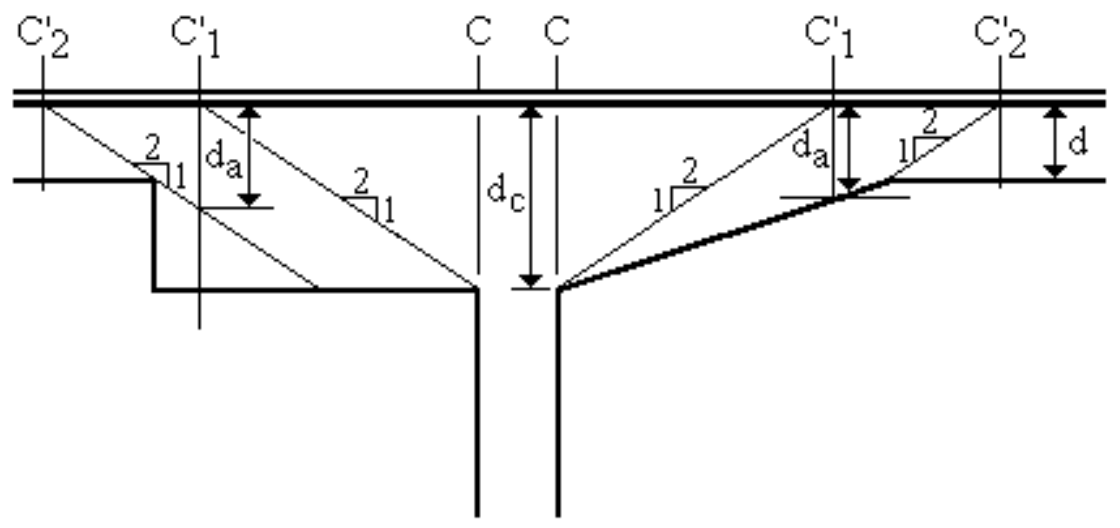

Fig. 19.3.6 - Definição da altura útil no caso de capitel

\section{" 19.3.2 Casos especiais de definição do perímetro crítico}

Se o contorno $\mathrm{C}$ apresentar reentrâncias, o contorno crítico $\mathrm{C}^{\prime}$ será paralelo ao polígono circunscrito ao contorno $\mathrm{C}$.

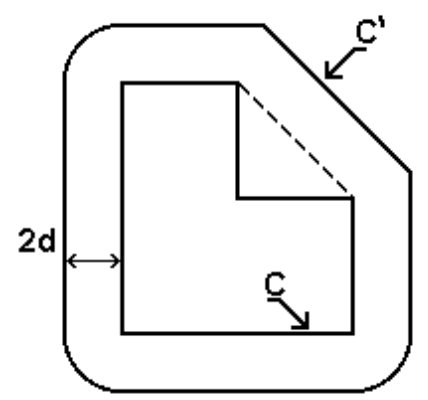

Fig. 19.3.7 - Perímetro crítico no caso do contorno C apresentar reentrância

Se existir na laje uma abertura situada a menos de $8 \mathrm{~d}$ do contorno $\mathrm{C}$, não será considerado o trecho do contorno crítico $\mathrm{C}^{\prime}$ entre as duas retas que passam pelo centro de gravidade da área de aplicação da carga e tangenciam o contorno da abertura. " 


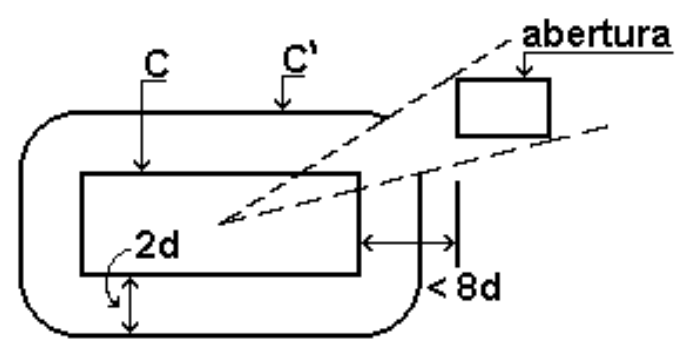

Fig. 19.3.8 - Perímetro crítico junto a abertura na laje

É interessante observar que o CEB/90 nada fala a respeito de aberturas, sendo necessário recorrer à sua versão mais antiga, o CEB/78. Observase, ainda, que o texto base não apresenta informações sobre como ficam definidos os perímetros críticos ( $\mu)$, localizados a uma distância de $2 d$ dos pilares, quando estes se localizam próximos a bordas livres (Figura extra 4).

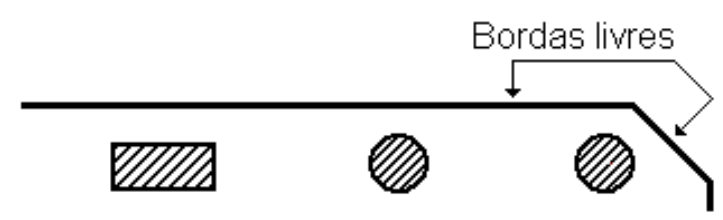

Figura extra 4 - Pilares próximos a bordas livres

Já a NBR 6118/82 menciona que, para o caso de segmentos do perímetro crítico $C^{\prime}$, situados a uma distância inferior a $3 d$ de uma borda livre, estes segmentos não serão considerados no valor do perímetro mencionado. É importante frisar que, para esta norma, a distância do perímetro crítico em relação ao contorno da área carregada é de $d / 2$.

\section{" 19.3.3 Interação entre solicitações normais e tangenciais}

Não se exige a verificação da influência das solicitações normais, decorrentes de flexão simples ou composta da laje, na resistência à punção. " 


\section{" 19.3.4 Sapatas}

Em sapatas rígidas não ocorre punção, apenas nas flexíveis. Ver Capítulo 22.

\subsubsection{Estado Limite Último}

\subsubsection{Verificação da compressão no concreto}

$$
\tau_{\mathrm{Sd}} \leq \tau_{\mathrm{Rd} 2}=\nu \mathrm{f}_{\mathrm{cd}}
$$

onde:

$v=$ conforme item 17.3.2.1

$\mathrm{f}_{\mathrm{cd}}=$ resistência à compressão de cálculo do concreto

Essa verificação deve ser feita no contorno C.

Para pilares de borda: $\quad \mu=c_{2}+3 d \leq c_{2}+2 c_{1}$

Para pilares de canto: $\quad \mu=3 \mathrm{~d} \leq \mathrm{c}_{1}+\mathrm{c}_{2}$ "

Teria faltado definir que, para pilares internos, o termo $\mu$ pode ser tomado como sendo o perímetro definido pelo contorno C. Além disso, apesar de se mencionar o item referente ao cálculo de v, esse item não foi encontrado. Portanto, apesar desta verificação ser extremamente importante, faltam dados para que ela seja feita segundo o texto base da NB-1/94. Sendo assim, optou-se por se transcrever aqui a formulação dada pelo CEB/90, sem se fazer qualquer adaptação ao texto base.

O CEB/90 define que o máximo valor da resistência à punção, para qualquer tipo de ligação, incluindo as reforçadas com armaduras de punção e as protendidas, é dado pela seguinte expressão:

$$
\frac{P_{\text {Sd,ef }}}{u_{o} d} \leq 0,5 f_{c d 2}
$$


onde:

para pilares internos : $u_{O}=$ perímetro do pilar;

para pilares de borda: $u_{O}=c_{x}+3 d \leq c_{x}+2 c_{y}$;

para pilares de canto: $u_{O}=3 d \leq c_{x}+c_{y}$;

$c_{x}=$ dimensão do pilar paralela à borda livre (análogo a $c_{2}$ );

$c_{y}=$ dimensão do pilar perpendicular à borda livre (análogo a $\left.c_{1}\right)$.

No cálculo, $P_{s d, e f}$ é a reação de apoio majorada de forma a se considerarem os efeitos de uma eventual transferência de momentos da laje para o pilar.

Para um pilar interno:

$$
\mathrm{P}_{\mathrm{Sd}, \mathrm{ef}}=\mathrm{P}_{\mathrm{Sd}}\left(1+\mathrm{K} \frac{\mathrm{M}_{\mathrm{Sd}}}{\mathrm{P}_{\mathrm{Sd}}} \frac{\mathrm{u}_{1}}{\mathrm{~W}_{1}}\right)
$$

onde, fazendo-se uma analogia com os termos do texto base da NB-1/94, tem-se que:

$K=$ constante análoga a $K$ para pilares internos;

$M_{S d}=$ momento fletor análogo a $M_{S d}$, para pilares internos;

$P_{S d}=$ termo análogo a $F_{S d}$;

$u_{1}=$ termo análogo ao perímetro crítico $\mu$, para pilares internos;

$W_{1}=$ termo análogo a $W_{P}$, para pilares internos.

Para um pilar de borda:

$$
\mathrm{P}_{\mathrm{Sd}, \mathrm{ef}}=\mathrm{P}_{\mathrm{Sd}}\left(1+\mathrm{K} \frac{\mathrm{M}_{\mathrm{Sd}}}{\mathrm{P}_{\mathrm{Sd}}} \frac{\mathrm{u}_{1}^{*}}{\mathrm{~W}_{1}}\right)
$$

onde, fazendo-se uma analogia com os termos do texto base da NB-1/94, tem-se que:

$K=$ constante tabelada em função $d a$ relação $c_{1} / 2 c_{2}$, para pilares de borda (esta constante é obtida de forma análoga, mas não igual a $K_{2}$ );

$M_{S d}=$ momento fletor análogo a $M_{S d 2}$, para pilares de borda;

$P_{S d}=$ termo análogo a $F_{S d}$;

$u_{1}{ }^{*}=$ termo análogo ao perímetro crítico reduzido $\mu^{*}$, para pilares de borda;

$W_{1}=$ termo análogo a $W_{P 2}$, para pilares de borda. 
Para um pilar de canto:

$$
P_{\text {Sd, ef }}=P_{\text {Sd }}
$$

$J a ́ o f_{c d 2}$ é dado pela seguinte expressão:

$$
\mathrm{f}_{\mathrm{cd} 2}=0,60\left(1-\frac{\mathrm{f}_{\mathrm{ck}}}{250}\right) \mathrm{f}_{\mathrm{cd}}
$$

onde $f_{c k}, f_{c d}$ e $f_{c d 2}$ são dados em MPa. Uma vez que se está utilizando as recomendações do CEB/90 com relação a este item, recomenda-se adotar, para esta verificação, o valor de $\gamma_{c}$ como sendo igual a 1,5.

\section{" 19.3.5.2 Verificação da armadura de punção}

Comentário: As duas equações abaixo, ítens A e B, apresentam coeficientes ligeiramente superiores aos do $\mathrm{CEB} / 90$ porque o coeficiente de ponderação da resistência do concreto $\gamma_{\mathrm{c}}$ foi reduzido de 1,5 para 1,4 .

A - Peças ou trechos sem armadura de cisalhamento

$$
\tau_{\mathrm{Sd}} \leq \tau_{\mathrm{Rd} 1}=0,13(1+\sqrt{20 / \mathrm{d}})\left(100 \rho \mathrm{f}_{\mathrm{ck}}\right)^{1 / 3}
$$

onde:

$\mathrm{d}$ = altura útil da laje ao longo do contorno crítico $\mathrm{C}^{\prime}$ da área de aplicação da carga, em centímetros

$\mathrm{d}=\left(\mathrm{d}_{\mathrm{x}}+\mathrm{d}_{\mathrm{y}}\right) / 2$, sendo $\mathrm{d}_{\mathrm{x}}$ e $\mathrm{d}_{\mathrm{y}}$ as alturas úteis nas duas direções ortogonais

$\rho=$ taxa de armadura de flexão

$\rho=\sqrt{\rho_{\mathrm{x}} \rho_{\mathrm{y}}}$, sendo $\rho_{\mathrm{X}} \mathrm{e} \rho_{\mathrm{y}}$ as taxas de armadura nas duas direções ortogonais, calculadas com a largura igual à dimensão do pilar, ou da área carregada, mais $3 \mathrm{~d}$ para cada um dos lados (ou até a borda da laje, se esta estiver mais próxima) " 
" Essa verificação deve ser feita no contorno crítico $C^{\prime}$ ou em $C^{\prime}{ }_{1}$ e $C^{\prime} 2$ no caso de existir capitel. "

Apesar de não estar no texto base, subentende-se que a unidade de $f_{c k}$ seja MPa, de forma a se obter, como resultado, o valor de $\tau_{\mathrm{Rd}} 1$ expresso também em MPa.

" B - Peças ou trechos com armadura de cisalhamento

$$
\tau_{\mathrm{Sd}} \leq 0,10(1+\sqrt{20 / \mathrm{d}})\left(100 \rho \mathrm{f}_{\mathrm{ck}}\right)^{1 / 3}+1,5 \frac{\mathrm{d}}{\mathrm{s}_{\mathrm{r}}}\left(\mathrm{A}_{\mathrm{Sw}} \mathrm{f}_{\mathrm{ywd}} \operatorname{sen} \alpha\right) / \mu \mathrm{d} \quad "
$$

Sugere-se que o termo $\underline{\mu \mathrm{d}}$, que divide a segunda parcela da soma, seja colocado entre parênteses: ( $\mu \mathrm{d})$.

" sendo:

$\mathrm{s}_{\mathrm{r}} \quad=$ espaçamentos radiais entre linhas de armadura de cisalhamento não maior do que $0,75 d$

$\mathrm{A}_{\mathrm{Sw}}=$ área da armadura de cisalhamento numa linha de armadura homotética a $\mathrm{C}^{\prime}$ "

Na realidade, $A_{S w}$ é a armadura contida ao longo de uma linha homotética ao pilar, definida conforme a Figura extra 5.

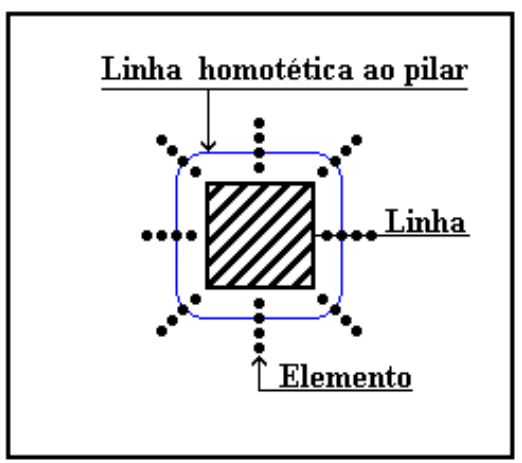

Figura extra 5 - Definição de $A_{S w}$, referente a uma linha homotética ao pilar

" Essa armadura deve ser preferencialmente constituída por três ou mais linhas de conectores tipo pino com extremidades alargadas, homotéticas a $\mathrm{C}^{\prime}$ e dispostas como indica a figura 19.3.9. Cada uma dessas extremidades deve estar ancorada para fora do plano da armadura de flexão correspondente. " 

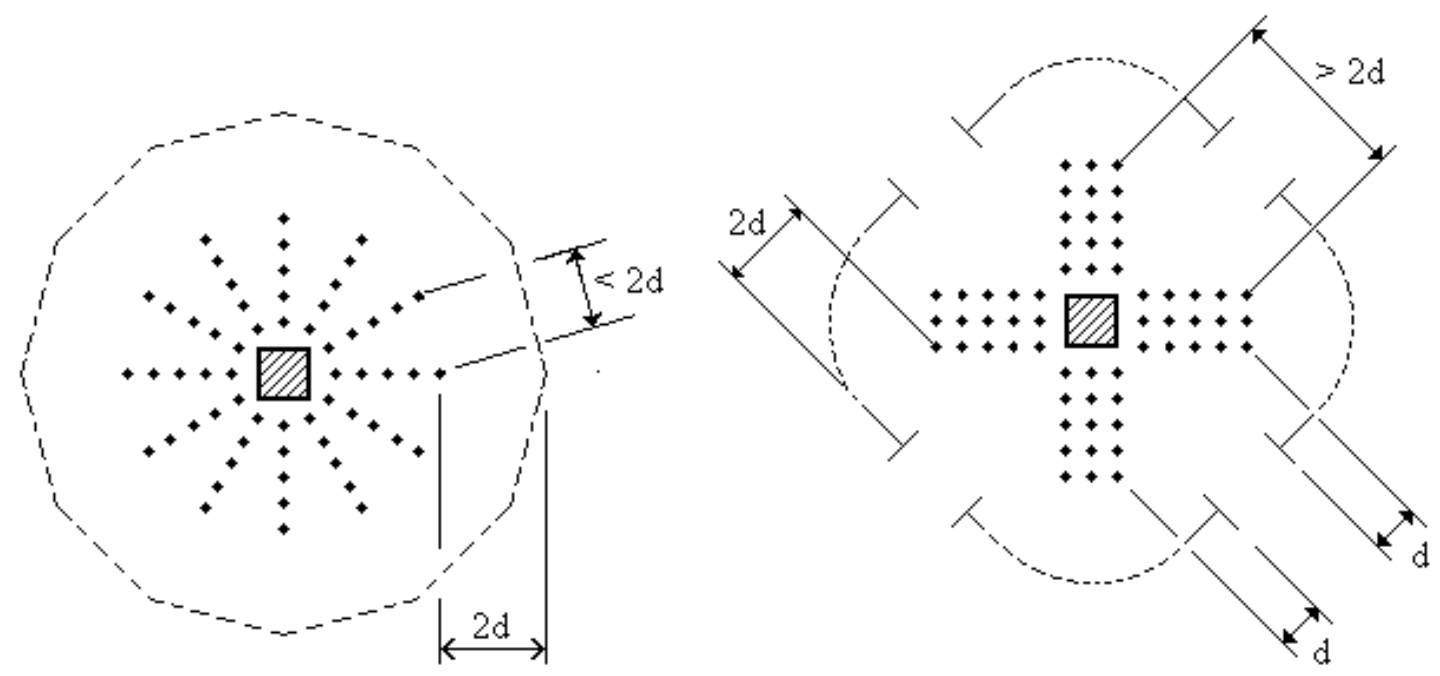

Fig. 19.3.9 - Disposição da armadura de punção em planta

Com relação ao cálculo do perímetro crítico externo à região armada, adotado em função da disposição dos conectores em cruz, sugere-se a seguinte formulação, baseada na Figura extra 6.

$$
\mu_{\mathrm{n}}=2\left\{4 \mathrm{~d}+2 \pi\left[\left(2 \mathrm{~d}+\frac{\mathrm{x}^{\prime}}{\operatorname{sen} \eta}\right)\left(\frac{2 \eta}{360}\right)+\left(2 \mathrm{~d}+\frac{\mathrm{y}^{\prime}}{\operatorname{sen} \theta}\right)\left(\frac{2 \theta}{360}\right)\right]\right\}
$$

onde:

$\mu_{n}=$ perímetro crítico externo à região armada;

$\theta, \eta=$ angulos definidos na Figura extra 6, dados em graus e relacionados, respectivamente, a $x^{\prime}$ e a $y^{\prime}$;

$x^{\prime}=$ distância entre a linha de conectores mais próxima do canto do pilar até o eixo paralelo ao lado $c_{1}$ e que passa pelo centro do pilar;

$y^{\prime}=$ distância entre a linha de conectores mais próxima do canto do pilar até o eixo paralelo ao lado $c_{2}$ e que passa pelo centro do pilar. 


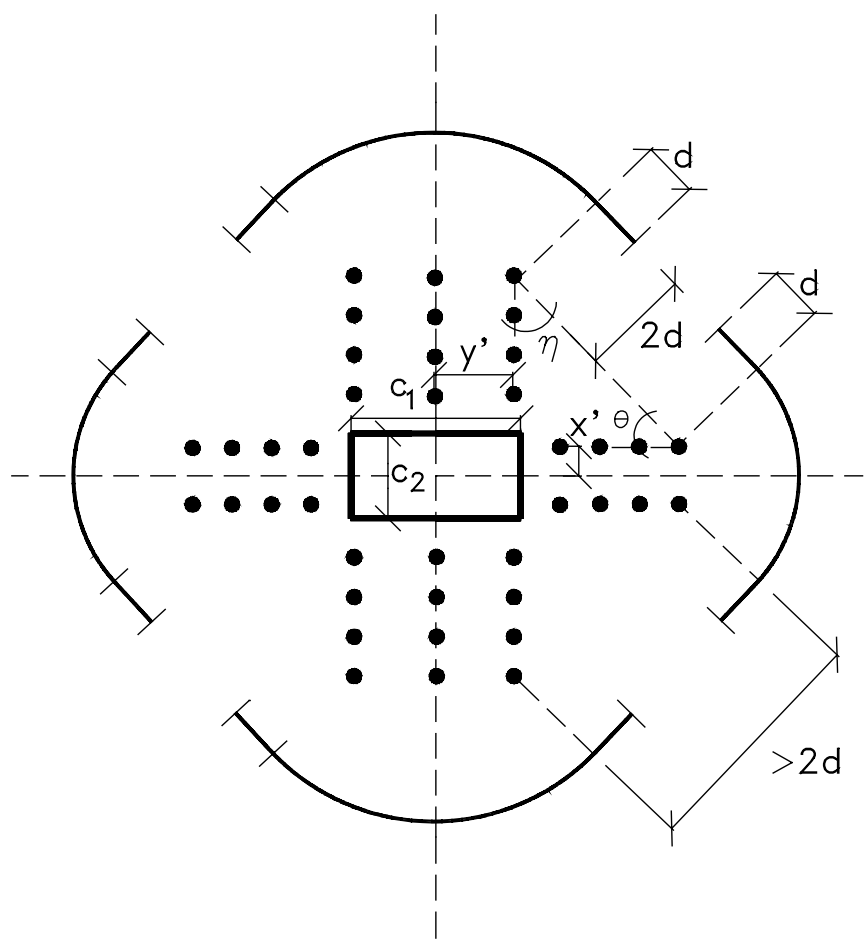

Figura extra 6 - Perímetro crítico externo $\mu_{n}$ (disposição em cruz)

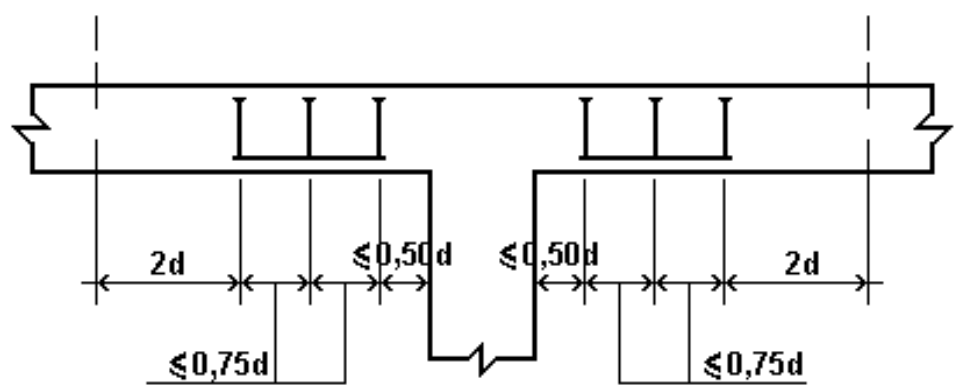

Fig. 19.3.10 - Disposição da armadura de punção em corte

É de vital importância que a armadura esteja devidamente ancorada, pois, caso contrário, poderá estar se levando em conta uma resistência adicional na ligação que, na realidade, não existe. A Figura extra 7 ilustra um exemplo de ancoragem de estribos com ganchos na extremidade superior e também de conectores tipo pino. É muito importante que não exista folga na região de contato da armadura de flexão com os ganchos. Já para os conectores tipo pino, deve-se garantir que a armadura de flexão negativa esteja abaixo da chapa de ancoragem superior do conector. 


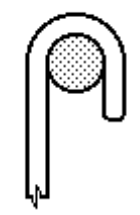

(certo)

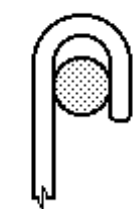

(errado)

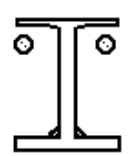

(certo)

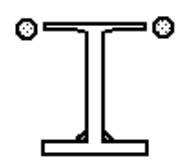

(errado)

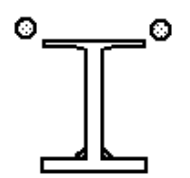

(errado)

a) ganchos

b) conectores tipo pino

Figura extra 7 - Ancoragem
" $\mathrm{f}_{\mathrm{ywd}}=$ resistência de cálculo da armadura de cisalhamento, não maior do que $300 \mathrm{MPa}$ para conectores ou $250 \mathrm{MPa}$ para estribos.

Comentário: Será definido o tipo de detalhamento de estribo a ser aceito pela norma
$\alpha$ = ângulo de inclinação entre o eixo da armadura de cisalhamento e o plano da laje
$\mu=$ perímetro crítico ou perímetro crítico reduzido no caso de pilares de borda ou canto. "

A sugestão agora apresentada apenas visa evitar uma certa confusão com relação às unidades utilizadas na expressão do item 19.3.5.2B. Sugere-se que $A_{S w}$ seja dada em $\mathrm{cm}^{2} ; d$, s $s_{r}$ e $\mu$ sejam dados em $\mathrm{cm} ; f_{y w d}$ e $f_{c k}$ sejam dados em MPa.

Deve-se atentar para o fato de que, enquanto o valor da tensão atuante de cálculo é geralmente calculado em $\mathrm{kN} / \mathrm{cm}^{2}$, o valor da tensão resistente de cálculo é obtido em MPa.

Observou-se ainda que, enquanto no item 19.3.5.2A se compara uma tensão atuante de cálculo com uma tensão resistente de cálculo, definida logo a seguir por uma expressão, no item 19.3.5.2B compara-se a tensão atuante de cálculo diretamente com outra expressão. Portanto, sugere-se a definição de um $\tau_{\mathrm{Rd} 1}$ também para a expressão 19.3.5.2B. 
O CEB/90 apresenta ainda uma recomendação a mais que o texto base da NB-1/94, no que diz respeito à disposição de armaduras de punção, para pilares de borda e de canto. Esta recomendação está resumida na Figura extra 8:

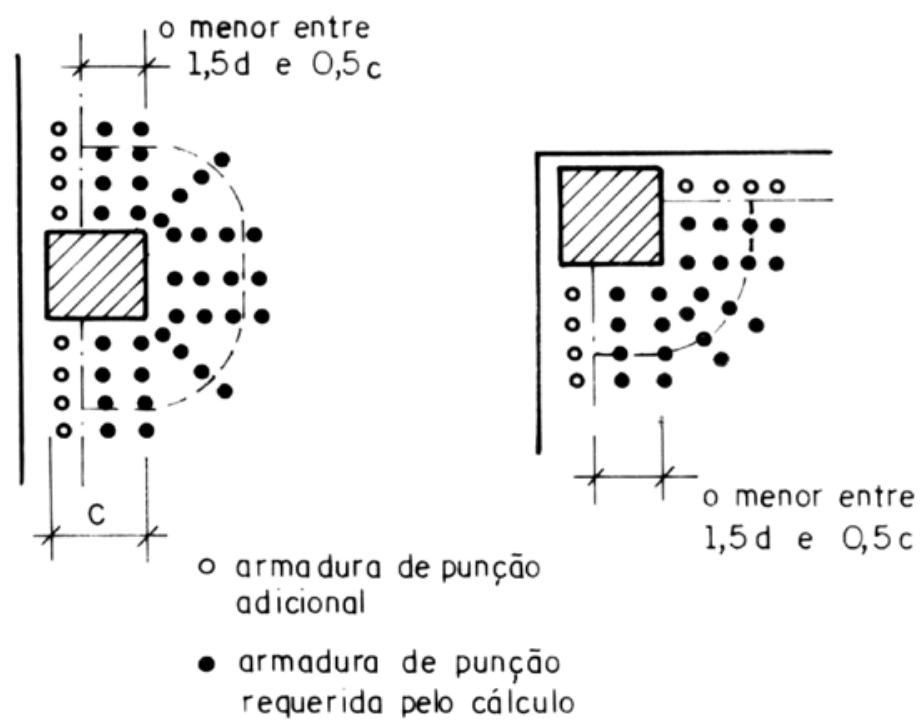

Figura extra 8 - Armadura de punção para pilares de borda e de canto
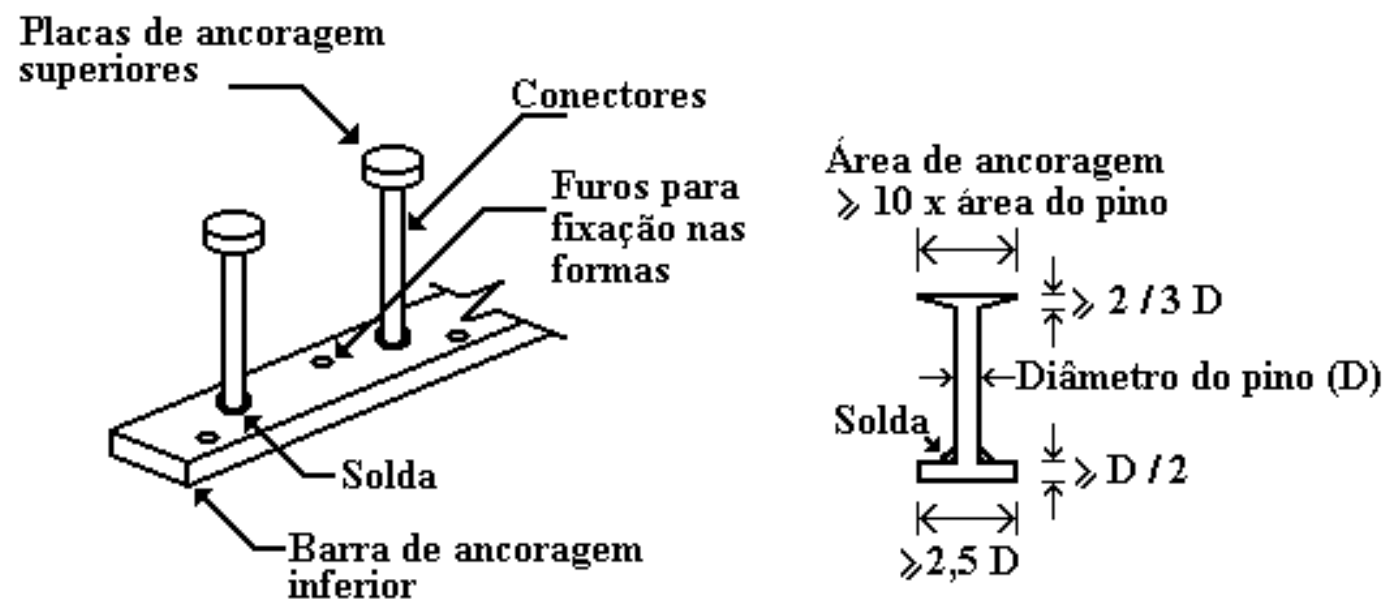

Fig. 19.3.11 - Detalhe dos conectores 
" Esse caso exige três tipos de verificações:

a. Compressão do concreto no contorno C "

É importante frisar que esta verificação, dada segundo o item 19.3.5.1, deve ser feita tanto para lajes com, como para lajes sem armadura de punção.

" b. Punção com armadura de cisalhamento em cada um dos contornos definidos pelas linhas de armadura. Para a disposição de armadura da figura 19.3.9 essas verificações são todas idênticas. "

Esta verificação deve ser feita através do item 19.3.5.2B para cada uma das linhas homotéticas ao pilar, já definidas segundo a Figura extra 5. Desta forma, se o tipo, disposição e quantidade de armadura for o mesmo para cada linha homotética, basta que se verifique apenas uma delas. Esta verificação é feita exclusivamente para ligações que possuam armadura de punção.

" c. Punção sem armadura de cisalhamento no contorno afastado de $2 \mathrm{~d}$ da última linha de armadura. "

Esta verificação possui a finalidade de se evitar que a superficie de ruína ocorra além da região armada. Desta forma, recalcula-se a tensão atuante de cálculo em relação ao novo perímetro crítico adotado (Figura 19.3.9). Esta verificação também é feita exclusivamente para ligações que possuam armadura de punção.

Resumindo, para lajes sem armadura de punção, basta que se verifiquem os itens 19.3.5.1, que trata da compressão no concreto, e 19.3.5.2A, que trata da punção em peças ou trechos sem armadura de cisalhamento. Já para lajes com armadura de punção, devem ser verificadas as três situações descritas no item 19.3.5.2B, que tratam da punção em peças ou trechos com armadura de cisalhamento. 
" No caso da estabilidade global da estrutura depender da resistência da laje à punção, a armadura deverá equilibrar um mínimo de 50\% da carga. "

\section{" 19.3.5.3 Verificação de peças protendidas}

$$
\tau_{\mathrm{Sd}, \mathrm{ef}}=\tau_{\mathrm{Sd}}-\tau_{\mathrm{Pd}}
$$

sendo:

$\tau_{\mathrm{Pd}}=$ tensão devida ao efeito dos cabos de protensão inclinados que atravessam o contorno considerado e passam a menos de $\mathrm{d} / 2$ da face do pilar. Ver figura 19.3.12

$$
\tau_{\mathrm{Pd}}=\frac{\sum \mathrm{P}_{\mathrm{kinf}, \mathrm{i}} \operatorname{sen} \alpha_{\mathrm{i}}}{\mu \mathrm{d}}
$$

onde:

$\mathrm{P}_{\mathrm{kinf}, \mathrm{i}}=$ força de protensão no cabo $\mathrm{i}$

$\alpha_{i}=$ inclinação do cabo i em relação ao plano da laje no contorno considerado

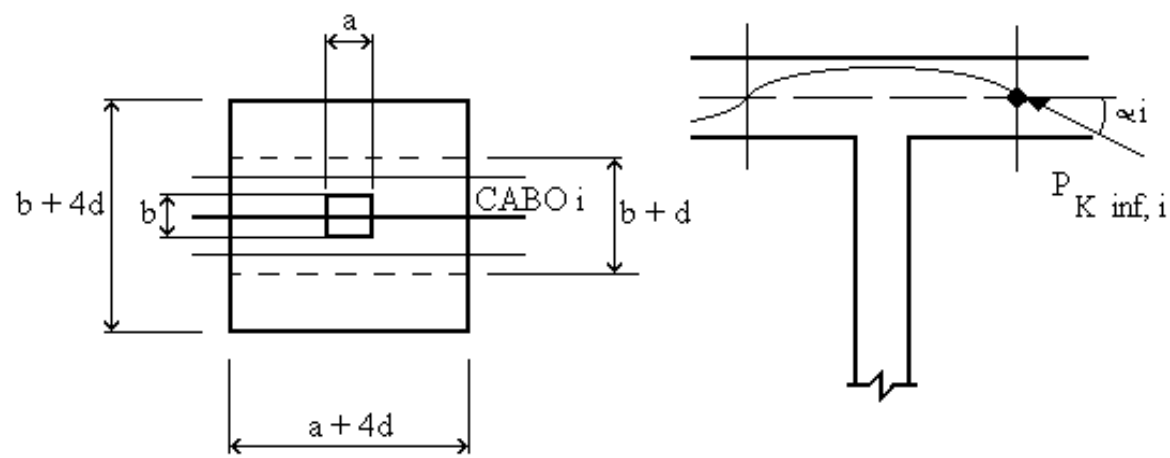

Fig. 19.3.12 - Efeito favorável dos cabos inclinados

\subsubsection{Colapso progressivo}

Para proteção contra o colapso progressivo a armadura de flexão inferior, que atravessar a projeção da área em que se aplica a reação de apoio, deve estar suficientemente ancorada além do perímetro $C^{\prime}$, conforme figura 19.3.13, e deve ser tal que:

$$
A_{\text {S }} f_{y d} \geq F_{S d}
$$


Caso a estabilidade global da estrutura dependa da resistência das lajes à punção, deverá ser providenciada armadura de punção, mesmo que $\tau_{\mathrm{Sd}}$ seja menor ou igual a זRd1."

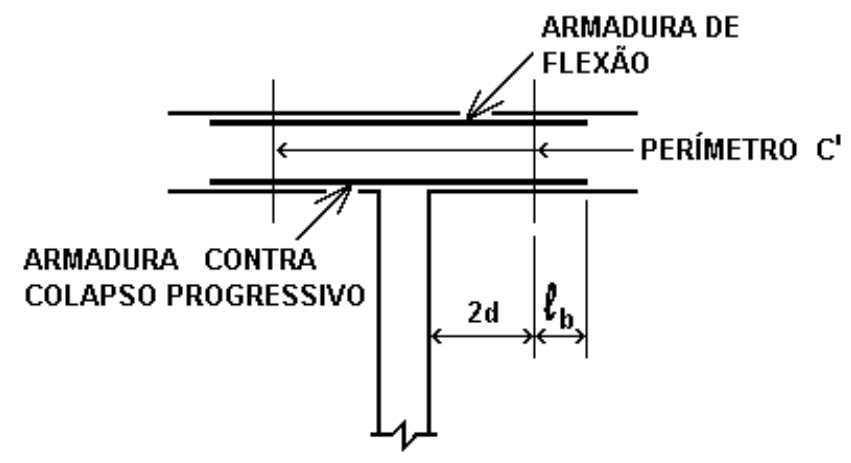

Fig. 19.3.13 - Armadura contra colapso progressivo

\subsection{OBSERVAÇÕES GERAIS}

Estudos mostram que a presença de vigas no contorno de edifícios em lajes-cogumelo proporcionam uma melhora significativa no comportamento estrutural do edifício como um todo, além de evitar o problema da punção em pilares de borda e de canto. Esta melhora do comportamento estrutural também é observada através de simulações numéricas. Deve-se, portanto, sempre que possível, evitar a solução com apoios discretos na extremidade da laje.

Outro fato muito importante não mencionado pela NB-1/94, mas mencionado pelo CEB/90, é que, a menos de evidências experimentais, o valor de $\mathrm{f}_{\text {ck }}$ deve ser limitado em $50 \mathrm{MPa}$ nas verificações da laje a esforços de cisalhamento. Esta limitação da resistência do concreto a $50 \mathrm{MPa}$ também é observada no EUROCODE N.2. Desta forma, entende-se que faltam recomendações para o cálculo da verificação à punção para lajes com concreto de alta resistência. Tal fato ilustra que são necessários mais estudos sobre este assunto. Somente assim é que se poderá desenvolver uma metodologia para a verificação à punção para estruturas construídas com outros tipos de materiais, como é o caso do concreto de alta resistência e do concreto com fibras. 
Por fim, observa-se que o texto base necessita de ajustes e complementações, de forma a abranger mais situações de cálculo e também de se tornar mais prático e eficiente. 


\section{EXEMPLOS SEGUNDO O TEXTO BASE $D A N B-1 / 94$}

São apresentados exemplos de verificação à punção, para ligações da laje com pilares internos, de borda e de canto. Para cada tipo de ligação, será avaliada a influência da armadura de punção. Observa-se que as dimensões adotadas para a espessura da laje e para os lados do pilar não são as usualmente empregadas. Na realidade estes exemplos foram adaptados de ensaios experimentais.

\subsection{PILAR INTERNO SEM ARMADURA DE PUNÇÃO}

Os esquemas referentes a este exemplo estão ilustrados na Figura 4.1 e na Figura 4.2. Para este item, $c_{1}$ e $c_{2}$ são definidos como sendo, respectivamente, os lados do pilar paralelos aos eixos x e y.

Dados Gerais:

- seção do pilar: $\quad 15 \mathrm{~cm}$ x $20 \mathrm{~cm}$

- espessura da laje: $10 \mathrm{~cm}$

- resistência do concreto: $\mathrm{f}_{\mathrm{ck}}=25 \mathrm{MPa}$

- reação de apoio no pilar: $\mathrm{F}_{\mathrm{Sd}}=135 \mathrm{kN}$

- momentos fletores: $\quad \mathrm{M}_{\mathrm{X}}=10 \mathrm{kN} . \mathrm{m}$ $\mathrm{M}_{\mathrm{y}}=12 \mathrm{kN} \cdot \mathrm{m}$
- armadura de flexão negativa aço CA $50 \mathrm{~A}$

Bitola: $\phi 10 \mathrm{~mm}$ / Área: $0,80 \mathrm{~cm}^{2}$ Distribuição: malha de $5,6 \mathrm{~cm}$ x 4,5 cm

Direção $\mathrm{x}: \rho_{\mathrm{X}}=0,0222 \mathrm{~d}_{\mathrm{X}}=8 \mathrm{~cm}$

Direção y: $\rho_{\mathrm{y}}=0,0159 \mathrm{~d}_{\mathrm{y}}=9 \mathrm{~cm}$

Portanto: $\quad \rho=0,0188 \quad \mathrm{~d}=8,5 \mathrm{~cm}$

Para a verificação da ligação, as tensões atuante $\left(\tau_{\mathrm{Sd}}\right)$ e resistente $\left(\tau_{\mathrm{Rd}}\right)$ de cálculo deverão ser calculadas e, a seguir, comparadas. 


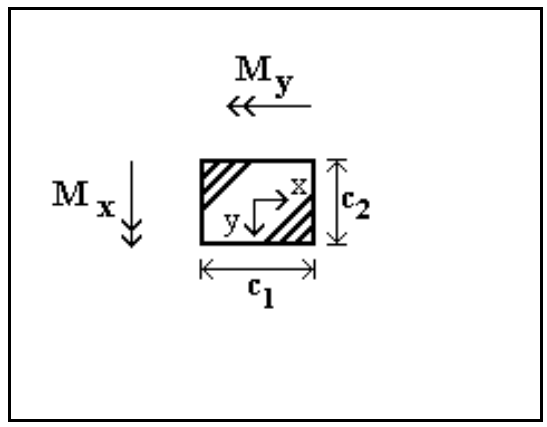

Figura 4.1 - Geometria e momentos fletores

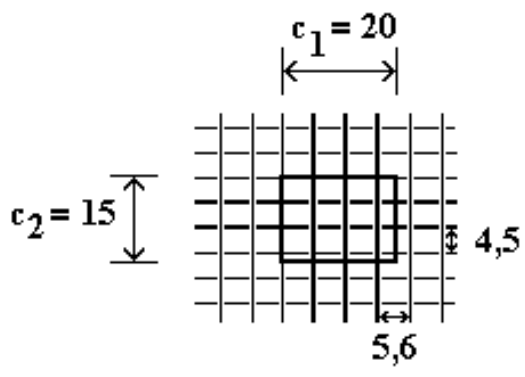

Figura 4.2 - Armadura de flexão (unidades em $\mathrm{cm}$ )

\subsubsection{TENSÃO ATUANTE DE CÁLCULO}

O texto base da NB-1/94 não é claro com relação ao caso de pilares internos com momentos fletores aplicados segundo as duas direções $\underline{x}$ e $\underline{y}$.

Para o caso de pilares internos com momento fletor aplicado segundo uma direção, o item 19.3.1B do texto base quantifica a influência desse momento fletor através do termo $\left(\mathrm{K}_{\mathrm{Sd}}\right) /\left(\mathrm{W}_{\mathrm{P}} \mathrm{d}\right)$, na expressão dada a seguir:

$$
\tau_{\mathrm{Sd}}=\frac{\mathrm{F}_{\mathrm{Sd}}}{\mu \mathrm{d}}+\frac{\mathrm{K} \mathrm{M}_{\mathrm{Sd}}}{\mathrm{W}_{\mathrm{P}} \mathrm{d}} \leq \tau_{\mathrm{Rd}}
$$

Portanto, para se levar em consideração a influência de outro momento fletor, atuando segundo outra direção, optou-se, neste trabalho, por se adicionar o termo $\left(\mathrm{K}^{\prime} \mathrm{M}_{\mathrm{Sd}}^{\prime}\right) /\left(\mathrm{W}_{\mathrm{P}}^{\prime} \mathrm{d}\right)$ na expressão (4.1). Esta nova parcela é calculada de forma análoga àquela correspondente à outra direção $\left(\mathrm{K}_{\mathrm{Sd}}\right) /\left(\mathrm{W}_{\mathrm{P}} \mathrm{d}\right)$. Desta forma, a expressão utilizada para a obtenção da tensão atuante de cálculo, para este item, é a seguinte:

$$
\tau_{S d}=\frac{F_{S d}}{\mu d}+\frac{K_{S d}}{W_{P} d}+\frac{K^{\prime} M_{S d}^{\prime}}{W_{P}^{\prime} d} \leq \tau_{R d}
$$


Com base nos dados e na notação adotada na Figura 4.3, tem-se que:

$$
\begin{aligned}
& \mu=2 \mathrm{c}_{1}+2 \mathrm{c}_{2}+2 \pi(2 \mathrm{~d})=40+30+106,81=176,81 \mathrm{~cm} \\
& \mathrm{~K}=0,633\left(\mathrm{c}_{1} / \mathrm{c}_{2}=1,333\right) \\
& \mathrm{MSd}=\mathrm{M}_{\mathrm{X}}=1000 \mathrm{kN} . \mathrm{cm} \\
& \mathrm{W}_{\mathrm{P}}=\frac{\mathrm{c}_{1}^{2}}{2}+\mathrm{c}_{1} \mathrm{c}_{2}+4 \mathrm{c}_{2} \mathrm{~d}+16 \mathrm{~d}^{2}+2 \pi \mathrm{dc}=3234,14 \mathrm{~cm}^{2}
\end{aligned}
$$

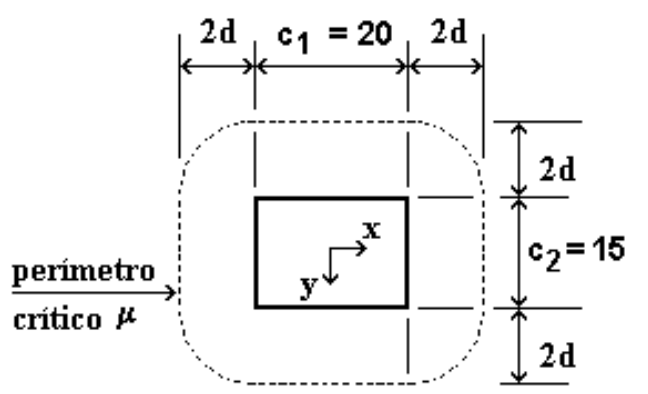

Figura 4.3 - Notação (unidades em cm)

Com relação ao termo adicionado:

$$
\begin{aligned}
& \mathrm{K}^{\prime}=0,525\left(\mathrm{c}_{2} / \mathrm{c}_{1}=0,75\right) \\
& \mathrm{M}^{\prime} \mathrm{Sd}=\mathrm{M}_{\mathrm{y}}=1200 \mathrm{kN} . \mathrm{cm} \\
& \mathrm{W}_{\mathrm{P}}^{\prime}=\frac{\mathrm{c}_{2}^{2}}{2}+\mathrm{c}_{2} \mathrm{c}_{1}+4 \mathrm{c}_{1} \mathrm{~d}+16 \mathrm{~d}^{2}+2 \pi \mathrm{d} \mathrm{c}_{2}=3049,61 \mathrm{~cm}^{2}
\end{aligned}
$$

Substituindo-se os valores numéricos na expressão (4.2) :

$$
\tau_{\mathrm{Sd}}=\frac{135}{176,81 \times 8,5}+\frac{0,633 \times 1000}{3234,14 \times 8,5}+\frac{0,525 \times 1200}{3049,61 \times 8,5}=0,1372 \mathrm{kN} / \mathrm{cm}^{2}=1,372 \mathrm{MPa}
$$

\subsubsection{TENSÃO RESISTENTE DE CÁLCULO}

A expressão da tensão resistente de cálculo é fornecida pelo item 19.3.5.2A do texto base da NB-1/94: 


$$
\tau_{\mathrm{Sd}} \leq \tau_{\mathrm{Rd} 1}=0,13\left(1+\sqrt{\frac{20}{\mathrm{~d}}}\right)\left(100 \rho \mathrm{ff}_{\mathrm{ck}}\right)^{1 / 3}=0,13\left(1+\sqrt{\frac{20}{8,5}}\right)(100 \times 0,0188 \times 25)^{1 / 3}=1,189 \mathrm{MPa}
$$

Comparando as tensões atuante e resistente de cálculo, tem-se que:

$$
\left.\tau_{\mathrm{Sd}}=1,372 \mathrm{MPa}>\tau_{\mathrm{Rd} 1}=1,189 \mathrm{MPa} \text { (Armadura necessária } !\right)
$$

Como a tensão atuante de cálculo é maior que a resistente, faz-se necessário o uso de algum tipo de armadura de punção ou de outro recurso que eleve a resistência da ligação. Caso a ligação apresentasse resistência suficiente, deveria ainda ser feita a verificação da compressão no concreto.

\subsection{PILAR INTERNO COM ARMADURA DE PUNÇÃO}

Neste exemplo serão utilizados os dados referentes ao item anterior, complementados com dados referentes à armadura de punção utilizada.

- Tipo de armadura de punção: conectores tipo pino

- Bitola: $\phi 6,3 \mathrm{~mm} \quad$ Aço: CA 50A Área do pino (Asy): 0,32 cm²

- $\mathrm{f}_{\mathrm{ywd}}=434,78 \mathrm{MPa}$

- Disposição dos conectores: radial (Figura 4.4)

Apesar do valor da resistência de cálculo $\left(\mathrm{f}_{\mathrm{ywd}}\right)$ da armadura de punção ser igual a 434,78 MPa, o texto base limita este valor em $300 \mathrm{MPa}$ para conectores tipo pino.

Para lajes com armadura de punção, o texto base da NB-1/94 recomenda que se façam as três verificações mostradas a seguir: compressão no concreto, região armada e além da região armada. 


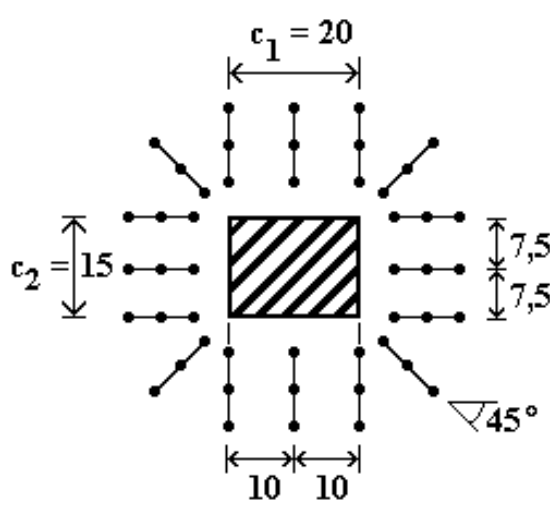

a) em planta

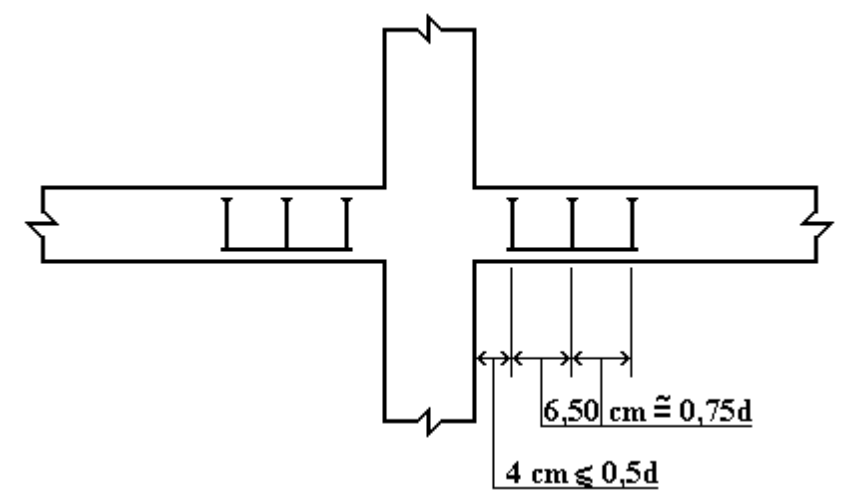

b) em corte

Figura 4.4 - Disposição dos conectores (unidades em cm)

\subsubsection{VERIFICAÇÃO DA COMPRESSÃO NO CONCRETO}

Em vista das recomendações do texto base da NB-1/94 ainda não estarem completamente definidas, foi feita aqui a verificação recomendada pelo CEB/90, dada através da seguinte expressão:

$$
\frac{F_{S d, e f}}{u_{o} d} \leq 0,5 f_{c d 2}
$$

Para pilares internos: $\mathrm{u}_{\mathrm{O}}=$ perímetro do pilar $=2 \mathrm{c}_{1}+2 \mathrm{c}_{2}=40+30=70 \mathrm{~cm}$.

$\mathrm{F}_{\mathrm{Sd}, \text { ef }}=$ reação de apoio majorada, de forma a se considerarem os efeitos de uma eventual transferência de momentos da laje ao pilar.

O CEB/90 não menciona a situação de pilares internos com momentos fletores atuando segundo duas direções, apresentando, apenas, a formulação para pilares internos com momento fletor aplicado segundo uma direção. Analogamente ao que foi feito no item 4.1.1, fez-se a adição do termo $\left(\mathrm{K}^{\prime} \mathrm{M}_{\mathrm{Sd}}^{\prime} \mu\right) /\left(\mathrm{F}_{\mathrm{Sd}} \mathrm{W}_{\mathrm{P}}^{\prime}\right)$ à expressão que define o $\mathrm{F}_{\mathrm{Sd} \text {,ef }}$, de forma a se levar em conta a atuação dos momentos fletores segundo as duas direções $\underline{\mathrm{x}} \mathrm{e} \underline{\mathrm{y}}$. Sendo assim:

$$
\mathrm{F}_{\mathrm{Sd}, \mathrm{ef}}=\mathrm{F}_{\mathrm{Sd}}\left[1+\frac{\mathrm{KM}_{\mathrm{Sd}} \mu}{\mathrm{F}_{\mathrm{Sd}} \mathrm{W}_{\mathrm{P}}}+\frac{\mathrm{K}^{\prime} \mathrm{M}_{\mathrm{Sd}}^{\prime} \mu}{\mathrm{F}_{\mathrm{Sd}} \mathrm{W}_{\mathrm{P}}^{\prime}}\right]=135(1+0,256+0,271)=206,15 \mathrm{kN}
$$


Como esta verificação está sendo baseada no CEB/90, optou-se por se adotar o coeficiente de segurança $\gamma_{c}$ igual a 1,5 , utilizado na determinação de $\mathrm{f}_{\mathrm{cd}}$ :

$$
\mathrm{f}_{\mathrm{cd}}=\mathrm{f}_{\mathrm{ck}} / 1,5
$$

Para o cálculo de $\mathrm{f}_{\mathrm{cd} 2}$, tanto o $\mathrm{f}_{\mathrm{cd}}$ como o $\mathrm{f}_{\mathrm{ck}}$ deverão estar em $\mathrm{MPa}$ :

$$
\begin{aligned}
& \mathrm{f}_{\mathrm{cd} 2}=0,60\left(1-\frac{\mathrm{f}_{\mathrm{ck}}}{250}\right) \mathrm{f}_{\mathrm{cd}} \\
& \mathrm{f}_{\mathrm{cd} 2}=0,60\left(1-\frac{25}{250}\right) \frac{25}{1,5}=9,0 \mathrm{MPa}
\end{aligned}
$$

Substituindo-se os valores calculados na expressão (4.3), tem-se que:

$$
\begin{aligned}
& \frac{206,15 \mathrm{kN}}{70 \mathrm{~cm} \times 8,5 \mathrm{~cm}} \leq 0,5 \times 9,0 \mathrm{MPa} \\
& 0,346 \mathrm{kN} / \mathrm{cm}^{2}=3,46 \mathrm{MPa} \leq 4,5 \mathrm{MPa} \quad(\mathrm{OK} !)
\end{aligned}
$$

\subsubsection{VERIFICAÇÃO DA REGIÃO ARMADA}

A expressão utilizada para esta verificação é fornecida através do item 19.3.5.2B do texto base:

$$
\tau_{\mathrm{Sd}} \leq 0,10(1+\sqrt{20 / d})\left(100 \rho \mathrm{f}_{\mathrm{ck}}\right)^{1 / 3}+1,5 \frac{\mathrm{d}}{\mathrm{s}_{\mathrm{r}}}\left(\mathrm{A}_{\mathrm{Sw}} \mathrm{f}_{\mathrm{ywd}} \operatorname{sen} \alpha\right) /(\mu \mathrm{d})
$$

- $\tau_{S d}$ é a tensão atuante de cálculo, já obtida no item 4.1.1;

- distância entre a face do pilar e a linha homotética que passa pela armadura de punção mais próxima a essa face: $4,0 \mathrm{~cm} \leq 0,5 \mathrm{~d}=4,25 \mathrm{~cm}$;

- $\mathrm{s}_{\mathrm{r}}=6,5 \mathrm{~cm} \approx 0,75 \mathrm{~d}=6,38 \mathrm{~cm}$;

- $\mathrm{A}_{\mathrm{Sw}}=16 \mathrm{~A}_{\mathrm{sy}}=16 \times 0,32=5,12 \mathrm{~cm}^{2}$;

- $\alpha=90^{\circ}$;

- $\mathrm{f}_{\mathrm{ywd}}=300 \mathrm{MPa}$;

- $\mu=$ perímetro crítico $($ caso de pilar interno $)=176,81 \mathrm{~cm}$. 
Portanto:

$$
\begin{aligned}
& \tau_{\mathrm{Sd}} \leq 0,10\left(1+\sqrt{\frac{20}{8,5}}\right)(100 \times 0,0188 \times 25)^{(1 / 3)}+1,5 \frac{8,5}{6,5}(5,12 \times 300 \times 1) \frac{1}{(176,81 \times 8,5)} \\
& \tau_{\mathrm{Sd}}=1,372 \mathrm{MPa} \leq 0,914+2,005=2,92 \mathrm{MPa} \quad(\mathrm{OK} !)
\end{aligned}
$$

\subsubsection{VERIFICAÇÃO ALÉM DA REGIÃO ARMADA}

Neste item, a tensão atuante de cálculo deve ser recalculada com base nos parâmetros relativos ao novo perímetro crítico adotado, localizado a uma distância de $2 \mathrm{~d}$ além da linha homotética que passa pela armadura de punção mais distante do pilar. É esta nova tensão atuante de cálculo que deve, então, ser comparada com a tensão resistente de cálculo, relativa a peças ou trechos sem armadura de punção, dada no item 19.3.5.2A do texto base.

\section{a) Tensão atuante de cálculo $\tau_{\mathrm{Sdn}}$}

A expressão a ser utilizada para a obtenção da nova tensão atuante de cálculo deverá ser análoga à adaptada no item 4.1.1, a fim de que se leve em conta a existência de momentos fletores aplicados segundo as duas direções $\underline{x}$ e y.

$$
\tau_{\mathrm{Sdn}}=\frac{\mathrm{F}_{\mathrm{Sd}}}{\mu_{\mathrm{n}} \mathrm{d}}+\frac{\mathrm{K} \mathrm{M}_{\mathrm{Sd}}}{\mathrm{W}_{\mathrm{Pn}} \mathrm{d}}+\frac{\mathrm{K}^{\prime} \mathrm{M}_{\mathrm{Sd}}^{\prime}}{\mathrm{W}_{\mathrm{Pn}}^{\prime} \mathrm{d}} \leq \tau_{\mathrm{Rd}}
$$

$\tau_{\mathrm{Sdn}}=$ nova tensão atuante de cálculo relacionada ao novo perímetro crítico;

$\mu_{\mathrm{n}} \quad=$ novo perímetro crítico;

$\mathrm{M}_{\mathrm{Sd}}=$ momento fletor atuante na direção $\mathrm{x}$;

$\mathrm{M}_{\text {Sd }}=$ momento fletor atuante na direção y;

$\mathrm{W}_{\mathrm{Pn}}=$ módulo de resistência plástica perpendicular à direção y, calculado em relação ao novo perímetro crítico $\mu_{\mathrm{n}}$;

$\mathrm{W}^{\prime} \mathrm{Pn}=$ módulo de resistência plástica paralela à direção $\mathrm{y}$, calculado em relação ao novo perímetro crítico $\mu_{\mathrm{n}}$. 
- Cálculo do novo perímetro crítico (Figura 4.5)

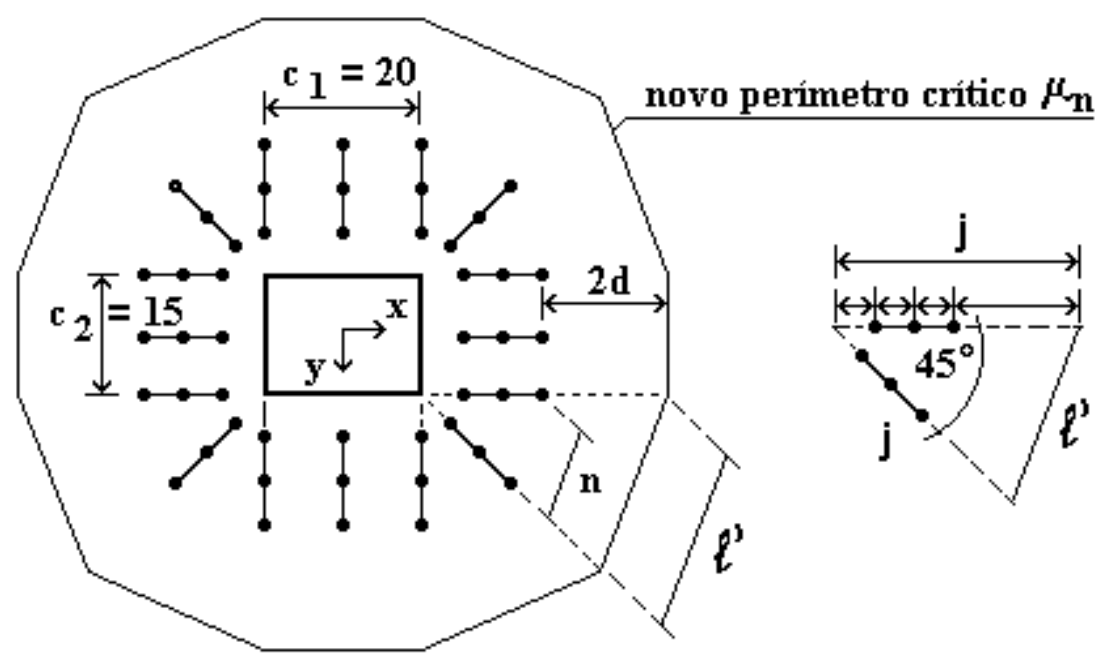

Figura 4.5 - Esquema de cálculo para $\mu_{\mathrm{n}}$

$\mu_{\mathrm{n}}=$ perímetro localizado a $2 \mathrm{~d}$ além da região armada $=2 \mathrm{c}_{1}+2 \mathrm{c}_{2}+8 \ell^{\prime}$ $\mathrm{j}=4+2 \times 6,5+2 \times 8,5=34 \mathrm{~cm}$

Pela lei dos cossenos:

$$
\begin{aligned}
& \ell^{\prime 2}=2 j^{2}\left(1-\cos 45^{\circ}\right)=677,17 \\
& \ell^{\prime}=26,02 \mathrm{~cm}
\end{aligned}
$$

Portanto:

$$
\mu_{\mathrm{n}}=278,16 \mathrm{~cm}
$$

Para a utilização da disposição radial da armadura de punção, deve-se verificar a seguinte condição: $\mathrm{n} \leq 2 \mathrm{~d}$

Pela lei dos cossenos: $n^{2}=2(4+6,5 \times 2)^{2}\left(1-\cos 45^{\circ}\right)=169,29$

$$
\mathrm{n}=13,01 \mathrm{~cm} \leq 2 \mathrm{~d}=17,0 \mathrm{~cm} \text { (distribuição radial adequada !) }
$$


- Cálculo de $\mathrm{W}_{\mathrm{Pn}}$

O módulo de resistência plástico pode ser calculado como sendo a somatória dos seguintes produtos: comprimento de cada segmento do novo perímetro crítico, multiplicado pela distância do seu centro de gravidade até o eixo perpendicular à direção na qual o momento fletor está atuando. De forma a facilitar este cálculo, o perímetro crítico foi subdividido em segmentos (Figura 4.6).

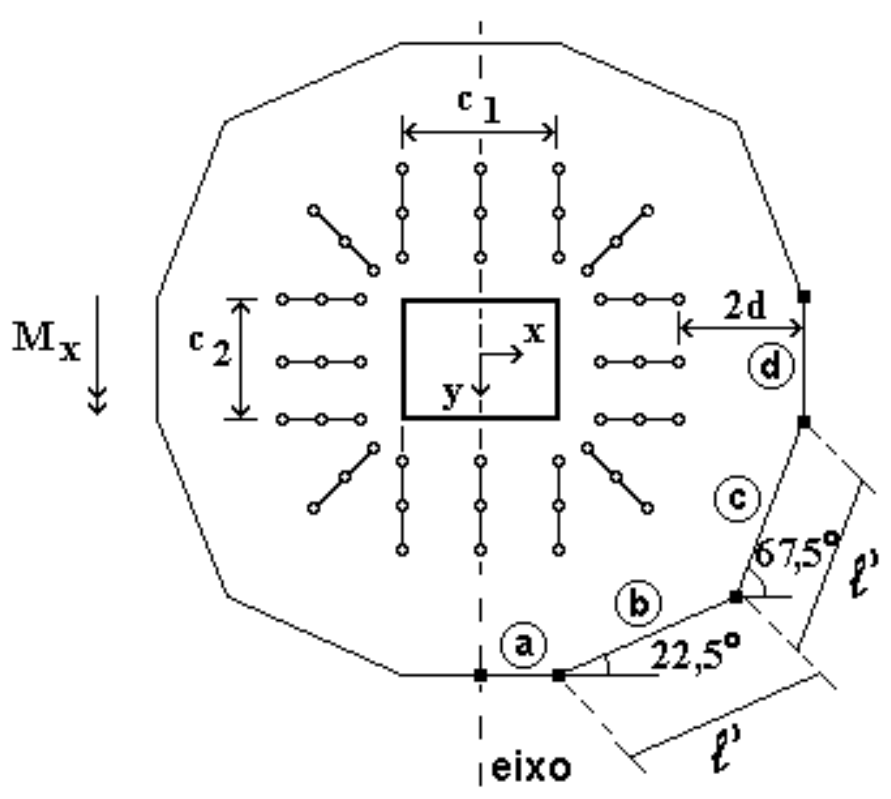

Figura 4.6 - Esquema de cálculo para $\mathrm{W}_{\mathrm{Pn}}$

Trecho a: $\mathrm{W}_{\text {Pna }}=$ comprimento do segmento $\mathrm{x}$ distância do seu c.g. ao eixo $\mathrm{W}_{\text {Pna }}=10 \times 5=\underline{50 \mathrm{~cm}^{2}}$

Trecho b: $\mathrm{W}_{\mathrm{Pnb}}=26,02 \times\left[10+26,02 \times\left(\cos 22,5^{\circ}\right) / 2\right]=\underline{572,95 \mathrm{~cm}^{2}}$

Trecho c: $\mathrm{W}_{\mathrm{Pnc}}=26,02 \times\left[10+26,02 \times \cos 22,5^{\circ}+26,02 \times\left(\cos 67,5^{\circ}\right) / 2\right]$ $\mathrm{W}_{\text {Pnc }}=\underline{1015,25 \mathrm{~cm}^{2}}$

Trecho d: $\mathrm{W}_{\text {Pnd }}=15 \times(10+4+2 \times 6,5+2 \times 8,5)=\underline{660 \mathrm{~cm}^{2}}$

Desta forma: $\mathrm{W}_{\mathrm{Pn}}=4\left[\mathrm{~W}_{\text {Pna }}+\mathrm{W}_{\text {Pnb }}+\mathrm{W}_{\text {Pnc }}\right]+2 \mathrm{~W}_{\text {Pnd }}=7872,80 \mathrm{~cm}^{2}$ 
- Cálculo de W'Pn

Este parâmetro é calculado de forma análoga a $W_{P n}$ (Figura 4.7).

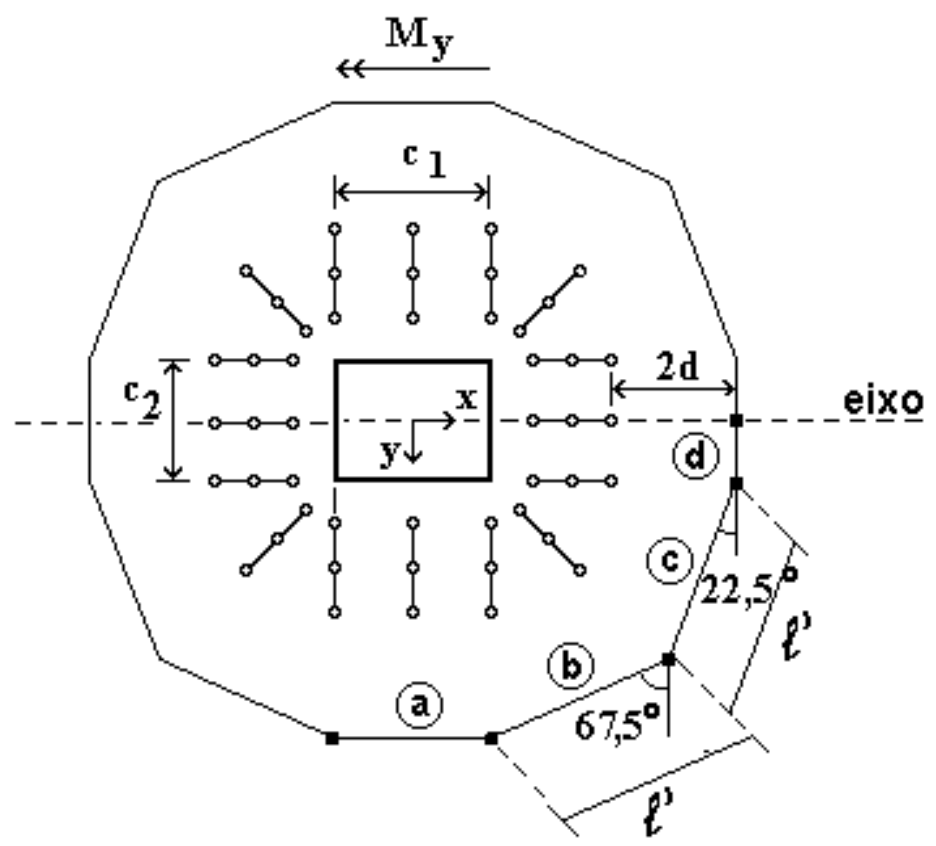

Figura 4.7 - Esquema de cálculo para W'Pn

Trecho a: $\mathrm{W}^{\prime}$ Pna $=20 \times(7,5+4+2 \times 6,5+2 \times 8,5)=\underline{830 \mathrm{~cm}^{2}}$

Trecho b: $\mathrm{W}^{\prime} \mathrm{Pnb}=26,02 \times\left[7,5+26,02 \times \cos 22,5^{\circ}+26,02 \times\left(\cos 67,5^{\circ}\right) / 2\right]$ $\mathrm{W}^{\prime} \mathrm{Pnb}=\underline{950,20 \mathrm{~cm}^{2}}$

Trecho c: $\mathrm{W}^{\prime} \mathrm{Pnc}=26,02 \times\left[7,5+26,02 \times\left(\cos 22,5^{\circ}\right) / 2\right]=\underline{507,90 \mathrm{~cm}^{2}}$

Trecho d: W'Pnd $=7,5 \times 7,5 / 2=\underline{28,125 \mathrm{~cm}^{2}}$

Desta forma:

$\mathrm{W}_{\text {Pn }}^{\prime}=2 \mathrm{~W}_{\text {Pna }}^{\prime}+4\left[\mathrm{~W}_{\mathrm{Pnb}}^{\prime}+\mathrm{W}^{\prime} \mathrm{Pnc}+\mathrm{W}_{\text {Pnd }}^{\prime}\right]=7604,90 \mathrm{~cm}^{2}$ 
- Cálculo da nova tensão atuante

Substituindo-se os valores numéricos na expressão (4.5), tem-se que:

$\tau_{\mathrm{Sdn}}=\frac{135}{278,16 \times 8,5}+\frac{0,633 \times 1000}{7872,80 \times 8,5}+\frac{0,525 \times 1200}{7604,90 \times 8,5}=0,0763 \mathrm{kN} / \mathrm{cm}^{2}=0,763 \mathrm{MPa}$

\section{b) Tensão resistente de cálculo $\tau_{\mathbf{R d}}$}

Comparando-se o valor de $\tau_{\mathrm{Sdn}}$ com o valor de $\tau_{\mathrm{Rd} 1}$ (já calculado no item 4.1.2), tem-se que:

$$
\tau_{\mathrm{Sdn}}=0,763 \mathrm{MPa} \leq \tau_{\mathrm{Rd} 1}=1,189 \mathrm{MPa}(\mathrm{OK} !)
$$

Observa-se que a presença da armadura de punção proporcionou resistência suficiente à ligação para resistir aos esforços solicitantes.

\subsection{PILAR DE BORDA SEM ARMADURA DE PUNÇÃO}

São apresentados os seguintes dados gerais referentes a este caso (Figura 4.8 e Figura 4.9):

- seção do pilar:

$15 \mathrm{~cm} \times 20 \mathrm{~cm}$

$10 \mathrm{~cm}$

- espessura da laje:

- resistência do concreto: $\mathrm{f}_{\mathrm{ck}}=25 \mathrm{MPa}$
- reação de apoio no pilar: $\mathrm{FSd}_{\mathrm{Sd}}=100 \mathrm{kN}$

- momentos fletores:

$\mathrm{M}_{\mathrm{X}}=10 \mathrm{kN} \cdot \mathrm{m}$ $\mathrm{M}_{\mathrm{y}}=12 \mathrm{kN} \cdot \mathrm{m}$
- armadura de flexão negativa aço CA $50 \mathrm{~A}$

Bitola: $\phi 10 \mathrm{~mm}$ / Área: $0,80 \mathrm{~cm}^{2}$ Distribuição: malha de $5,6 \mathrm{~cm} \mathrm{x} \mathrm{4,5} \mathrm{cm}$ Direção $\mathrm{x}: \rho_{\mathrm{X}}=0,0222 \mathrm{~d}_{\mathrm{X}}=8 \mathrm{~cm}$ Direção y: $\rho_{\mathrm{y}}=0,0159 \mathrm{~d}_{\mathrm{y}}=9 \mathrm{~cm}$ Portanto: $\rho=0,0188 \mathrm{~d}=8,5 \mathrm{~cm}$

Para este caso, define-se $\mathrm{c}_{1}$ como sendo o lado do pilar perpendicular à borda livre. 


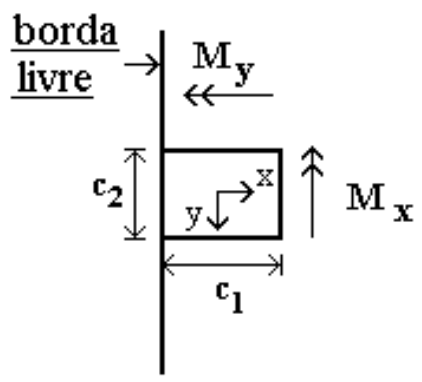

Figura 4.8 - Geometria e momentos fletores

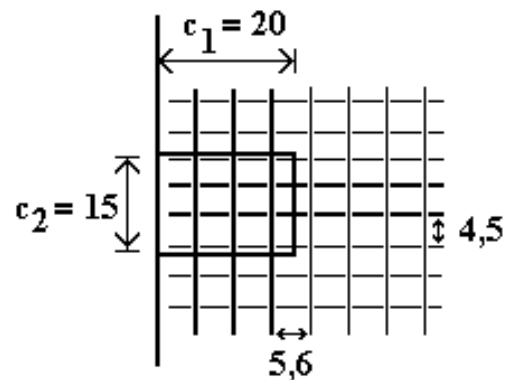

Figura 4.9 - Armadura de flexão (unidades em $\mathrm{cm}$ )

Serão comparadas as tensões atuante e resistente de cálculo. Observase que, neste caso, $\mathrm{M}_{\mathrm{X}}$ é o momento que atua na direção perpendicular à borda livre enquanto que $\mathrm{M}_{\mathrm{y}}$ é o momento que na direção paralela à borda livre.

\subsubsection{TENSÃO ATUANTE DE CÁLCULO}

A expressão utilizada para a obtenção da tensão atuante de cálculo é dada no item 19.3.1C do texto base:

$$
\tau_{\mathrm{Sd}}=\frac{\mathrm{F}_{\mathrm{Sd}}}{\mu^{*} \mathrm{~d}}+\frac{\mathrm{K}_{1} \mathrm{M}_{\mathrm{Sd}}}{\mathrm{W}_{\mathrm{P} 1} \mathrm{~d}}+\frac{\mathrm{K}_{2} \mathrm{M}_{\mathrm{Sd} 2}}{\mathrm{~W}_{\mathrm{P} 2} \mathrm{~d}} \leq \tau_{\mathrm{Rd}}
$$

Com base na Figura extra 1, mostrada no capítulo 3, e nas expressões desenvolvidas para WP1, e* e WP2, também presentes no capítulo 3, tem-se que:

$$
\begin{aligned}
& \mu^{*}=2 \mathrm{a}+\mathrm{c}_{2}+2 \pi(2 \mathrm{~d}) / 2=20+15+53,41 \quad=88,41 \mathrm{~cm} \\
& \mathrm{~W}_{\mathrm{P} 1}=\frac{\mathrm{c}_{1}^{2}}{2}+\frac{\mathrm{c}_{1} \mathrm{c}_{2}}{2}+2 \mathrm{c}_{2} \mathrm{~d}+8 \mathrm{~d}^{2}+\pi \mathrm{dc}_{1}=1717,07 \mathrm{~cm}^{2} \\
& \mathrm{~W}_{\mathrm{P} 2}=\frac{\mathrm{c}_{2}^{2}}{4}+\mathrm{c}_{1} \mathrm{c}_{2}+4 \mathrm{c}_{1} \mathrm{~d}+8 \mathrm{~d}^{2}+\pi \mathrm{d} \mathrm{c}_{2}=2014,80 \mathrm{~cm}^{2} \\
& \mathrm{e}^{*}=\frac{\mathrm{c}_{1} \mathrm{a}-\mathrm{a}^{2}+\frac{\mathrm{c}_{1} \mathrm{c}_{2}}{2}+2 \mathrm{dc}_{2}+\pi \mathrm{dc}_{1}+8 \mathrm{~d}^{2}}{2 \mathrm{a}+\mathrm{c}_{2}+2 \pi \mathrm{d}}=18,29 \mathrm{~cm}
\end{aligned}
$$




$$
\begin{aligned}
& \mathrm{M}_{\mathrm{Sd} 1}=\mathrm{M}_{\mathrm{X}}=1000 \mathrm{kN} \cdot \mathrm{cm} \\
& \mathrm{M}_{\mathrm{Sd}^{*}}=\mathrm{F}_{\mathrm{Sd}} \cdot \mathrm{e}^{*}=100 \times 18,29=1829 \mathrm{kN} \cdot \mathrm{cm} \\
& \mathrm{M}_{\mathrm{Sd}}=\mathrm{M}_{\mathrm{Sd} 1}-\mathrm{MSd}^{*}=1000-1829=-829<0 \longrightarrow \mathrm{MSd}_{\mathrm{Sd}} \longrightarrow 0 \\
& \mathrm{MSd}_{\mathrm{S}}=\mathrm{M}_{\mathrm{y}}=1200 \mathrm{kN} \cdot \mathrm{cm} \\
& \mathrm{K}_{1}=0,633\left(\mathrm{c}_{1} / \mathrm{c}_{2}=1,333\right) \\
& \mathrm{K}_{2}=0,450\left(\mathrm{c}_{2} / 2 \mathrm{c} 1=0,375\right)
\end{aligned}
$$

Adotou-se como valor de $\mathrm{K}_{2} \mathrm{o}$ valor correspondente à menor relação $c_{2} / 2 c_{1}$ existente na tabela 19.3.1 do texto base da NB-1/94, uma vez que a relação $\mathrm{c}_{2} / 2 \mathrm{c}_{1}$, obtida para este exemplo, é inferior ao valor mínimo existente na tabela mencionada.

Substituindo-se os valores calculados na expressão (4.6), obtém-se :

$$
\tau_{\mathrm{Sd}}=\frac{100}{88,41 \times 8,5}+\frac{0,633 \times 0}{1717,07 \times 8,5}+\frac{0,45 \times 1200}{2014,80 \times 8,5}=0,1646 \mathrm{kN} / \mathrm{cm}^{2}=1,646 \mathrm{MPa}
$$

\subsubsection{TENSÃO RESISTENTE DE CÁLCULO}

Utilizando-se novamente a expressão dada no item 19.3.5.2A do texto base, tem-se-que:

$$
\begin{gathered}
\tau_{\mathrm{Sd}} \leq \tau_{\mathrm{Rd} 1}=0,13\left(1+\sqrt{\frac{20}{\mathrm{~d}}}\right)\left(100 \rho \mathrm{ff}_{\mathrm{ck}}\right)^{1 / 3}=0,13\left(1+\sqrt{\frac{20}{8,5}}\right)(100 \mathrm{x} 0,0188 \mathrm{x} 25)^{1 / 3}=1,189 \mathrm{MPa} \\
\tau_{\mathrm{Sd}}=1,646 \mathrm{MPa}>\tau_{\mathrm{Rd} 1}=1,189 \mathrm{MPa} \text { (Armadura necessária !) }
\end{gathered}
$$

Novamente, faz-se necessário o uso de algum tipo de armadura de punção para elevar a resistência da ligação. Também neste caso deveria ser feita a verificação da compressão no concreto, caso a ligação tivesse apresentado resistência suficiente. 


\subsection{PILAR DE BORDA COM ARMADURA DE PUNÇÃO}

Com relação ao item 4.3, são apresentados os seguintes dados complementares referentes à armadura de punção a ser utilizada.

- Tipo de armadura de punção: conectores tipo pino

- Bitola: $\phi 6,3 \mathrm{~mm} \quad$ Aço: CA 50A Área do pino $\left(\mathrm{A}_{\mathrm{sy}}\right): 0,32 \mathrm{~cm}^{2}$

- $\mathrm{f}_{\mathrm{ywd}}=300 \mathrm{MPa}$ (valor máximo dado segundo o texto base da NB-1/94)

- Disposição dos conectores: radial (Figura 4.10)

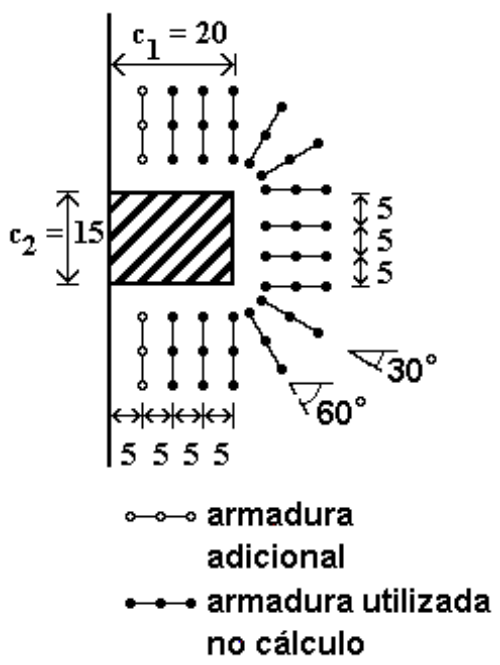

a) em planta

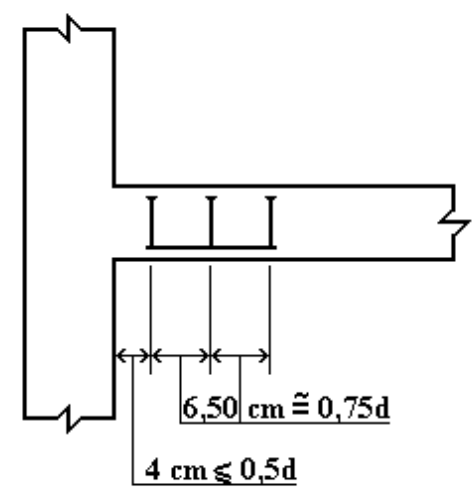

b) em corte

Figura 4.10 - Disposição dos conectores (unidades em cm)

Apesar de não ter sido mencionada pelo texto base, foi considerada, neste exemplo, a recomendação dada pelo CEB/90 com relação à armadura de punção adicional, ilustrada na Figura 4.10. Faz-se agora as três verificações recomendadas pelo texto base.

\subsubsection{VERIFICAÇÃO DA COMPRESSÃO NO CONCRETO}

O procedimento a ser seguido neste item é análogo ao procedimento descrito no item 4.2.1. A diferença básica entre os ítens está na modificação de algumas expressões, pelo fato de se tratar aqui de um pilar de borda. 
Verificação: $\quad \frac{\mathrm{F}_{\text {Sd,ef }}}{\mathrm{u}_{\mathrm{o}} \mathrm{d}} \leq 0,5 \mathrm{f}_{\mathrm{cd} 2}$

- $\mathrm{u}_{\mathrm{O}}=\mathrm{c}_{2}+3 \mathrm{~d} \leq \mathrm{c}_{2}+2 \mathrm{c}_{1} \longrightarrow \mathrm{u}_{\mathrm{O}}=40,50 \mathrm{~cm}$

- $\mathrm{K}=0,50 \quad\left(\mathrm{c}_{1} / 2 \mathrm{c}_{2}=0,667\right)$

- $\mathrm{F}_{\mathrm{Sd}, \mathrm{ef}}=\mathrm{F}_{\mathrm{Sd}}\left[1+\frac{\mathrm{KM}_{\mathrm{Sd} 2} \mu^{*}}{\mathrm{~F}_{\mathrm{Sd}} \mathrm{W}_{\mathrm{P} 2}}\right]=100\left[1+\frac{0,50 \times 1200 \times 88,41}{100 \times 2014,80}\right]=126,30 \mathrm{kN}$

- $\mathrm{f}_{\mathrm{cd} 2}=0,60\left(1-\frac{\mathrm{f}_{\mathrm{ck}}}{250}\right) \mathrm{f}_{\mathrm{cd}}=0,60\left(1-\frac{25}{250}\right) \frac{25}{1,5}=9,0 \mathrm{MPa}$

Fazendo-se a verificação: $\frac{126,30 \mathrm{kN}}{40,50 \mathrm{~cm} \times 8,5 \mathrm{~cm}} \leq 0,5 \times 9 \mathrm{MPa}$

$$
0,367 \mathrm{kN} / \mathrm{cm}^{2}=3,67 \mathrm{MPa} \leq 4,5 \mathrm{MPa}
$$

\subsubsection{VERIFICAÇÃO DA REGIÃO ARMADA}

Esta verificação é dada através do item 19.3.5.2B do texto base:

$\tau_{\mathrm{Sd}} \leq 0,10(1+\sqrt{20 / \mathrm{d}})\left(100 \rho \mathrm{f}_{\mathrm{ck}}\right)^{1 / 3}+1,5 \frac{\mathrm{d}}{\mathrm{s}_{\mathrm{r}}}\left(\mathrm{A}_{\mathrm{Sw}} \mathrm{f}_{\mathrm{ywd}} \operatorname{sen} \alpha\right) /(\mu * \mathrm{~d})$

- $\tau_{\mathrm{Sd}}$ é a tensão atuante de cálculo, já obtida no item 4.3.1;

- distância entre a face do pilar e a linha homotética que passa pela armadura de punção mais próxima a essa face: $4,0 \mathrm{~cm} \leq 0,5 \mathrm{~d}=4,25 \mathrm{~cm}$;

- $\mathrm{s}_{\mathrm{r}} \quad=6,5 \mathrm{~cm} \approx 0,75 \mathrm{~d}=6,38 \mathrm{~cm}$;

- $\mathrm{A}_{\mathrm{Sw}}=14 \mathrm{~A}_{\mathrm{sy}}=14 \times 0,32=4,48 \mathrm{~cm}^{2}$ (armadura considerada no cálculo);

- $\alpha=90^{\circ}$;

- $\mathrm{f}_{\mathrm{ywd}}=300 \mathrm{MPa}$;

- $\mu^{*} \quad=$ perímetro crítico reduzido $($ caso de pilar de borda) $=88,41 \mathrm{~cm}$. 
Portanto:

$$
\begin{aligned}
& \tau_{\mathrm{Sd}}=0,10\left(1+\sqrt{\frac{20}{8,5}}\right)(100 \times 0,0188 \times 25)^{(1 / 3)}+1,5 \frac{8,5}{6,5}(4,48 \times 300 \times 1) \frac{1}{(88,41 \times 8,5)} \\
& \tau_{\mathrm{Sd}}=1,646 \mathrm{MPa} \leq 4,423 \mathrm{MPa} \quad(\mathrm{OK} !)
\end{aligned}
$$

\subsubsection{VERIFICAÇÃO ALÉM DA REGIÃO ARMADA}

Assim como no item 4.2.3, a tensão atuante de cálculo a ser utilizada nesta verificação deverá ser recalculada em função dos parâmetros relativos aos novos perímetros crítico e crítico reduzido (localizados a uma distância de $2 \mathrm{~d}$ além da linha homotética que passa pela armadura de punção mais distante do pilar). $\mathrm{O}$ procedimento para o cálculo dos novos parâmetros é análogo ao mostrado no item 4.2.3. Sendo assim, a expressão utilizada deverá ser análoga à dada no item 19.3.1C do texto base da NB-1/94, para pilares de borda quando agir momento no plano paralelo à borda livre. Já a tensão resistente, é aquela referente a peças sem armadura de punção, dada no item 19.3.5.2A do texto base e já calculada no item 4.3.2.

\section{a) Tensão atuante de cálculo $\tau_{\mathrm{Sdn}}$}

A expressão utilizada para o cálculo da nova tensão atuante, referente aos novos perímetros crítico e crítico reduzido adotados (Figura 4.11), é dada a seguir:

$$
\tau_{\mathrm{Sdn}}=\frac{\mathrm{F}_{\mathrm{Sd}}}{\mu_{\mathrm{n}}{ }^{\mathrm{d}}}+\frac{\mathrm{K}_{1} \mathrm{M}_{\mathrm{Sdn}}}{\mathrm{W}_{\mathrm{P} 1 \mathrm{n}} \mathrm{d}}+\frac{\mathrm{K}_{2} \mathrm{M}_{\mathrm{Sd} 2}}{\mathrm{~W}_{\mathrm{P} 2 \mathrm{n}} \mathrm{d}} \leq \tau_{\mathrm{Rd}}
$$

$\tau_{\mathrm{Sdn}}=$ nova tensão atuante de cálculo;

$\mu_{\mathrm{n}} \quad=$ novo perímetro crítico, localizado a $2 \mathrm{~d}$ além da linha homotética que passa pela armadura de punção mais distante do pilar;

$\mu_{\mathrm{n}}{ }^{*} \quad=$ novo perímetro crítico reduzido;

$\mathrm{M}_{\mathrm{Sdn}}=\left(\mathrm{M}_{\mathrm{Sd} 1}-\mathrm{M}_{\mathrm{Sdn}}{ }^{*}\right) \geq 0$; 

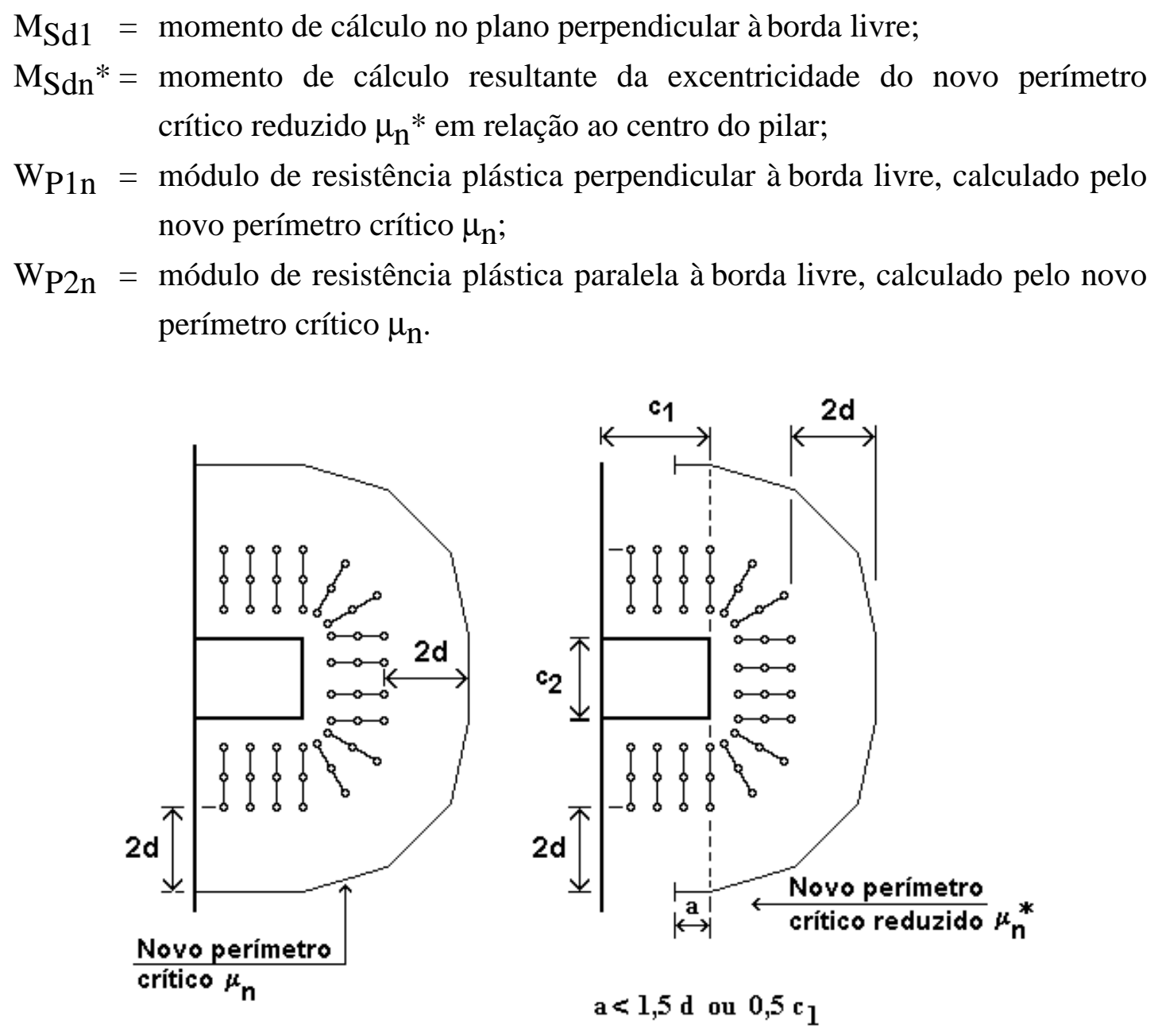

Figura 4.11 - Definição dos novos perímetros crítico e crítico reduzido

- Cálculo do novo perímetro crítico $\mu_{\mathrm{n}}$ (Figura 4.12)

$$
\begin{aligned}
& \mu_{\mathrm{n}}=2 \mathrm{c}_{1}+\mathrm{c}_{2}+6 \ell^{\prime} \\
& \mathrm{j}=4+2 \times 6,5+2 \times 8,5=34 \mathrm{~cm}
\end{aligned}
$$

Pela lei dos cossenos: $\quad \ell^{\prime 2}=2 \mathrm{j}^{2}\left(1-\cos 30^{\circ}\right)=309,75$

$$
\ell^{\prime}=17,60 \mathrm{~cm}
$$

Portanto:

$$
\mu_{\mathrm{n}}=160,60 \mathrm{~cm}
$$




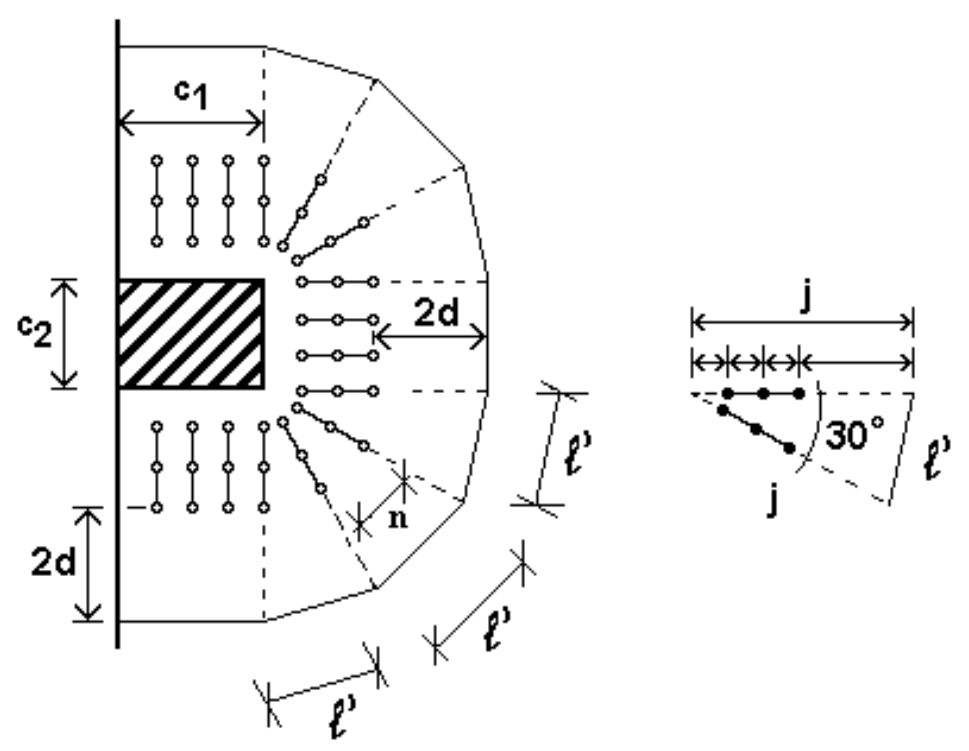

Figura 4.12 - Esquema para cálculo de $\mu_{n}$

Para a utilização da disposição radial da armadura de punção, deve-se verificar a seguinte condição: $\mathrm{n} \leq 2 \mathrm{~d}$

Pela lei dos cossenos: $n^{2}=2(4+6,5 \times 2)^{2}\left(1-\cos 30^{\circ}\right)=77,44$

$\mathrm{n}=8,80 \mathrm{~cm} \leq 2 \mathrm{~d}=17,0 \mathrm{~cm}$ (distribuição radial adequada!)

- Cálculo do novo perímetro crítico reduzido $\mu_{\mathrm{n}} *$

$\mu_{\mathrm{n}}^{*}=2 \mathrm{a}+\mathrm{c}_{2}+6 \ell^{\prime}=2 \times 10+15+6 \times 17,60=140,60 \mathrm{~cm}$

- Cálculo do $\mathrm{M}_{\mathrm{Sdn}}: \mathrm{M}_{\mathrm{Sdn}}=\left(\mathrm{M}_{\mathrm{Sd} 1}-\mathrm{M}_{\mathrm{Sdn}}{ }^{*}\right) \geq 0$

$$
\begin{aligned}
& \mathrm{M}_{\mathrm{Sd} 1}=\mathrm{M}_{\mathrm{X}}=1000 \mathrm{kN} . \mathrm{cm} \\
& \mathrm{M}_{\mathrm{Sdn}}{ }^{*}=\mathrm{FSd}_{\mathrm{Sd}} \cdot \mathrm{e}_{\mathrm{n}}{ }^{*}
\end{aligned}
$$


- Cálculo do $\mathrm{e}_{\mathrm{n}} *$

Esta excentricidade pode ser calculada através da seguinte forma: primeiramente subdivide-se em segmentos o novo perímetro crítico reduzido (Figura 4.13); a seguir, calcula-se a somatória dos produtos dos comprimentos desses segmentos pelas respectivas distâncias de seus centros de gravidade ao eixo perpendicular à direção segundo a qual o momento fletor atua e que passa pelo centro do pilar; por fim, faz-se a divisão da somatória desses produtos pelo comprimento do perímetro crítico reduzido, obtendo-se, desta forma, o valor da excentricidade.

Portanto:

Trecho a: $\mathrm{D}_{\mathrm{a}}=$ compr/to do seg/to x dist. do c.g. do seg/to ao eixo $=10 \times 5=\underline{50 \mathrm{~cm}^{2}}$

Trecho b: $\mathrm{D}_{\mathrm{b}}=17,6 \times\left[10+17,60 \times\left(\cos 15^{\circ}\right) / 2\right]=\underline{325,6 \mathrm{~cm}^{2}}$

Trecho c: $\mathrm{D}_{\mathrm{c}}=17,6 \mathrm{x}\left[10+17,60 \mathrm{x} \cos 15^{\circ}+17,60 \times\left(\cos 45^{\circ}\right) / 2\right]=\underline{584,72 \mathrm{~cm}^{2}}$

Trecho d:

$\mathrm{D}_{\mathrm{d}}=17,6 \mathrm{x}\left[10+17,60 \times \cos 15^{\circ}+17,60 \times \cos 45^{\circ}+17,60 \times\left(\cos 75^{\circ}\right) / 2\right]=\underline{734,32 \mathrm{~cm}^{2}}$

Trecho e: $\mathrm{D}_{\mathrm{e}}=15 \times(10+4+2 \times 6,5+2 \times 8,5)=\underline{660 \mathrm{~cm}^{2}}$

Desta forma:

$e_{n} *=\left[2\left(D_{a}+D_{b}+D_{c}+D_{d}\right)+D_{e}\right] / \mu_{n} *=4049,28 / 140,60=28,80 \mathrm{~cm}$

Portanto:

$\mathrm{M}_{\mathrm{Sdn}}=1000-100 \cdot \mathrm{e}_{\mathrm{n}}^{*}=-1880 \mathrm{kN} \cdot \mathrm{cm}<0 \longrightarrow \mathrm{M}_{\mathrm{Sdn}}=0$

Como o MSdn calculado apresentou valor nulo, então a segunda parcela da expressão (4.7) se anula e, consequentemente, não é necessário que se calcule o WP1n. 


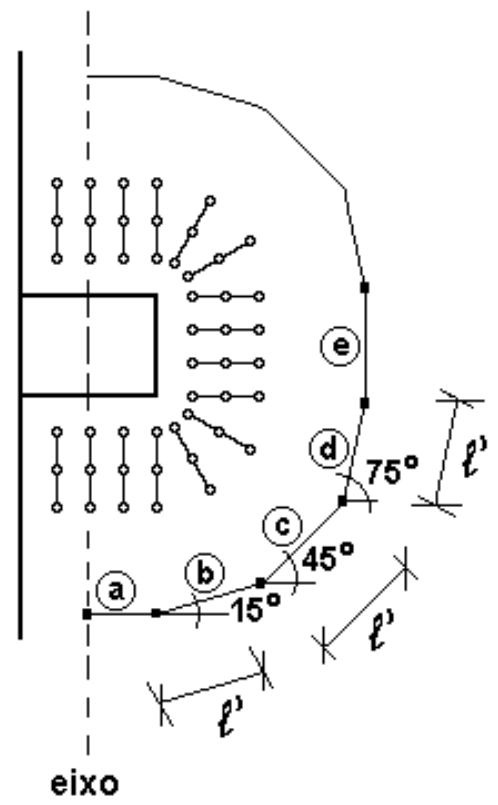

Figura 4.13 - Esquema para cálculo de $\mathrm{e}_{\mathrm{n}}{ }^{*}$

- Cálculo do WP2n

O cálculo deste parâmetro é feito de forma análoga ao já visto no item 4.2.3 e o seu esquema está ilustrado na Figura 4.14.

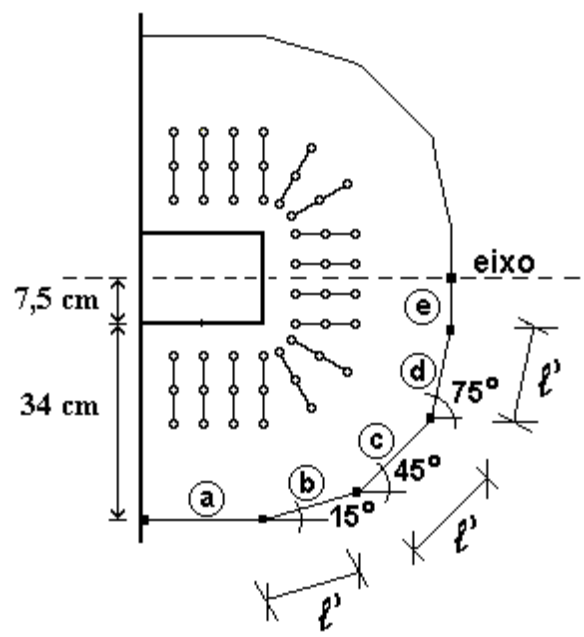

Desta forma:

Trecho a: $\mathrm{W}_{\mathrm{P} 2 \mathrm{a}}=830 \mathrm{~cm}^{2}$

Trecho b: $\mathrm{W}_{\mathrm{P} 2 \mathrm{~b}}=690,32 \mathrm{~cm}^{2}$

Trecho c: $\mathrm{W}_{\mathrm{P} 2 \mathrm{c}}=540,72 \mathrm{~cm}^{2}$

Trecho d: $\mathrm{WP}_{\mathrm{P} 2 \mathrm{~d}}=281,60 \mathrm{~cm}^{2}$

Trecho e: $\mathrm{W}_{\mathrm{P} 2 \mathrm{e}}=28,13 \mathrm{~cm}^{2}$

Figura 4.14 - Esquema para cálculo de $\mathrm{W}_{\mathrm{P} 2 \mathrm{n}}$

Portanto: $\mathrm{W}_{\mathrm{P} 2 \mathrm{n}}=2\left(\mathrm{~W}_{\mathrm{P} 2 \mathrm{a}}+\mathrm{W}_{\mathrm{P} 2 \mathrm{~b}}+\mathrm{W}_{\mathrm{P} 2 \mathrm{c}}+\mathrm{W}_{\mathrm{P} 2 \mathrm{~d}}+\mathrm{W}_{\mathrm{P} 2 \mathrm{e}}\right)=4741,54 \mathrm{~cm}^{2}$ 
Substituindo-se os valores calculados na expressão (4.7), tem-se que:

$$
\tau_{\mathrm{Sdn}}=\frac{100}{140,60 \times 8,5}+\frac{0,45 \times 1200}{4741,54 \times 8,5}=0,0971 \mathrm{kN} / \mathrm{cm}^{2}=0,971 \mathrm{MPa}
$$

\section{b) Tensão resistente de cálculo $\tau_{\mathbf{R d}}$}

Comparando-se o valor de $\tau_{\mathrm{Sdn}}$ com o valor de $\tau_{\mathrm{Rd} 1}$ (já calculado no item 4.3.2), tem-se que:

$$
\tau_{\mathrm{Sdn}}=0,971 \mathrm{MPa} \leq \tau_{\mathrm{Rd} 1}=1,189 \mathrm{MPa}(\mathrm{OK} !)
$$

Observa-se que a presença da armadura de punção proporcionou à laje resistência suficiente para resistir aos esforços solicitantes.

\subsection{PILAR DE CANTO SEM ARMADURA DE PUNÇÃO}

Dados gerais e esquemas (Figura 4.15 e Figura 4.16):

- seção do pilar:

- espessura da laje:

$15 \mathrm{~cm} \times 20 \mathrm{~cm}$

$10 \mathrm{~cm}$

- resistência do concreto: $\mathrm{f}_{\mathrm{ck}}=25 \mathrm{MPa}$

- reação de apoio no pilar: $\mathrm{F}_{\mathrm{Sd}}=50 \mathrm{kN}$

- momentos fletores:

$$
\begin{aligned}
& \mathrm{M}_{\mathrm{X}}=10 \mathrm{kN} . \mathrm{m} \\
& \mathrm{M}_{\mathrm{y}}=12 \mathrm{kN} . \mathrm{m}
\end{aligned}
$$

- armadura de flexão negativa aço CA $50 \mathrm{~A}$

Bitola: $\phi 10 \mathrm{~mm}$ / Área: $0,80 \mathrm{~cm}^{2}$

Distribuição: malha de $5,6 \mathrm{~cm} \mathrm{x} 4,5 \mathrm{~cm}$

Direção $\mathrm{x}: \rho_{\mathrm{X}}=0,0222 \mathrm{~d}_{\mathrm{X}}=8 \mathrm{~cm}$

Direção y: $\rho_{\mathrm{y}}=0,0159 \quad \mathrm{~d} y=9 \mathrm{~cm}$

Portanto: $\rho=0,0188 \quad \mathrm{~d}=8,5 \mathrm{~cm}$ 


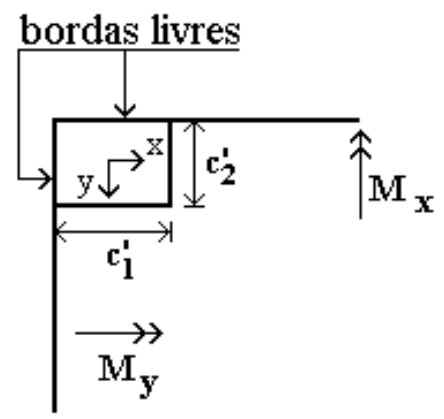

Figura 4.15 - Geometria e momentos fletores

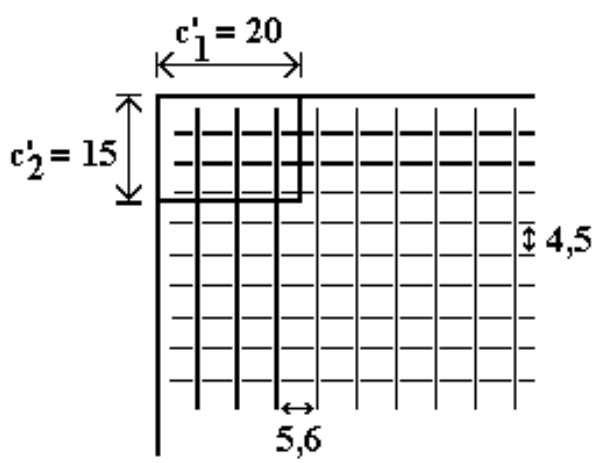

Figura 4.16 - Armadura de flexão (unidades em $\mathrm{cm}$ )

Neste exemplo, o pilar de canto foi considerado como sendo um pilar de borda quando não age momento no plano paralelo à borda livre. Como no pilar de borda existe apenas uma borda livre enquanto que no pilar de canto existem duas, o cálculo deve então ser feito ignorando-se, alternadamente, cada uma das bordas livres. Desta forma, obtém-se a tensão atuante de cálculo segundo as direções $\underline{x}$ e $\underline{y}$, e, a seguir, compara-se o maior valor encontrado com a tensão resistente de cálculo.

Para este caso, $c^{\prime}{ }_{1}$ e c' 2 são definidos como sendo, respectivamente, os lados paralelos aos eixos x e y, uma vez que, para a correta utilização das expressões fornecidas no capítulo 3 , deve-se definir $\mathrm{c}_{1}$ como sendo o lado perpendicular à borda livre adotada, enquanto que $\mathrm{c}_{2}$ fica sendo o lado paralelo à borda livre adotada.

\subsubsection{TENSÃo ATUANTE de CÁlCULO $\tau_{\mathrm{Sdx}}$}

Neste item, ignora-se a borda livre paralela ao eixo x. Na Figura 4.17 é mostrada a notação utilizada.

Para se obter a tensão atuante de cálculo, é utilizada a expressão:

$$
\tau_{\mathrm{Sdx}}=\frac{\mathrm{F}_{\mathrm{Sd}}}{\mu^{*} \mathrm{~d}}+\frac{\mathrm{K}_{1} \mathrm{M}_{\mathrm{Sd}}}{\mathrm{W}_{\mathrm{P} 1 \mathrm{x}} \mathrm{d}} \leq \tau_{\mathrm{Rd}}
$$

$\mathrm{K}_{1}=0,633\left(\mathrm{c}_{1} / \mathrm{c}_{2}=1,333\right)$

$\mathrm{MSd}_{\mathrm{Sd}}=\mathrm{MSd}_{1}-\mathrm{MSd}^{*}=\mathrm{M}_{\mathrm{X}}-\mathrm{FSd}_{\mathrm{Sd}} \cdot \mathrm{e}_{\mathrm{X}} *=1000-50 \mathrm{e}_{\mathrm{X}}{ }^{*}$ 


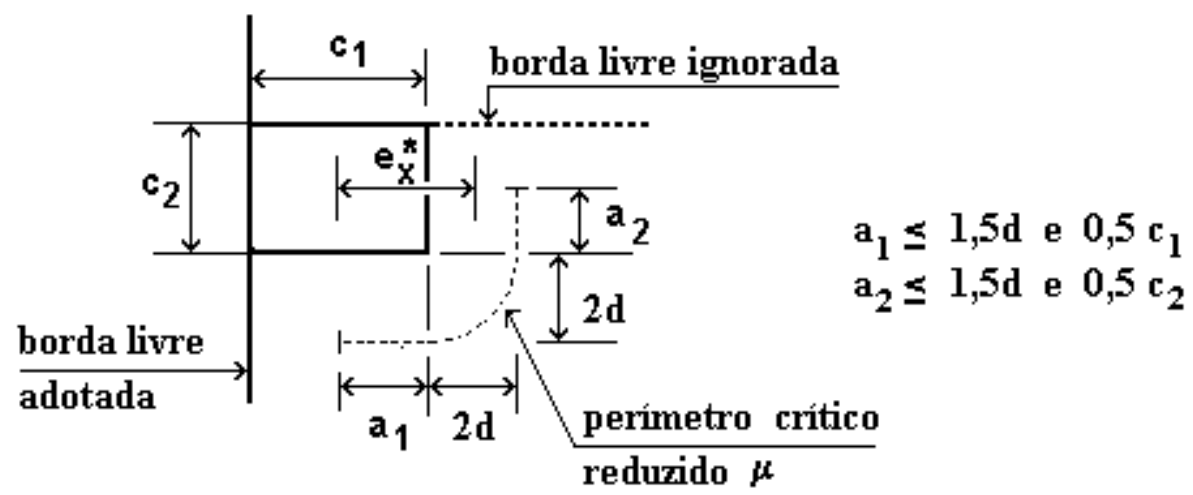

Figura 4.17 - Notação para o cálculo de $\mathrm{e}_{\mathrm{X}}{ }^{*}$

De acordo com a Figura 4.17 e com as expressões desenvolvidas no capítulo 3, tem-se que:

$$
\begin{aligned}
& \mathrm{a}_{1}=10 \mathrm{~cm} \\
& \mathrm{a}_{2}=7,5 \mathrm{~cm} \\
& \mu^{*}=\mathrm{a}_{1}+\mathrm{a}_{2}+2 \pi(2 \mathrm{~d}) / 4=10+7,5+26,70=44,20 \mathrm{~cm} \\
& \mathrm{e}_{\mathrm{x}}^{*}=\frac{\mathrm{c}_{1} \mathrm{a}_{1}-\mathrm{a}_{1}^{2}+\mathrm{c}_{1} \mathrm{a}_{2}+4 \mathrm{a}_{2} \mathrm{~d}+\pi \mathrm{c}_{1} \mathrm{~d}+8 \mathrm{~d}^{2}}{2\left(\mathrm{a}_{1}+\mathrm{a}_{2}+\pi \mathrm{d}\right)}=18,29 \mathrm{~cm} \\
& \mathrm{~W}_{\mathrm{P} 1 \mathrm{x}}=\frac{\mathrm{c}_{1}{ }^{2}+\frac{\mathrm{c}_{1} \mathrm{c}_{2}}{2}+2 \mathrm{c}_{2} \mathrm{~d}+4 \mathrm{~d}^{2}+\frac{\mathrm{c}_{1} \pi \mathrm{d}}{2}=1061,04 \mathrm{~cm}^{2}}{\mathrm{MSd}_{\mathrm{S}}=1000-50 \mathrm{x} 18,29=85,5 \mathrm{kN} . \mathrm{cm}}
\end{aligned}
$$

Substituindo-se os valores numéricos na expressão (4.8):

$$
\tau_{\mathrm{Sdx}}=\frac{50}{44,20 \times 8,5}+\frac{0,633 \times 85,5}{1061,04 \times 8,5}=0,1391 \mathrm{kN} / \mathrm{cm}^{2}=1,391 \mathrm{MPa}
$$




\subsubsection{TENSÃO ATUANTE DE CÁLCULO $\tau_{\text {Sdy }}$}

Já neste item ignora-se a borda perpendicular ao eixo x. A determinação de $\tau_{S d y}$ é feita de maneira análoga à realizada no item anterior, tomando-se o devido cuidado de adaptar $c_{1}$ e $c_{2}$ com relação à nova borda livre adotada (Figura 4.18).

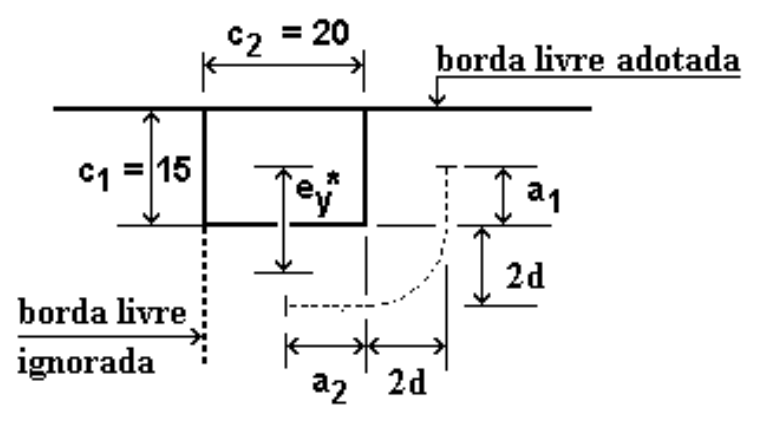

Figura 4.18 - Mudança da notação para o cálculo de $\mathrm{e}_{\mathrm{y}}{ }^{*}$

Portanto:

$$
\tau_{\text {Sdy }}=\frac{F_{S d}}{\mu^{*} d}+\frac{K_{1} M_{S d}}{W_{P 1 y} d} \leq \tau_{R d}
$$

$$
\begin{aligned}
& \mathrm{a}_{1}=7,5 \mathrm{~cm} \\
& \mathrm{a}_{2}=10 \mathrm{~cm} \\
& \mu^{*}=44,20 \mathrm{~cm} \\
& \mathrm{~K}_{1}=0,525\left(\mathrm{c}_{1} / \mathrm{c}_{2}=0,75\right) \\
& \mathrm{MSd}_{\mathrm{S}}=\mathrm{MSd}_{1}-\mathrm{MSd}^{*}=\mathrm{My}_{\mathrm{y}}-\mathrm{FSd} \cdot \mathrm{e}_{\mathrm{y}}^{*}=1200-50 \mathrm{e}_{\mathrm{y}}^{*}
\end{aligned}
$$

Com base na notação adotada na Figura 4.18 e nas expressões desenvolvidas no capítulo 3 , tem-se que:

$$
\begin{aligned}
& \mathrm{e}_{\mathrm{y}} *=\frac{\mathrm{c}_{1} \mathrm{a}_{1}-\mathrm{a}_{1}^{2}+\mathrm{c}_{1} \mathrm{a}_{2}+4 \mathrm{a}_{2} \mathrm{~d}+\pi \mathrm{c}_{1} \mathrm{~d}+8 \mathrm{~d}^{2}}{2\left(\mathrm{a}_{1}+\mathrm{a}_{2}+\pi \mathrm{d}\right)}=17,25 \mathrm{~cm} \\
& \mathrm{~W}_{\mathrm{P} 1 \mathrm{y}}=\frac{\mathrm{c}_{1}^{2}}{4}+\frac{\mathrm{c}_{1} \mathrm{c}_{2}}{2}+2 \mathrm{c}_{2} \mathrm{~d}+4 \mathrm{~d}^{2}+\frac{\mathrm{c}_{1} \pi \mathrm{d}}{2}=1035,53 \mathrm{~cm}^{2} \\
& \mathrm{MSd}_{\mathrm{S}}=1200-50 \times 17,25=337,50 \mathrm{kN} \mathrm{cm}
\end{aligned}
$$


Substituindo-se os valores na expressão (4.9), tem-se que: $\tau_{\mathrm{Sdy}}=1,532 \mathrm{MPa}$.

Verifica-se que esta tensão atuante de cálculo é a mais crítica.

\subsubsection{TENSÃO RESISTENTE DE CÁLCULO $\tau_{\mathrm{Rd}}$}

Compara-se a máxima tensão atuante de cálculo encontrada com a tensão resistente, dada segundo o item 19.3.5.2A do texto base:

$\tau_{\mathrm{Sd}} \leq \tau_{\mathrm{Rd} 1}=0,13\left(1+\sqrt{\frac{20}{\mathrm{~d}}}\right)\left(100 \rho \mathrm{ff}_{\mathrm{ck}}\right)^{1 / 3}=0,13\left(1+\sqrt{\frac{20}{8,5}}\right)(100 \times 0,0188 \times 25)^{1 / 3}=1,189 \mathrm{MPa}$

Portanto:

$\tau_{\mathrm{Sdy}}=1,532 \mathrm{MPa}>\tau_{\mathrm{Rd} 1}=1,189 \mathrm{MPa}$ (Armadura necessária !)

Conforme já visto anteriormente, a resistência da ligação não é suficiente para resistir aos esforços solicitantes. No exemplo seguinte será utilizada uma armadura de punção para aumentar a resistência da ligação. Caso a resistência da laje tivesse sido suficiente para resistir a esses esforços solicitantes, deveria ainda ter sido feita a verificação da compressão no concreto.

\subsection{PILAR DE CANTO COM ARMADURA DE PUNÇÃO}

São apresentados os dados complementares ao exemplo anterior, referentes à armadura de punção a ser utilizada neste item:

- Tipo de armadura de punção: conectores tipo pino

- Bitola: $\phi 6,3 \mathrm{~mm} \quad$ Aço: CA 50A Área do pino $\left(\mathrm{A}_{\mathrm{sy}}\right): 0,32 \mathrm{~cm}^{2}$

- $\mathrm{f}_{\mathrm{ywd}}=300 \mathrm{MPa}$ (valor limitado pelo texto base da NB-1/94)

- Disposição dos conectores: radial (Figura 4.19) 


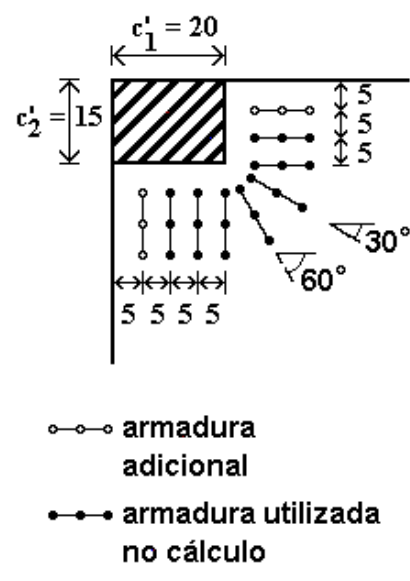

a) em planta

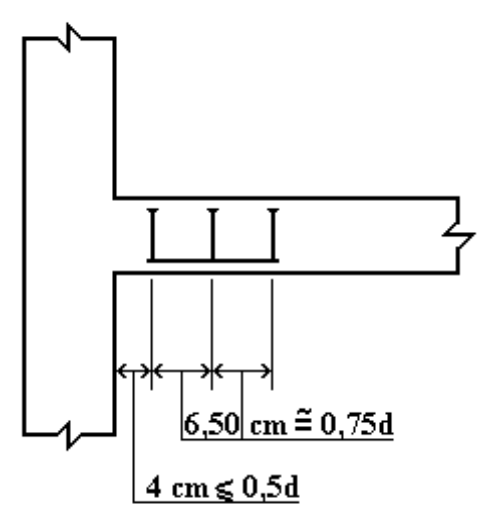

b) em corte

Figura 4.19 - Disposição dos conectores

Apesar de não ter sido mencionada pelo texto base, foi considerada, neste exemplo, a recomendação dada pelo CEB/90 com relação à armadura de punção adicional, ilustrada na Figura 4.19. Serão feitas, a seguir, as três verificações dadas segundo o texto base.

\subsubsection{VERIFICAÇÃO DA COMPRESSÃO NO CONCRETO}

Esta verificação, já exemplificada para pilares internos no item 4.2.1 e para pilares de borda no item 4.4.1, é agora aplicada para pilares de canto:

$$
\text { Verificação: } \quad \frac{\mathrm{F}_{\mathrm{Sd}, \mathrm{ef}}}{\mathrm{u}_{\mathrm{o}} \mathrm{d}} \leq 0,5 \mathrm{f}_{\mathrm{cd} 2}
$$

$$
\text { - } \mathrm{u}_{\mathrm{O}}=3 \mathrm{~d} \leq \mathrm{c}_{2}^{\prime}+\mathrm{c}_{1} \longrightarrow \mathrm{u}_{\mathrm{O}}=25,50 \mathrm{~cm}
$$

- $\mathrm{F}_{\mathrm{Sd}, \mathrm{ef}}=\mathrm{F}_{\mathrm{Sd}}=50 \mathrm{kN}$

$$
\text { - } \mathrm{f}_{\mathrm{cd} 2}=0,60\left(1-\frac{\mathrm{f}_{\mathrm{ck}}}{250}\right) \mathrm{f}_{\mathrm{cd}}=0,60\left(1-\frac{25}{250}\right) \frac{25}{1,5}=9,0 \mathrm{MPa}
$$

Fazendo-se a verificação: $\quad \frac{50 \mathrm{kN}}{25,5 \mathrm{~cm} \times 8,5 \mathrm{~cm}} \leq 0,5 \times 9 \mathrm{MPa}$ 


\subsubsection{VERIFICAÇÃO DA REGIÃO ARMADA}

Compara-se a máxima tensão atuante de cálculo obtida através dos ítens 4.5.1 e 4.5.2, com a tensão resistente, dada pelo item 19.3.5.2B do texto base da NB-1/94:

$$
\tau_{\mathrm{Sd}} \leq 0,10(1+\sqrt{20 / \mathrm{d}})\left(100 \rho \mathrm{f}_{\mathrm{ck}}\right)^{1 / 3}+1,5 \frac{\mathrm{d}}{\mathrm{sr}_{\mathrm{r}}}\left(\mathrm{A}_{\mathrm{Sw}} \mathrm{f}_{\mathrm{ywd}} \operatorname{sen} \alpha\right) /(\mu * \mathrm{~d})
$$

- $\tau_{\mathrm{Sd}}$ é a maior das tensões atuantes de cálculo, obtidas segundo os ítens 4.5.1 e 4.5.2;

- distância entre a face do pilar e a linha homotética que passa pela armadura de punção mais próxima a essa face: $4,0 \mathrm{~cm} \leq 0,5 \mathrm{~d}=4,25 \mathrm{~cm}$;

- $\mathrm{s}_{\mathrm{r}}=6,5 \mathrm{~cm} \approx 0,75 \mathrm{~d}=6,38 \mathrm{~cm}$;

- $\mathrm{A}_{\mathrm{Sw}}=7 \mathrm{~A}_{\mathrm{Sy}}=7 \times 0,32=2,24 \mathrm{~cm}^{2}$ (armadura considerada no cálculo);

- $\alpha=90^{\circ}$;

- $\mathrm{f}_{\mathrm{ywd}}=300 \mathrm{MPa}$;

- $\mu^{*}=$ perímetro crítico reduzido $($ caso de pilares de canto $)=44,20 \mathrm{~cm}$.

Portanto:

$\tau_{\mathrm{Sd}} \leq 0,10(1+\sqrt{20 / 8,5})(100 \times 0,0188 \times 25)^{1 / 3}+1,5 \frac{8,5}{6,5}(2,24 \times 300 \times 1) /(44,20 \times 8,5)$

$\tau_{\mathrm{Sd}}=1,532 \mathrm{MPa} \leq 4,423 \mathrm{MPa} \quad(\mathrm{OK} !)$

\subsubsection{VERIFICAÇÃO ALÉM DA REGIÃO ARMADA}

As tensões atuantes de cálculo deverão ser recalculadas com base em parâmetros referentes aos novos perímetros crítico $\mu_{\mathrm{n}}$ e crítico reduzido $\mu_{\mathrm{n}}$ * (Figura 4.20), localizados a $2 \mathrm{~d}$ da linha homotética que passa pela armadura de punção mais distante do pilar, ignorando-se, alternadamente, as bordas paralela e perpendicular ao eixo $\mathrm{x}$. 

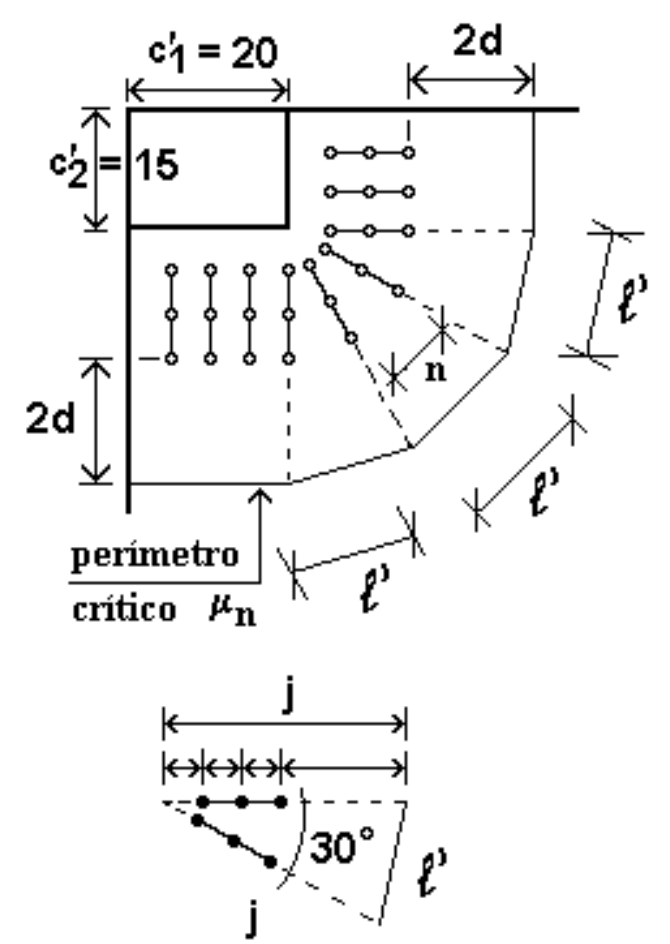

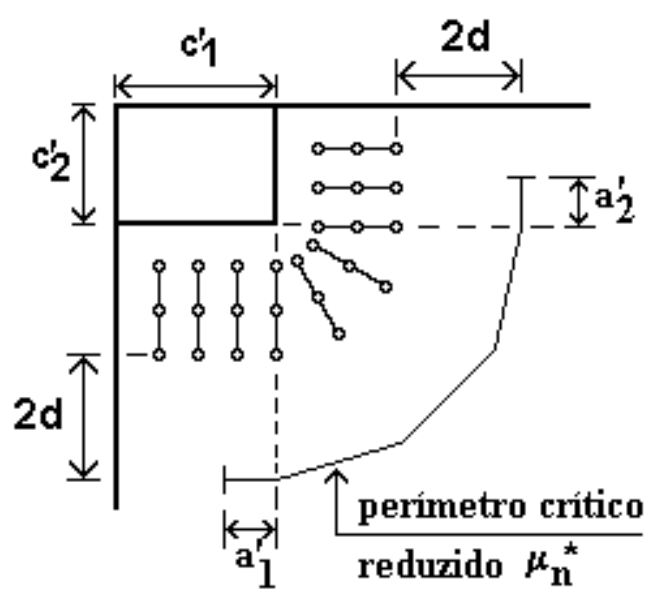

$$
\begin{aligned}
& \mathbf{a}_{1}^{\prime}<1,5 \mathrm{~d} \text { e } 0,5 \mathbf{c}_{1}^{\prime} \\
& \mathrm{a}_{2}^{\prime}<1,5 \mathrm{~d} \text { e } 0,5 \mathbf{c}_{2}^{\prime}
\end{aligned}
$$

Figura 4.20 - Novos perímetros crítico e crítico reduzido adotados (unidades em cm)

- Cálculo do novo perímetro crítico

$$
\begin{aligned}
& \mu_{n}=20+15+3 \ell^{\prime} \\
& j=4+2 \times 6,5+2 \times 8,5=34 \mathrm{~cm}
\end{aligned}
$$

Pela lei dos cossenos: $\ell^{2}=2 \mathrm{j}^{2}\left(1-\cos 30^{\circ}\right)=309,75$

$$
\ell^{\prime}=17,60 \mathrm{~cm}
$$

Portanto:

$$
\mu_{\mathrm{n}}=87,80 \mathrm{~cm}
$$

Para a utilização da disposição radial da armadura de punção, deve-se verificar a seguinte condição: $\mathrm{n} \leq 2 \mathrm{~d}$

Pela lei dos cossenos: $n^{2}=2(4+6,5 \times 2)^{2}\left(1-\cos 30^{\circ}\right)=77,44$

$$
\mathrm{n}=8,80 \mathrm{~cm} \leq 2 \mathrm{~d}=17,0 \mathrm{~cm} \text { (distribuição radial adequada!) }
$$


- Cálculo do novo perímetro crítico reduzido

$\mathrm{a}^{\prime}{ }_{1}=$ trecho do novo perímetro crítico reduzido $\mu_{\mathrm{n}}{ }^{*}$, paralelo a $\mathrm{c}_{1}=10 \mathrm{~cm}$

$\mathrm{a}_{2}=$ trecho do novo perímetro crítico reduzido $\mu_{\mathrm{n}}{ }^{*}$, paralelo a $\mathrm{c}_{2}=7,5 \mathrm{~cm}$ $\mu_{\mathrm{n}}^{*}=\mathrm{a}_{1}+3 \ell^{\prime}+\mathrm{a}_{2}=70,3 \mathrm{~cm}$

\section{a) Tensão atuante de cálculo $\tau_{\operatorname{Sdnx}}$ (ignora-se a borda paralela ao eixo $x$ )}

O valor da nova tensão atuante de cálculo é dado pela expressão:

$$
\tau_{\mathrm{Sdnx}}=\frac{\mathrm{F}_{\mathrm{Sd}}}{\mu_{\mathrm{n}}{ }^{*} \mathrm{~d}}+\frac{\mathrm{K}_{1} \mathrm{M}_{\mathrm{Sdn}}}{\mathrm{W}_{\mathrm{P} 1 \mathrm{nx}} \mathrm{d}} \leq \tau_{\mathrm{Rd}}
$$

$\tau_{\mathrm{Sdnx}}=$ tensão atuante de cálculo relacionada ao novo perímetro crítico adotado;

$\mathrm{M}_{\mathrm{Sdn}}=\left(\mathrm{M}_{\mathrm{Sd} 1}-\mathrm{M}_{\mathrm{Sdn}}{ }^{*}\right) \geq 0$

$\mathrm{M}_{\mathrm{Sd} 1}=$ momento de cálculo no plano perpendicular à borda livre adotada;

$\mathrm{M}_{\mathrm{Sdn}}{ }^{*}=$ momento de cálculo resultante da excentricidade do novo perímetro crítico reduzido $\mu_{\mathrm{n}} *$ em relação ao centro do pilar;

$\mathrm{W}_{\mathrm{P} 1 \mathrm{nx}}=$ módulo de resistência plástica perpendicular à borda livre adotada, calculado pelo novo perímetro crítico $\mu_{\mathrm{n}}$.

- Cálculo do $\mathrm{M}_{\mathrm{Sd}}$ :

$$
\begin{aligned}
& M_{S d n}=\left(M_{S d 1}-M_{S d n} *\right) \geq 0 \\
& M_{S d 1}=M_{X}=1000 \mathrm{kN} \cdot c m \\
& M_{S d n} *=F_{S d} \cdot e_{X n} *
\end{aligned}
$$

- Cálculo do $\mathrm{e}_{\mathrm{xn}}{ }^{*}$

A excentricidade pode ser calculada de maneira análoga à mostrada no item 4.4.3a. Na Figura 4.21, é mostrado o novo perímetro crítico reduzido subdividido em segmentos. 


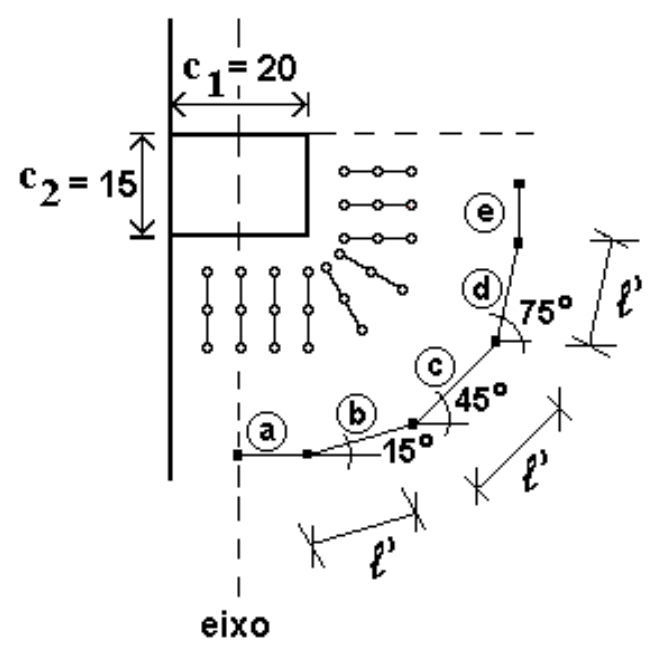

Portanto:

Trecho a: $\mathrm{D}_{\mathrm{a}}=50 \mathrm{~cm}^{2}$

Trecho b: $\mathrm{D}_{\mathrm{b}}=325,6 \mathrm{~cm}^{2}$

Trecho c: $\mathrm{D}_{\mathrm{c}}=584,72 \mathrm{~cm}^{2}$

Trecho d: $\mathrm{D}_{\mathrm{d}}=734,32 \mathrm{~cm}^{2}$

Trecho e: $\mathrm{D}_{\mathrm{e}}=330 \mathrm{~cm}^{2}$

Figura 4.21 - Segmentos do perímetro crítico

reduzido

Desta forma:

$\mathrm{e}_{\mathrm{xn}} *=\left(\mathrm{D}_{\mathrm{a}}+\mathrm{D}_{\mathrm{b}}+\mathrm{D}_{\mathrm{c}}+\mathrm{D}_{\mathrm{d}}+\mathrm{D}_{\mathrm{e}}\right) / \mu_{\mathrm{n}} *=2024,64 \mathrm{~cm}^{2} / 70,30 \mathrm{~cm}=28,80 \mathrm{~cm}$

$\mathrm{M}_{\mathrm{Sdn}}=1000-50 \mathrm{e}_{\mathrm{xn}}{ }^{*}=-440 \mathrm{kN} \cdot \mathrm{cm}<0 \longrightarrow \mathrm{M}_{\mathrm{Sdn}}=0$

Como $\mathrm{M}_{\mathrm{Sd}}$ deve ser maior ou igual a zero, então a segunda parcela da expressão (4.10) se anula e, consequentemente, não é necessário que se calcule o WP1nx.

Substituindo-se os valores calculados na expressão (4.10), tem-se:

$$
\tau_{\mathrm{Sdnx}}=\frac{\mathrm{F}_{\mathrm{Sd}}}{\mu_{\mathrm{n}} * \mathrm{~d}}=\frac{50}{70,3 \times 8,5}=0,0837 \mathrm{kN} / \mathrm{cm}^{2}=0,837 \mathrm{MPa}
$$

\section{b) Tensão atuante de cálculo $\tau_{\text {Sdny }}$ (ignora-se a borda paralela ao eixo y)}

Calculando-se a nova tensão atuante de cálculo de forma análoga ao item anterior e tomando-se o devido cuidado na adaptação da notação das expressões utilizadas, tem-se que:

$$
\tau_{\text {Sdny }}=\frac{F_{S d}}{\mu_{n} * d}+\frac{K_{1} M_{S d n}}{W_{P 1 n y} d} \leq \tau_{R d}
$$




$$
\begin{aligned}
& \mathrm{e}_{\mathrm{yn}}{ }^{*}=1955,76 \mathrm{~cm}^{2} / 70,30 \mathrm{~cm}=27,82 \mathrm{~cm} \\
& M_{S d n}=F_{S d} \cdot e_{y_{n}} *=1390 \mathrm{kN} \cdot \mathrm{cm} \\
& M_{S d n}=M_{y}-M_{S d n} *=-190 \mathrm{kN} \cdot \mathrm{cm}<0 \longrightarrow M_{S d n}=0
\end{aligned}
$$

Substituindo-se os valores numéricos na expressão (4.11):

$$
\tau_{\mathrm{Sdny}}=\tau_{\mathrm{Sdnx}}=0,0837 \mathrm{kN} / \mathrm{cm} 2=0,837 \mathrm{MPa}
$$

\section{c) Tensão resistente de cálculo $\tau_{\mathbf{R d}}$}

Comparando-se o valor de $\tau_{\mathrm{Sd}}$ com o valor de $\tau_{\mathrm{Rd} 1}$ (já calculado no item 4.5.3), tem-se que:

$$
\tau_{\mathrm{Sdnx}}=\tau_{\mathrm{Sdny}}=0,837 \mathrm{MPa} \leq \tau_{\mathrm{Rd}}=1,189 \mathrm{MPa}(\mathrm{OK} !)
$$

Observa-se que a presença da armadura de punção proporcionou à laje resistência suficiente para resistir aos esforços solicitantes.

\subsection{COLAPSO PROGRESSIVO}

Segundo EL DEBS (1992), o colapso progressivo pode ser definido como um tipo de ruína "incremental", de forma que os danos ocorridos não são proporcionais à causa inicial. Uma das soluções para este problema é propiciar caminhos alternativos para as cargas de uma estrutura. Para os exemplos analisados, deverá supor-se uma malha para armadura positiva idêntica às indicadas nas Figuras 4.2, 4.9 e 4.16, para pilares internos, de borda e de canto, respectivamente. Apenas as barras em negrito nas figuras acima mencionadas é que foram computadas nesta verificação. Estas barras, embora não esteja explícito, passam por dentro da armadura principal do pilar. $\mathrm{O}$ detalhamento destas armaduras não será abordado. No entanto, ele deve estar de acordo com a Figura 19.3.13 do texto base da NB-1/94, fornecida no capítulo 3. Observa-se, ainda, que não há informações para a situação de pilares de canto. O CEB/90 apresenta mais detalhes com relação à disposição dessa armadura. Esses detalhes estão apresentados no item 6.7 do capítulo 6. 


\subsubsection{PILAR INTERNO}

A armadura $A_{S}$ que cruza a interface da ligação laje-pilar, para este caso, corresponde a 10 barras. Portanto:

$A_{S} f_{y d}=\left(10 \times 0,80 \mathrm{~cm}^{2}\right) \times 43,48 \mathrm{kN} / \mathrm{cm}^{2}=347,84 \mathrm{kN}>F_{S d}=135 \mathrm{kN} \quad(O K !)$

\subsubsection{PILAR DE BORDA}

Neste caso, a armadura $\mathrm{A}_{\mathrm{S}}$ corresponde a 8 barras. Portanto:

$A_{S} f_{y d}=\left(8 \times 0,80 \mathrm{~cm}^{2}\right) \times 43,48 \mathrm{kN} / \mathrm{cm}^{2}=278,27 \mathrm{kN}>F_{S d}=100 \mathrm{kN} \quad(O K !)$

\subsubsection{PILAR DE CANTO}

Neste caso, a armadura $\mathrm{A}_{\mathrm{S}}$ corresponde a 5 barras. Portanto:

$$
A_{S} f_{y d}=\left(5 \times 0,80 \mathrm{~cm}^{2}\right) \times 43,48 \mathrm{kN} / \mathrm{cm}^{2}=173,92 \mathrm{kN}>F_{S d}=50 \mathrm{kN} \quad(\mathrm{OK} !)
$$

\subsection{OBSERVAÇÕES GERAIS}

Verifica-se, nos processos de cálculo desenvolvidos, que a presença da armadura de punção eleva substancialmente a resistência da ligação laje-pilar.

Observa-se também uma certa complexidade no cálculo dos parâmetros relativos à verificação da punção além da região armada. Para as situações analisadas neste capítulo, pode-se sugerir a adoção de um novo perímetro crítico, composto por trechos retos e por quartos de circunferência, análogo ao mostrado na Figura 4.3, de forma que se possa, dessa maneira, desenvolver expressões e, consequentemente, obter uma maior simplicidade no cálculo desta verificação. 
Com relação ao colapso progressivo, observa-se ainda que seria interessante que houvesse um melhor detalhamento para a armadura utilizada em pilares de borda e de canto. 


\section{EXEMPLOS SEGUNDO EUROCODE N.2 (1992)}

São apresentados aqui os mesmos exemplos mostrados no capítulo 4 , só que verificados segundo as recomendações do EUROCODE N.2.

Nos cálculos seguintes, a altura útil (d) adotada será igual à média aritmética das observadas segundo as duas direções ortogonais x e y. Já a taxa de armadura à flexão $\left(\rho_{1}\right)$ será a média geométrica das observadas segundo as duas direções x e y. O valor de $\rho_{1}$, no entanto, está limitado em 0,015. Portanto:

$$
\begin{aligned}
& d=\left(d_{x}+d_{y}\right) / 2 \\
& \rho_{1}=\sqrt{\rho_{x} \rho_{y}} \leq 0,015
\end{aligned}
$$

Observa-se que para os exemplos com armaduras de punção, a laje não apresenta a espessura mínima de $200 \mathrm{~mm}$, dada em função da dificuldade de se ancorar este tipo de armadura. No entanto, pode-se evitar este problema através da utilização de chapas de ancoragem fixadas nas extremidades dos conectores tipo pino.

As condições necessárias para que as recomendações deste código possam ser aplicadas aos casos analisados são as seguintes:

Para seção retangular:

(1) perímetro do pilar $\leq 11 \mathrm{~d} \rightarrow$ perímetro $=70 \mathrm{~cm} \leq 11 \mathrm{~d}=93,5 \mathrm{~cm} \quad(\mathrm{OK}$ !)

(2) relação lado maior / lado menor $\leq 2 \rightarrow 20 / 15=1,333 \leq 2 \quad$ (OK!) 
Para pilares alongados, na falta de uma análise mais apurada, o EUROCODE N.2 recomenda que se considere apenas certos trechos do perímetro crítico, uma vez que, para estes casos, o esforço cortante se concentra nos cantos dos apoios. Esta recomendação é ilustrada através da Figura 5.1.
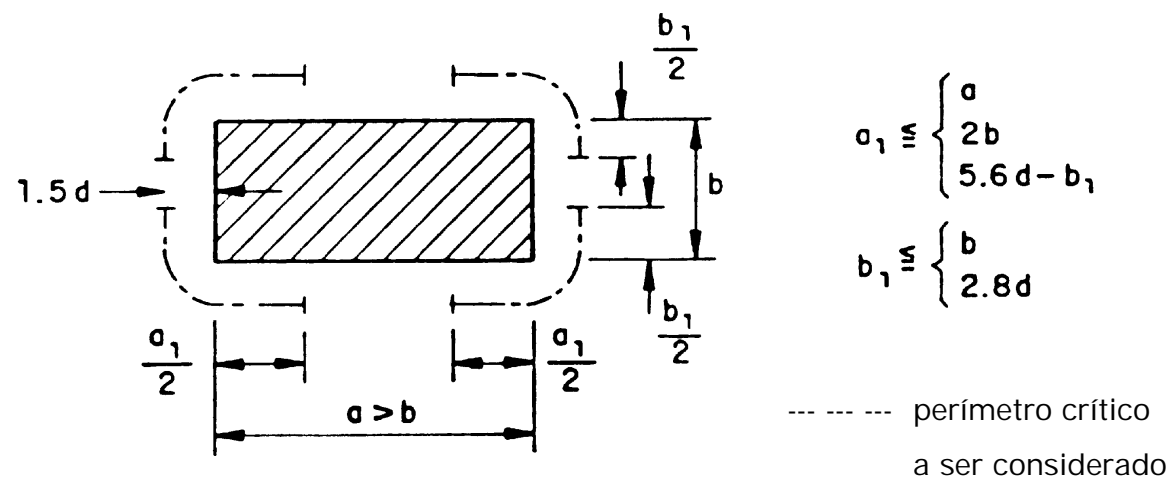

Figura 5.1 - Consideração do perímetro crítico para pilares alongados

\subsection{PILAR INTERNO SEM ARMADURA DE PUNÇÃO}

Os esquemas referentes a este exemplo estão ilustrados nas Figuras 4.1 e 4.2 do capítulo 4 . Nesses esquemas, define-se $c_{1}$ como sendo o lado do pilar paralelo ao eixo $\mathrm{x}$, enquanto que $\mathrm{c}_{2}$ é o lado perpendicular a este eixo.

Dados Gerais:

- seção do pilar: $\quad 15 \mathrm{~cm}$ x $20 \mathrm{~cm}$

- espessura da laje: $10 \mathrm{~cm}$

- resistência do concreto: $\mathrm{f}_{\mathrm{ck}}=25 \mathrm{MPa}$

- reação de apoio no pilar: $\mathrm{V}_{\mathrm{Sd}}=135 \mathrm{kN}$

- momentos fletores: $\quad \mathrm{M}_{\mathrm{X}}=10 \mathrm{kN} . \mathrm{m}$ $\mathrm{M}_{\mathrm{y}}=12 \mathrm{kN} \cdot \mathrm{m}$
- armadura de flexão negativa aço CA $50 \mathrm{~A}$

Bitola: $\phi 10 \mathrm{~mm}$ / Área: $0,80 \mathrm{~cm}^{2}$ Distribuição: malha de $5,6 \mathrm{~cm} \mathrm{x} 4,5 \mathrm{~cm}$

Direção $\mathrm{x}$ : $\rho_{\mathrm{X}}=0,0222 \mathrm{~d}_{\mathrm{X}}=8 \mathrm{~cm}$

Direção y: $\rho_{\mathrm{y}}=0,0159 \mathrm{~d}_{\mathrm{y}}=9 \mathrm{~cm}$

Para ligações sem armadura de punção, deverão ser feitas, basicamente, duas verificações. 
A primeira delas verifica a possibilidade de se dispensar a armadura de punção na ligação. Já a segunda, é destinada ao caso de carregamentos excêntricos, no qual será verificado se a laje está devidamente armada para resistir a um determinado momento fletor, dado em função de uma parcela do valor da reação do pilar. Esta última verificação visa garantir a possibilidade da laje desenvolver integralmente toda a sua resistência à punção.

\subsubsection{PRIMEIRA VERIFICAÇÃO}

Para que se dispense a armadura transversal em ligações, deve ser feita a seguinte verificação:

$$
\mathrm{v}_{\mathrm{Sd}} \leq \mathrm{v}_{\mathrm{Rd} 1}
$$

$\mathrm{v}_{\mathrm{Sd}}=$ esforço cortante de cálculo, dado por unidade de comprimento de um perímetro crítico u, localizado a 1,5d do contorno do pilar (Figura 5.2);

$\mathrm{v}_{\mathrm{Rd} 1}=$ esforço resistente de cálculo, dado por unidade de comprimento do perímetro crítico u, para uma laje sem armadura de punção.

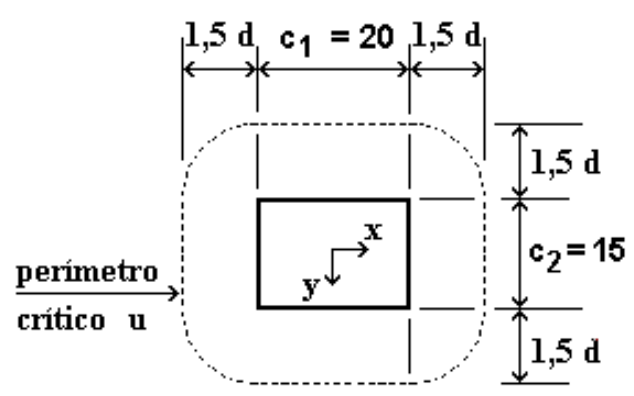

Figura 5.2 - Perímetro crítico (unidades em $\mathrm{cm}$ )

a) Cálculo de $v_{S d}$

$$
\text { O valor de } v_{S d} \text { é dado através da expressão: } \quad v_{S d}=\frac{v_{S d} \beta}{u}
$$

onde $\beta$ é o coeficiente que leva em conta os efeitos da excentricidade da carga. 
Nos casos em que não houver excentricidade do carregamento, $\beta$ pode ser adotado como igual a 1,0. Em outros casos, os valores dados segundo a Figura 5.3 podem ser adotados. Para análises mais rigorosas, outros valores de $\beta$ poderão ser utilizados, desde que associados a métodos adequados, que garantam a ancoragem da armadura posicionada na borda da laje.

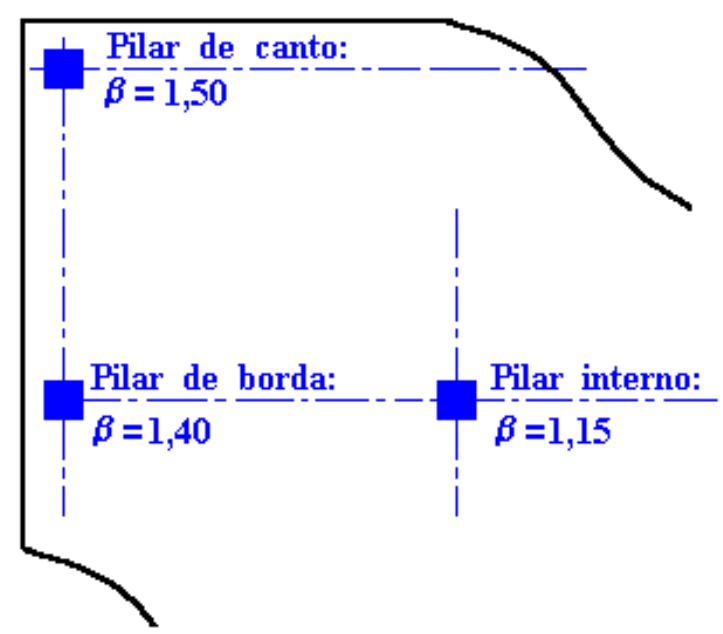

Figura 5.3 - Valores aproximados de $\beta$

$$
\text { Portanto: } \quad \mathrm{v}_{\mathrm{Sd}}=\frac{135 \mathrm{kN} \times 1,15}{1,501 \mathrm{~m}}=103,43 \mathrm{kN} / \mathrm{m}
$$

\section{b) Cálculo de $\mathbf{v}_{\text {Rd1 }}$}

Já $v_{R d 1}$ é obtido através da seguinte expressão:

$$
\mathrm{v}_{\mathrm{Rd} 1}=\tau_{\mathrm{Rd}} \mathrm{k}\left(1+40 \rho_{1}\right) \mathrm{d}
$$

$\tau_{\mathrm{Rd}}$ é fornecido através da tabela 5.1, extraída do EUROCODE N.2:

Tabela 5.1 - Valores de $\tau_{\mathrm{Rd}}$

\begin{tabular}{c||c|c|c|c|c|c|c|c|c}
\hline $\mathrm{f}_{\mathrm{ck}}(\mathrm{MPa})$ & 12 & 16 & 20 & 25 & 30 & 35 & 40 & 45 & 50 \\
\hline$\tau_{\mathrm{Rd}}\left(\mathrm{N} / \mathrm{mm}^{2}\right)$ & 0,18 & 0,22 & 0,26 & 0,30 & 0,34 & 0,37 & 0,41 & 0,44 & 0,48 \\
\hline
\end{tabular}


$\tau_{\mathrm{Rd}}\left(\right.$ para $\left.\mathrm{f}_{\mathrm{ck}}=25 \mathrm{MPa}\right)=0,30 \mathrm{~N} / \mathrm{mm}^{2}=300 \mathrm{kN} / \mathrm{m}^{2}$

$\mathrm{k}=|1,6-\mathrm{d}|=|1,6-0,085|=1,515 \geq 1,0$ (d em metros)

$\rho_{1}=0,0188>0,015 \rightarrow$ Portanto adota-se $\rho_{1}=0,015$

$\mathrm{d}=0,085$ metros

Desta forma: $\mathrm{v}_{\mathrm{Rd} 1}=300 \times 1,515 \times(1+40 \times 0,015) \times 0,085=61,81 \mathrm{kN} / \mathrm{m}$

c) Comparação dos parâmetros calculados

Fazendo-se a verificação, tem-se que: $\quad \mathrm{v}_{\mathrm{Sd}}=103,43 \mathrm{kN} / \mathrm{m}>\mathrm{v}_{\mathrm{Rd} 1}=61,81 \mathrm{kN} / \mathrm{m}$

Conclui-se que é necessário aumentar a resistência da ligação, sendo a solução adotada a de se adicionar armadura de punção à ligação.

\subsubsection{SEGUNDA VERIFICAÇÃO}

Como a ligação não passou na primeira verificação, não faz sentido passar para a próxima, que será mostrada no caso da ligação com armadura de punção.

\subsection{PILAR INTERNO COM ARMADURA DE PUNÇÃO}

Neste exemplo serão utilizados os dados referentes ao item 5.1, complementados com dados referentes à armadura de punção utilizada. A disposição da armadura de punção está ilustrada na Figura 4.4, no capítulo 4.

- Tipo de armadura de punção: conectores tipo pino

- Bitola: $\phi 6,3 \mathrm{~mm} \quad$ Aço: CA 50A Área do pino $\left(\mathrm{A}_{\mathrm{sy}}\right): 0,32 \mathrm{~cm}^{2}$

- $\mathrm{f}_{\mathrm{yd}}=434,78 \mathrm{MPa}$ (tensão de escoamento da armadura de punção) 
Visando padronizar os exemplos, observa-se que, apesar dos espaçamentos da armadura de punção estarem de acordo com as recomendações do EUROCODE N.2, parte da armadura de punção está localizada fora da região considerada crítica, região esta limitada pela linha distante de $1,5 \mathrm{~d}$ do contorno do pilar. Esta situação decorre do fato de que o exemplo foi, inicialmente, elaborado para atender às recomendações do texto base da NB-1/94. Sendo assim, desconsiderou-se a influência da armadura fora da região considerada crítica, no cálculo da resistência da ligação na região armada (Figura 5.4).

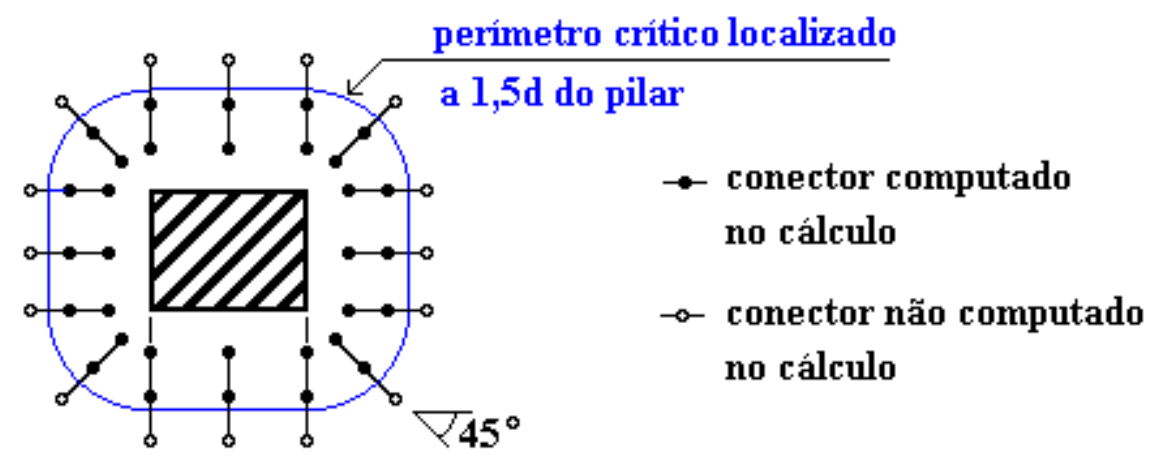

Figura 5.4 - Armadura de punção efetiva

Para este caso deverão ser feitas três verificações, detalhadas a seguir.

\subsubsection{PRIMEIRA VERIFICAÇÃO}

O valor do esforço cortante de cálculo $\left(\mathrm{v}_{\mathrm{Sd}}\right)$, já calculado no item 5.1.1, deverá ser comparado com dois parâmetros:

$\mathrm{v}_{\mathrm{Rd} 2}=$ resistência de cálculo máxima, dada por unidade de comprimento do perímetro crítico;

$\mathrm{v}_{\mathrm{Rd} 3}=$ resistência de cálculo, dada por unidade de comprimento do perímetro crítico, para lajes com armadura de punção. 
Desta forma, devem ser verificadas as seguintes relações:

$$
\begin{array}{llll}
\text { Se } & v_{\mathrm{Rd} 2} \leq v_{\mathrm{Rd} 3} & \text { então } & v_{\mathrm{Sd}} \leq \mathrm{v}_{\mathrm{Rd} 2} \\
\text { Se } & v_{\mathrm{Rd} 3} \leq \mathrm{v}_{\mathrm{Rd} 2} & \text { então } & v_{\mathrm{Sd}} \leq \mathrm{v}_{\mathrm{Rd} 3} .
\end{array}
$$

\section{a) Cálculo de $\mathbf{v}_{\mathbf{R d} 2}$}

$$
\mathrm{v}_{\mathrm{Rd} 2}=1,6 \mathrm{v}_{\mathrm{Rd} 1}
$$

Como $v_{\text {Rd1 }}$ já foi calculado no item 5.1.1, tem-se que:

$$
\mathrm{v}_{\mathrm{Rd} 2}=1,6 \times 61,81 \mathrm{kN} / \mathrm{m}=98,90 \mathrm{kN} / \mathrm{m}
$$

\section{b) Cálculo de $\mathbf{v}_{\mathbf{R d} 3}$}

$$
\mathrm{v}_{\mathrm{Rd} 3}=\mathrm{v}_{\mathrm{Rd} 1}+\sum \mathrm{A}_{\mathrm{Sw}} \mathrm{f}_{\mathrm{yd}} \operatorname{sen} \alpha / \mathrm{u}
$$

$\sum \mathrm{A}_{\mathrm{Sw}} \mathrm{f}_{\mathrm{yd}} \operatorname{sen} \alpha=$ soma da projeção dos esforços de cálculo da armadura de punção na direção da aplicação da reação da laje, sendo $\alpha$ o ângulo entre a armadura e o plano médio da laje.

Deve-se verificar se a taxa de armadura mínima $\rho_{\mathrm{w}}$ para armadura transversal não é inferior a $60 \%$ dos valores dados segundo a tabela 5.2, extraída do EUROCODE N.2 e utilizada para o dimensionamento de vigas:

Tabela 5.2 - Valores de $\rho_{\mathrm{w}}$

\begin{tabular}{c|c|c|c}
\hline \multirow{2}{*}{$\begin{array}{c}\text { Classes do } \\
\text { Concreto } *\end{array}$} & \multicolumn{3}{|c}{ Classes do aço } \\
\cline { 2 - 4 } & S220 & S400 & S500 \\
\hline C12/15 e C20/25 & 0,0016 & 0,0009 & 0,0007 \\
\hline C25/30 a C35/45 & 0,0024 & 0,0013 & 0,0011 \\
\hline C40/50 a C50/60 & 0,0030 & 0,0016 & 0,0013 \\
\hline
\end{tabular}

* como assumida em projeto 
A classe do aço é representada através do valor de sua tensão característica de escoamento, dada em MPa.

Portanto: $\quad \rho_{\mathrm{w}}=\frac{\sum \mathrm{A}_{\mathrm{SW}} \operatorname{sen} \alpha}{\left(\mathrm{A}_{\text {crit }}-\mathrm{A}_{\text {pilar }}\right)}$

$\sum \mathrm{A}_{\mathrm{Sw}} \operatorname{sen} \alpha=$ área total da armadura transversal disposta na área crítica, projetada na direção da reação na laje;

$\sum \mathrm{A}_{\mathrm{Sw}}=32 \mathrm{~A}_{\mathrm{sy}}=32 \times 0,32 \mathrm{~cm}^{2}=10,24 \mathrm{~cm}^{2}$

$\mathrm{A}_{\text {crit }}=$ área limitada pelo perímetro crítico;

$\mathrm{A}_{\text {crit }}=\left(3 \mathrm{~d}+\mathrm{c}_{1}\right)\left(\mathrm{c}_{2}\right)+3 \mathrm{dc}_{1}+\pi(1,5 \mathrm{~d})^{2}=1703,21 \mathrm{~cm}^{2}$

$\mathrm{A}_{\text {pilar }}=$ área do pilar $=\mathrm{c}_{1} \cdot \mathrm{c}_{2}=300 \mathrm{~cm}^{2}$

$\operatorname{sen} \alpha=1$

Portanto: $\rho_{\mathrm{W}}=0,0073$

$$
\mathrm{v}_{\mathrm{Rd} 3}=61,81 \mathrm{kN} / \mathrm{m}+296,61 \mathrm{kN} / \mathrm{m}=358,42 \mathrm{kN} / \mathrm{m}
$$

Observa-se que, independente da classe do aço, a taxa de armadura de punção utilizada é superior a $60 \%$ dos valores dados pela tabela.

\section{c) Comparação dos valores obtidos com $v_{S d}$}

Como o valor de $v_{\mathrm{Rd} 2}$ é menor que o valor de $\mathrm{v}_{\mathrm{Rd} 3}$, deve-se então comparar o valor de $\mathrm{v}_{\mathrm{Sd}}$ com o valor de $\mathrm{v}_{\mathrm{Rd} 2}$ :

$$
\mathrm{v}_{\mathrm{Sd}}=103,43 \mathrm{kN} / \mathrm{m} \approx \mathrm{v}_{\mathrm{Rd} 2}=98,90 \mathrm{kN} / \mathrm{m} \quad(\mathrm{OK} !)
$$

Como a diferença entre $v_{S d}$ e $v_{R d 2}$ é pequena, considerou-se que a ligação tenha passado nesta verificação.

\subsubsection{SEGUNDA VERIFICAÇÃO}

Para ligações submetidas a carregamentos excêntricos, deve-se garantir que os valores da resistência à punção, dados pelas expressões 5.1, 5.2 e 5.3, possam ser alcançados. 
Isto se faz através do dimensionamento da ligação para resistir a momentos fletores mínimos ( $\mathrm{m}_{\mathrm{Sdx}}$ e $\mathrm{mSdy}$ ), dados por unidade de largura e definidos para as faixas de atuação mostradas na Figura 5.5. Análises mais apuradas, no entanto, poderão conduzir a valores maiores.

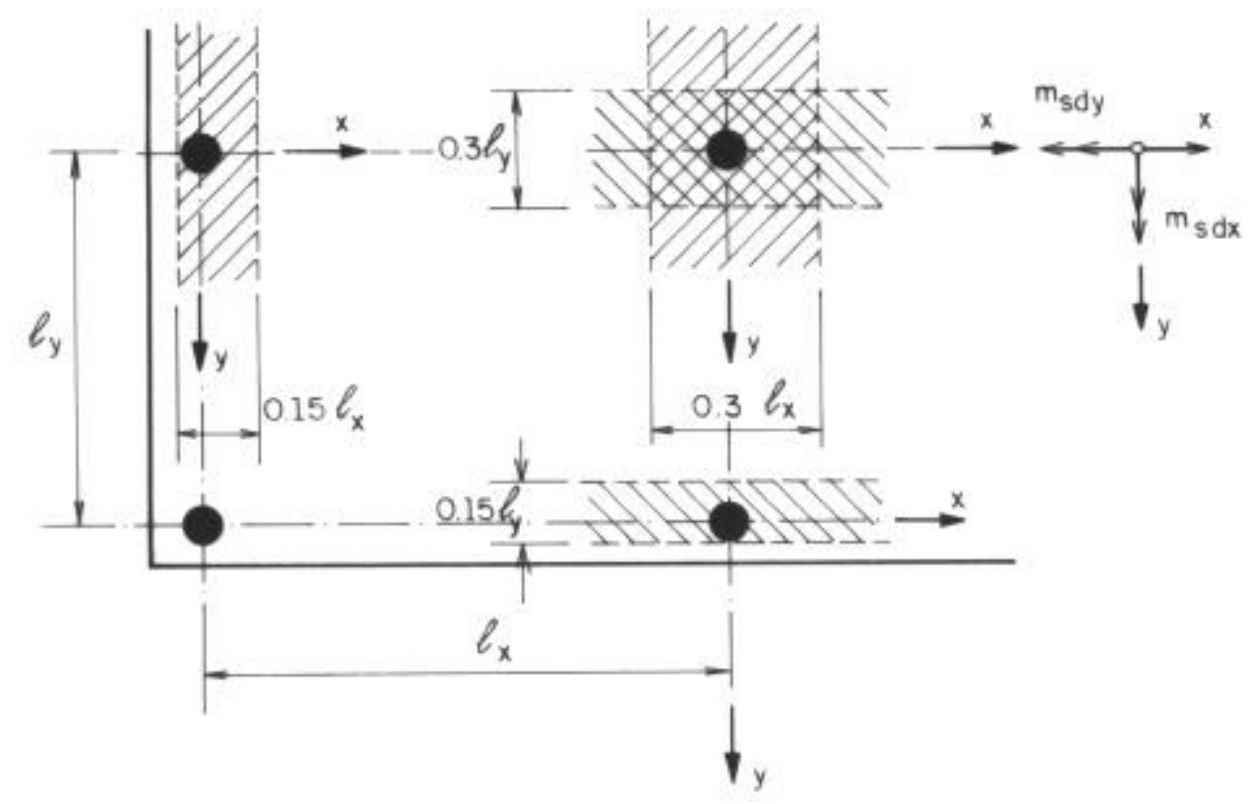

Figura 5.5 - Momentos fletores mSdx e mSdy

Portanto, na falta de uma análise mais apurada, deverá ser verificada a seguinte expressão:

$$
\mathrm{m}_{\mathrm{Sdx}}\left(\text { ou } \mathrm{m}_{\mathrm{Sdy}}\right) \geq \eta \mathrm{V}_{\mathrm{Sd}}
$$

onde :

$\mathrm{V}_{\mathrm{Sd}} \quad=$ reação do pilar;

$\eta \quad=$ coeficiente dado pela tabela 5.3 (extraída do EUROCODE N.2). 
No cálculo dos momentos resistentes correspondentes, apenas a armadura ancorada além da região crítica deverá ser levada em conta. A Figura 5.6, extraída do EUROCODE N.2, ilustra esta situação apenas para pilares de borda e de canto.

Tabela 5.3 - Valores de $\eta$

\begin{tabular}{l|c|c|c|c|c|c}
\hline \multirow{2}{*}{ Posição da coluna } & \multicolumn{3}{|c|}{$\eta$ para $\mathrm{m}_{\mathrm{Sdx}}$} & \multicolumn{3}{c}{$\eta$ para $\mathrm{m}_{\mathrm{Sdy}}$} \\
\cline { 2 - 7 } & topo & fundo & $\begin{array}{c}\text { largura } \\
\text { efetiva }\end{array}$ & topo & fundo & $\begin{array}{c}\text { largura } \\
\text { efetiva }\end{array}$ \\
\hline pilar interno & $-0,125$ & 0 & $0,3 \ell_{\mathrm{y}}$ & $-0,125$ & 0 & $0,3 \ell_{\mathrm{X}}$ \\
\hline $\begin{array}{l}\text { pilares de borda, } \\
\text { com a borda livre } \\
\text { paralela ao eixo } \mathrm{x}\end{array}$ & $-0,25$ & 0 & $0,15 \ell_{\mathrm{y}}$ & $-0,125$ & $+0,125$ & (por m) \\
$\begin{array}{l}\text { pilares de borda, } \\
\text { com a borda livre } \\
\text { paralela ao eixo y }\end{array}$ & $-0,125$ & $+0,125$ & $($ por $\mathrm{m})$ & $-0,25$ & 0 & $0,15 \ell_{\mathrm{X}}$ \\
\hline \begin{tabular}{l} 
pilares de canto \\
\hline
\end{tabular} & $-0,5$ & $+0,5$ & (por m) & $+0,5$ & $-0,5$ & $($ por m) \\
\hline
\end{tabular}

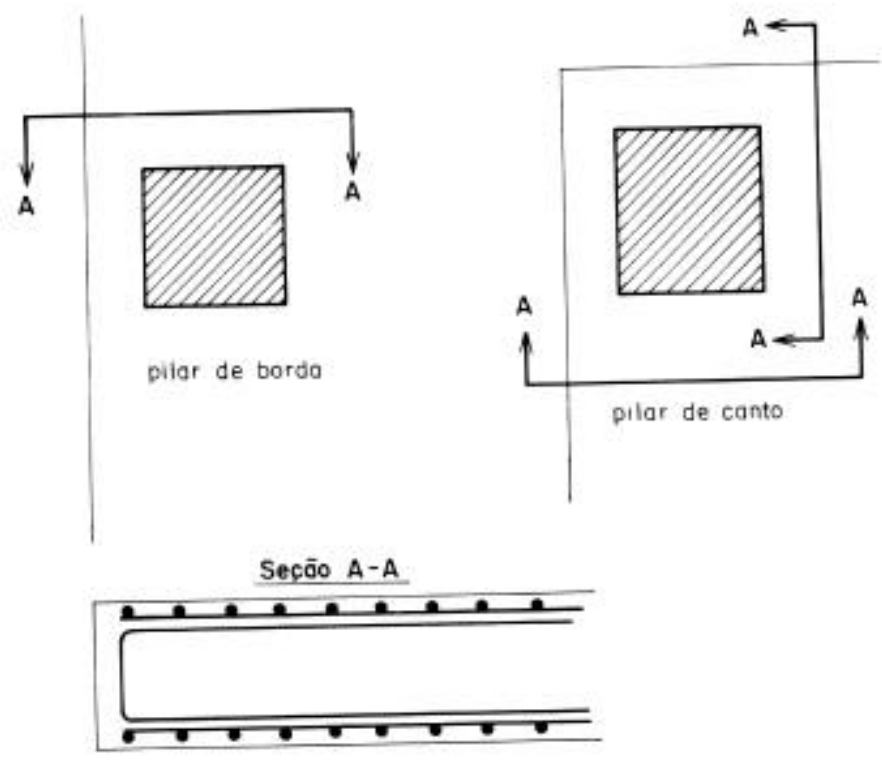

Figura 5.6 - Detalhamento da armadura para pilares de borda e de canto 
Neste exemplo, para que se possa definir as larguras efetivas das faixas que deverão resistir aos momentos fletores $m_{S d x}$ e $m_{S d y}$, deverão ser adotados os vãos de 3 e de 4 metros segundo as direções x e y, respectivamente (Figura 5.7). Portanto: $\quad \ell_{\mathrm{x}}=3$ metros;

$\ell_{\mathrm{y}}=4$ metros.

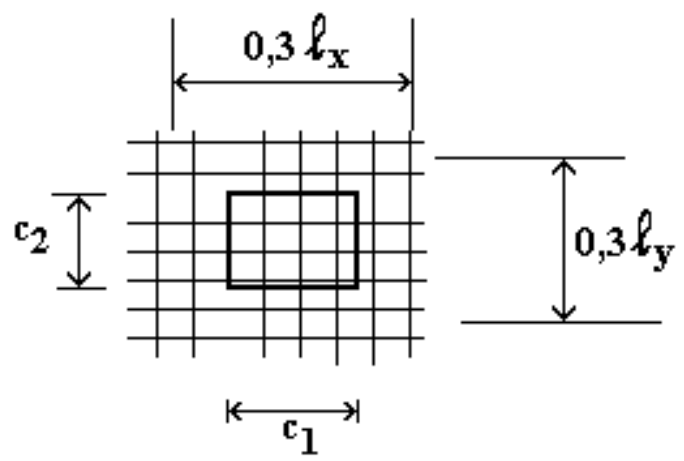

Figura 5.7 - Larguras efetivas das faixas analisadas

A metodologia do cálculo a ser realizado deverá ser a seguinte:

- para cada direção deverá ser calculado o momento fletor, dado através da expressão (5.4);

- a seguir, será calculada a armadura necessária para resistir a este momento;

- por fim, compara-se a armadura obtida com a já existente na laje, através dos valores das taxas de armadura; supondo que a armadura já existente no trecho seja superior à calculada, considera-se a laje verificada segundo esta condição.

Para este exemplo, observa-se que, para ambas as direções $\mathrm{x}$ e $\mathrm{y}, \mathrm{o}$ valor de $\eta$ é negativo para a borda superior e nulo para a borda inferior da laje. $\mathrm{O}$ sinal negativo indica que a face superior da laje é que está sendo tracionada, enquanto que o valor nulo indica que não há necessidade de se posicionar uma armadura adicional na face inferior da laje. Uma vez definido o significado dos sinais expressos na tabela 5.3, nos cálculos seguintes será utilizado o valor de $\eta$ em módulo. 


\section{a) Verificando a direção $x$}

- $\mathrm{m}_{\mathrm{Sdx}} \geq \eta \mathrm{V}_{\mathrm{Sd}}=0,125 \times 135 \mathrm{kN}=16,88 \mathrm{kN} \mathrm{cm} / \mathrm{cm}$

- largura da faixa $=0,3 \ell_{\mathrm{y}}=0,3 \times 400 \mathrm{~cm}=120 \mathrm{~cm}$.

- Portanto: $\mathrm{M}_{\mathrm{Sdx}}=16,88 \mathrm{kN} \mathrm{cm} / \mathrm{cm} \mathrm{x} 120 \mathrm{~cm}=2025 \mathrm{kN} \mathrm{cm}$

Utilizando-se PINHEIRO (1993), dimensionou-se a faixa analisada à flexão.

Para concreto com $\mathrm{f}_{\mathrm{ck}}=25 \mathrm{MPa}$ :

$\mathrm{k}_{\mathrm{c}}=\frac{120 \mathrm{~d}_{\mathrm{x}}}{\mathrm{M}_{\mathrm{Sdx}}}=\frac{120 \times 8}{2025}=3,79 \stackrel{\text { tabela }}{\longrightarrow} \mathrm{k}_{\mathrm{s}}=0,025$

$A_{S}=\frac{k_{S} M_{S d x}}{d_{x}}=\frac{0,025 \times 2025}{8}=6,33 \mathrm{~cm}^{2}$

Distribuindo-se a armadura calculada na faixa analisada, obtém-se a seguinte taxa de armadura $\left(\rho_{X}^{\prime}\right)$ :

$$
\rho_{X}^{\prime}=\frac{6,33 \mathrm{~cm}^{2}}{120 \mathrm{~cm} \mathrm{x} 8 \mathrm{~cm}}=0,0066
$$

Comparando-se o valor obtido com a taxa de armadura já existente $\left(\rho_{X}\right)$, tem-se que:

$$
\rho_{\mathrm{X}}=0,0222>\rho_{\mathrm{X}}^{\prime}=0,0066 \quad(\mathrm{OK} !)
$$

Desta forma, observa-se que a taxa de armadura já existente nesta direção é superior à calculada. Sendo assim, considera-se a laje verificada segundo esta direção. 


\section{b) Verificando a direção y}

- $\mathrm{m}_{\mathrm{Sdy}} \geq \eta \mathrm{V}_{\mathrm{Sd}}=0,125 \times 135 \mathrm{kN}=16,88 \mathrm{kN} \mathrm{cm} / \mathrm{cm}$

- largura da faixa $=0,3 \ell_{\mathrm{x}}=0,3 \times 300 \mathrm{~cm}=90 \mathrm{~cm}$.

- Portanto: MSdy $=16,88 \mathrm{kN} \mathrm{cm} / \mathrm{cm} \times 90 \mathrm{~cm}=1519,20 \mathrm{kN} \mathrm{cm}$

Analogamente ao que foi feito no item anterior, com base no momento fletor calculado, dimensionou-se uma armadura de flexão para a faixa analisada, obtendo-se, desta forma, uma taxa de armadura $\rho_{\mathrm{y}}^{\prime}$. Comparando-se esta taxa com a taxa de armadura já existente $\left(\rho_{y}\right)$, obteve-se o seguinte resultado:

$$
\rho_{y}=0,0159>\rho_{y}^{\prime}=0,0052
$$

Observa-se que a taxa de armadura já existente nesta direção é superior à calculada. Sendo assim, considera-se a laje verificada também segundo esta direção.

\subsubsection{TERCEIRA VERIFICAÇÃO}

O EUROCODE N.2 recomenda ainda que, onde necessário e considerando perímetros críticos adicionais, a resistência à punção da ligação deverá ser verificada fora da região armada.

Desta forma, optou-se por verificar um novo perímetro crítico localizado a 1,5d além da última linha de conectores, com forma análoga ao perímetro crítico já definido, adaptando-se, apenas, um novo raio para os cantos (Figura 5.8). A nova tensão atuante neste novo perímetro deverá, então, ser comparada com a tensão resistente para ligações sem armadura de punção.

Portanto: $\quad \mathrm{u}^{\prime}=2 \times 20+2 \times 15+2 \pi(17+1,5 \times 8,5)=256,92 \mathrm{~cm}=2,57 \mathrm{~m}$

$$
\begin{aligned}
& \mathrm{v}_{\mathrm{Sd}}^{\prime}=\frac{\mathrm{v}_{\mathrm{Sd}} \beta}{\mathrm{u}^{\prime}}=\frac{135 \mathrm{kN} \times 1,15}{2,57 \mathrm{~m}}=60,43 \mathrm{kN} / \mathrm{m} \\
& \mathrm{v}_{\mathrm{Rd} 1}=61,81 \mathrm{kN} / \mathrm{m} \text { (já calculado no item 5.1.1) }
\end{aligned}
$$




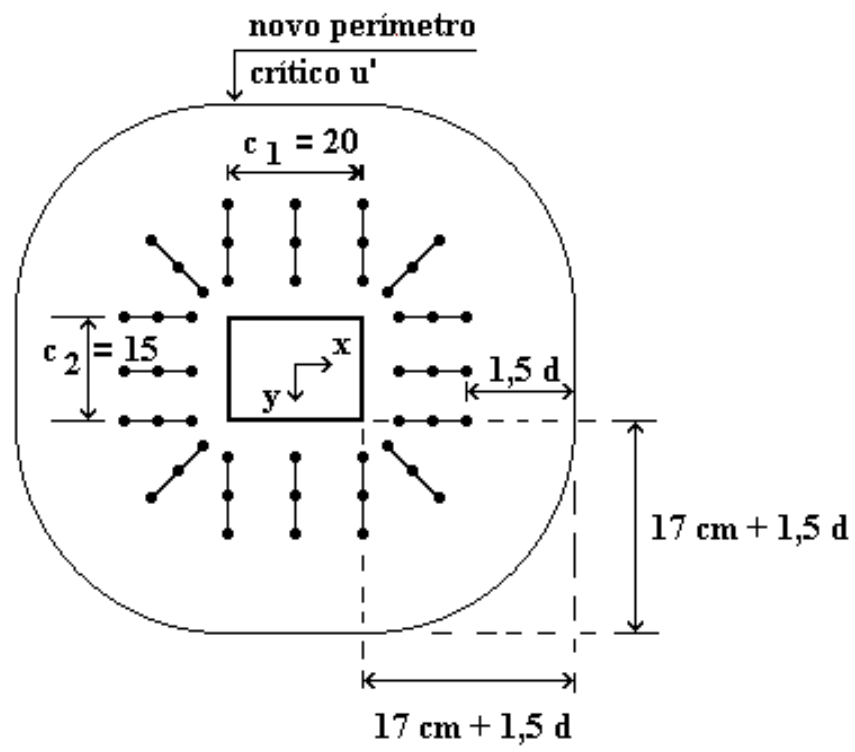

Figura 5.8 - Novo perímetro crítico

Comparando-se os parâmetros,tem-se que:

$$
\mathrm{v}_{\mathrm{Sd}}^{\prime}=60,43 \mathrm{kN} \leq \mathrm{v}_{\mathrm{Rd} 1}=61,81 \mathrm{kN} / \mathrm{m}
$$

Apesar da localização do novo perímetro crítico ter sido feita em relação aos conectores mais externos, localizados fora do perímetro crítico original (a 1,5d do pilar), considerou-se que, mesmo fora da região crítica original, estes conectores colaboram na transferência dos esforços, de modo a afastar a superfície de ruína da face do pilar.

Por fim, conclui-se que a laje resiste aos esforços solicitantes devido ao acréscimo de resistência à ligação proporcionado pela armadura de punção.

\subsection{PILAR DE BORDA SEM ARMADURA DE PUNÇÃO}

Os esquemas referentes a este exemplo estão ilustrados nas Figuras 4.8 e 4.9 do capítulo 4. 


\section{Dados Gerais:}

- seção do pilar:

- espessura da laje:

$15 \mathrm{~cm} \times 20 \mathrm{~cm}$

$10 \mathrm{~cm}$

- resistência do concreto: $\mathrm{f}_{\mathrm{ck}}=25 \mathrm{MPa}$

- reação de apoio no pilar: $\mathrm{V}_{\mathrm{Sd}}=100 \mathrm{kN}$

- momentos fletores:

$$
\mathrm{M}_{\mathrm{X}}=10 \mathrm{kN} \cdot \mathrm{m}
$$$$
\mathrm{M}_{\mathrm{y}}=12 \mathrm{kN} \cdot \mathrm{m}
$$

- armadura de flexão negativa aço CA 50 A

Bitola: $\phi 10 \mathrm{~mm}$ / Área: $0,80 \mathrm{~cm}^{2}$

Distribuição: malha de $5,6 \mathrm{~cm} \mathrm{x} 4,5 \mathrm{~cm}$

Direção x: $\rho_{\mathrm{X}}=0,0222 \mathrm{~d}_{\mathrm{X}}=8 \mathrm{~cm}$

Direção y: $\rho_{\mathrm{y}}=0,0159 \mathrm{~d}_{\mathrm{y}}=9 \mathrm{~cm}$

Define-se $\mathrm{c}_{1}$ como sendo o lado perpendicular à borda livre enquanto que $c_{2}$ é o lado paralelo à borda livre.

As condições necessárias para que as recomendações deste código possam ser aplicadas já foram feitas no item 5.1.

Analogamente ao que foi feito no item 5.1, para ligações com pilares internos, sem armadura de punção, também aqui deverão ser feitas duas verificações.

O perímetro crítico u para pilares de borda está ilustrado na Figura 5.9.

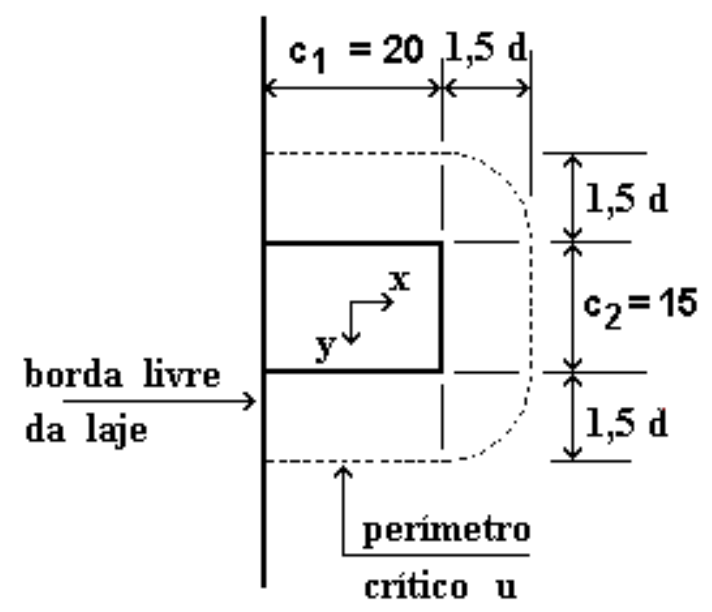

Figura 5.9 - Perímetro crítico para pilares de borda (unidades em $\mathrm{cm}$ ) 


\subsubsection{PRIMEIRA VERIFICAÇÃO}

$$
\mathrm{v}_{\mathrm{Sd}} \leq \mathrm{v}_{\mathrm{Rd} 1}
$$

Portanto:

$$
\begin{aligned}
& \mathrm{u}=2 \mathrm{c}_{1}+\mathrm{c}_{2}+2 \pi(1,5 \mathrm{~d}) / 2=95,06 \mathrm{~cm}=0,951 \mathrm{~m} \\
& \mathrm{v}_{\mathrm{Sd}}=\frac{\mathrm{V}_{\mathrm{Sd}} \beta}{\mathrm{u}}=\frac{100 \mathrm{kN} \times 1,40}{0,951 \mathrm{~m}}=147,28 \mathrm{kN} / \mathrm{m} \\
& \mathrm{v}_{\mathrm{Rd} 1}=\tau_{\mathrm{Rd}} \mathrm{k}\left(1+40 \rho_{1}\right) \mathrm{d}
\end{aligned}
$$

$$
\begin{aligned}
& \left.\tau_{\mathrm{Rd}} \text { (tabela } 5.1-\mathrm{f}_{\mathrm{ck}}=25 \mathrm{MPa}\right)=0,30 \mathrm{~N} / \mathrm{mm}^{2}=300 \mathrm{kN} / \mathrm{m}^{2} \\
& \mathrm{k} \quad=|1,6-\mathrm{d}|=|1,6-0,085|=1,515 \geq 1,0(\mathrm{~d} \text { em metros }) \\
& \rho_{1}=0,0188>0,015 \rightarrow \text { Portanto adota-se } \rho_{1}=0,015
\end{aligned}
$$

$$
\mathrm{v}_{\mathrm{Rd} 1}=300 \mathrm{x} 1,515 \mathrm{x}(1+40 \mathrm{x} 0,015) \times 0,085=61,81 \mathrm{kN} / \mathrm{m}
$$

Desta forma, fazendo-se a comparação dos parâmetros, tem-se que:

$$
\mathrm{v}_{\mathrm{Sd}}=147,28 \mathrm{kN} / \mathrm{m}>\mathrm{v}_{\mathrm{Rd} 1}=61,81 \mathrm{kN} / \mathrm{m}
$$

Conclui-se que é necessário adicionar armadura de punção à ligação.

\subsubsection{SEGUNDA VERIFICAÇÃO}

Como a ligação não passou na primeira verificação, não faz sentido passar para a próxima, que será mostrada no caso da ligação com armadura de punção.

\subsection{PILAR DE BORDA COM ARMADURA DE PUNÇÃO}

Neste exemplo serão utilizados os dados referentes ao item 5.3, complementados com dados referentes à armadura de punção utilizada. A disposição da armadura de punção está ilustrada na Figura 4.10 do capítulo 4. 
- Tipo de armadura de punção: conectores tipo pino

- Bitola: $\phi 6,3 \mathrm{~mm} \quad$ Aço: CA 50A Área do pino $\left(\mathrm{A}_{\mathrm{S}} \mathrm{y}\right): 0,32 \mathrm{~cm}^{2}$

- $\mathrm{f}_{\mathrm{yd}}=434,78 \mathrm{MPa}$ (tensão de escoamento da armadura de punção)

Analogamente ao ocorrido no item 5.2, parte da armadura de punção ficou localizada fora da região crítica. Sendo assim, desconsiderou-se a influência desta armadura no cálculo da resistência da ligação na região armada (Figura 5.10). Para este exemplo, não foi considerada a recomendação do CEB/90 referente à armadura de punção adicional, ilustrada na Figura 4.10. Para este caso, os conectores "adicionais" foram considerados no cálculo.

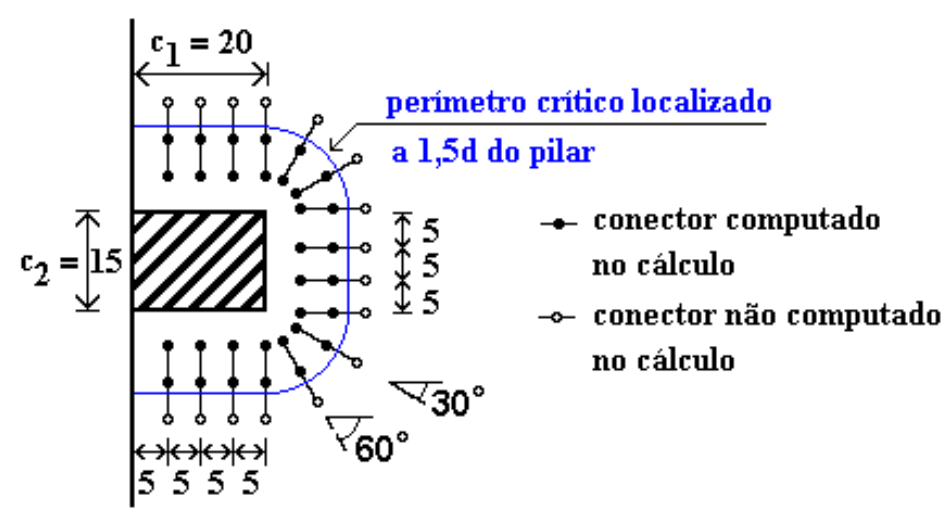

Figura 5.10 - Armadura de punção efetiva

Deverão ser feitas três verificações, detalhadas a seguir.

\subsubsection{PRIMEIRA VERIFICAÇÃO}

Conforme já visto no item 5.2, o valor do esforço cortante de cálculo $\mathrm{v}_{\mathrm{Sd}}$ deverá ser comparado com o menor dos dois parâmetros de resistência $v_{R d 2}$ e $v_{R d 3}$.

\section{a) Cálculo de $\mathbf{v}_{\mathrm{Rd2}}$ (expressão 5.2)}

$$
\mathrm{v}_{\mathrm{Rd} 2}=1,6 \mathrm{v}_{\mathrm{Rd} 1}\left(\mathrm{v}_{\mathrm{Rd} 1} \text { já calculado no item 5.3.1 }\right)=98,90 \mathrm{kN} / \mathrm{m}
$$




\section{b) Cálculo de $\mathbf{v}_{\mathrm{Rd3}}$ (expressão 5.3)}

- verificação da taxa de armadura mínima $\left(\rho_{\mathrm{w}}\right)$ - tabela 5.2:

$$
\rho_{\mathrm{W}}=\frac{\sum \mathrm{A}_{\mathrm{Sw}} \operatorname{sen} \alpha}{\left(\mathrm{A}_{\text {crit }}-\mathrm{A}_{\text {pilar }}\right)}
$$

$\sum \mathrm{A}_{\mathrm{Sw}}=32 \mathrm{~A}_{\mathrm{sy}}=32 \times 0,32 \mathrm{~cm}^{2}=10,24 \mathrm{~cm}^{2}$

$A_{\text {crit }}=\left(1,5 \mathrm{~d}+\mathrm{c}_{1}\right)\left(\mathrm{c}_{2}\right)+3 \mathrm{dc}_{1}+\pi(1,5 \mathrm{~d})^{2} / 2=1256,60 \mathrm{~cm}^{2}$

$A_{\text {pilar }}=$ área do pilar $=c_{1} \cdot c_{2}=300 \mathrm{~cm}^{2}$

sen $\alpha=1$

Portanto: $\quad \rho_{\mathrm{w}}=0,0107$

$$
\mathrm{v}_{\mathrm{Rd} 3}=\mathrm{v}_{\mathrm{Rd} 1}+\sum \mathrm{A}_{\mathrm{Sw}} \mathrm{f}_{\mathrm{yd}} \operatorname{sen} \alpha / \mathrm{u}=61,81+468,38=530,19 \mathrm{kN} / \mathrm{m}
$$

Observa-se que, independente da classe do aço, a taxa de armadura de punção é superior a $60 \%$ das fornecidas pela tabela acima mencionada.

\section{c) Comparação dos valores obtidos com $v_{S d}$}

Como $v_{\mathrm{Rd} 3}>\mathrm{v}_{\mathrm{Rd} 2}$, compara-se o valor de $\mathrm{v}_{\mathrm{Sd}}$ com o valor de $\mathrm{v}_{\mathrm{Rd} 2}$.

$\mathrm{v}_{\mathrm{Sd}}=147,28 \mathrm{kN} / \mathrm{m}$ (calculado no item 5.3.1) $>\mathrm{v}_{\mathrm{Rd} 2}=98,90 \mathrm{kN} / \mathrm{m}$ (não passou!)

Observa-se que, segundo este método, mesmo com a presença da armadura de punção, a ligação não apresentou resistência suficiente para resistir aos esforços solicitantes. A seguir, a título de ilustração, serão feitas as verificações seguintes. 


\subsubsection{SEGUNDA VERIFICAÇÃO}

Caso a ligação tivesse passado na verificação anterior, deveriam ser verificados os momentos de cálculo mínimos para ligações submetidas a carregamentos excêntricos, analogamente ao que foi feito no item 5.2.2.

$$
\mathrm{m}_{\mathrm{Sdx}}\left(\text { ou } \mathrm{m}_{\mathrm{Sdy}}\right) \geq \eta \mathrm{V}_{\mathrm{Sd}}
$$

A disposição destes momentos, bem como a definição de suas faixas de atuação já foram mostradas na Figura 5.5

Observa-se que, segundo a tabela 5.3, deverá existir uma armadura positiva segundo a direção x, que, por sua vez, deverá estar detalhada segundo a Figura 5.6. Desta forma, deve-se fazer, segundo esta direção, a verificação tanto na face superior como na face inferior da laje.

A metodologia a ser utilizada nos cálculos seguintes será análoga à definida no item 5.2.2.

Na Figura 5.11, estão mostradas as faixas da laje analisadas. Para que se possa definir a faixa de atuação segundo a direção y, adotou-se os vãos de 3 e de 4 metros, segundo as direções x e y, respectivamente.

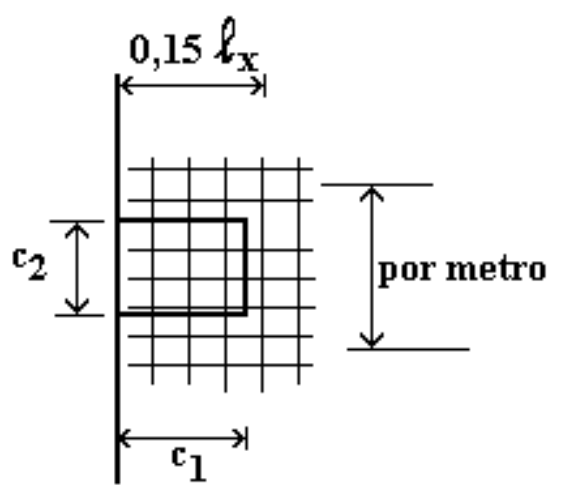

Figura 5.11 - Faixas de laje efetivas 


\section{a) Verificando a direção $x$}

- verificando a face superior da laje:

$$
\begin{aligned}
& \mathrm{m}_{\mathrm{Sdx}} \geq \eta \mathrm{V}_{\mathrm{Sd}}=0,125 \times 100 \mathrm{kN}=12,50 \mathrm{kN} \mathrm{cm} / \mathrm{cm} \\
& \text { largura da faixa }=1,00 \text { metro } \\
& \text { Portanto: } \quad \mathrm{M}_{\mathrm{Sdx}}=12,50 \mathrm{kN} \mathrm{cm} / \mathrm{cm} \times 100 \mathrm{~cm}=1250 \mathrm{kN} \mathrm{cm}
\end{aligned}
$$

Conforme já visto anteriormente, dimensionou-se a faixa à flexão com base no momento $\mathrm{M}_{\mathrm{Sdx}}$, de forma que, distribuindo-se a armadura calculada na largura efetiva da faixa, obteve-se uma taxa de armadura $\rho_{\mathrm{X}}^{\prime}$. Comparando-se o valor obtido com a taxa de armadura já existente $\left(\rho_{X}\right)$, tem-se que:

$$
\rho_{\mathrm{X}}=0,0222>\rho_{\mathrm{X}}^{\prime}=0,0049 \quad(\mathrm{OK} !)
$$

Observa-se que a taxa de armadura já existente nesta direção é superior à calculada. Sendo assim, considera-se a laje verificada segundo esta direção.

- verificando a face inferior da laje:

$$
\begin{aligned}
& \mathrm{m}_{\mathrm{Sdx}} \geq \eta \mathrm{V}_{\mathrm{Sd}}=0,125 \times 100 \mathrm{kN}=12,50 \mathrm{kN} \mathrm{cm} / \mathrm{cm} \\
& \text { largura da faixa }=1,00 \text { metro }
\end{aligned}
$$

Adotando-se para a face inferior a mesma distribuição da armadura de flexão utilizada na face superior da laje, mostrada na Figura 4.9 do capítulo 4, observa-se que, como não houve alterações quanto ao valor do momento fletor a ser dimensionado, pode-se considerar verificada a face inferior da laje. O detalhamento desta armadura, para pilares de canto e de borda, deve obedecer às recomendações mostradas na Figura 5.6. Esta armadura pode ser considerada como uma armadura adicional ou ainda como o prolongamento de uma armadura positiva (Figura 5.12).

Segundo o item 5.4.3.2.4 do EUROCODE N.2, ao longo de uma borda livre, a laje usualmente deve apresentar uma armadura longitudinal e uma armadura transversal, geralmente dispostas conforme mostrado na Figura 5.13. 


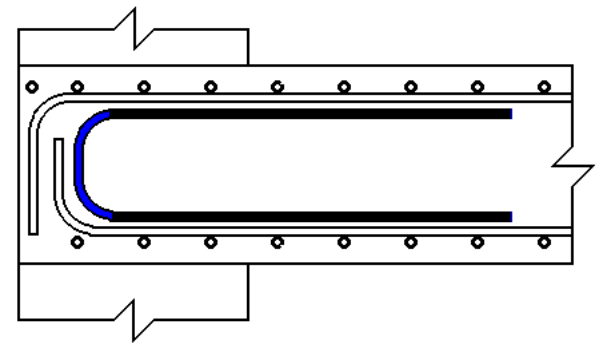

a) armadura adicional

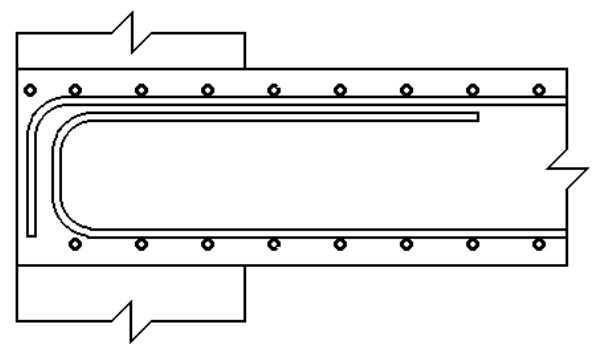

b) prolongamento da armadura positiva

Figura 5.12 - Armadura complementar

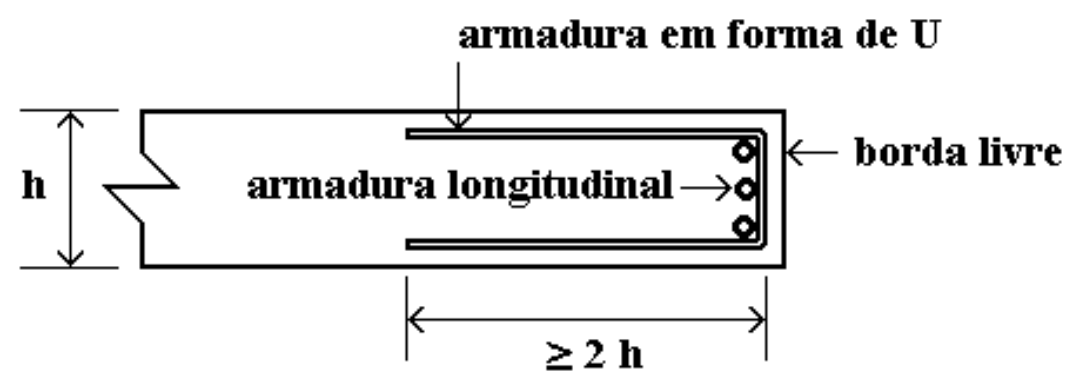

Figura 5.13 - Armadura para borda livre de uma laje

Observa-se que os ramos desta armadura, segundo o EUROCODE N.2, devem apresentar um comprimento superior a duas vezes a espessura da laje. Tem-se visto, no entanto, como uma recomendação geral para projetos, que os ramos dessa armadura tenham um comprimento da ordem de 3 vezes a espessura da laje.

\section{b) Verificando a direção y}

Observa-se que para a verificação segundo esta direção, deve-se detalhar apenas a armadura na face negativa da laje. 
Portanto:

$$
\begin{aligned}
& \mathrm{m}_{\text {Sdy }} \geq \eta \mathrm{V}_{\mathrm{Sd}}=0,25 \times 100 \mathrm{kN}=25,00 \mathrm{kN} \mathrm{cm} / \mathrm{cm} \\
& \text { largura da faixa }=0,15 \ell_{\mathrm{x}}=0,15 \times 300 \mathrm{~cm}=45 \mathrm{~cm} \\
& \text { Portanto: MSdy }=25,00 \mathrm{kN} \mathrm{cm} / \mathrm{cm} \times 45 \mathrm{~cm}=1125,00 \mathrm{kN} \mathrm{cm}
\end{aligned}
$$

Distribuindo-se a armadura calculada para a faixa da laje resistir ao momento fletor Msdy, obtém-se uma taxa de armadura $\left(\rho_{y}^{\prime}\right)$. Comparando-se este valor com a taxa de armadura já existente $\left(\rho_{y}\right)$, tem-se que:

$$
\rho_{\mathrm{y}}=0,0159>\rho_{\mathrm{y}}^{\prime}=0,008 \quad(\mathrm{OK} !)
$$

Observa-se que a taxa de armadura já existente nesta direção é superior à calculada. Sendo assim, considera-se a laje verificada também segundo esta direção.

\subsubsection{TERCEIRA VERIFICAÇÃO}

Conforme já visto no item 5.2, o EUROCODE N.2 recomenda que se verifique a resistência à punção fora da região armada, considerando perímetros críticos adicionais.

Analogamente ao que foi feito no item 5.2.3, verificou-se um novo perímetro crítico u', localizado a 1,5d além da última linha de armadura, com forma análoga ao perímetro crítico u já definido (Figura 5.14). A nova tensão atuante (v'Sd) neste novo perímetro crítico deverá, então, ser comparada com a tensão resistente, já calculada, para ligações sem armadura de punção, dada no item 5.3.1.

Portanto: $\quad \mathrm{u}^{\prime}=148,46 \mathrm{~cm}=1,485 \mathrm{~m}$

$$
\begin{aligned}
& \mathrm{v}_{\mathrm{Sd}}=\frac{100 \mathrm{kN} \times 1,40}{1,485 \mathrm{~m}}=94,30 \mathrm{kN} / \mathrm{m} \\
& \mathrm{v}_{\mathrm{Rd} 1}=61,81 \mathrm{kN} / \mathrm{m} \text { (já calculado no item 5.1.1) }
\end{aligned}
$$

Portanto: $\quad \mathrm{v}_{\mathrm{Sd}}^{\prime}=94,30 \mathrm{kN} \quad>\mathrm{v}_{\mathrm{Rd} 1}=61,81 \mathrm{kN} / \mathrm{m} \quad$ (não passou!) 


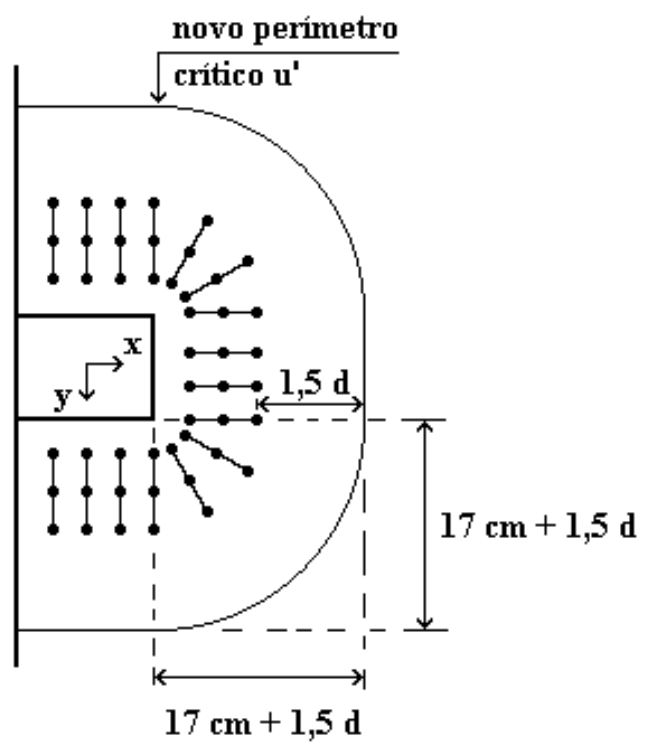

Figura 5.14 - Novo perímetro crítico

Por fim, conclui-se que a ligação não passou na primeira verificação e nem na terceira. Desta forma restam como alternativas aumentar a espessura da laje, utilizar capitéis e/ou "drop panels", aumentar a resistência do concreto, verificar a possibilidade de se alterar a arquitetura, modificando os vãos e, por fim, modificar o próprio sistema estrutural, inserindo vigas de borda, protensão ou mesmo partindo para o sistema convencional, com vigas.

\subsection{PILAR DE CANTO SEM ARMADURA DE PUNÇÃO}

Dados Gerais:

- seção do pilar:

$15 \mathrm{~cm} \times 20 \mathrm{~cm}$

- espessura da laje: $10 \mathrm{~cm}$

- resistência do concreto: $\mathrm{f}_{\mathrm{ck}}=25 \mathrm{MPa}$

- reação de apoio no pilar: $\mathrm{V}_{\mathrm{Sd}}=50 \mathrm{kN}$

- momentos fletores:

$$
\begin{aligned}
& \mathrm{M}_{\mathrm{X}}=10 \mathrm{kN} \cdot \mathrm{m} \\
& \mathrm{M}_{\mathrm{y}}=12 \mathrm{kN} \cdot \mathrm{m}
\end{aligned}
$$

- armadura de flexão negativa aço CA $50 \mathrm{~A}$

Bitola: $\phi 10 \mathrm{~mm}$ / Área: $0,80 \mathrm{~cm}^{2}$

Distribuição: malha de $5,6 \mathrm{~cm}$ x $4,5 \mathrm{~cm}$

Direção $\mathrm{x}: \rho_{\mathrm{X}}=0,0222 \mathrm{~d}_{\mathrm{X}}=8 \mathrm{~cm}$

Direção y: $\rho_{\mathrm{y}}=0,0159 \mathrm{~d}_{\mathrm{y}}=9 \mathrm{~cm}$ 
Os esquemas referentes a este caso estão representados nas Figuras 4.15 e 4.16 , presentes no capítulo 4. Define-se $\mathrm{c}_{1}$ como sendo o lado do pilar paralelo ao eixo x enquanto que $\mathrm{c}_{2}$ é o lado perpendicular ao eixo $\mathrm{x}$.

As condições necessárias para que as recomendações deste código possam ser aplicadas já foram feitas no item 5.1.1. Deverão ser feitas duas verificações para este caso. Na Figura 5.15 é esquematizado o perímetro crítico u para o pilar de canto analisado.

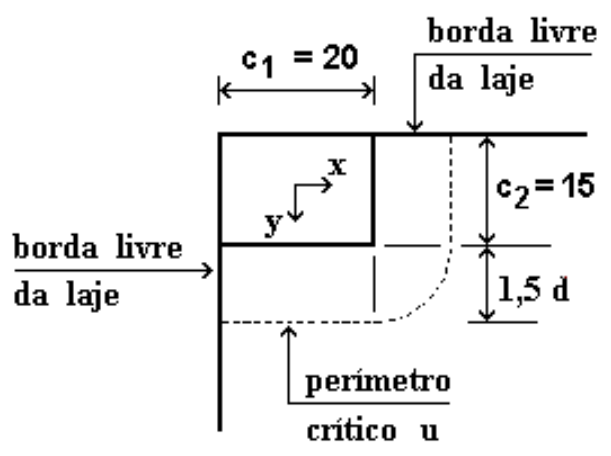

Figura 5.15 - Perímetro crítico para pilar de canto (unidades em $\mathrm{cm}$ )

\subsubsection{PRIMEIRA VERIFICAÇÃO}

$$
\mathrm{v}_{\mathrm{Sd}} \leq \mathrm{v}_{\mathrm{Rd} 1}
$$

Portanto: $\mathrm{u}=\mathrm{c}_{1}+\mathrm{c}_{2}+2 \pi(1,5 \mathrm{~d}) / 4=55,03 \mathrm{~cm}=0,55 \mathrm{~m}$

$$
\begin{aligned}
& \mathrm{v}_{\mathrm{Sd}}=\frac{\mathrm{V}_{\mathrm{Sd}} \beta}{\mathrm{u}}=\frac{50 \mathrm{kN} \times 1,50}{0,55 \mathrm{~m}}=136,36 \mathrm{kN} / \mathrm{m} \\
& \mathrm{v}_{\mathrm{Rd} 1}=\tau_{\mathrm{Rd}} \mathrm{k}\left(1+40 \rho_{1}\right) \mathrm{d}
\end{aligned}
$$

$\tau_{\mathrm{Rd}}\left(\right.$ tabela $5.1-$ para $\left.\mathrm{f}_{\mathrm{ck}}=25 \mathrm{MPa}\right)=0,30 \mathrm{~N} / \mathrm{mm}^{2}=300 \mathrm{kN} / \mathrm{m}^{2}$

$\mathrm{k}=|1,6-\mathrm{d}|=|1,6-0,085|=1,515 \geq 1,0$ (d em metros)

$\rho_{1}=0,0188>0,015 \rightarrow$ Portanto adota-se $\rho_{1}=0,015$

$\mathrm{v}_{\mathrm{Rd} 1}=300 \times 1,515 \times(1+40 \times 0,015) \times 0,085=61,81 \mathrm{kN} / \mathrm{m}$ 
Comparando-se os parâmetros, tem-se que:

$$
\mathrm{v}_{\mathrm{Sd}}=136,36 \mathrm{kN} / \mathrm{m}>\mathrm{v}_{\mathrm{Rd} 1}=61,81 \mathrm{kN} / \mathrm{m}
$$

Conclui-se que é necessário adicionar armadura de punção à ligação.

\subsubsection{SEGUNDA VERIFICAÇÃO}

Como a ligação não passou na primeira verificação, não faz sentido passar para a próxima, que será mostrada no caso da ligação com armadura de punção.

\subsection{PILAR DE CANTO COM ARMADURA DE PUNÇÃO}

Neste exemplo serão utilizados os dados referentes ao item 5.5, complementados com dados referentes à armadura de punção utilizada. A disposição dos conectores está mostrada na Figura 4.19 do capítulo 4.

- Tipo de armadura de punção: conectores tipo pino

- Bitola: $\phi 6,3 \mathrm{~mm} \quad$ Aço: CA 50A Área do pino $\left(\mathrm{A}_{\mathrm{s}} \mathrm{y}\right): 0,32 \mathrm{~cm}^{2}$

- $\mathrm{f}_{\mathrm{yd}}=434,78 \mathrm{MPa}$ (tensão de escoamento da armadura de punção)

Como visto nos ítens 5.2 e 5.4, parte dos conectores estão localizados fora da região crítica. Sendo assim, desconsiderou-se a influência desses conectores no cálculo da resistência da ligação, na região armada (Figura 5.16). Para este exemplo, não foi considerada a recomendação do CEB/90 referente à armadura de punção adicional, ilustrada na Figura 4.19. Para este caso, os conectores "adicionais" foram considerados no cálculo.

Deverão ser feitas três verificações, detalhadas a seguir. 


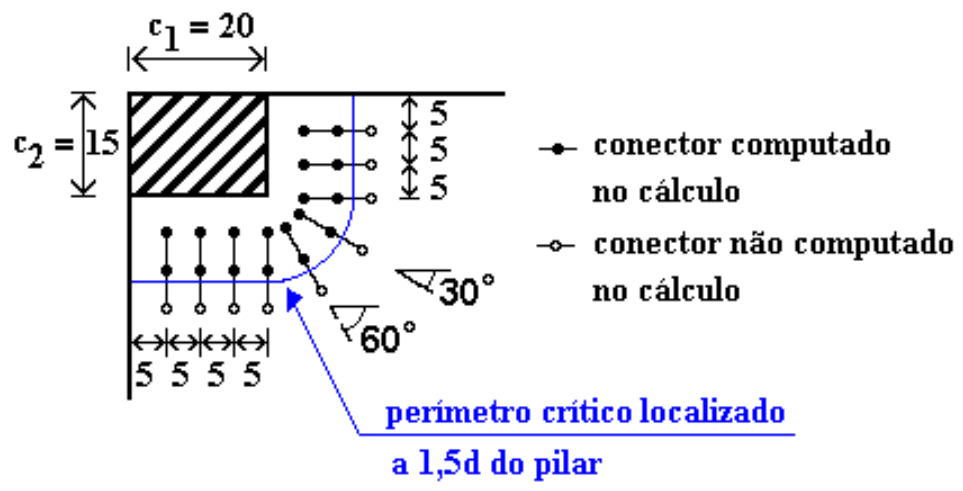

Figura 5.16 - Armadura de punção efetiva

\subsubsection{PRIMEIRA VERIFICAÇÃO}

Conforme já visto no item 5.2 e no item 5.4, o valor do esforço cortante de cálculo $\left(\mathrm{v}_{\mathrm{Sd}}\right)$ deverá ser comparado com o menor dos dois parâmetros de resistência $v_{\mathrm{Rd} 2}$ e $v_{\mathrm{Rd} 3}$.

\section{a) Cálculo de $\mathbf{v}_{\mathrm{Rd2}}$ (expressão 5.2)}

$\mathrm{v}_{\mathrm{Rd} 2}=1,6 \mathrm{v}_{\mathrm{Rd} 1}=1,6 \times 61,81=98,90 \mathrm{kN} / \mathrm{m}\left(\mathrm{v}_{\mathrm{Rd} 1}\right.$ já foi calculado no item 5.5.1)

\section{b) Cálculo de $\mathbf{v}_{\operatorname{Rd3}}$ (expressão 5.3)}

Verificando a taxa de armadura $\rho_{\mathrm{w}}: \quad \rho_{\mathrm{W}}=\frac{\sum \mathrm{A}_{\mathrm{SW}} \operatorname{sen} \alpha}{\left(\mathrm{A}_{\mathrm{crit}}-\mathrm{A}_{\text {pilar }}\right)}$

$$
\begin{aligned}
& \mathrm{A}_{\text {crit }}=\left(1,5 \mathrm{~d}+\mathrm{c}_{1}\right)\left(\mathrm{c}_{2}\right)+1,5 \mathrm{~d} \mathrm{c}_{1}+\pi(1,5 \mathrm{~d}) / 4=873,93 \mathrm{~cm}^{2} \\
& \mathrm{~A}_{\text {pilar }}=\text { área do pilar }=\mathrm{c}_{1} \cdot \mathrm{c}_{2}=300 \mathrm{~cm}^{2} \\
& \sum \mathrm{A}_{\mathrm{Sw}}=18 \mathrm{~A}_{\mathrm{Sy}}=18 \times 0,32 \mathrm{~cm}^{2}=5,76 \mathrm{~cm}^{2} \\
& \operatorname{sen} \alpha=1
\end{aligned}
$$

Portanto: $\rho_{\mathrm{W}}=0,01$

$$
\mathrm{v}_{\mathrm{Rd} 3}=\mathrm{v}_{\mathrm{Rd} 1}+\sum \mathrm{A}_{\mathrm{Sw}} \mathrm{f}_{\mathrm{yd}} \operatorname{sen} \alpha / \mathrm{u}=61,81+455,11=516,92 \mathrm{kN} / \mathrm{m}
$$


Observa-se que, independente da classe do aço, a taxa de armadura de punção é superior a $60 \%$ das fornecidas pela tabela 5.2.

\section{c) Comparação dos valores obtidos com $v_{S d}$}

Como $v_{\mathrm{Rd} 3}>\mathrm{v}_{\mathrm{Rd} 2}$, compara-se o valor de $\mathrm{v}_{\mathrm{Sd}}$ com o valor de $\mathrm{v}_{\mathrm{Rd} 2}$. $\mathrm{v}_{\mathrm{Sd}}\left(\right.$ calculado no item 5.5.1) $=136,36 \mathrm{kN} / \mathrm{m}>\mathrm{v}_{\mathrm{Rd} 2}=98,90 \mathrm{kN} / \mathrm{m}$ (não passou!)

Observa-se que, segundo este método, nem mesmo com a presença da armadura de punção a ligação apresentou resistência suficiente para resistir aos esforços solicitantes. Portanto, apenas a título de ilustração, serão feitas as verificações seguintes.

\subsubsection{SEGUNDA VERIFICAÇÃO}

A metodologia a ser utilizada para esta verificação será análoga à definida para os ítens 5.2.2 e 5.4.2.

$$
\mathrm{m}_{\mathrm{Sdx}}\left(\text { ou } \mathrm{m}_{\mathrm{Sdy}}\right) \geq \eta \mathrm{V}_{\mathrm{Sd}}
$$

\section{a) Verificando a direção $x$}

- na face superior da laje

$$
\begin{aligned}
& \mathrm{m}_{\mathrm{Sdx}} \geq \eta \mathrm{V}_{\mathrm{Sd}}=0,5 \times 50 \mathrm{kN}=25 \mathrm{kN} \mathrm{cm} / \mathrm{cm} \\
& \text { largura da faixa }=1,00 \text { metro } \\
& \text { Portanto: } \mathrm{M}_{\mathrm{Sdx}}=25 \mathrm{kN} \mathrm{cm} / \mathrm{cm} \times 100 \mathrm{~cm}=2500 \mathrm{kN} \mathrm{cm}
\end{aligned}
$$

Conforme já visto anteriormente, baseado no momento fletor, dimensionou-se uma taxa de armadura $\rho_{X}^{\prime}$ para a faixa analisada. Comparando-se esta taxa com a já existente $\rho_{\mathrm{X}}$, tem-se que:

$$
\rho_{\mathrm{X}}=0,0222>\rho_{\mathrm{X}}^{\prime}=0,0106 \quad(\mathrm{OK} !)
$$


Observa-se que a taxa de armadura já existente nesta direção é superior à calculada. Sendo assim, considera-se a laje verificada segundo esta direção.

- na face inferior da laje

$$
\begin{aligned}
& \mathrm{m}_{\mathrm{Sdx}} \geq \eta \mathrm{V}_{\mathrm{Sd}}=0,125 \times 100 \mathrm{kN}=12,50 \mathrm{kN} \mathrm{cm} / \mathrm{cm} \\
& \text { largura da faixa }=1,00 \text { metro }
\end{aligned}
$$

Supondo-se que a face inferior conte com uma disposição de armadura à flexão idêntica à observada para a face superior e, não havendo alterações quanto ao valor do momento fletor a ser dimensionado, considera-se a verificação segundo esta direção concluída. No final deste item será vista uma sugestão para o detalhamento destas armaduras.

\section{b) Verificando a direção y}

- na face superior da laje

$$
\begin{aligned}
& \mathrm{m}_{\text {Sdy }} \geq \eta \mathrm{V}_{\mathrm{Sd}}=0,5 \times 50 \mathrm{kN}=25 \mathrm{kN} \mathrm{cm} / \mathrm{cm} \\
& \text { largura da faixa }=1,00 \text { metro } \\
& \text { Portanto: } \mathrm{M}_{\text {Sdy }}=25 \mathrm{kN} \mathrm{cm} / \mathrm{cm} \times 100 \mathrm{~cm}=2500 \mathrm{kN} \mathrm{cm}
\end{aligned}
$$

Conforme já visto no item anterior, baseado no momento fletor, dimensionou-se uma taxa de armadura $\rho_{y}^{\prime}$ para a faixa analisada. Comparando-se esta taxa com a já existente $\rho_{y}$, tem-se que:

$$
\rho_{\mathrm{y}}=0,0159>\rho_{\mathrm{y}}^{\prime}=0,008
$$

Observa-se que a taxa de armadura já existente nesta direção é superior à calculada. Sendo assim, considera-se a laje verificada segundo esta direção. 
- na face inferior da laje

$$
\begin{aligned}
& \mathrm{m}_{\mathrm{Sdy}} \geq \eta \mathrm{V}_{\mathrm{Sd}}=0,5 \times 50 \mathrm{kN}=25 \mathrm{kN} \mathrm{cm} / \mathrm{cm} \\
& \text { largura da faixa }=1,00 \text { metro }
\end{aligned}
$$

Pelas mesmas razões descritas na análise da face inferior da laje segundo a direção x, considera-se esta direção verificada. É mostrada na Figura 5.17 uma sugestão para o detalhamento destas armaduras. Neste exemplo, considerou-se o prolongamento da armadura positiva através de um gancho como sendo a armadura necessária para resistir aos momentos de cálculo mínimos $\mathrm{m}_{\mathrm{Sdx}}$ e $\mathrm{m}_{\mathrm{Sdy}}$.

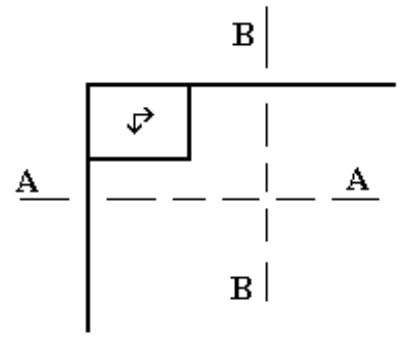

a) vista em planta

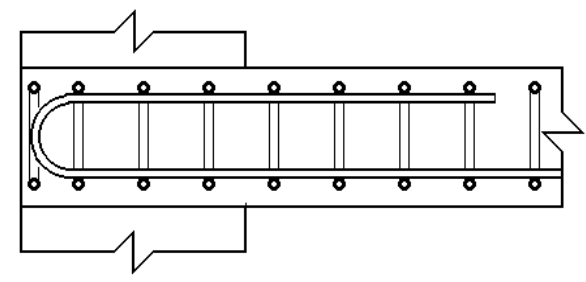

b) Corte A-A

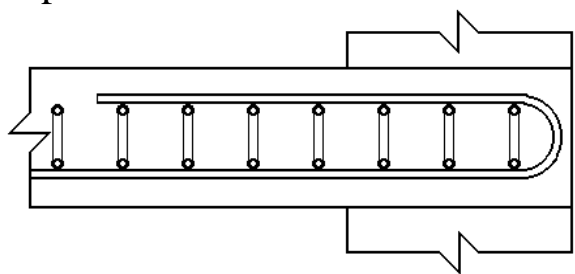

c) Corte B-B

Figura 5.17 - Detalhamento da armadura necessária para resistir a $\mathrm{m}_{\mathrm{Sdx}}$ e a $\mathrm{m}_{\mathrm{Sdy}}$

\subsubsection{TERCEIRA VERIFICAÇÃO}

Conforme já visto nos ítens 5.2.3 e 5.4.3, verifica-se neste item um novo perímetro crítico u', localizado a 1,5d além da última linha de armadura de punção, com forma análoga ao perímetro crítico u já definido (Figura 5.18). A nova tensão atuante ( $\left.v_{S d}\right)$ neste novo perímetro deverá, então, ser comparada com a tensão resistente, já calculada, para ligações sem armadura de punção. 


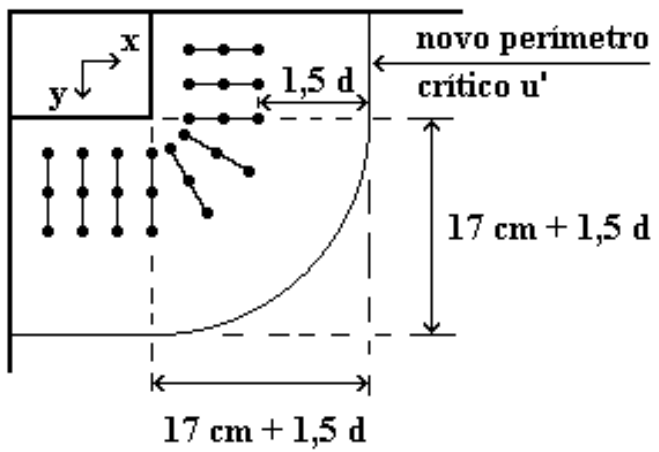

Figura 5.18 - Novo perímetro crítico

Portanto: $\mathrm{u}^{\prime}=20+15+2 \pi(17+1,5 \times 8,5) / 4=81,73 \mathrm{~cm}=0,817 \mathrm{~m}$

$$
\begin{aligned}
& \mathrm{v}_{\mathrm{Sd}}^{\prime}=\frac{\mathrm{v}_{\mathrm{Sd}} \beta}{\mathrm{u}^{\prime}}=\frac{50 \mathrm{kN} \times 1,50}{0,817 \mathrm{~m}}=91,80 \mathrm{kN} / \mathrm{m} \\
& \mathrm{v}_{\mathrm{Rd} 1}=61,81 \mathrm{kN} / \mathrm{m} \text { (já calculado no item 5.5.1) }
\end{aligned}
$$

Desta forma: $\mathrm{v}_{\mathrm{Sd}}^{\prime}=91,80 \mathrm{kN}>\mathrm{v}_{\mathrm{Rd} 1}=61,81 \mathrm{kN} / \mathrm{m}$

(não passou!)

Por fim, conclui-se que a laje não passou na primeira verificação e nem na terceira. Desta forma restam como alternativas aumentar a espessura da laje, utilizar capitéis e/ou "drop panels", aumentar a resistência do concreto, verificar a possibilidade de se alterar a arquitetura, modificando os vãos, e, por fim, modificar o próprio sistema estrutural, inserindo vigas de borda, ou mesmo partindo para o sistema convencional.

\subsection{OBSERVAÇÕES GERAIS}

Observa-se que estas recomendações não podem ser aplicadas a ligações feitas com concretos de alta resistência, uma vez que o valor limite da resistência do concreto utilizada para a obtenção de $\tau_{\mathrm{Rd}}$ é de $50 \mathrm{MPa}$. 
Ainda com relação a $\tau_{\mathrm{Rd}}$, é importante frisar que, na tabela, estes valores estão relacionados com um $\gamma_{c}$ igual a 1,5. No entanto, não se fez qualquer correção com relação a este fato nos exemplos desenvolvidos.

O EUROCODE recomenda na seção 5.4.3.3 que a espessura mínima para lajes contendo armadura de punção seja de $20 \mathrm{~cm}$.

Com relação ao texto base da NB-1/94, o EUROCODE N.2 apresentou o detalhamento de uma armadura adicional a ser disposta perpendicularmente à(s) borda(s) livre(s) da laje.

Observa-se que o EUROCODE N.2 apresentou resultados mais conservadores que os do texto base da NB1/94. Enquanto que o texto base considerou verificadas todas as ligações com armadura de punção, o EUROCODE N.2 considerou verificada apenas a situação de pilares internos.

Observa-se ainda que o EUROCODE é bem menos trabalhoso que o texto base da NB-1/94, uma vez que ele não avalia diretamente a influência dos momentos fletores, mas sim através de um coeficiente $\beta$. 


\section{EXEMPLOS SEGUNDO O CEB/90}

São apresentados aqui os mesmos exemplos vistos nos capítulos 4 e 5, só que agora verificados segundo as recomendações do CEB/90. São definidos como gerais os seguintes parâmetros:

- altura útil efetiva da laje (d):

- taxa de armadura $(\rho)$ :

$$
\begin{aligned}
& d=\left(d_{x}+d_{y}\right) / 2 \\
& \rho=\sqrt{\rho_{x} \rho_{y}}
\end{aligned}
$$

Os índices x e y indicam as duas direções ortogonais utilizadas para definir as direções das armaduras de flexão.

Para as ligações laje-pilar que não possuam armadura de punção, são feitas duas verificações: na primeira, compara-se uma tensão nominal atuante, atuando uniformemente ao longo de um perímetro crítico, localizado a $2 \mathrm{~d}$ do contorno do pilar, com uma tensão nominal resistente; na segunda, verifica-se a compressão do concreto através do cálculo de tensões uniformemente distribuídas que atuam ao longo de outra seção crítica, definida através do contorno do pilar. Já para ligações com armadura de punção, as verificações passam a ser três: verificação da compressão no concreto, verificação da região armada transversalmente e verificação de uma região localizada além da região armada, todas estas feitas através da comparação de forças concentradas atuantes e resistentes. Observa-se que o CEB/90 e o texto base da NB-1/94 apresentam semelhanças em alguns conceitos, como, por exemplo, na forma e na definição de perímetros críticos, no conceito de módulo de resistência plástico $\mathrm{W}_{1}$ e $\mathrm{W}_{\mathrm{P}}$, dados, respectivamente, segundo o $\mathrm{CEB} / 90$ e o texto base da NB-1/94, além de outras constantes e variáveis utilizadas por ambos os métodos. No entanto, cabe aqui ressaltar que os códigos apresentam recomendações diferentes para pilares de borda e de canto. 


\subsection{PILAR INTERNO SEM ARMADURA DE PUNÇÃO}

Os esquemas referentes a este exemplo estão ilustrados na Figura 4.1 e na Figura 4.2 do capítulo 4. Dados gerais:

- seção do pilar:

$15 \mathrm{~cm} \times 20 \mathrm{~cm}$

- espessura da laje:

$10 \mathrm{~cm}$

- resistência do concreto: $\mathrm{f}_{\mathrm{ck}}=25 \mathrm{MPa}$

- reação de apoio no pilar: $\mathrm{P}_{\mathrm{Sd}}=135 \mathrm{kN}$

- momentos fletores:
- armadura de flexão negativa aço CA $50 \mathrm{~A}$

Bitola: $\phi 10 \mathrm{~mm}$ / Área: $0,80 \mathrm{~cm}^{2}$ Distribuição: malha de $5,6 \mathrm{~cm}$ x $4,5 \mathrm{~cm}$

Direção $\mathrm{x}: \rho_{\mathrm{X}}=0,0222 \mathrm{~d}_{\mathrm{X}}=8 \mathrm{~cm}$

Direção y: $\rho_{\mathrm{y}}=0,0159 \mathrm{~d}_{\mathrm{y}}=9 \mathrm{~cm}$

Portanto: $\quad \rho=0,0188 \quad \mathrm{~d}=8,5 \mathrm{~cm}$

O CEB/90 não apresenta uma recomendação para o caso de pilares internos com momentos fletores atuando segundo duas direções. Sendo assim, sugere-se que, para quantificar a influência de um segundo momento fletor no cálculo da tensão nominal atuante, adote-se, para ele, o mesmo critério utilizado para quantificar a influência do primeiro momento fletor levado em consideração. Verifica-se que este procedimento é análogo ao que foi feito no capítulo 4, referente às considerações do texto base da NB-1/94.

\subsubsection{PRIMEIRA VERIFICAÇÃO}

É verificada aqui a tensão nominal atuante que atua ao longo do perímetro crítico ilustrado na Figura 4.3 do capítulo 4. Portanto: $\tau_{\mathrm{Sd}} \leq \tau_{\mathrm{Rd}}$

\section{a) Cálculo de $\tau_{\mathrm{Sd}}$}

$$
\tau_{\mathrm{Sd}}=\frac{\mathrm{P}_{\mathrm{Sd}}}{\mathrm{u}_{1} \mathrm{~d}}+\frac{\mathrm{K} \mathrm{M}_{\mathrm{Sd}}}{\mathrm{W}_{1} \mathrm{~d}}+\frac{\mathrm{K}^{\prime} \mathrm{M}_{\mathrm{Sd}}^{\prime}}{\mathrm{W}_{1}^{\prime} \mathrm{d}} \leq \tau_{\mathrm{Rd}}
$$


$\mathrm{u}_{1}=$ perímetro crítico idêntico ao perímetro crítico $\mu($ Figura 4.3$)=176,81 \mathrm{~cm}$;

$\mathrm{K}=$ constante tabelada idêntica à $\mathrm{K}$ (dada no capítulo 4$)=0,633\left(\mathrm{c}_{1} / \mathrm{c}_{2}=1,333\right)$;

$\mathrm{MSd}=\mathrm{M}_{\mathrm{X}}=1000 \mathrm{kN} \cdot \mathrm{cm}$;

$\mathrm{W}_{1}$ = parâmetro do perímetro crítico, calculado em relação a $\mathrm{u}_{1}$, idêntico ao módulo de resistência plástico $\mathrm{W}_{\mathrm{P}}$, dado no capítulo 4;

$\mathrm{W}_{1}\left(=\mathrm{W}_{\mathrm{P}}\right)=\frac{\mathrm{c}_{1}^{2}}{2}+\mathrm{c}_{1} \mathrm{c}_{2}+4 \mathrm{c}_{2} \mathrm{~d}+16 \mathrm{~d}^{2}+2 \pi \mathrm{dc} \mathrm{c}_{1}=3234,14 \mathrm{~cm}^{2}$;

$\mathrm{K}^{\prime} \quad=$ constante tabelada idêntica à $\mathrm{K}^{\prime}($ dada no capítulo 4$)=0,525\left(\mathrm{c}_{2} / \mathrm{c}_{1}=0,75\right)$;

$\mathrm{M}^{\prime} \mathrm{Sd}=\mathrm{M}_{\mathrm{y}}=1200 \mathrm{kN} \cdot \mathrm{cm}$;

$\mathrm{W}_{1}{ }_{1}=$ parâmetro do perímetro crítico, calculado em relação a $\mathrm{u}_{1}$, idêntico ao módulo de resistência plástico $\mathrm{W}^{\prime} \mathrm{P}$, dado no capítulo 4 ;

$\mathrm{W}_{1}^{\prime}\left(=\mathrm{W}_{\mathrm{P}}^{\prime}\right)=\frac{\mathrm{c}_{2}^{2}}{2}+\mathrm{c}_{2} \mathrm{c}_{1}+4 \mathrm{c}_{1} \mathrm{~d}+16 \mathrm{~d}^{2}+2 \pi \mathrm{d} \mathrm{c}_{2}=3049,61 \mathrm{~cm}^{2}$.

Substituindo-se os valores numéricos na expressão (6.1):

$\tau_{\mathrm{Sd}}=\frac{135}{176,81 \times 8,5}+\frac{0,633 \times 1000}{3234,14 \times 8,5}+\frac{0,525 \times 1200}{3049,61 \times 8,5}=0,1372 \mathrm{kN} / \mathrm{cm}^{2}=1,372 \mathrm{MPa}$

\section{b) Cálculo de $\tau_{\mathbf{R d}}$}

Observando-se que o valor de $\tau_{\mathrm{Rd}}$, definido como uma tensão nominal resistente, é dado em MPa, tem-se que:

$$
\tau_{\mathrm{Rd}}=0,12 \xi\left(100 \rho f_{\mathrm{ck}}\right)^{1 / 3} \text { onde: } \xi=1+\sqrt{\frac{200}{\mathrm{~d}}} \quad \text { (com d em mm); }
$$

Portanto: $\quad \tau_{\mathrm{Rd}}=0,12\left(1+\sqrt{\frac{200}{85}}\right)(100 \times 0,0188 \times 25)^{1 / 3}=1,097 \mathrm{MPa}$

\section{c) Comparação dos parâmetros calculados}

$$
\tau_{\mathrm{Sd}}=1,372 \mathrm{MPa}>\tau_{\mathrm{Rd}}=1,097 \mathrm{MPa} \text { (Armadura necessária !) }
$$


Como a tensão nominal atuante é maior que a tensão nominal resistente, faz-se necessário o uso de algum tipo de armadura de punção ou de outro recurso que eleve a resistência da ligação. Apesar da ligação não ter passado nesta verificação, será apresentada a próxima, a título de exemplo.

\subsubsection{SEGUNDA VERIFICAÇÃO}

É feita aqui a verificação da compressão no concreto:

$$
\frac{P_{\text {Sd,ef }}}{u_{\mathrm{o}} \mathrm{d}} \leq 0,5 \mathrm{f}_{\mathrm{cd} 2}
$$

$\mathrm{u}_{\mathrm{O}}($ para pilares internos $)=$ perímetro do pilar $=2 \mathrm{c}_{1}+2 \mathrm{c}_{2}=40+30=70 \mathrm{~cm}$;

Para pilares internos com momento fletor atuando em uma direção, tem-se a seguinte expressão:

$$
\mathrm{P}_{\mathrm{Sd}, \mathrm{ef}}=\mathrm{P}_{\mathrm{Sd}}\left[1+\mathrm{K} \frac{\mathrm{M}_{\mathrm{Sd}} \mathrm{u}_{1}}{\mathrm{P}_{\mathrm{Sd}}} \mathrm{W}_{1}\right]
$$

Como o CEB/90 não menciona a situação de pilares internos com momentos fletores atuando segundo duas direções, analogamente ao que foi feito no item anterior, fez-se a adição do termo $\left(\mathrm{K}^{\prime} \mathrm{M}^{\prime}{ }_{\mathrm{Sd}} \mathrm{u}_{1}\right) /\left(\mathrm{P}_{\mathrm{Sd}} \mathrm{W}_{1}^{\prime}\right)$ à expressão que define o PSd,ef. Dessa forma, procura-se levar em conta a atuação simultânea de momentos fletores segundo as duas direções $\underline{x}$ e $y$. Portanto:

$$
\mathrm{P}_{\mathrm{Sd}, \mathrm{ef}}=\mathrm{P}_{\mathrm{Sd}}\left[1+\mathrm{K} \frac{\mathrm{M}_{\mathrm{Sd}}}{\mathrm{P}_{\mathrm{Sd}}} \frac{\mathrm{u}_{1}}{\mathrm{~W}_{1}}+\mathrm{K}^{\prime} \frac{\mathrm{M}_{\mathrm{Sd}}^{\prime}}{\mathrm{P}_{\mathrm{Sd}}} \frac{\mathrm{u}_{1}}{\mathrm{~W}_{1}^{\prime}}\right]=135(1+0,256+0,271)=205,15 \mathrm{kN}
$$

Observa-se que, segundo o CEB/90, o coeficiente de minoração da resistência do concreto $\left(\gamma_{c}\right)$ a ser adotado é igual a 1,5. Desta forma: $f_{c d}=f_{c k} / 1,5$.

$$
\mathrm{f}_{\mathrm{cd} 2}=0,60\left(1-\frac{\mathrm{f}_{\mathrm{ck}}}{250}\right) \mathrm{f}_{\mathrm{cd}}=0,60\left(1-\frac{25}{250}\right) \frac{25}{1,5}=9,0 \mathrm{MPa}
$$


Substituindo-se os valores calculados na expressão (6.2), tem-se que:

$$
\begin{aligned}
& \frac{206,15 \mathrm{kN}}{70 \mathrm{~cm} \times 8,5 \mathrm{~cm}} \leq 0,5 \times 9,0 \mathrm{MPa} \\
& 0,346 \mathrm{kN} / \mathrm{cm}^{2}=3,46 \mathrm{MPa} \leq 4,5 \mathrm{MPa} \quad(\mathrm{OK} !)
\end{aligned}
$$

\subsection{PILAR INTERNO COM ARMADURA DE PUNÇÃO}

Serão utilizados os dados relativos ao item anterior, complementados com os referentes à armadura de punção:

- Tipo de armadura de punção: conectores tipo pino

- Bitola: $\phi 6,3 \mathrm{~mm} \quad$ Aço: CA 50A Área do pino $\left(\mathrm{A}_{\mathrm{S}} \mathrm{y}\right): 0,32 \mathrm{~cm}^{2}$

- $\mathrm{f}_{\mathrm{ywd}}=434,78 \mathrm{MPa}$

Apesar do valor da resistência de cálculo $\left(\mathrm{f}_{\mathrm{ywd}}\right)$ da armadura de punção ser igual a 434,78 $\mathrm{MPa}$, o CEB/90 limita este valor em $300 \mathrm{MPa}$. A disposição da armadura está ilustrada na Figura 4.4, no capítulo 4.

\subsubsection{PRIMEIRA VERIFICAÇÃO}

Verifica-se a zona adjacente ao pilar:

$$
\mathrm{P}_{\mathrm{Sd}} \leq \mathrm{u}_{\mathrm{o}} \mathrm{d}\left(0,5 \mathrm{f}_{\mathrm{cd} 2}\right)
$$

No entanto, para pilares internos aos quais são transferidos momentos fletores, o valor de $\mathrm{P}_{\mathrm{Sd}}$ deve ser majorado a um valor $\mathrm{P}_{\mathrm{Sd} \text {,ef }}$, de forma a se levar em consideração a influência desta transferência. Utilizando-se os dados e resultados obtidos no item 6.1.2, tem-se que:

$$
\mathrm{u}_{\mathrm{o}}=70 \mathrm{~cm} ; \quad \mathrm{f}_{\mathrm{cd} 2}=0,9 \mathrm{kN} / \mathrm{cm}^{2} ; \quad \mathrm{P}_{\mathrm{Sd}, \mathrm{ef}}=206,15 \mathrm{kN} ;
$$

Portanto: $\quad P_{\text {Sd, ef }}=206,15 \mathrm{kN} \leq \mu_{\mathrm{o}} \mathrm{d}\left(0,5 \mathrm{f}_{\mathrm{cd} 2}\right)=267,75 \mathrm{kN}(\mathrm{OK} !)$ 


\subsubsection{SEGUNDA VERIFICAÇÃO}

Verifica-se a região armada com base nas seguintes expressões:

$$
\begin{aligned}
& \mathrm{P}_{\mathrm{Sd}} \leq 0,09 \xi\left(100 \rho f_{\mathrm{ck}}\right)^{1 / 3} \mathrm{u}_{1} \mathrm{~d}+1,5 \frac{\mathrm{d}}{\mathrm{s}_{\mathrm{r}}} \mathrm{A}_{\mathrm{Sw}} \mathrm{f}_{\mathrm{ywd}} \operatorname{sen} \alpha \\
& 1,5 \frac{\mathrm{d}}{\mathrm{s}_{\mathrm{r}}} \mathrm{A}_{\mathrm{Sw}} \mathrm{f}_{\mathrm{ywd}} \operatorname{sen} \alpha \geq 0,03\left(100 \rho \mathrm{f}_{\mathrm{ck}}\right)^{1 / 3} \mathrm{u}_{1} \mathrm{~d}
\end{aligned}
$$

- PSd é a reação do pilar; este valor deve ser majorado a um valor $\mathrm{P}_{\mathrm{Sd} \text {,ef }}$ de forma a se levar em conta a influência da transferência dos momentos fletores;

-PSd,ef $=206,15 \mathrm{kN}$ (já calculado no item 6.1.2);

- $\mathrm{s}_{\mathrm{r}} \quad=$ espaçamento radial dos conectores $=6,5 \mathrm{~cm}$;

- $\mathrm{A}_{\mathrm{Sw}}=$ área dos conectores contidos em cada linha homotética ao pilar, que passa pela armadura transversal;

- $\mathrm{A}_{\mathrm{Sw}}=16 \mathrm{~A}_{\mathrm{Sy}}=16 \times 0,32=5,12 \mathrm{~cm}^{2}$;

- $\alpha \quad=90^{\circ}$;

- $\mathrm{f}_{\mathrm{ywd}}=300 \mathrm{MPa}=30 \mathrm{kN} / \mathrm{cm}^{2}$ (valor máximo permitido pelo CEB/90).

Deve-se tomar muito cuidado na manipulação das unidades porque, enquanto os termos $0,09 \xi\left(100 \rho f_{c k}\right)^{1 / 3}$ e $0,03\left(100 \rho f_{c k}\right)^{1 / 3}$ estão em MPa, os outros estão em $\mathrm{kN}$ e em cm.

- verificando a expressão (6.4):

$\mathrm{P}_{\mathrm{Sd}, \mathrm{ef}} \leq 0,823 \mathrm{MPa} \times(176,81 \mathrm{~cm} \times 8,5 \mathrm{~cm})+1,5 \frac{8,5 \mathrm{~cm}}{6,5 \mathrm{~cm}}\left(5,12 \mathrm{~cm}^{2} \times 30 \mathrm{kN} / \mathrm{cm}^{2} \times 1\right)$

$\mathrm{P}_{\mathrm{Sd}, \mathrm{ef}} \leq 0,0823 \mathrm{kN} / \mathrm{cm}^{2} \times(176,81 \mathrm{~cm} \times 8,5 \mathrm{~cm})+301,29 \mathrm{kN}$

$206,15 \mathrm{kN} \leq 424,98 \mathrm{kN} \quad(\mathrm{OK} !)$ 
- verificando a expressão (6.5):

$1,5 \frac{8,5 \mathrm{~cm}}{6,5 \mathrm{~cm}}\left(5,12 \mathrm{~cm}^{2} \times 30 \mathrm{kN} / \mathrm{cm}^{2} \times 1\right) \geq 0,1083 \mathrm{MPa} \times 176,81 \mathrm{~cm} 8,5 \mathrm{~cm}$ $301,29 \mathrm{kN} \geq 0,01083 \mathrm{kN} / \mathrm{cm}^{2} \times 176,81 \mathrm{~cm} 8,5 \mathrm{~cm}$

$301,29 \mathrm{kN} \geq 16,27 \mathrm{kN} \quad(\mathrm{OK} !)$

\subsubsection{TERCEIRA VERIFICAÇÃO}

Esta verificação deve ser feita fora da região armada, ou seja, a uma distância de 2d de uma linha homotética ao pilar, que passe pela armadura transversal mais distante desse pilar.

$$
\mathrm{P}_{\mathrm{Sd}} \leq 0,12 \xi\left(100 \rho f_{\mathrm{ck}}\right)^{1 / 3} \mathrm{u}_{\mathrm{n}, \mathrm{ef}} \mathrm{d}
$$

Conforme já visto nos ítens anteriores, o valor de $\mathrm{P}_{\mathrm{Sd}}$ deverá ser majorado a um valor $\mathrm{P}_{\mathrm{Sd}, \mathrm{ef}}$, de forma a se levar em conta a transferência dos momentos fletores. Novamente, foi necessário adaptar uma formulação que levasse em consideração a presença de momentos fletores atuando segundo duas direções diferentes. Portanto, esta majoração foi feita da seguinte forma:

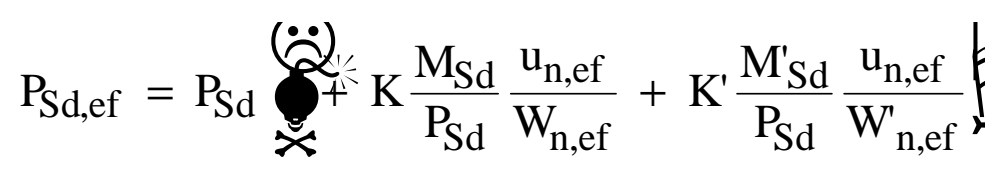

- $\mathrm{u}_{\mathrm{n}, \mathrm{ef}}=$ novo perímetro crítico adotado análogo a $\mu_{\mathrm{n}}$, mostrado na Figura 4.5 do capítulo 4. Este perímetro foi adotado em função da distância circunferencial entre os conectores mais externos não ter ultrapassado o comprimento de $2 \mathrm{~d}$, conforme mostrado no item 4.2.3a do capítulo 4; $\mathrm{u}_{\mathrm{n}, \mathrm{ef}}\left(=\mu_{\mathrm{n}}\right)=278,16 \mathrm{~cm}$;

- $\mathrm{M}_{\mathrm{Sd}}$ = momento fletor atuando segundo a direção $\mathrm{x}$; 
- $\mathrm{W}_{\mathrm{n}, \mathrm{ef}}=$ parâmetro referente ao novo perímetro crítico $\mathrm{u}_{\mathrm{n}, \mathrm{ef}}$, calculado de forma análoga a $\mathrm{W}_{\mathrm{Pn}}$, dado segundo o item 4.2.3 do capítulo 4:

$\mathrm{W}_{\mathrm{n}, \mathrm{ef}}\left(=\mathrm{W}_{\mathrm{Pn}}\right)=7872,80 \mathrm{~cm}^{2}$;

- $\mathrm{M}_{\mathrm{Sd}}=$ momento fletor atuando segundo a direção y;

- $\mathrm{W}_{\mathrm{n}, \mathrm{ef}}=$ parâmetro referente ao novo perímetro crítico $\mathrm{u}_{\mathrm{n}, \mathrm{ef}}$, calculado de forma análoga a $\mathrm{W}^{\prime} \mathrm{Pn}$, dado segundo o item 4.2.3 do capítulo 4. $\mathrm{W}_{\mathrm{n}, \mathrm{ef}}^{\prime}\left(=\mathrm{W}^{\prime} \mathrm{Pn}\right)=7604,90 \mathrm{~cm}^{2}$.

Portanto:

$$
P_{S d, e f}=135\left[1+0,633 \frac{1000}{135} \frac{278,16}{7872,80}+0,525 \frac{1200}{135} \frac{278,16}{7604,90}\right]=180,41 k N
$$

Novamente, fazendo-se a verificação, deve-se tomar muito cuidado com as unidades a serem utilizadas, uma vez que o termo $0,12 \xi\left(100 \rho f_{c k}\right)^{1 / 3}$ é dado em MPa. Substituindo-se os valores encontrados na expressão (6.6) tem-se que:

$180,41 \mathrm{kN} \leq 1,097 \mathrm{MPa} \times 278,16 \mathrm{~cm} \times 8,5 \mathrm{~cm}$

$180,41 \mathrm{kN} \leq 0,1097 \mathrm{kN} / \mathrm{cm}^{2}$ x $278,16 \mathrm{~cm} \mathrm{x} 8,5 \mathrm{~cm}$

$180,41 \mathrm{kN} \leq 259,45 \mathrm{kN} \quad(\mathrm{OK} !)$

\subsubsection{VERIFICAÇÕES ADICIONAIS}

Devem ser verificadas ainda algumas condições quanto à disposição da armadura de punção:

a) espaçamento radial $\left(\mathrm{s}_{\mathrm{r}}\right) \leq 0,75 \mathrm{~d} \rightarrow \mathrm{s}_{\mathrm{r}}=6,5 \mathrm{~cm} \approx 0,75 \mathrm{~d}=6,38 \mathrm{~cm}(\mathrm{OK}$ !);

b) a armadura de punção deve ser ancorada na posição ou além dos planos da armadura tracionada e da resultante proveniente do concreto comprimido. 
c) distância entre a face do pilar e a linha homotética que passa pela armadura mais próxima a essa face deve ser inferior a $\beta \mathrm{d}$, onde $\beta$ é dado através da seguinte expressão:

$$
\beta=\frac{\text { capacidade da laje sem armadura de punção }}{\text { capacidade requerida }} \leq 0,5
$$

Define-se a capacidade requerida como sendo a máxima resistência que a laje com a armadura de punção pode desenvolver. Desta forma, este valor é definido como sendo o menor valor das resistências calculadas nos ítens 6.2.1, 6.2.2a e 6.2.3:

- item 6.2.1: máxima resistência na região adjacente ao pilar $=267,75 \mathrm{kN}$;

- item 6.2.2a: máxima resistência na região armada $\quad=424,98 \mathrm{kN}$;

- item 6.2.3: máxima resistência além da região armada $\quad=259,45 \mathrm{kN}$.

Portanto:

- capacidade da laje sem armadura de punção $\left(\mathrm{P}_{\mathrm{rd}}\right)$ :

$\mathrm{P}_{\mathrm{rd}}=\tau_{\mathrm{Rd}} \times$ perímetro crítico $\mathrm{x}$ altura $=0,1097 \times 176,81 \times 8,5=164,87 \mathrm{kN}$;

- capacidade requerida $=259,45 \mathrm{kN}$;

Resulta: $\quad \beta=\frac{164,87 \mathrm{kN}}{259,45 \mathrm{kN}}=0,64>0,5 \longrightarrow \beta=0,5$.

Distância adotada $=4 \mathrm{~cm} \leq \beta \mathrm{d}=4,25 \mathrm{~cm} \quad(\mathrm{OK} !)$.

Considera-se, portanto, que a armadura de punção é suficiente para elevar a resistência da ligação acima dos esforços solicitantes. 


\subsection{PILAR DE BORDA SEM ARMADURA DE PUNÇÃO}

São apresentados os seguintes dados gerais referentes a este caso:

- seção do pilar:

$15 \mathrm{~cm} \times 20 \mathrm{~cm}$ $10 \mathrm{~cm}$

- espessura da laje:

- resistência do concreto: $\mathrm{f}_{\mathrm{ck}}=25 \mathrm{MPa}$

- reação de apoio no pilar: $\mathrm{P}_{\mathrm{Sd}}=100 \mathrm{kN}$

- momentos fletores: $\quad \mathrm{M}_{\mathrm{X}}=10 \mathrm{kN} . \mathrm{m}$ $\mathrm{M}_{\mathrm{y}}=12 \mathrm{kN} \cdot \mathrm{m}$
- armadura de flexão negativa aço CA 50 A

Bitola: $\phi 10 \mathrm{~mm}$ / Área: $0,80 \mathrm{~cm}^{2}$

Distribuição: malha de $5,6 \mathrm{~cm}$ x 4,5 cm

Direção x: $\rho_{\mathrm{X}}=0,0222 \mathrm{~d}_{\mathrm{X}}=8 \mathrm{~cm}$

Direção y: $\rho_{\mathrm{y}}=0,0159 \mathrm{~d}_{\mathrm{y}}=9 \mathrm{~cm}$

Portanto: $\quad \rho=0,0188 \quad \mathrm{~d}=8,5 \mathrm{~cm}$

Os esquemas estão mostrados nas Figuras 4.8 e 4.9 do capítulo 4.

A metodologia de cálculo utilizada aqui, é semelhante à adotada no item 6.1. Observa-se que, enquanto $M_{X}$ é o momento que atua na direção perpendicular à borda livre, $\mathrm{M}_{\mathrm{y}}$ é o momento que atua na direção paralela à borda livre.

\subsubsection{PRIMEIRA VERIFICAÇÃO}

$$
\tau_{\mathrm{Sd}} \leq \tau_{\mathrm{Rd}}
$$

a) Cálculo de $\tau_{\mathrm{Sd}}$

$$
\tau_{\mathrm{Sd}}=\frac{\mathrm{P}_{\mathrm{Sd}}}{\mathrm{u}_{1}^{*} \mathrm{~d}}+\frac{\mathrm{K} \mathrm{M}_{\mathrm{Sd}}}{\mathrm{W}_{1} \mathrm{~d}}
$$

$\mathrm{u}_{1} *=$ perímetro crítico reduzido (Figura 6.1) $=2 \mathrm{a}+\mathrm{c}_{2}+2 \pi(2 \mathrm{~d}) / 2=88,41 \mathrm{~cm}$;

$\mathrm{K}=$ constante obtida em função da relação $\mathrm{c}_{1} / 2 \mathrm{c}_{2}$, dada através de uma tabela do CEB/90, idêntica à tabela 19.3.1 do texto base, presente no capítulo 3;

$\mathrm{K}=0,5 \quad\left(\mathrm{c}_{1} / 2 \mathrm{c}_{2}=0,667\right)$; 
MSd $=$ momento atuante na direção paralela à borda livre $\left(=\mathrm{M}_{\mathrm{y}}=1200 \mathrm{kN} . \mathrm{cm}\right)$;

$\mathrm{W}_{1}$ = parâmetro calculado em relação ao perímetro crítico $\mathrm{u}_{1}$ (Figura 6.1), idêntico ao parâmetro $\mathrm{W}_{\mathrm{P} 2}$, já calculado no item 4.3.1 do capítulo 4;

$\mathrm{W}_{1}=\frac{\mathrm{c}_{2}^{2}}{4}+\mathrm{c}_{1} \mathrm{c}_{2}+4 \mathrm{c}_{1} \mathrm{~d}+8 \mathrm{~d}^{2}+\pi \mathrm{dc} \mathrm{c}_{2}=2014,80 \mathrm{~cm}^{2}$.
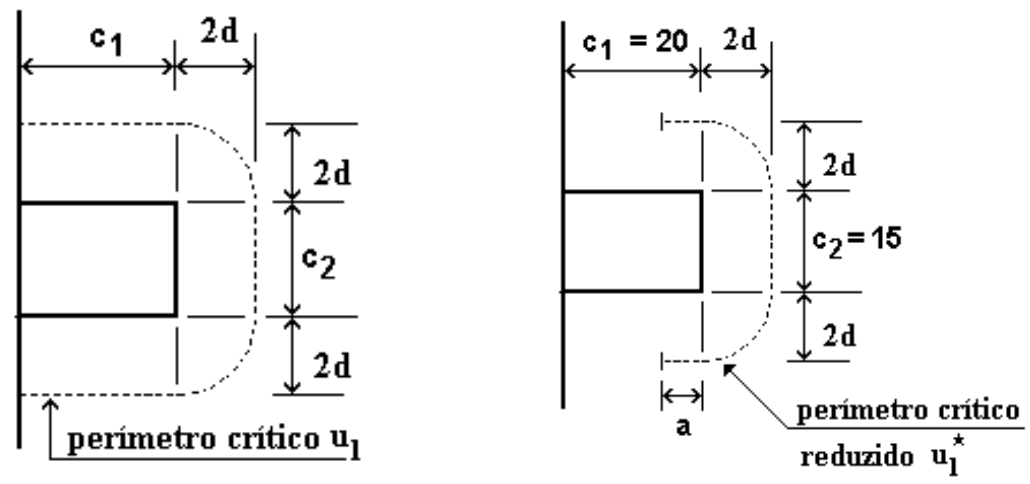

$\mathrm{a} \leq 1,5 \mathrm{~d}$ ou $0,5 \mathrm{c}_{1}$

Figura 6.1 - Perímetros crítico e crítico reduzido (unidades em cm)

Portanto: $\quad \tau_{\mathrm{Sd}}=\frac{100}{88,41 \times 8,5}+\frac{0,5 \times 1200}{2014,80 \times 8,5}=0,1681 \mathrm{kN} / \mathrm{cm}^{2}=1,681 \mathrm{MPa}$

\section{b) Cálculo de $\tau_{\mathbf{R d}}$}

$\tau_{R d}=0,12 \xi\left(100 \rho f_{c k}\right)^{1 / 3} \operatorname{com} \quad \xi=1+\sqrt{\frac{200}{\mathrm{~d}}}(\mathrm{~d} \mathrm{em} \mathrm{mm}) \longrightarrow \tau_{\mathrm{Rd}}=1,097 \mathrm{MPa}$

c) Comparação dos parâmetros calculados

$$
\tau_{\mathrm{Sd}}=1,681 \mathrm{MPa}>\tau_{\mathrm{Rd}}=1,097 \mathrm{MPa} \text { (Armadura necessária !) }
$$

Como a tensão nominal atuante é maior que a tensão nominal resistente, a ligação não passou nesta verificação. No entanto, apenas a título de ilustração, será apresentada a próxima verificação. 


\subsubsection{SEGUNDA VERIFICAÇÃO}

Verificação da compressão no concreto (expressão 6.2): $\frac{\mathrm{P}_{\mathrm{Sd}, \mathrm{ef}}}{\mathrm{u}_{\mathrm{o}} \mathrm{d}} \leq 0,5 \mathrm{f}_{\mathrm{cd} 2}$

$\mathrm{u}_{\mathrm{O}}$ (para pilares de borda $)=\mathrm{c}_{2}+3 \mathrm{~d} \leq \mathrm{c}_{2}+2 \mathrm{c}_{1} \longrightarrow \mathrm{u}_{\mathrm{O}}=40,50 \mathrm{~cm}$;

$$
\begin{aligned}
& P_{S d, e f}=P_{S d}\left[1+K \frac{M_{S d}}{P_{S d}} \frac{u_{1}^{*}}{W_{1}}\right]=100(1+0,263)=126,30 \mathrm{kN} \\
& f_{c d 2}=0,60\left(1-\frac{f_{c k}}{250}\right) f_{c d}=0,60\left(1-\frac{25}{250}\right) \frac{25}{1,5}=9,0 \mathrm{MPa}
\end{aligned}
$$

Substituindo-se os valores calculados na expressão (6.2), tem-se que:

$\frac{126,30 \mathrm{kN}}{40,50 \mathrm{~cm} \times 8,5 \mathrm{~cm}} \leq 0,5 \times 9,0 \mathrm{MPa} \longrightarrow 0,367 \mathrm{kN} / \mathrm{cm}^{2}=3,67 \mathrm{MPa} \leq 4,5 \mathrm{MPa} \quad(\mathrm{OK} !)$

\subsection{PILAR DE BORDA COM ARMADURA DE PUNÇÃO}

Com relação ao item 6.3, são apresentados os seguintes dados complementares referentes à armadura de punção.

- Tipo de armadura de punção: conectores tipo pino

- Bitola: $\phi 6,3 \mathrm{~mm} \quad$ Aço: CA 50A Área do pino $\left(\mathrm{A}_{\mathrm{sy}}\right): 0,32 \mathrm{~cm}^{2}$

- $\mathrm{f}_{\mathrm{ywd}}=300 \mathrm{MPa}$ (valor máximo limitado pelo CEB/90)

A disposição da armadura de punção está ilustrada na Figura 4.10 do capítulo 4 . 


\subsubsection{PRIMEIRA VERIFICAÇÃO}

Verificação da zona adjacente ao pilar (expressão 6.3): $\quad P_{S d} \leq u_{o} d\left(0,5 f_{c d 2}\right)$

Para pilares de borda com momento fletor paralelo à borda livre, o valor de $\mathrm{P}_{\mathrm{Sd}}$ deve ser majorado a um valor $\mathrm{P}_{\mathrm{Sd} \text {,ef. Desta forma, utilizando-se os }}$ dados e resultados obtidos no item 6.3.2, tem-se que:

$$
\mathrm{u}_{\mathrm{o}}=40,5 \mathrm{~cm} ; \quad \mathrm{f}_{\mathrm{cd} 2}=0,9 \mathrm{kN} / \mathrm{cm}^{2} ; \quad \mathrm{P}_{\mathrm{Sd}, \mathrm{ef}}=126,30 \mathrm{kN} ;
$$

Portanto: $\quad$ PSd,ef $_{\text {S }}=126,30 \mathrm{kN} \leq \mu_{\mathrm{o}} \mathrm{d}\left(0,5 \mathrm{f}_{\mathrm{cd} 2}\right)=154,91 \mathrm{kN}(\mathrm{OK} !)$

\subsubsection{SEGUNDA VERIFICAÇÃO}

Devem ser verificadas as expressões (6.4) e (6.5), de forma que, para pilares de borda e de canto, deve-se substituir o valor do perímetro crítico $\mathrm{u}_{1}$, pelo valor do perímetro crítico reduzido $\mathrm{u}_{1} *$. Desta forma, tem-se que:

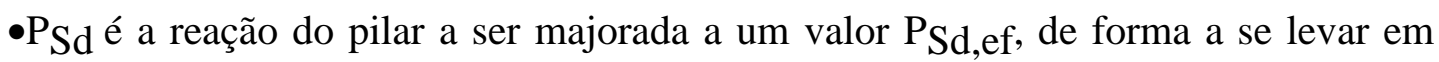
conta a influência do momento fletor paralelo à borda livre;

- Sd,ef $_{\text {e }} 126,30 \mathrm{kN}$ (já calculado no item anterior);

- $\mathrm{s}_{\mathrm{r}} \quad=$ espaçamento radial dos conectores $=6,5 \mathrm{~cm}$;

- $\mathrm{A}_{\mathrm{Sw}}=$ área dos conectores contidos em cada linha homotética ao pilar, que passa pela armadura transversal;

- $\mathrm{A}_{\mathrm{Sw}}=14 \mathrm{~A}_{\mathrm{sy}}=14 \times 0,32=4,48 \mathrm{~cm}^{2}$;

- $\alpha=90^{\circ}$;

- $\mathrm{f}_{\mathrm{ywd}}=300 \mathrm{MPa}=30 \mathrm{kN} / \mathrm{cm}^{2}$ (valor máximo permitido pelo CEB).

Conforme visto na Figura 4.10 do capítulo 4, o CEB/90 recomenda a utilização de uma armadura próxima à borda livre, mas que não seja considerada no cálculo relativo à resistência da ligação. Essa recomendação está resumida na Figura extra 8 do capítulo 3. Conforme visto no item 6.2.2, recomenda-se tomar muito cuidado na manipulação das unidades. 
- verificando a expressão (6.4):

$\mathrm{P}_{\mathrm{Sd}, \mathrm{ef}} \leq 0,823 \mathrm{MPa} \times(88,41 \mathrm{~cm} \times 8,5 \mathrm{~cm})+1,5 \frac{8,5 \mathrm{~cm}}{6,5 \mathrm{~cm}}\left(4,48 \mathrm{~cm}^{2} \times 30 \mathrm{kN} / \mathrm{cm}^{2} \times 1\right)$

$\mathrm{P}_{\mathrm{Sd}, \mathrm{ef}} \leq 0,0823 \mathrm{kN} / \mathrm{cm}^{2} \times(88,41 \mathrm{~cm} \times 8,5 \mathrm{~cm})+263,63 \mathrm{kN}$

$126,30 \mathrm{kN} \leq 325,47 \mathrm{kN}$

$(\mathrm{OK} !)$

- verificando a expressão (6.5):

$1,5 \frac{8,5 \mathrm{~cm}}{6,5 \mathrm{~cm}}\left(4,48 \mathrm{~cm}^{2} \times 30 \mathrm{kN} / \mathrm{cm}^{2} \times 1\right) \geq 0,1083 \mathrm{MPa} \times 88,41 \mathrm{~cm} \times 8,5 \mathrm{~cm}$ $263,63 \mathrm{kN} \geq 8,14 \mathrm{kN} \quad(\mathrm{OK} !)$

\subsubsection{TERCEIRA VERIFICAÇÃO}

A princípio, para esta verificação, deveria ter sido utilizada a expressão (6.6). No entanto, por se tratar aqui de um pilar de borda, o termo referente ao novo perímetro crítico $\left(\mathrm{u}_{\mathrm{n}, \mathrm{ef}}\right)$ deverá ser substituído, na expressão (6.6), pelo termo referente ao novo perímetro crítico reduzido $\left(\mathrm{u}_{\mathrm{n}, \mathrm{ef}}{ }^{*}\right)$, seguindo-se a linha de raciocínio utilizada para pilares de borda sem armadura de punção. Portanto, a verificação deverá ser feita através da seguinte expressão:

$$
P_{S d} \leq 0,12 \xi\left(100 \rho f_{c k}\right)^{1 / 3} u_{n, e f} * d
$$

Utilizando-se um raciocínio análogo, o valor de $\mathrm{P}_{\mathrm{Sd}}$ deverá ser majorado a um valor $\mathrm{P}_{\mathrm{Sd}, \mathrm{ef}}$, de forma a se levar em conta a presença do momento fletor paralelo à borda livre, através da seguinte expressão:

$$
P_{S d, e f}=P_{S d}\left[1+K \frac{M_{S d}}{P_{S d}} \frac{u_{n, e f} *}{W_{n, e f}}\right]
$$


- $\mathrm{u}_{\mathrm{n}, \mathrm{ef}} \mathrm{f}^{*}=$ novo perímetro crítico reduzido adotado, idêntico a $\mu_{\mathrm{n}}^{*}$, que, por sua vez, está mostrado na Figura 4.11 do capítulo 4. Portanto:

$\mathrm{u}_{\mathrm{n}, \mathrm{ef}} *\left(=\mu_{\mathrm{n}} *\right)=140,60 \mathrm{~cm}$

- $\mathrm{M}_{\mathrm{Sd}}=$ momento fletor atuando segundo a direção y;

- $\mathrm{W}_{\mathrm{n}, \mathrm{ef}}=$ calculado de forma absolutamente análoga a $\mathrm{W}_{\mathrm{P} 2 \mathrm{n}}$, no capítulo 4: $\mathrm{W}_{\mathrm{n}, \mathrm{ef}}\left(=\mathrm{W}_{\mathrm{P} 2 \mathrm{n}}\right)=4741,54 \mathrm{~cm}^{2}$.

Portanto: $\quad P_{S d, e f}=100\left[1+0,5 \frac{1200}{100} \frac{140,60}{4741,54}\right]=100[1+0,1779]=117,79 \mathrm{kN}$

Substituindo-se os valores encontrados na expressão (6.7), tem-se que:

$117,79 \mathrm{kN} \leq 1,097 \mathrm{MPa} \times 140,60 \mathrm{~cm} \times 8,5 \mathrm{~cm}$

$117,79 \mathrm{kN} \leq 131,10 \mathrm{kN}$

$(\mathrm{OK} !)$

\subsubsection{VERIFICAÇÕES ADICIONAIS}

Devem ser verificadas as mesmas condições mencionadas no item 6.2.4, quanto à disposição da armadura de punção:

a) espaçamento radial $(\mathrm{sr}) \leq 0,75 \mathrm{~d} \rightarrow \mathrm{sr}=6,5 \mathrm{~cm} \approx 0,75 \mathrm{~d}=6,38 \mathrm{~cm}(\mathrm{OK} !)$

b) $\beta d$ (calculado de forma análoga ao item 6.2.4):

-capacidade da laje sem armadura de punção:

$$
\mathrm{P}_{\mathrm{rd}}=\tau_{\mathrm{Rd}} \mathrm{u}_{1}^{*} \mathrm{~d}=0,1097 \mathrm{kN} / \mathrm{cm}^{2} \text { x 88,41 } \mathrm{cm} \mathrm{x} 8,5 \mathrm{~cm}=82,44 \mathrm{kN}
$$


-capacidade requerida: menor valor das resistências calculadas nos ítens 6.4.1, $6.4 .2 \mathrm{a}$ e $6.4 .3=131,10 \mathrm{kN}$.

Portanto: $\quad \beta=\frac{82,44 \mathrm{kN}}{131,10 \mathrm{kN}}=0,63>0,5 \longrightarrow \beta=0,5$

Distância adotada $=4 \mathrm{~cm} \leq \beta \mathrm{d}=4,25 \mathrm{~cm} \quad(\mathrm{OK} !)$

Considera-se, portanto, que a ligação passou nas verificações.

\subsection{PILAR DE CANTO SEM ARMADURA DE PUNÇÃO}

Dados Gerais:

- seção do pilar:

- espessura da laje:

$15 \mathrm{~cm} \times 20 \mathrm{~cm}$

$10 \mathrm{~cm}$

- resistência do concreto: $\mathrm{f}_{\mathrm{ck}}=25 \mathrm{MPa}$

- reação de apoio no pilar: $\mathrm{PSd}_{\mathrm{Sd}}=50 \mathrm{kN}$

- momentos fletores:
- armadura de flexão negativa aço CA $50 \mathrm{~A}$

Bitola: $\phi 10 \mathrm{~mm}$ / Área: $0,80 \mathrm{~cm}^{2}$

Distribuição: malha de $5,6 \mathrm{~cm}$ x $4,5 \mathrm{~cm}$

Direção x: $\rho_{\mathrm{X}}=0,0222 \mathrm{~d}_{\mathrm{X}}=8 \mathrm{~cm}$

Direção y: $\rho_{\mathrm{y}}=0,0159 \mathrm{~d}_{\mathrm{y}}=9 \mathrm{~cm}$

Portanto: $\quad \rho=0,0188 \quad \mathrm{~d}=8,5 \mathrm{~cm}$

Os esquemas referentes a este caso estão representados nas

Figuras 4.15 e 4.16 , presentes no capítulo 4 .

\subsubsection{PRIMEIRA VERIFICAÇÃO}

$$
\tau_{\mathrm{Sd}} \leq \tau_{\mathrm{Rd}}
$$




\section{a) Cálculo de $\tau_{\mathbf{S d}}$}

Em princípio, a distribuição da força cortante deve ser feita ao redor do perímetro crítico $u_{1}$, mostrado na Figura 6.2. Entretanto, desde que se garanta que a excentricidade está localizada na direção do interior da laje, $\tau_{\mathrm{Sd}}$ pode ser calculado como uma tensão uniforme ao longo do perímetro crítico reduzido $\mathrm{u}_{1}{ }^{*}$, também mostrado na Figura 6.2. Portanto:

$$
\begin{aligned}
& \mathrm{u}_{1} *=\mathrm{a}_{1}+\mathrm{a}_{2}+2 \pi(2 \mathrm{~d}) / 4=44,20 \mathrm{~cm} \\
& \tau_{\mathrm{Sd}}=\frac{\mathrm{P}_{\mathrm{Sd}}}{\mathrm{u}_{1}^{*} \mathrm{~d}}=\frac{50}{44,20 \times 8,5}=0,1331 \mathrm{kN} / \mathrm{cm}^{2}=1,331 \mathrm{MPa} \\
& \underbrace{}_{2 \mathrm{~d}} \\
& \text { istico } \\
& a_{1} \leqslant 1,5 \text { d e } 0,5 c_{1} \\
& a_{2} \leqslant 1,5 \text { d e } 0,5 c_{2}
\end{aligned}
$$

Figura 6.2 - Perímetros críticos para pilares de canto

\section{b) Cálculo de $\tau_{\mathbf{R d}}$}

$$
\begin{aligned}
& \tau_{R d}=0,12 \xi\left(100 \rho f_{c k}\right)^{1 / 3} \text { com } \xi=1+\sqrt{\frac{200}{\mathrm{~d}}} \quad(\mathrm{~d} \mathrm{em} \mathrm{mm}) \\
& \tau_{\mathrm{Rd}}=1,097 \mathrm{MPa}
\end{aligned}
$$


c) Comparação dos parâmetros calculados

$$
\tau_{\mathrm{Sd}}=1,331 \mathrm{MPa}>\tau_{\mathrm{Rd}}=1,097 \mathrm{MPa} \text { (Armadura necessária !) }
$$

Apesar da ligação não ter passado nesta verificação, será apresentada a próxima.

\subsubsection{SEGUNDA VERIFICAÇÃO}

Verificação da compressão no concreto (expressão 6.2): $\frac{\mathrm{P}_{\mathrm{Sd}, \mathrm{ef}}}{\mathrm{u}_{\mathrm{O}} \mathrm{d}} \leq 0,5 \mathrm{f}_{\mathrm{cd} 2}$

$\mathrm{u}_{\mathrm{O}}$ (para pilares de canto $)=3 \mathrm{~d} \leq \mathrm{c}_{2}+\mathrm{c}_{1} \quad \rightarrow \quad \mathrm{u}_{\mathrm{O}}=25,50 \mathrm{~cm}$

$$
\begin{aligned}
& \mathrm{P}_{\mathrm{Sd}, \mathrm{ef}}=\mathrm{P}_{\mathrm{Sd}}=50 \mathrm{kN} \\
& f_{c d 2}=0,60\left(1-\frac{f_{c k}}{250}\right) f_{c d}=0,60\left(1-\frac{25}{250}\right) \frac{25}{1,5}=9,0 \mathrm{MPa}
\end{aligned}
$$

Substituindo-se os valores calculados na expressão (6.2), tem-se que:

$$
\begin{aligned}
& \frac{50 \mathrm{kN}}{25,5 \mathrm{~cm} \times 8,5 \mathrm{~cm}} \leq 0,5 \times 9,0 \mathrm{MPa} \\
& 0,231 \mathrm{kN} / \mathrm{cm}^{2}=2,31 \mathrm{MPa} \leq 4,5 \mathrm{MPa} \quad(\mathrm{OK} !)
\end{aligned}
$$

\subsection{PILAR DE CANTO COM ARMADURA DE PUNÇ̃̃O}

São apresentados os dados complementares ao exemplo anterior, referentes à armadura de punção a ser utilizada neste item: 
- Tipo de armadura de punção: conectores tipo pino

- Bitola: $\phi 6,3 \mathrm{~mm}$ Aço: CA 50A Área do pino $\left(\mathrm{A}_{\mathrm{s}} \mathrm{y}\right): 0,32 \mathrm{~cm}^{2}$

- $\mathrm{f}_{\mathrm{ywd}}=300 \mathrm{MPa}$ (valor máximo limitado pelo CEB/90)

A disposição dos conectores está mostrada na Figura 4.19 do capítulo 4.

\subsubsection{PRIMEIRA VERIFICAÇÃO}

$$
\mathrm{P}_{\mathrm{Sd}} \leq \mathrm{u}_{\mathrm{o}} \mathrm{d}\left(0,5 \mathrm{f}_{\mathrm{cd} 2}\right)
$$

Utilizando-se os dados e resultados obtidos no item 6.5.2, tem-se que:

$$
\mathrm{u}_{\mathrm{o}}=25,5 \mathrm{~cm} ; \quad \mathrm{f}_{\mathrm{cd} 2}=0,9 \mathrm{kN} / \mathrm{cm}^{2} ; \quad \mathrm{P}_{\mathrm{Sd}}=50 \mathrm{kN} ;
$$

Portanto: $\quad \mathrm{P}_{\mathrm{Sd}}=50 \mathrm{kN} \leq \mu_{\mathrm{O}} \mathrm{d}\left(0,5 \mathrm{f}_{\mathrm{cd} 2}\right)=97,54 \mathrm{kN}(\mathrm{OK} !)$

\subsubsection{SEGUNDA VERIFICAÇÃO}

Devem ser verificadas as expressões (6.4) e (6.5), substituindo-se, nas expressões, $o$ valor de $u_{1}$ pelo valor de $u_{1}$ *.

- $\mathrm{s}_{\mathrm{r}} \quad=$ espaçamento radial dos conectores $=6,5 \mathrm{~cm}$;

- $\alpha=90^{\circ} ;$

- $\mathrm{f}_{\mathrm{ywd}}=300 \mathrm{MPa}=30 \mathrm{kN} / \mathrm{cm}^{2}$ (valor máximo permitido pelo CEB);

- $\mathrm{A}_{\mathrm{SW}}=$ área dos conectores contidos em cada linha homotética ao pilar, que passa pela armadura transversal;

- $\mathrm{A}_{\mathrm{Sw}}=7 \mathrm{~A}_{\mathrm{sy}}=7 \times 0,32=2,24 \mathrm{~cm}^{2}$.

Análogo ao observado no item 6.4.2, o $\mathrm{CEB} / 90$ recomenda a utilização de uma armadura transversal próxima à borda livre, mas que não seja considerada no cálculo relativo à resistência da ligação.

Conforme já visto nos ítens 6.2.2 e 6.4.2, deve-se tomar muito cuidado na manipulação das unidades dos termos. 
- Expressão (6.4):

$\mathrm{P}_{\mathrm{Sd}, \text { ef }} \leq 0,823 \mathrm{MPa} \times(44,20 \mathrm{~cm} \times 8,5 \mathrm{~cm})+1,5 \frac{8,5 \mathrm{~cm}}{6,5 \mathrm{~cm}}\left(2,24 \mathrm{~cm}^{2} \times 30 \mathrm{kN} / \mathrm{cm}^{2} \times 1\right)$

$50 \mathrm{kN} \leq 162,73 \mathrm{kN} \quad(\mathrm{OK} !)$

- Expressão (6.5):

$1,5 \frac{8,5 \mathrm{~cm}}{6,5 \mathrm{~cm}}\left(2,24 \mathrm{~cm}^{2} \times 30 \mathrm{kN} / \mathrm{cm}^{2} \times 1\right) \geq 0,1083 \mathrm{MPa} \times 44,20 \mathrm{~cm} \times 8,5 \mathrm{~cm}$

$131,81 \mathrm{kN} \geq 4,07 \mathrm{kN} \quad(\mathrm{OK} !)$

\subsubsection{TERCEIRA VERIFICAÇÃO}

Fazendo-se uma analogia com a verificação de ligações sem armadura de punção, deverá ser utilizada a seguinte expressão:

$$
P_{S d} \leq 0,12 \xi\left(100 \rho f_{c k}\right)^{1 / 3} u_{n, e f} * d
$$

- $\mathrm{u}_{\mathrm{n}, \mathrm{ef}}{ }^{*}=$ novo perímetro crítico reduzido adotado, análogo a $\mu_{\mathrm{n}}{ }^{*}$, mostrado na Figura 4.20 do item 4.6 .3 do capítulo 4.

$\mathrm{u}_{\mathrm{n}, \mathrm{ef}} *\left(=\mu_{\mathrm{n}} *\right)=70,3 \mathrm{~cm}$.

Portanto: $\mathrm{P}_{\mathrm{Sd}} \leq 1,097 \mathrm{MPa} \times 70,3 \mathrm{~cm} \times 8,5 \mathrm{~cm} \longrightarrow 50 \mathrm{kN} \leq 65,55 \mathrm{kN} \quad(\mathrm{OK} !)$

\subsubsection{VERIFICAÇÕES ADICIONAIS}

Devem ser verificadas ainda algumas condições quanto à disposição da armadura de punção:

a) espaçamento radial $\left(\mathrm{s}_{\mathrm{r}}\right) \leq 0,75 \mathrm{~d} \rightarrow \mathrm{s}_{\mathrm{r}}=6,5 \mathrm{~cm} \approx 0,75 \mathrm{~d}=6,38 \mathrm{~cm}(\mathrm{OK}$ !) 
b) $\beta d$ (calculado de forma análoga ao item 6.2.4):

-capacidade da laje sem armadura de punção:

$$
\mathrm{P}_{\mathrm{rd}}=\tau_{\mathrm{Rd}} \mathrm{u}_{1}{ }^{*} \mathrm{~d}=0,1097 \mathrm{kN} / \mathrm{cm}^{2} \text { x 44,20 } \mathrm{cm} \mathrm{x} \mathrm{8,5} \mathrm{cm}=41,21 \mathrm{kN}
$$

-capacidade requerida: menor valor das resistências calculadas nos ítens 6.6.1, 6.6.2a e $6.6 .3=65,55 \mathrm{kN}$.

Portanto: $\quad \beta=\frac{41,21 \mathrm{kN}}{65,55 \mathrm{kN}}=0,63>0,5 \longrightarrow \beta=0,5$

Distância adotada $=4 \mathrm{~cm} \leq \beta \mathrm{d}=4,25 \mathrm{~cm} \quad(\mathrm{OK} !)$

Considera-se, portanto, que ligação passou nas verificações.

\subsection{COLAPSO PROGRESSIVO}

Segundo o CEB/90, para reduzir o risco de um colapso progressivo na eventualidade de uma ruína local na ligação laje-pilar, devem ser verificadas as seguintes recomendações com relação à armadura de flexão, localizada na face inferior da laje e que cruza a interface laje-pilar:

- a área total de armadura $A_{S}$ que cruza a interface laje-pilar deve ser tal que:

$$
A_{s} \quad f_{y d} \geq P_{S d}
$$

Para cada lado da interface, o aço contribuinte em $A_{S}$ deve ser ancorado da seguinte forma:

- na laje: pelo comprimento de ancoragem $+\mathrm{d}$;

- no pilar: ou pela sua ancoragem na laje através do outro lado do pilar, ou pelo posicionamento do comprimento de ancoragem dentro do pilar (Figura 6.3). 
É importante observar que as barras ancoradas devem passar por dentro da armadura principal do pilar. O CEB/90 apresenta como detalhamentos os indicados na Figura 6.3.
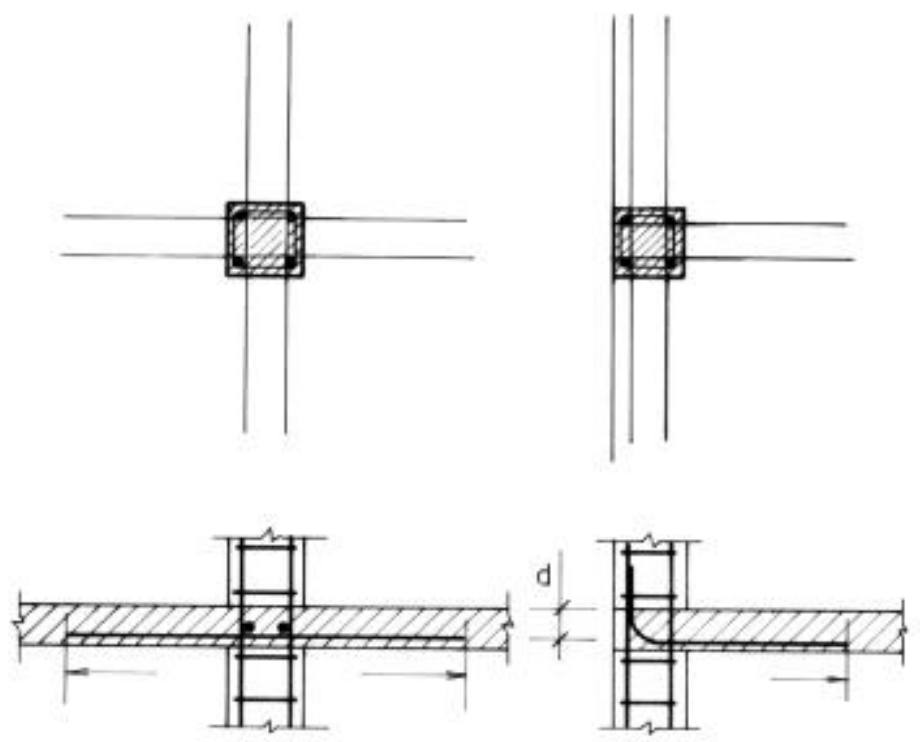

Pilar Interno

Pilar de bordo

Figura 6.3 - Detalhes de ancoragem dados pelo CEB/90

Tomando-se como exemplo a Figura 6.3, tem-se que a área $A_{\mathrm{S}}$ é referente a 8 barras para o pilar interno, enquanto que, para o pilar de borda, $\mathrm{A}_{\mathrm{S}}$ é referente a 6 barras.

Serão agora verificados os exemplos dados neste capítulo. É adotada como armadura inferior a mesma já mostrada nas Figuras 4.2, 4.9 e 4.16, para pilares internos, de borda e de canto, respectivamente. $\mathrm{O}$ detalhamento não será abordado, devendo, no entanto, ser seguidas as recomendações mencionadas. Para o pilar de canto, supõe-se que deva ser dado o mesmo tratamento ao observado na Figura 6.13, referente a pilares de borda ancorados no pilar. 


\subsubsection{PILAR INTERNO $\left(\mathrm{A}_{\mathrm{s}}=10\right.$ barras $)$}

$\mathrm{A}_{\mathrm{S}} \mathrm{f}_{\mathrm{yd}}=\left(10 \times 0,80 \mathrm{~cm}^{2}\right) \times 43,48 \mathrm{kN} / \mathrm{cm}^{2}=347,84 \mathrm{kN}>\mathrm{P}_{\mathrm{Sd}}=135 \mathrm{kN} \quad(\mathrm{OK} !)$

\subsubsection{PILAR DE BORDA $\left(A_{s}=8\right.$ barras $)$}

$$
A_{\mathrm{s}} f_{y d}=\left(8 \times 0,80 \mathrm{~cm}^{2}\right) \times 43,48 \mathrm{kN} / \mathrm{cm}^{2}=278,27 \mathrm{kN}>P_{S d}=100 \mathrm{kN}
$$

\subsubsection{PILAR DE CANTO $\left(A_{s}=5\right.$ barras $)$}

$$
A_{\mathrm{s}} f_{y d}=\left(5 \times 0,80 \mathrm{~cm}^{2}\right) \times 43,48 \mathrm{kN} / \mathrm{cm}^{2}=173,92 \mathrm{kN}>P_{S d}=50 \mathrm{kN}
$$

\subsection{OBSERVAÇÕES GERAIS}

Observa-se que, ao contrário do EUROCODE N.2 e assim como o texto base da NB-1/94, todos os exemplos passaram nas verificações feitas segundo os critérios dados pelo CEB/90. Porém, analogamente ao ocorrido no texto base da NB-1/94, o CEB/90 não fornece recomendações quanto à situação de pilares internos com momentos fletores atuando segundo duas direções.

O CEB/90 fornece recomendações mais detalhadas que o texto base da NB-1/94, com relação ao colapso progressivo.

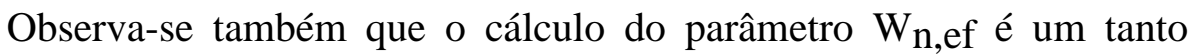
trabalhoso. Sugere-se, portanto, a adoção de um novo perímetro crítico para a região situada além da armadura de punção, a ser composta por trechos retos e por quartos de circunferência, análogo ao mostrado na Figura 4.3, desde que a distância circunferencial dos elementos da armadura de punção mais externos seja inferior a 2d. Desta forma, pode-se então obter uma maior simplicidade no cálculo desta verificação com o desenvolvimento de expressões apropriadas. 
Assim como o EUROCODE N.2, o CEB/90 menciona que a armadura de flexão perpendicular à borda livre deve ser dobrada e extendida até a outra face da laje, a fim de proporcionar-lhe resistência à torção. Como alternativa, barras em forma de $\mathrm{U}$ podem ser inseridas na borda através das armaduras de flexão positivas e negativas.

Outra semelhança entre o CEB/90 e o EUROCODE N.2 é que o valor de $\gamma_{c}$ utilizado é o mesmo, ou seja, igual a 1,5.

A menos de evidências experimentais relevantes, o valor da resistência característica à compressão do concreto deve ser limitado em $50 \mathrm{MPa}$. Desta forma, as recomendações vistas neste capítulo não podem ser diretamente aplicadas a concretos de alta resistência.

O CEB/90 ainda menciona que, para lajes com espessura inferior a $250 \mathrm{~mm}$, o detalhamento da ancoragem da armadura de punção requer atenção especial. 


\title{
7 EXEMPLOS SEGUNDO O ACI 318/89
}

\author{
São apresentados aqui os mesmos exemplos vistos nos \\ capítulos 4, 5 e 6, só que agora verificados segundo as recomendações do \\ ACI 318/89. Estas recomendações são resumidas e apresentadas a seguir, de forma a \\ facilitar a sua aplicação aos exemplos mencionados.
}

\subsection{RECOMENDAÇÕES DO ACI 318/89}

Para os casos nos quais existe a transferência de momentos fletores desbalanceados para o pilar, devem ser comparadas as seguintes tensões:

$$
\mathrm{v}_{\mathrm{u}} \leq \phi \mathrm{v}_{\mathrm{n}}
$$

\footnotetext{
$\mathrm{v}_{\mathrm{u}}=$ tensão nominal atuante;

$\mathrm{v}_{\mathrm{n}}=$ tensão nominal resistente ;

$\phi=$ coeficiente de minoração da resistência da ligação, igual a 0,85 para o caso de torção e de cisalhamento.
}

\subsubsection{TENSÃO NOMINAL RESISTENTE $\left(v_{n}\right)$}

O cálculo de $v_{n}$ é definido, basicamente, em função da presença ou não da armadura de punção. 


\section{a) Ligações sem armadura de punção}

Para este caso: $\quad \mathrm{v}_{\mathrm{n}}=\mathrm{v}_{\mathrm{c}}$

onde $\mathrm{v}_{\mathrm{c}}$ é a resistência obtida através da contribuição do concreto. $\mathrm{O}$ valor de $\mathrm{v}_{\mathrm{c}}$ é o menor valor obtido através das seguintes expressões:

$$
\begin{aligned}
& \mathrm{v}_{\mathrm{c}}=0,08303\left(2+\frac{4}{\beta_{\mathrm{c}}}\right) \sqrt{\mathrm{f}_{\mathrm{c}}{ }^{\prime}} \\
& \mathrm{v}_{\mathrm{c}}=0,08303\left(\frac{\alpha_{\mathrm{s}} \mathrm{d}}{\mathrm{b}_{\mathrm{o}}}+2\right) \sqrt{\mathrm{f}_{\mathrm{c}}{ }^{\prime}} \\
& \mathrm{v}_{\mathrm{c}}=0,3321 \sqrt{\mathrm{f}_{\mathrm{c}}{ }^{\prime}}
\end{aligned}
$$

$\beta_{\mathrm{c}}=$ razão entre os lados mais longo e mais curto do pilar;

$\mathrm{f}_{\mathrm{c}^{\prime}}=$ resistência à compressão do concreto (semelhante ao $\mathrm{f}_{\mathrm{ck}}$ e dado em MPa);

$\mathrm{b}_{\mathrm{o}}=$ comprimento do perímetro crítico localizado a $\mathrm{d} / 2$ do contorno do pilar (Figura 7.1);

$\mathrm{d}=$ altura útil da laje (média aritmética das alturas segundo as duas direções $\mathrm{x}$ e $\mathrm{y})$;

$\alpha_{\mathrm{S}}=$ constante que assume os seguintes valores: 40 para pilares internos, 30 para pilares de borda e 20 para pilares de canto.
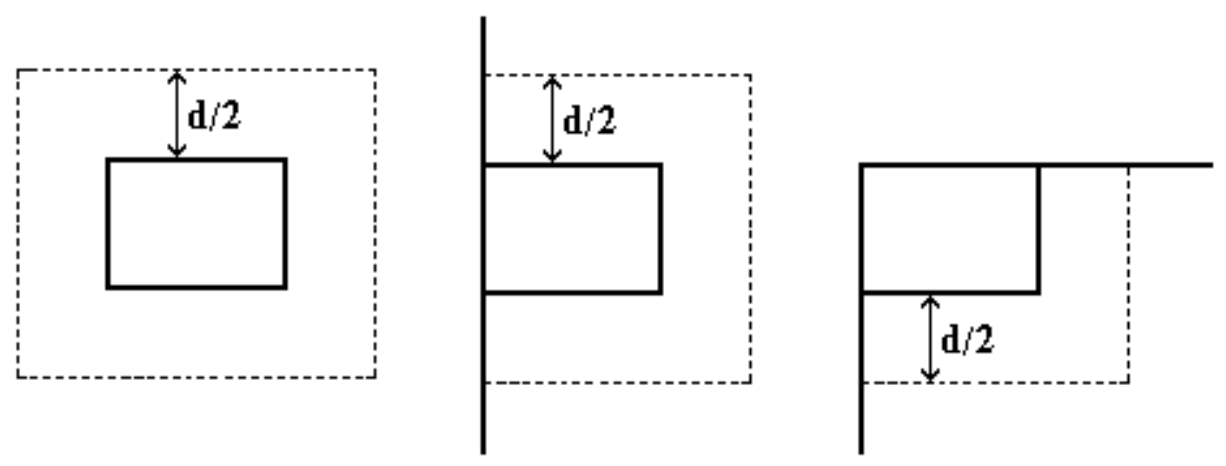

Figura 7.1 - Definição do perímetro crítico $b_{0}$ 
Inicialmente, o valor para tensões de cisalhamento correspondentes a carregamentos últimos estava limitado pela expressão (7.4). Observou-se que este valor não era conservativo para casos em que o coeficiente $\beta_{\mathrm{c}}$ assumia valores maiores que 2 , tratando-se, portanto, de pilares retangulares alongados. Para estes pilares, a tensão real de cisalhamento na seção crítica, correspondente à situação de ruína por punção, atinge o valor máximo dado pela expressão (7.4) apenas na região dos cantos do pilar, diminuindo este valor em direção à região central do lado do pilar. Ensaios realizados constataram ainda que, na medida em que o valor da razão $\mathrm{b}_{\mathrm{o}} / \mathrm{d}$ aumentava, o valor de $\mathrm{v}_{\mathrm{c}}$ diminuía. Baseados nestes aspectos é que foram desenvolvidas as expressões (7.2) e (7.3), de forma a se levar em consideração os fatores mencionados no cálculo de $\mathrm{v}_{\mathrm{C}}$.

\section{b) Ligações com armadura de cisalhamento}

Já para este caso, $v_{n}$ é calculado da seguinte forma:

$$
\mathrm{v}_{\mathrm{n}}=\mathrm{v}_{\mathrm{c}}+\mathrm{v}_{\mathrm{s}} \leq 0,4982 \sqrt{\mathrm{f}_{\mathrm{c}}{ }^{\prime}}
$$

Enquanto $\mathrm{v}_{\mathrm{c}}$ é a contribuição do concreto, $\mathrm{v}_{\mathrm{S}}$ representa a contribuição da armadura de punção na resistência da ligação. Estas tensões são calculadas através das seguintes expressões:

$$
\begin{aligned}
& \mathrm{v}_{\mathrm{c}}=0,1661 \sqrt{\mathrm{f}_{\mathrm{c}}{ }^{\prime}} \\
& \mathrm{v}_{\mathrm{s}}=\frac{\mathrm{A}_{\mathrm{v}} \mathrm{f}_{\mathrm{y}}}{\mathrm{s} \mathrm{b}_{\mathrm{O}}}
\end{aligned}
$$

$\mathrm{s}$ = espaçamento da armadura de punção, que não deve ser superior a $\mathrm{d} / 2$;

$\mathrm{A}_{\mathrm{V}}=$ área da armadura de punção dentro da distância s;

$\mathrm{f}_{\mathrm{y}}=$ tensão de escoamento da armadura, não podendo ser superior a $400 \mathrm{MPa}$.

Segundo o ACI 318/89, existe uma certa dificuldade em se ancorar a armadura de punção nas lajes com espessura inferior a $25 \mathrm{~cm}$. Portanto, para estas lajes, devem ser usados estribos retangulares fechados, envolvendo a armadura longitudinal de flexão, de forma que, pelo menos um elemento desta armadura passe em cada canto do estribo, conforme mostrado na Figura 7.2, retirada do ACI 318/89. 


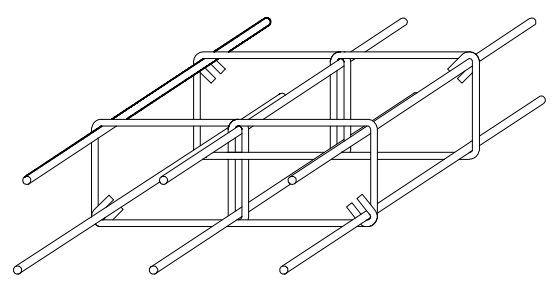

Figura 7.2 - Estribos

O ACI 318/89 menciona ainda que tem sido utilizada, com sucesso, um tipo de armadura de punção composta por elementos verticais, cujas extremidades estejam ancoradas mecanicamente através de uma placa ou de segmentos dela, formando uma "cabeça", de forma a se garantir que a tensão de escoamento da armadura de punção seja atingida.

\subsubsection{TENSÃO NOMINAL ATUANTE $\left(v_{u}\right)$}

$\mathrm{O}$ valor de $\mathrm{v}_{\mathrm{u}}$ é calculado em função da força cortante atuante $\left(\mathrm{V}_{\mathrm{u}}\right)$, no caso a reação do pilar, e em função de eventuais momentos fletores desbalanceados $\left(\mathrm{M}_{\mathrm{U}}\right)$.

Para ligações sem armadura de punção, $v_{u}$ deve ser calculado com relação ao perímetro crítico mostrado na Figura 7.1 e comparado com o valor de $\mathrm{v}_{\mathrm{n}}$, dado no item 7.1.1a.

Já para ligações com armadura de punção, devem ser feitas duas verificações. Na primeira delas, faz-se a comparação de $v_{u}$, calculado com relação ao perímetro crítico mostrado na Figura 7.1, com o valor de $\mathrm{v}_{\mathrm{n}}$, dado segundo o item 7.1.1b. Na segunda, deve-se comparar uma nova tensão nominal atuante, calculada em relação a uma nova superfície crítica, localizada a d/2 da região armada, com o valor de $\mathrm{v}_{\mathrm{n}}$, calculado segundo o item 7.1.1a.

Será mostrado, a seguir, as recomendações dadas pelo ACI 318/89 para o cálculo da tensão nominal atuante nas duas seções consideradas críticas: a d/2 do pilar e a d/2 da região armada. Observa-se que o ACI 318/89 fornece recomendações apenas com relação a momentos fletores atuando na direção do eixo de simetria da superfície crítica, localizada a d/2 do contorno do pilar. 


\section{a) Seção crítica localizada a d/2 da face do pilar}

Para pilares internos e de borda, a forma com que as tensões de cisalhamento se distribuem ao longo da seção crítica, devida à presença de um momento fletor, está ilustrada na Figura 7.3, extraída do ACI 318/89.
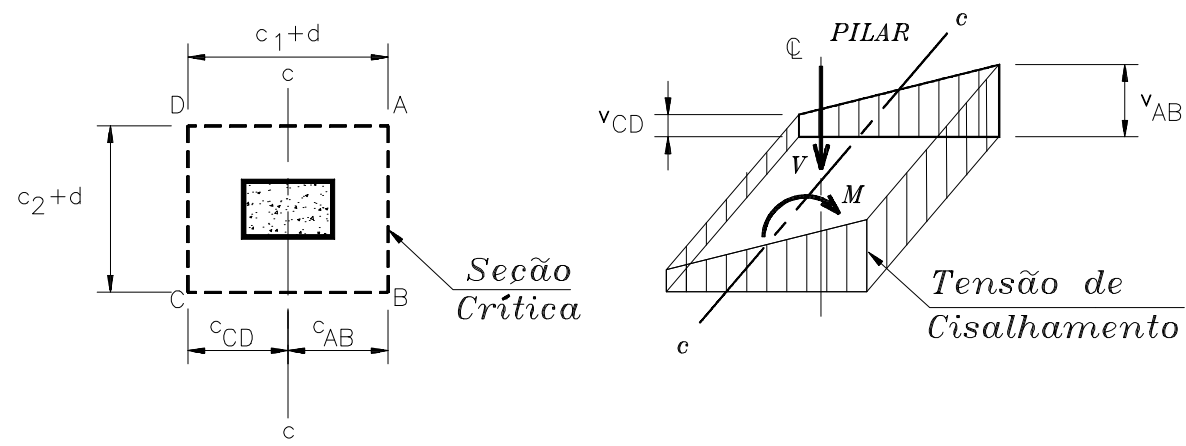

(a) PILAR INTERNO
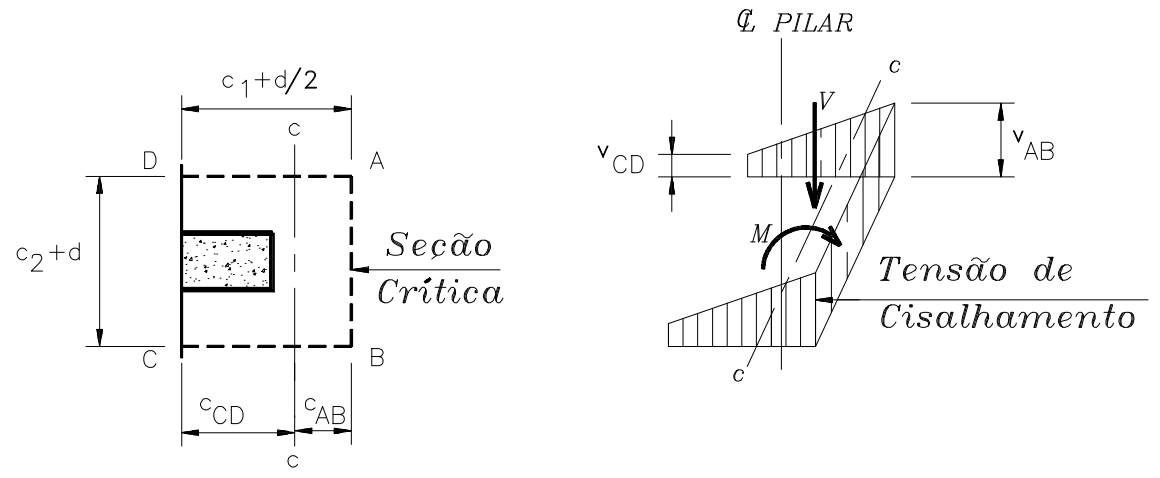

(b) PILAR DE BORDA

Figura 7.3 - Distribuição adotada para as tensões de cisalhamento

Tanto a força cortante $\mathrm{V}_{\mathrm{u}}$ como o momento desbalanceado $\mathrm{M}_{\mathrm{u}}$ estão relacionados ao eixo que passa pelo centróide do perímetro crítico e que é perpendicular à direção em que o momento fletor atua. Observa-se que as tensões máxima e mínima atuantes, dadas segundo a Figura 7.3, ocorrem, respectivamente, nas faces $\mathrm{AB}$ e $\mathrm{CD}$ da superfície crítica, sendo uniformemente distribuídas nessas faces. Já nas faces DA e CB, a tensão varia linearmente do valor mínimo até o valor máximo. Todas estas tensões são consideradas uniformemente distribuídas ao longo da altura útil d, na superfície crítica. 
As tensões máxima e mínima podem ser calculadas, respectivamente, através das seguintes expressões:

$$
\begin{aligned}
& \mathrm{v}_{\mathrm{u}(\mathrm{AB})}=\frac{\mathrm{V}_{\mathrm{u}}}{\mathrm{A}_{\mathrm{c}}}+\frac{\gamma_{\mathrm{v}} \mathrm{M}_{\mathrm{u}} \mathrm{c}_{\mathrm{AB}}}{\mathrm{J}_{\mathrm{c}}} \\
& \mathrm{v}_{\mathrm{u}(\mathrm{CD})}=\frac{\mathrm{V}_{\mathrm{u}}}{\mathrm{A}_{\mathrm{c}}}-\frac{\gamma_{\mathrm{v}} \mathrm{M}_{\mathrm{u}} \mathrm{c}_{\mathrm{CD}}}{\mathrm{J}_{\mathrm{c}}}
\end{aligned}
$$

$\mathrm{A}_{\mathrm{c}} \quad=$ área de concreto da superfície crítica;

$\gamma_{\mathrm{v}} \mathrm{M}_{\mathrm{u}}=$ parcela do momento fletor a ser transferida pela excentricidade da força cortante, dada em relação ao centróide da seção crítica. $O$ valor de $\gamma_{v}$ é dado através da seguinte expressão:

$$
\gamma_{\mathrm{v}}=1-\frac{1}{1+(2 / 3) \sqrt{\mathrm{b}_{1} / \mathrm{b}_{2}}}
$$

$b_{1}=$ comprimento da seção crítica medida na direção do vão para o qual o momento fletor foi determinado $\left(=\mathrm{c}_{1}+\mathrm{d}\right)$;

$\mathrm{b}_{2}=$ comprimento da seção seção crítica medida na direção perpendicular a $\mathrm{b}_{1}$ $\left(=\mathrm{c}_{2}+\mathrm{d}\right)$;

$\mathrm{J}_{\mathrm{c}}=$ propriedade análoga ao momento de inércia polar, relacionada à seção crítica.

Para pilares internos, o ACI 318/89 fornece as seguintes expressões:

$J_{c}=\frac{d\left(c_{1}+d\right)^{3}}{6}+\frac{\left(c_{1}+d\right) d^{3}}{6}+\frac{d\left(c_{2}+d\right)\left(c_{1}+d\right)^{2}}{2}$

$A_{c}=2 d\left(c_{1}+c_{2}+2 d\right)$

$\mathrm{c}_{\mathrm{AB}}=$ distância da face $\mathrm{AB}$ ao centróide da superfície crítica;

$\mathrm{c}_{\mathrm{CD}}=$ distância da face $\mathrm{CD}$ ao centróide da superfície crítica.

Segundo o ACI 318/89, podem ser desenvolvidas expressões similares de $A_{c}$ e $J_{c}$ para ligações com pilares de borda e de canto. 


\section{b) Seção crítica localizada a d/2 da região armada}

Para o caso de ligações com armadura de punção, deve-se investigar uma seção crítica externa à região transversalmente armada e dela distante de um valor igual a d/2. O ACI 318/89 ilustra o perímetro crítico desta seção através da Figura 7.4.

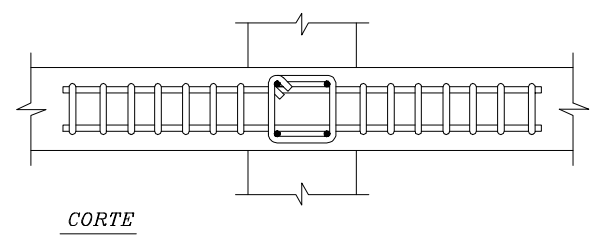

$\underline{\text { CORTE }}$

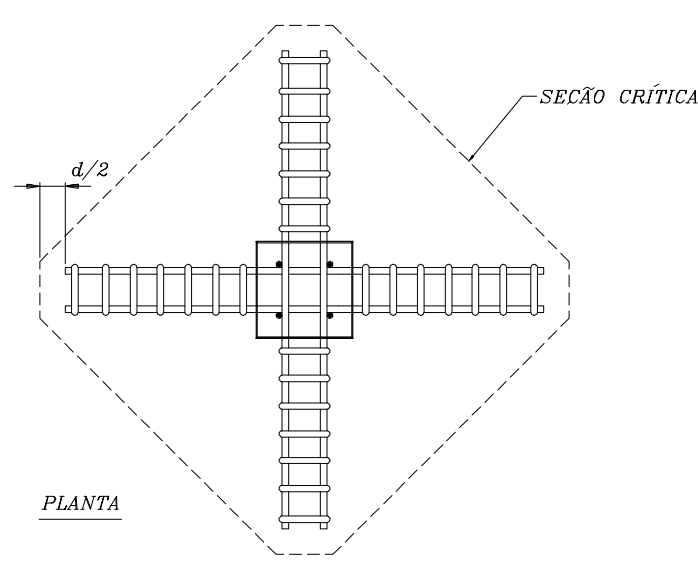

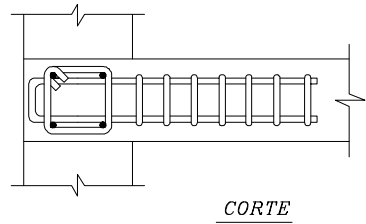

CORTE

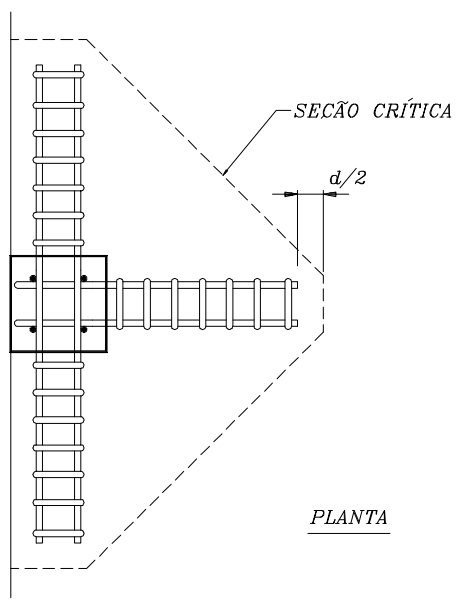

Figura 7.4 - Seções críticas externas à região armada (extraídas do ACI 318/89)

Na Figura 7.5, extraída de ANDRADE; GOMES (1994a), estão ilustrados os perímetros críticos considerados apropriados para uma distribuição radial e em cruz dos elementos da armadura de punção. 

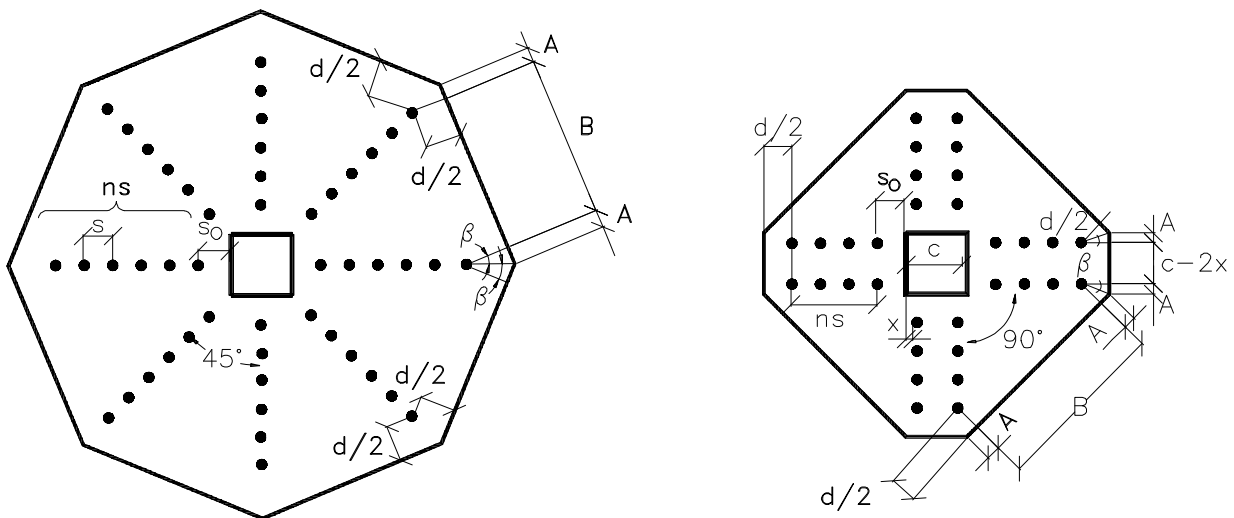

$$
\begin{aligned}
& \mathrm{U}=8[2 \mathrm{~A}+\mathrm{B}] \\
& \mathrm{A}=\mathrm{d}(\operatorname{tang} \beta) / 2 \\
& \mathrm{~B}=2 \operatorname{sen} \beta\left(\mathrm{s}_{\mathrm{O}}+\mathrm{ns}\right) \\
& \beta=22,5^{\circ}
\end{aligned}
$$

$$
\begin{aligned}
& \mathrm{U}=4[4 \mathrm{~A}+\mathrm{B}+\mathrm{c}-2 \mathrm{x}] \\
& \mathrm{A}=\mathrm{d}(\operatorname{tang} \beta) / 2 \\
& \mathrm{~B}=\sqrt{2}\left(\mathrm{~ns}+\mathrm{s}_{\mathrm{O}}+\mathrm{x}\right) \\
& \beta=22,5^{\circ}
\end{aligned}
$$

Figura 7.5 - Perímetros críticos recomendados por ANDRADE; GOMES (1994a)

O ACI 318/89 não fornece informações sobre a forma com que os momentos fletores influirão no cálculo das tensões atuantes nas novas seções críticas consideradas. Desta forma, adota-se o seguinte procedimento: para a obtenção da parcela da tensão de cisalhamento proveniente da força cortante, distribui-se esta força ao longo da superfície crítica externa à região armada, ilustrada na Figura 7.5. Já para a obtenção do valor da parcela proveniente da presença do momento fletor na ligação, adotou-se um outro perímetro crítico, retangular e circunscrito em relação ao anterior (Figura 7.6). Este procedimento permite adaptar as expressões referentes a $\mathbf{J}_{\mathrm{C}}$ e $\gamma_{\mathrm{v}}$ já mostradas nos ítens anteriores.
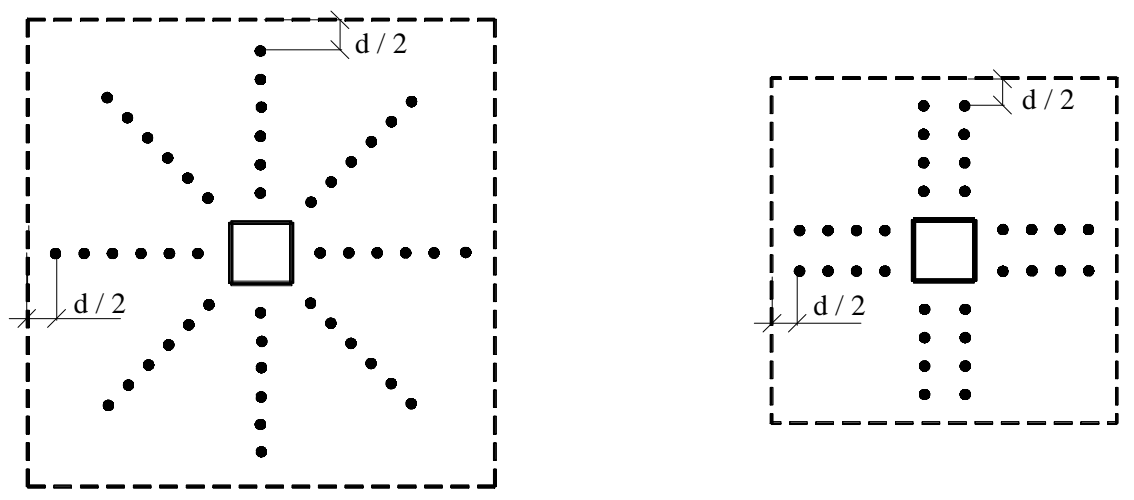

Figura 7.6 - Novo perímetro crítico referente a momentos fletores 
A utilização deste novo perímetro crítico, utilizado para o cálculo da parcela da tensão de cisalhamento proveniente do momento fletor, deve ser acatada, somente, como uma sugestão, dada no intuito de se considerar, de alguma forma, a influência do momento fletor nesta verificação.

Como os exemplos, mostrados a seguir, estão sujeitos a momentos fletores atuando segundo duas direções x e y, será feita uma superposição das tensões de cisalhamento, de forma a se obter o valor da máxima tensão nominal atuante. Nos exemplos, utilizam-se os índices 1 e 2 para indicar dimensões que estejam paralelas aos eixos $\mathrm{x}$ e $\mathrm{y}$, respectivamente.

\subsection{PILAR INTERNO SEM ARMADURA DE PUNÇÃO}

Os esquemas referentes a este exemplo estão ilustrados nas Figuras 4.1 e 4.2 do capítulo 4 .

Dados gerais:

- seção do pilar:

$15 \mathrm{~cm} \times 20 \mathrm{~cm}$

$10 \mathrm{~cm}$

- espessura da laje:

- resistência do concreto: $\mathrm{f}_{\mathrm{c}^{\prime}}=25 \mathrm{MPa}$
- reação de apoio no pilar: $\mathrm{V}_{\mathrm{u}}=135 \mathrm{kN}$

- momentos fletores: $\quad \mathrm{M}_{\mathrm{X}}=10 \mathrm{kN} . \mathrm{m}$ $\mathrm{M}_{\mathrm{y}}=12 \mathrm{kN} \cdot \mathrm{m}$
- armadura de flexão negativa aço CA $50 \mathrm{~A}$

Bitola: $\phi 10 \mathrm{~mm}$ / Área: $0,80 \mathrm{~cm}^{2}$ Distribuição: malha de $5,6 \mathrm{~cm} \mathrm{x} 4,5 \mathrm{~cm}$

Direção $\mathrm{x}: \rho_{\mathrm{X}}=0,0222 \mathrm{~d}_{\mathrm{X}}=8 \mathrm{~cm}$

Direção y: $\rho_{\mathrm{y}}=0,0159 \mathrm{~d}_{\mathrm{y}}=9 \mathrm{~cm}$ $\mathrm{d}=8,5 \mathrm{~cm}$

\subsubsection{TENSÃO NOMINAL ATUANTE $\left(v_{u}\right)$}

Fazendo-se a superposição das tensões de cisalhamento, conforme ilustrado na Figura 7.7, verifica-se que a máxima tensão nominal atuante irá ocorrer no canto D da seção crítica. 

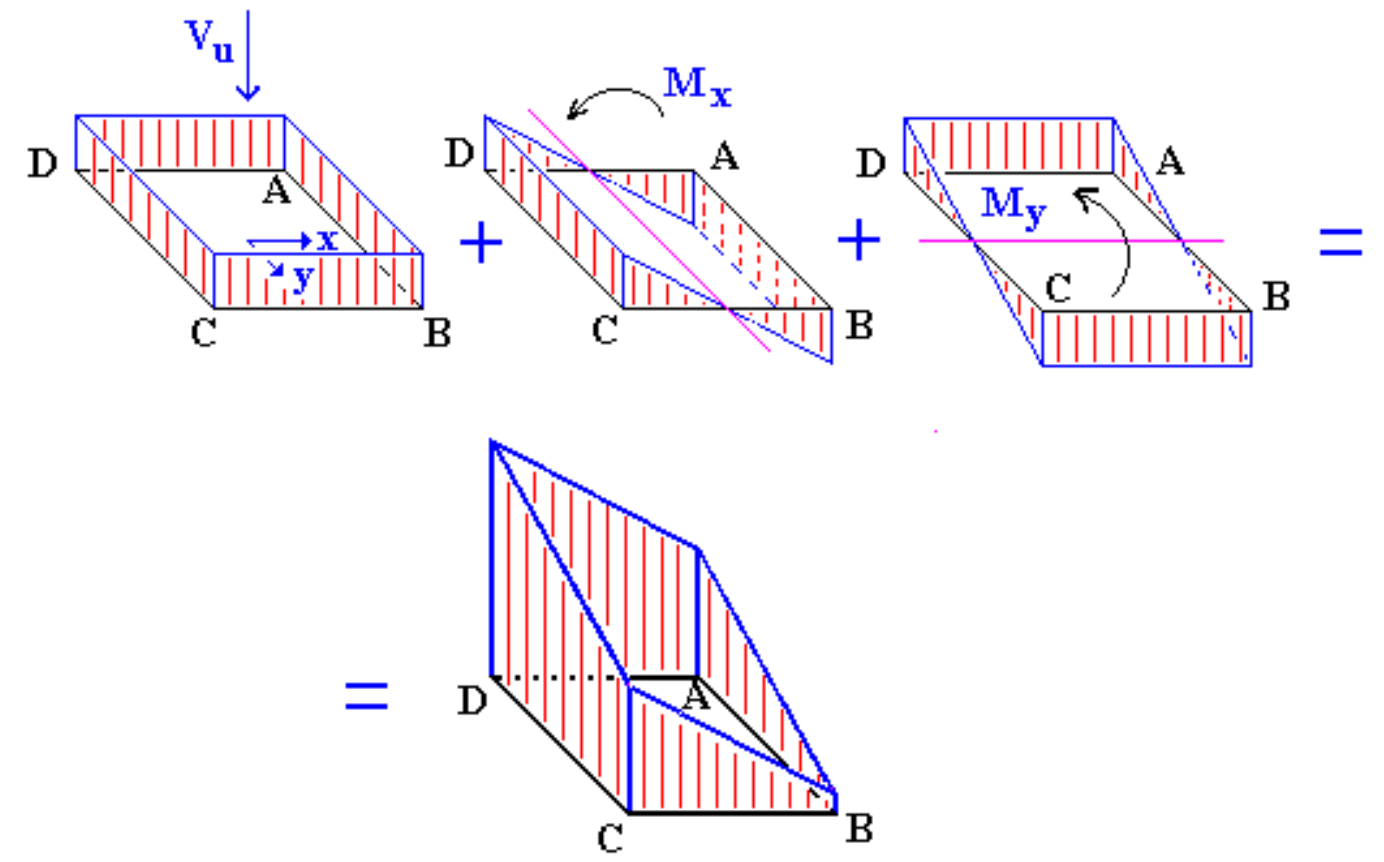

Figura 7.7 - Superposição de efeitos $\left(\mathrm{V}_{\mathrm{u}}, \mathrm{M}_{\mathrm{x}}, \mathrm{M}_{\mathrm{y}}\right)$

Com base na notação mostrada na Figura 7.8, calcula-se esta tensão através da seguinte expressão:

$\mathrm{v}_{\mathrm{u}}=\mathrm{v}_{\mathrm{u}, \max }=\mathrm{v}_{\mathrm{D}}=\frac{\mathrm{V}_{\mathrm{u}}}{\mathrm{A}_{\mathrm{c}}}+\frac{\gamma_{\mathrm{x}} \mathrm{M}_{\mathrm{x}} \mathrm{c}_{\mathrm{CD}}}{\mathrm{J}_{\mathrm{x}}}+\frac{\gamma_{\mathrm{y}} \mathrm{M}_{\mathrm{y}} \mathrm{c}_{\mathrm{AD}}}{\mathrm{J}_{\mathrm{y}}}$

Portanto:

$\mathrm{c}_{1}=$ lado do pilar paralelo ao eixo $\mathrm{x}=20 \mathrm{~cm}$;

$\mathrm{c}_{2}=$ lado do pilar perpendicular ao eixo $\mathrm{x}=15 \mathrm{~cm}$;

$\mathrm{b}_{1}=$ lado do perímetro crítico paralelo ao eixo $\mathrm{x}\left(\right.$ igual $\left.\mathrm{a}_{1}+\mathrm{d}\right)=28,5 \mathrm{~cm}$;

$\mathrm{b}_{2}=$ lado do perímetro crítico perpendicular ao eixo $\mathrm{x}$ (igual a $\mathrm{c}_{2}+\mathrm{d}$ ) $=23,5 \mathrm{~cm}$;

$\mathrm{c}_{\mathrm{CD}}=$ distância do eixo c-c, paralelo ao eixo y e que passa pelo centróide da seção crítica, até a face CD (igual a $\left.\mathrm{b}_{1} / 2\right)=14,25 \mathrm{~cm}$;

$\mathrm{c}_{\mathrm{AD}}=$ distância do eixo $\mathrm{c}^{\prime}-\mathrm{c}^{\prime}$, paralelo ao eixo $\mathrm{x}$ e que passa pelo centróide da seção crítica, até a face $A D$ (igual a $b_{2} / 2$ ) $=11,75 \mathrm{~cm}$;

$\mathrm{A}_{\mathrm{c}}=$ área da superfície crítica $=2 \mathrm{~d}\left(\mathrm{~b}_{1}+\mathrm{b}_{2}\right)=884 \mathrm{~cm}^{2}$; 


$$
\begin{aligned}
& \gamma_{x}=1-\frac{1}{1+(2 / 3) \sqrt{b_{1} / b_{2}}}=0,423 \\
& J_{x}=\frac{b_{1}^{3} d}{6}+\frac{b_{1} d^{3}}{6}+2 b_{2} d\left(\frac{b_{1}}{2}\right)^{2}=116835 \mathrm{~cm}^{4} ; \\
& \gamma_{y}=1-\frac{1}{1+(2 / 3) \sqrt{b_{2} / b_{1}}}=0,377 \\
& J_{y}=\frac{b_{2}{ }^{3} d}{6}+\frac{b_{2} d^{3}}{6}+2 b_{1} d\left(\frac{b_{2}}{2}\right)^{2}=87682 \mathrm{~cm}^{4} .
\end{aligned}
$$

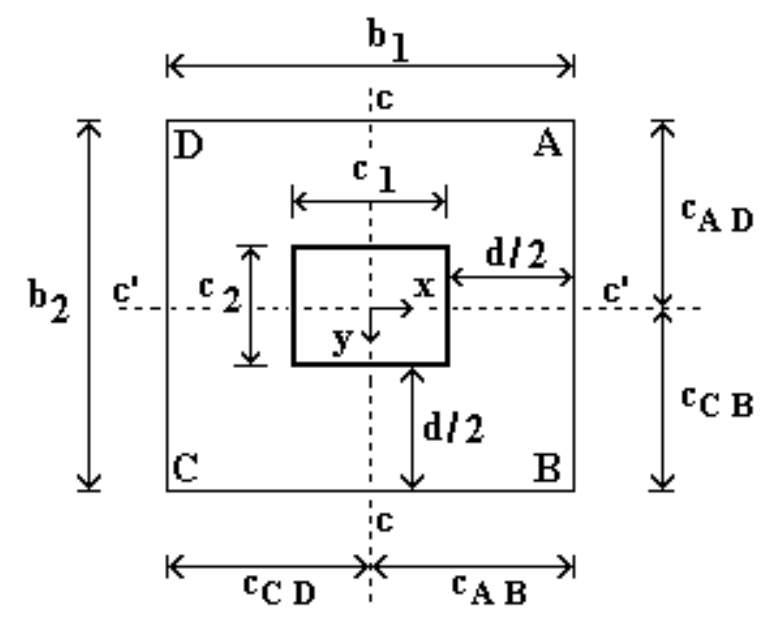

Figura 7.8 - Notação adotada para o cálculo da tensão nominal atuante

Portanto, substituindo-se os valores na expressão (7.11), tem-se que:

$$
\mathrm{v}_{\mathrm{u}}=0,265 \mathrm{kN} / \mathrm{cm}^{2}=2,65 \mathrm{MPa} .
$$

\subsubsection{TENSÃO NOMINAL RESISTENTE $\left(v_{n}\right)$}

Adota-se o menor valor dos obtidos através das expressões (7.2), (7.3) e (7.4), calculados a seguir: 
a) expressão (7.2):

com $\beta_{\mathrm{c}}=1,333 ; \quad \mathrm{f}_{\mathrm{c}}{ }^{\prime}=25 \mathrm{MPa} ; \quad$ tem-se que: $\mathrm{v}_{\mathrm{c}}=2,07 \mathrm{MPa}$.

b) expressão (7.3):

$\operatorname{com} \alpha_{\mathrm{S}}=40 ; \mathrm{b}_{\mathrm{o}}=2\left(\mathrm{~b}_{1}+\mathrm{b}_{2}\right)=104 \mathrm{~cm} ; \mathrm{f}_{\mathrm{c}}^{\prime}=25 \mathrm{MPa}$; tem-se que: $\mathrm{v}_{\mathrm{c}}=2,19 \mathrm{MPa}$.

c) expressão (7.4):

com $\mathrm{f}_{\mathrm{c}}{ }^{\prime}=25 \mathrm{MPa}$, tem-se que: $\mathrm{v}_{\mathrm{c}}=1,66 \mathrm{MPa}$.

Portanto: $\quad \mathrm{v}_{\mathrm{n}}=1,66 \mathrm{MPa}$.

\subsubsection{COMPARAÇÃO DAS TENSÕES}

Fazendo-se a comparação de $v_{u} \operatorname{com} \phi v_{n}$, tem-se que:

$\mathrm{v}_{\mathrm{u}}=2,65 \mathrm{MPa}>\phi \mathrm{v}_{\mathrm{n}}=0,85 \times 1,66=1,41 \mathrm{MPa}$.

Portanto, necessita-se aumentar a resistência da ligação.

\subsection{PILAR INTERNO COM ARMADURA DE PUNÇÃO}

Serão utilizados os dados referentes ao item anterior, complementados com dados referentes à armadura de punção utilizada. O ACI 318/89 limita o valor da tensão de escoamento da armadura de punção em $400 \mathrm{MPa}$. A disposição desta armadura está ilustrada na Figura 4.4, no capítulo 4.

- Tipo de armadura de punção: conectores tipo pino

- Bitola: $\phi 6,3 \mathrm{~mm} \quad$ Aço: CA 50A Área do pino $\left(\mathrm{A}_{\mathrm{Sy}}\right): 0,32 \mathrm{~cm}^{2}$

- $\mathrm{f}_{\mathrm{y}}=400 \mathrm{MPa}$

Deverão ser verificadas cada uma das duas seções consideradas críticas (a d/2 do pilar e a d/2 da região armada). 


\subsubsection{SEÇÃO CRÍTICA A d/2 DO PILAR}

a) Cálculo de $v_{u}$ (já calculado no item 7.2.1): $\quad v_{\mathrm{u}}=2,65 \mathrm{MPa}$.

b) Cálculo de vn:

$\mathrm{v}_{\mathrm{c}}=0,1661 \sqrt{\mathrm{f}_{\mathrm{c}}{ }^{\prime}}=0,831 \mathrm{MPa}$

$\mathrm{v}_{\mathrm{s}}=\frac{\mathrm{A}_{\mathrm{v}} \mathrm{f}_{\mathrm{y}}}{\mathrm{s} \mathrm{b}_{\mathrm{o}}}=0,303 \mathrm{kN} / \mathrm{cm}^{2}=3,03 \mathrm{MPa}$

$A_{V}=5,12 \mathrm{~cm}^{2} ; \quad s=6,5 \mathrm{~cm}>d / 2=4,25 \mathrm{~cm} ; \quad f_{y}=40 \mathrm{kN} / \mathrm{cm}^{2} ; \quad b_{O}=104 \mathrm{~cm} ;$

$\mathrm{v}_{\mathrm{n}}=\mathrm{v}_{\mathrm{c}}+\mathrm{v}_{\mathrm{s}} \leq 0,4982 \sqrt{\mathrm{f}_{\mathrm{c}}{ }^{\prime}}$

Dessa forma: $\quad \mathrm{v}_{\mathrm{n}}=3,861 \mathrm{MPa}>2,491 \mathrm{MPa} \stackrel{\text { Por tan to }}{\longrightarrow} \mathrm{v}_{\mathrm{n}}=2,491 \mathrm{MPa}$

Verificou-se que o espaçamento radial dos conectores não está de acordo com a recomendação do ACI 318/89. A princípio, o espaçamento deveria ser corrigido, mas visto tratar-se aqui apenas de um exemplo, será dado prosseguimento às verificações.

c) Comparação das tensões:

$\mathrm{v}_{\mathrm{u}}=2,65 \mathrm{MPa}>\phi \mathrm{v}_{\mathrm{n}}=0,85 \times 2,491=2,12 \mathrm{MPa}$

Portanto, nem mesmo com a presença da armadura de punção a laje passou na verificação. A princípio, não seria necessário realizar a próxima verificação; no entanto, a título de ilustração, ela será feita. 


\subsubsection{SEÇÃO CRÍTICA A d/2 DA REGIÃO ARMADA}

Calcula-se uma nova tensão nominal atuante $\left(\mathrm{v}_{\mathrm{u}}{ }^{\prime}\right)$, relativa à nova seção crítica, localizada a d/2 da região armada. A seguir, compara-se esta tensão com a tensão nominal resistente, dada para ligações sem armadura de punção.

Devido à falta de recomendações do ACI 318/89 quanto à presença de momentos fletores atuando nesta nova seção crítica, $\mathrm{vu}_{\mathrm{u}}$ foi obtido através do procedimento descrito no item 7.1.2b: enquanto a tensão proveniente da força cortante foi considerada uniformemente distribuída ao longo do perímetro crítico U, mostrado na Figura 7.9, a tensão proveniente dos momentos fletores foi considerada distribuída ao longo do perímetro crítico U', mostrado na Figura 7.10, variando linearmente ao longo das direções de atuação dos momentos fletores. A seguir, adicionou-se o valor da tensão uniformemente distribuída no perímetro $\mathrm{U}$, ao valor referente à máxima tensão obtida através da combinação dos momentos fletores no perímetro crítico U'.

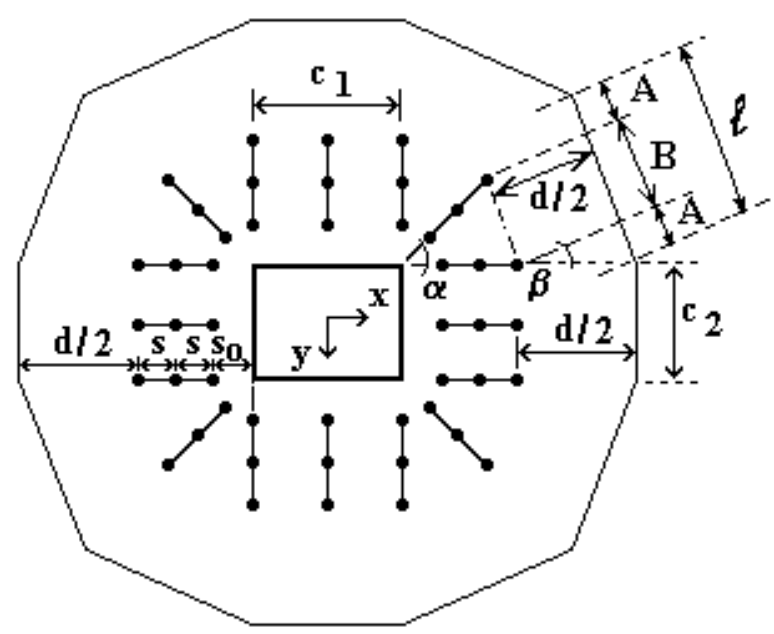

Figura 7.9 - Perímetro crítico U 


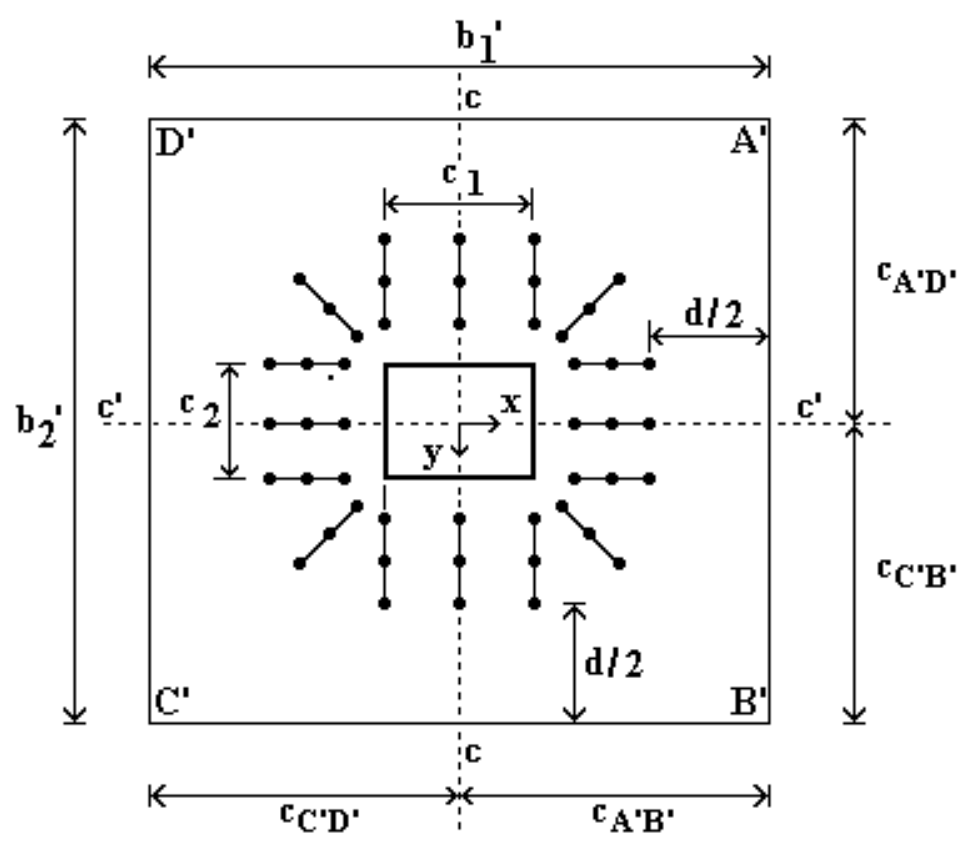

Figura 7.10 - Perímetro crítico U'

a) Cálculo da nova tensão nominal atuante $\left(\mathbf{v}_{\mathbf{u}}{ }^{\prime}\right)$

A expressão a ser utilizada deverá ser a seguinte:

$\mathrm{v}_{\mathrm{u}}{ }^{\prime}=\mathrm{v}_{\mathrm{u}, \max }^{\prime}=\mathrm{v}_{\mathrm{D}}^{\prime}=\frac{\mathrm{V}_{\mathrm{u}}}{\mathrm{A}_{\mathrm{c}}{ }^{\prime}}+\frac{\gamma_{\mathrm{x}}{ }^{\prime} \mathrm{M}_{\mathrm{x}} \mathrm{c}_{\mathrm{C}^{\prime} \mathrm{D}^{\prime}}}{\mathrm{J}_{\mathrm{x}}{ }^{\prime}}+\frac{\gamma_{\mathrm{y}}{ }^{\prime} \mathrm{M}_{\mathrm{y}} \mathrm{c}_{\mathrm{A}^{\prime} \mathrm{D}^{\prime}}}{\mathrm{J}_{\mathrm{y}}{ }^{\prime}} \quad \operatorname{expressão}$ (7.12)

onde, com relação ao perímetro crítico U, tem-se que:

$$
\begin{array}{lll}
\alpha=45^{\circ} ; & \mathrm{s}_{\mathrm{O}}=4 \mathrm{~cm} ; & \mathrm{A}=(\mathrm{d} \tan \beta) / 2=1,76 \mathrm{~cm} ; \\
\beta=\alpha / 2=22,5^{\circ} ; & \mathrm{s}=6,5 \mathrm{~cm}(>\mathrm{d} / 2) ; & \mathrm{B}=2 \operatorname{sen} \beta\left(\mathrm{s}_{\mathrm{O}}+2 \mathrm{~s}\right)=13,01 \mathrm{~cm} ; \\
& \ell=\mathrm{B}+2 \mathrm{~A}=16,53 \mathrm{~cm} ; \\
\mathrm{U}=2\left(\mathrm{c}_{1}+\mathrm{c}_{2}\right)+8 \ell=202,24 \mathrm{~cm} ; & \\
\mathrm{A}_{\mathrm{c}}^{\prime}=\mathrm{Ud}=1719 \mathrm{~cm}^{2} ; &
\end{array}
$$


e, com relação ao perímetro crítico U', tem-se que:

$$
\begin{array}{l|l}
\mathrm{b}_{1}{ }^{\prime}=\mathrm{c}_{1}+2\left(\mathrm{~s}_{\mathrm{O}}+2 \mathrm{~s}\right)+\mathrm{d}=62,5 \mathrm{~cm} ; & \mathrm{c}_{\mathrm{C}^{\prime} \mathrm{D}^{\prime}}=\mathrm{b}_{1} / 2=31,25 \mathrm{~cm} ; \\
\mathrm{b}_{2}{ }^{\prime}=\mathrm{c}_{2}+2\left(\mathrm{~s}_{\mathrm{O}}+2 \mathrm{~s}\right)+\mathrm{d}=57,5 \mathrm{~cm} ; & \mathrm{c}_{\mathrm{A}^{\prime} \mathrm{D}^{\prime}}=\mathrm{b}_{2} / 2=28,75 \mathrm{~cm} ; \\
\gamma_{\mathrm{x}}{ }^{\prime}=1-\frac{1}{1+(2 / 3) \sqrt{\mathrm{b}_{1}{ }^{\prime} / \mathrm{b}_{2}{ }^{\prime}}}=0,41 ; & \gamma_{\mathrm{y}}{ }^{\prime}=1-\frac{1}{1+(2 / 3) \sqrt{\mathrm{b}_{2}{ }^{\prime} / \mathrm{b}_{1}{ }^{\prime}}}=0,39 ; \\
\mathrm{J}_{\mathrm{x}}{ }^{\prime}=\frac{\mathrm{b}_{1}{ }^{3} \mathrm{~d}}{6}+\frac{\mathrm{b}_{1}{ }^{\prime} \mathrm{d}^{3}}{6}+2 \mathrm{~b}_{2}{ }^{\prime} \mathrm{d}\left(\frac{\mathrm{b}_{1}{ }^{\prime}}{2}\right)^{2} ; & \mathrm{J}_{\mathrm{y}}{ }^{\prime}=\frac{\mathrm{b}_{2}{ }^{\prime 3} \mathrm{~d}}{6}+\frac{\mathrm{b}_{2}{ }^{\prime} \mathrm{d}^{3}}{6}+2 \mathrm{~b}_{1}{ }^{\prime} \mathrm{d}\left(\frac{\mathrm{b}_{2}{ }^{\prime}}{2}\right)^{2} ; \\
\mathrm{J}_{\mathrm{x}}{ }^{\prime}=1306853 \mathrm{~cm}^{4} ; & \mathrm{J}_{\mathrm{y}}{ }^{\prime}=1153430 \mathrm{~cm}^{4} .
\end{array}
$$

Portanto, substituindo-se os valores na expressão (7.12), tem-se que:

$$
\mathrm{v}_{\mathrm{u}^{\prime}}=0,100 \mathrm{kN} / \mathrm{cm}^{2}=1,00 \mathrm{MPa} .
$$

\section{b) Cálculo da tensão nominal resistente $\left(v_{n}\right)$}

Calculando-se o menor valor das tensões resistentes, dadas pelas expressões (7.2), (7.3) e (7.4), tem-se que: $v_{n}=1,528 \mathrm{MPa}$.

Observa-se que este valor foi obtido através da expressão (7.2), ao substituir-se o perímetro $b_{\mathrm{O}}$, localizado a $\mathrm{d} / 2$ da face do pilar, pelo perímetro $\mathrm{U}$, localizado a d/2 da região armada.

\section{c) Comparação das tensões}

Fazendo-se a comparação de vu' com $\phi v_{n}$, tem-se que:

$$
\mathrm{v}_{\mathrm{u}}{ }^{\prime}=1,00 \mathrm{MPa} \quad<\quad \phi \mathrm{v}_{\mathrm{n}}=0,85 \times 1,528=1,30 \mathrm{MPa} . \quad(\mathrm{OK} !)
$$

Portanto, apesar da ligação não ter passado na primeira verificação feita, ela teria passado nesta. 


\subsection{PILAR DE BORDA SEM ARMADURA DE PUNÇÃO}

São apresentados os seguintes dados gerais:

- seção do pilar:

$15 \mathrm{~cm} \times 20 \mathrm{~cm}$ $10 \mathrm{~cm}$

- espessura da laje:

- resistência do concreto: $\mathrm{f}_{\mathrm{c}^{\prime}}=25 \mathrm{MPa}$

- reação de apoio no pilar: $\mathrm{V}_{\mathrm{u}}=100 \mathrm{kN}$

- momentos fletores: $\quad \mathrm{M}_{\mathrm{X}}=10 \mathrm{kN} . \mathrm{m}$ $\mathrm{M}_{\mathrm{y}}=12 \mathrm{kN} \cdot \mathrm{m}$
- armadura de flexão negativa aço CA $50 \mathrm{~A}$

Bitola: $\phi 10 \mathrm{~mm}$ / Área: $0,80 \mathrm{~cm}^{2}$

Distribuição: malha de $5,6 \mathrm{~cm} \mathrm{x} \mathrm{4,5} \mathrm{cm}$

Direção $\mathrm{X}$ : $\rho_{\mathrm{X}}=0,0222 \mathrm{~d}_{\mathrm{X}}=8 \mathrm{~cm}$

Direção y: $\rho_{\mathrm{y}}=0,0159 \mathrm{~d}_{\mathrm{y}}=9 \mathrm{~cm}$ $\mathrm{d}=8,5 \mathrm{~cm}$

Os esquemas referentes a este caso estão mostrados nas Figuras 4.8 e 4.9 do capítulo 4. Definiu-se ainda o eixo x como sendo a direção perpendicular à borda livre. Observa-se que $\mathrm{M}_{\mathrm{X}}$ é o momento que atua na direção perpendicular à borda livre enquanto que $\mathrm{M}_{\mathrm{y}}$ é o momento que atua na direção paralela à borda livre.

\subsubsection{TENSÃO NOMINAL ATUANTE $\left(v_{u}\right)$}

Baseado na Figura 7.11, tem-se a seguinte expressão para o cálculo de $\left(\mathrm{v}_{\mathrm{u}}\right)$ :

$\mathrm{v}_{\mathrm{u}}=\mathrm{v}_{\mathrm{u}, \max }=\mathrm{v}_{\mathrm{A}}=\frac{\mathrm{v}_{\mathrm{u}}}{\mathrm{A}_{\mathrm{c}}}+\frac{\gamma_{\mathrm{x}} \mathrm{M}_{\mathrm{x}} \mathrm{c}_{\mathrm{AB}}}{\mathrm{J}_{\mathrm{x}}}+\frac{\gamma_{\mathrm{y}} \mathrm{M}_{\mathrm{y}} \mathrm{c}_{\mathrm{AD}}}{\mathrm{J}_{\mathrm{y}}}$

Portanto:

$c_{1}=20 \mathrm{~cm} ; \quad c_{2}=15 \mathrm{~cm} ; \quad b_{1}=c_{1}+d / 2=24,25 \mathrm{~cm} ; \quad b_{2}=c_{2}+d=23,5 \mathrm{~cm} ;$

$\mathrm{c}_{\mathrm{CD}}=$ distância da borda livre (Face CD) até o eixo c-c, paralelo ao eixo y e que passa pelo centróide da seção crítica;

$c_{C D}=\frac{b_{1}^{2}+b_{1} b_{2}}{2 b_{1}+b_{2}}=16,08 \mathrm{~cm} ;$ 
$\mathrm{c}_{\mathrm{AB}}=$ distância entre o eixo c-c, paralelo ao eixo y e que passa pelo centróide da seção crítica até a face interna do pilar (Face AB);

$\mathrm{c}_{\mathrm{AB}}=\frac{\mathrm{b}_{1}^{2}}{2 \mathrm{~b}_{1}+\mathrm{b}_{2}}=8,17 \mathrm{~cm}$

$\mathrm{c}_{\mathrm{AD}}=$ distância do eixo $\mathrm{c}^{\prime}$-c', paralelo ao eixo $\mathrm{x}$ e que passa pelo centróide da seção crítica, até a Face AD (igual a $\left.b_{2} / 2\right)=11,75 \mathrm{~cm}$;

$\mathrm{c}_{\mathrm{AD}}=\mathrm{b}_{2} / 2=11,75 \mathrm{~cm} ;$

$\mathrm{c}_{\mathrm{CB}}=$ distância do eixo $\mathrm{c}^{\prime}$-c', paralelo ao eixo $\mathrm{x}$ e que passa pelo centróide da seção crítica, até a Face CB;

$\mathrm{c}_{\mathrm{CB}}=\mathrm{b}_{2} / 2=11,75 \mathrm{~cm} ;$

$\mathrm{A}_{\mathrm{c}}=$ área da superfície crítica $=\mathrm{d}\left(2 \mathrm{~b}_{1}+\mathrm{b}_{2}\right)=612 \mathrm{~cm}^{2}$;

$\gamma_{\mathrm{x}}=1-\frac{1}{1+(2 / 3) \sqrt{\mathrm{b}_{1} / \mathrm{b}_{2}}}=0,404$

$\mathrm{J}_{\mathrm{x}}=\frac{\mathrm{b}_{1}{ }^{3} \mathrm{~d}}{6}+\frac{\mathrm{b}_{1} \mathrm{~d}^{3}}{6}+\frac{\mathrm{b}_{1}{ }^{3} \mathrm{~b}_{2}{ }^{2} \mathrm{~d}}{2\left(2 \mathrm{~b}_{1}+\mathrm{b}_{2}\right)^{2}}+\frac{\mathrm{b}_{1}{ }^{4} \mathrm{~b}_{2} \mathrm{~d}}{\left(2 \mathrm{~b}_{1}+\mathrm{b}_{2}\right)^{2}}=42466 \mathrm{~cm}^{4}$

$\gamma_{\mathrm{y}}=1-\frac{1}{1+(2 / 3) \sqrt{\mathrm{b}_{2} / \mathrm{b}_{1}}}=0,396$

$\mathrm{J}_{\mathrm{y}}=\frac{\mathrm{b}_{2}^{3} \mathrm{~d}}{12}+\frac{\mathrm{b}_{2} \mathrm{~d}^{3}}{12}+\frac{\mathrm{b}_{1} \mathrm{~b}_{2}^{2} \mathrm{~d}}{2}=67312 \mathrm{~cm}^{4}$ 


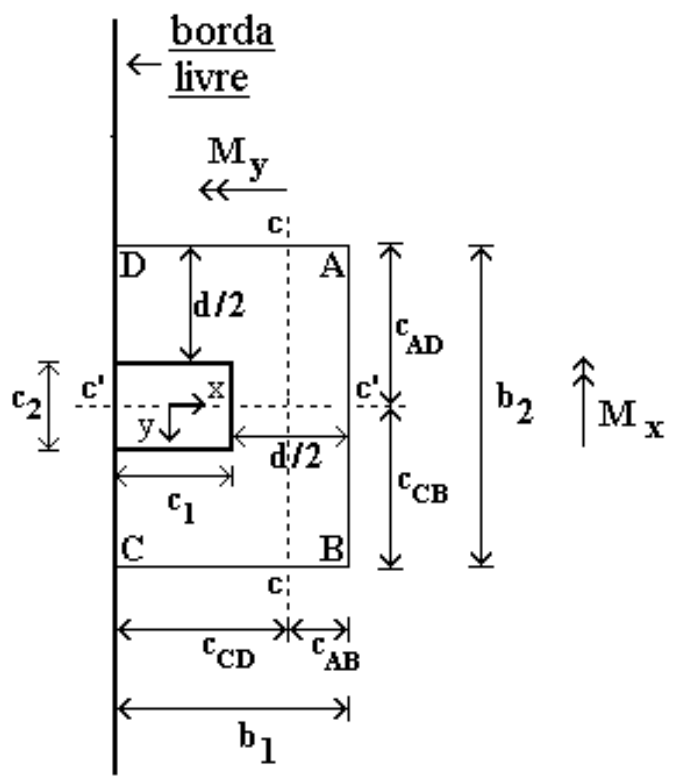

a) notação utilizada

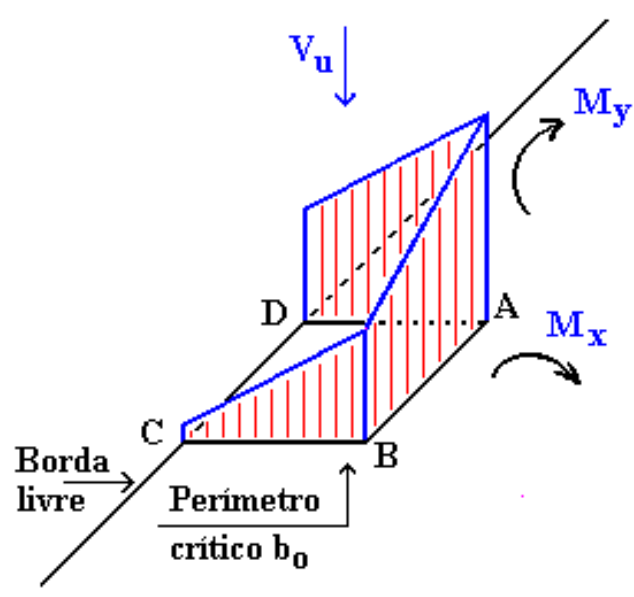

b) superposição de efeitos

Figura 7.11 - Notação

Portanto, substituindo-se os valores na expressão (7.13) tem-se que:

$$
\mathrm{v}_{\mathrm{u}}=0,324 \mathrm{kN} / \mathrm{cm}^{2}=3,24 \mathrm{MPa}
$$

\subsubsection{TENSÃO NOMINAL RESISTENTE $\left(v_{n}\right)$}

Adota-se o menor valor dos obtidos através das expressões (7.2), (7.3) e (7.4), calculados a seguir:

a) expressão (7.2):

com $\beta_{\mathrm{c}}=1,333 ; \quad \mathrm{f}_{\mathrm{c}}{ }^{\prime}=25 \mathrm{MPa} ; \quad$ tem-se que: $\mathrm{v}_{\mathrm{c}}=2,07 \mathrm{MPa}$.

b) expressão (7.3):

com $\alpha_{\mathrm{S}}=30 ; \mathrm{b}_{\mathrm{O}}=2 \mathrm{~b}_{1}+\mathrm{b}_{2}=72 \mathrm{~cm} ; \mathrm{f}_{\mathrm{c}}{ }^{\prime}=25 \mathrm{MPa} ;$ tem-se que: $\mathrm{v}_{\mathrm{c}}=2,30 \mathrm{MPa}$.

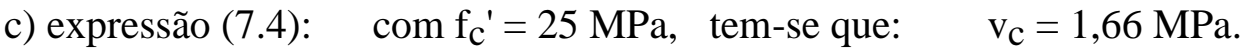

Portanto: $\quad \mathrm{vn}_{\mathrm{n}}=1,66 \mathrm{MPa}$. 


\subsubsection{COMPARAÇÃO DAS TENSÕES}

Fazendo-se a comparação de $v_{u}$ com $\phi v_{n}$, tem-se que:

$\mathrm{v}_{\mathrm{u}}=3,24 \mathrm{MPa}>\phi \mathrm{v}_{\mathbf{n}}=0,85 \times 1,66=1,41 \mathrm{MPa}$.

Portanto, necessita-se aumentar a resistência da ligação.

\subsection{PILAR DE BORDA COM ARMADURA DE PUNÇÃO}

Serão utilizados os dados referentes ao item anterior, complementados com dados referentes à armadura de punção utilizada. A disposição desta armadura está ilustrada na Figura 4.10 do capítulo 4. Para este exemplo, não foi considerada a recomendação do $\mathrm{CEB} / 90$ referente à armadura de punção adicional, ilustrada na Figura 4.10. Para este caso, os conectores "adicionais" foram considerados no cálculo. Deverão ser verificadas cada uma das duas seções consideradas críticas (a $\mathrm{d} / 2$ do pilar e a d/2 da região armada).

- Tipo de armadura de punção: conectores tipo pino

- Bitola: $\phi 6,3 \mathrm{~mm} \quad$ Aço: CA 50A Área do pino $\left(\mathrm{A}_{\mathrm{Sy}}\right): 0,32 \mathrm{~cm}^{2}$

- $\mathrm{f}_{\mathrm{y}}=400 \mathrm{MPa}$ (valor máximo permitido pelo ACI 318/89)

\subsubsection{SEÇÃO CRÍTICA A d/2 DO PILAR}

a) Cálculo de $v_{\boldsymbol{u}}$ (já calculado no item 7.4.1): $\quad \mathrm{v}_{\mathrm{u}}=3,24 \mathrm{MPa}$.

\section{b) Cálculo de $v_{n}$ :}

$\mathrm{v}_{\mathrm{c}}=0,1661 \sqrt{\mathrm{f}_{\mathrm{c}}{ }^{\prime}}=0,831 \mathrm{MPa}$

$\mathrm{v}_{\mathrm{s}}=\frac{\mathrm{A}_{\mathrm{v}} \mathrm{f}_{\mathrm{y}}}{\mathrm{s} \mathrm{b}_{\mathrm{o}}}=0,438 \mathrm{kN} / \mathrm{cm}^{2}=4,38 \mathrm{MPa}$

$A_{V}=5,12 \mathrm{~cm}^{2} ; \quad s=6,5 \mathrm{~cm}>d / 2=4,25 \mathrm{~cm} ; \quad f_{y}=40 \mathrm{kN} / \mathrm{cm}^{2} ; \quad b_{\mathrm{o}}=72 \mathrm{~cm}$;

$\mathrm{v}_{\mathrm{n}}=\mathrm{v}_{\mathrm{c}}+\mathrm{v}_{\mathrm{s}} \leq 0,4982 \sqrt{\mathrm{f}_{\mathrm{c}}{ }^{\prime}}$ 
Desta forma: $\mathrm{v}_{\mathrm{n}}=5,211 \mathrm{MPa}>2,491 \mathrm{MPa} \longrightarrow \mathrm{v}_{\mathrm{n}}=2,491 \mathrm{MPa}$.

Verificou-se que o espaçamento radial dos conectores não está de acordo com a recomendação do ACI 318/89. A princípio, o espaçamento deveria ser corrigido, mas visto tratar-se aqui apenas de um exemplo, será dado prosseguimento às verificações.

c) Comparação das tensões nominais atuante e resistente:

$$
\mathrm{v}_{\mathrm{u}}=3,24 \mathrm{MPa}>\phi \mathrm{v}_{\mathrm{n}}=0,85 \times 2,491=2,12 \mathrm{MPa} .
$$

Portanto, nem mesmo com a presença da armadura de punção a laje passou na verificação. A princípio, não seria necessário realizar a próxima verificação; no entanto, a título de ilustração, ela será feita.

\subsubsection{SEÇÃO CRÍTICA A d/2 DA REGIÃO ARMADA}

O cálculo da nova tensão nominal atuante $\left(v_{u}\right.$ ') foi feito de forma análoga à mostrada no item 7.3.2. Os novos perímetros $U$ e U', utilizados no cálculo das parcelas da máxima tensão nominal atuante, relativas, respectivamente, à força cortante $V_{u}$ e aos momentos fletores atuantes $M_{x}$ e $M_{y}$, estão mostrados nas Figuras 7.12 e 7.13 .

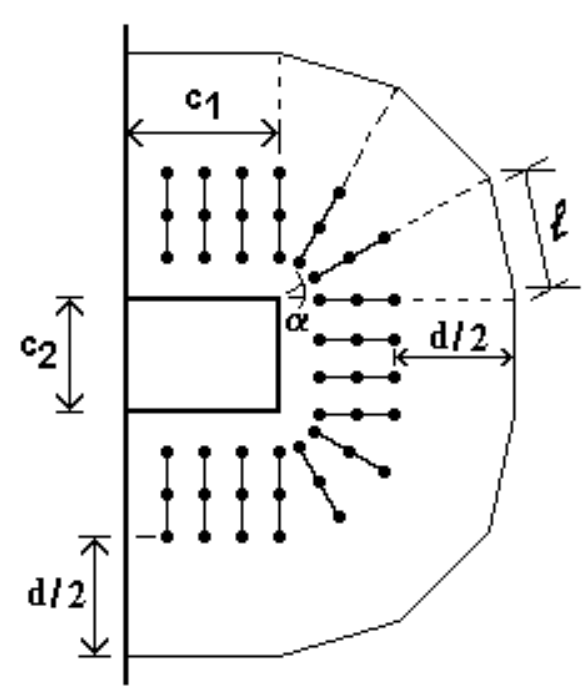

Figura 7.12 - Perímetro crítico U

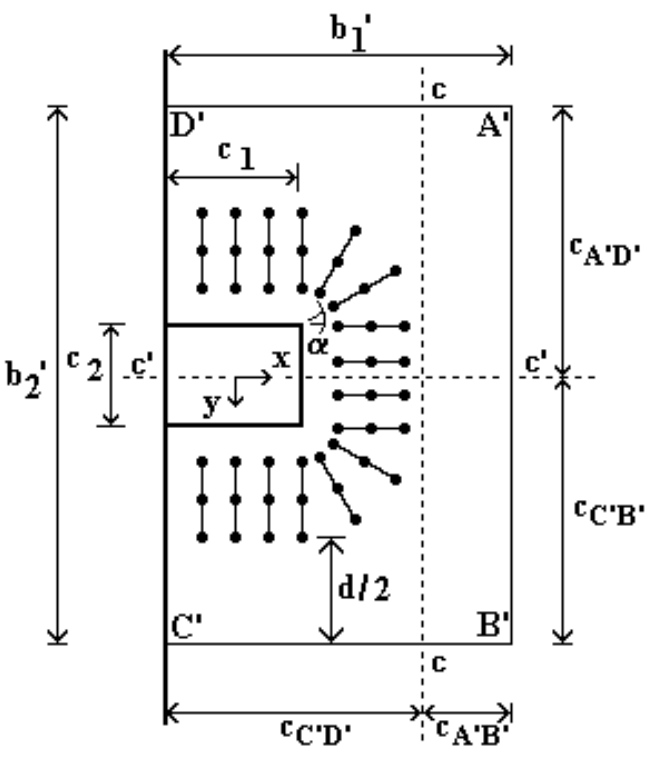

Figura 7.13 - Perímetro crítico U' 


\section{a) Cálculo da nova tensão nominal atuante $\left(\mathbf{v}_{\mathbf{u}}{ }^{\prime}\right)$}

A expressão a ser utilizada deverá ser a seguinte:

$\mathrm{v}_{\mathrm{u}}{ }^{\prime}=\mathrm{v}_{\mathrm{u}, \max }^{\prime}=\mathrm{v}_{\mathrm{A}}^{\prime}=\frac{\mathrm{V}_{\mathrm{u}}}{\mathrm{A}_{\mathrm{c}}{ }^{\prime}}+\frac{\gamma_{\mathrm{x}}{ }^{\prime} \mathrm{M}_{\mathrm{x}} \mathrm{c}_{\mathrm{A}^{\prime} \mathrm{B}^{\prime}}}{\mathrm{J}_{\mathrm{x}}{ }^{\prime}}+\frac{\gamma_{\mathrm{y}}{ }^{\prime} \mathrm{M}_{\mathrm{y}} \mathrm{c}_{\mathrm{A}^{\prime} \mathrm{D}^{\prime}}}{\mathrm{J}_{\mathrm{y}}{ }^{\prime}}$

onde, com relação ao perímetro crítico $\mathrm{U}$, tem-se que:

$$
\begin{array}{lll}
\alpha=30^{\circ} ; & \mathrm{s}_{\mathrm{O}}=4 \mathrm{~cm} ; & \mathrm{A}=(\mathrm{d} \tan \beta) / 2=1,14 \mathrm{~cm} ; \\
\beta=\alpha / 2=15^{\circ} ; & \mathrm{s}=6,5 \mathrm{~cm}(>\mathrm{d} / 2) ; & \mathrm{B}=2 \operatorname{sen} \beta\left(\mathrm{s}_{\mathrm{O}}+2 \mathrm{~s}\right)=8,80 \mathrm{~cm} ; \\
& & \ell=\mathrm{B}+2 \mathrm{~A}=11,08 \mathrm{~cm} ;
\end{array}
$$

$\mathrm{U}=2 \mathrm{c}_{1}+\mathrm{c}_{2}+6 \ell=121,48 \mathrm{~cm}$;

$\mathrm{A}_{\mathrm{c}}{ }^{\prime}=\mathrm{Ud}=1033 \mathrm{~cm}^{2}$;

e, com relação ao perímetro crítico U', tem-se que:

$$
\begin{array}{l|l}
\mathrm{b}_{1}{ }^{\prime}=\mathrm{c}_{1}+\mathrm{s}_{\mathrm{O}}+2 \mathrm{~s}+\mathrm{d} / 2=41,25 \mathrm{~cm} ; & \mathrm{b}_{2}{ }^{\prime}=\mathrm{c}_{2}+2\left(\mathrm{~s}_{\mathrm{O}}+2 \mathrm{~s}\right)+\mathrm{d}=57,5 \mathrm{~cm} ; \\
\mathrm{c}_{\mathrm{C}^{\prime} \mathrm{D}^{\prime}}=\frac{\mathrm{b}_{1}{ }^{\prime 2}+\mathrm{b}_{1}{ }^{\prime} \mathrm{b}_{2}{ }^{\prime}}{2 \mathrm{~b}_{1}{ }^{\prime}+\mathrm{b}_{2}{ }^{\prime}}=29,10 \mathrm{~cm} ; & \mathrm{c}_{\mathrm{A}^{\prime} \mathrm{B}^{\prime}}=\frac{\mathrm{b}_{1}{ }^{\prime 2}}{2 \mathrm{~b}_{1}{ }^{\prime}+\mathrm{b}_{2}{ }^{\prime}}=12,15 \mathrm{~cm} ; \\
\mathrm{c}_{\mathrm{C}^{\prime} \mathrm{B}^{\prime}}=\mathrm{b}_{2}{ }^{\prime} / 2=28,75 \mathrm{~cm} ; & \mathrm{c}_{\mathrm{A}^{\prime} \mathrm{D}^{\prime}}=\mathrm{b}_{2}{ }^{\prime} / 2=28,75 \mathrm{~cm} ; \\
\gamma_{\mathrm{x}}{ }^{\prime}=1-\frac{1}{1+(2 / 3) \sqrt{\mathrm{b}_{1}{ }^{\prime} / \mathrm{b}_{2}{ }^{\prime}}=0,36 ;} & \gamma_{\mathrm{y}}{ }^{\prime}=1-\frac{1}{1+(2 / 3) \sqrt{\mathrm{b}_{2}{ }^{\prime} / \mathrm{b}_{1}{ }^{\prime}}}=0,44 ; \\
\mathrm{J}_{\mathrm{x}}{ }^{\prime}=\frac{\mathrm{b}_{1}{ }^{\prime 3} \mathrm{~d}}{6}+\frac{\mathrm{b}_{1}{ }^{\prime} \mathrm{d}^{3}}{6}+\frac{\mathrm{b}_{1}{ }^{\prime 3} \mathrm{~b}_{2}{ }^{\prime 2} \mathrm{~d}}{2\left(2 \mathrm{~b}_{1}{ }^{\prime}+\mathrm{b}_{2}{ }^{\prime}\right)^{2}}+\frac{\mathrm{b}_{1}{ }^{\prime 4} \mathrm{~b}_{2}{ }^{\prime} \mathrm{d}}{\left(2 \mathrm{~b}_{1}{ }^{\prime}+\mathrm{b}_{2}{ }^{\prime}\right)^{2}}=226175 \mathrm{~cm}^{4} ; \\
\mathrm{J}_{\mathrm{y}}{ }^{\prime}=\frac{\mathrm{b}_{2}{ }^{\prime 3} \mathrm{~d}}{12}+\frac{\mathrm{b}_{2}{ }^{\prime} \mathrm{d}^{3}}{12}+\frac{\mathrm{b}_{1}{ }^{\prime} \mathrm{b}_{2}{ }^{\prime 2} \mathrm{~d}}{2}=717230 \mathrm{~cm}^{4} .
\end{array}
$$

Portanto, substituindo-se os valores na expressão (7.14) tem-se que:

$$
\mathrm{v}_{\mathrm{u}}{ }^{\prime}=0,137 \mathrm{kN} / \mathrm{cm}^{2}=1,37 \mathrm{MPa}
$$




\section{b) Cálculo da tensão nominal resistente $\left(v_{n}\right)$}

Calculando-se o menor valor das tensões resistentes dadas pelas expressões (7.2), (7.3) e (7.4), tem-se que: $\quad v_{n}=1,66 \mathrm{MPa}$

Observa-se que para o cálculo do valor fornecido pela expressão (7.2), deve-se substituir o valor do perímetro crítico $b_{o}$, localizado a d/2 do pilar, pelo valor do perímetro crítico definido a d/2 da região armada.

\section{c) Comparação das tensões}

Fazendo-se a comparação de $v_{u}{ }^{\prime} \operatorname{com} \phi v_{n}$, tem-se que:

$$
\mathrm{v}_{\mathrm{u}^{\prime}}=1,37 \mathrm{MPa}<\phi \mathrm{v}_{\mathrm{n}}=0,85 \times 1,66=1,41 \mathrm{MPa}
$$

Portanto, apesar da ligação não ter passado na primeira verificação, ela teria passado nesta.

\subsection{PILAR DE CANTO SEM ARMADURA DE PUNÇÃO}

São apresentados os seguintes dados gerais referentes a este caso:

- seção do pilar:

- espessura da laje:

$15 \mathrm{~cm} \times 20 \mathrm{~cm}$

$10 \mathrm{~cm}$

- resistência do concreto: $\mathrm{f}_{\mathrm{C}^{\prime}}=25 \mathrm{MPa}$

- reação de apoio no pilar: $\mathrm{V}_{\mathrm{u}}=50 \mathrm{kN}$

- momentos fletores:

$$
\mathrm{M}_{\mathrm{X}}=10 \mathrm{kN} . \mathrm{m}
$$$$
\mathrm{M}_{\mathrm{y}}=12 \mathrm{kN} . \mathrm{m}
$$

- armadura de flexão negativa aço CA $50 \mathrm{~A}$

Bitola: $\phi 10 \mathrm{~mm}$ / Área: $0,80 \mathrm{~cm}^{2}$ Distribuição: malha de $5,6 \mathrm{~cm} \times 4,5 \mathrm{~cm}$

Direção $\mathrm{x}: \rho_{\mathrm{X}}=0,0222 \mathrm{~d}_{\mathrm{X}}=8 \mathrm{~cm}$

Direção y: $\rho_{\mathrm{y}}=0,0159 \quad \mathrm{dy}=9 \mathrm{~cm}$ $\mathrm{d}=8,5 \mathrm{~cm}$

Os esquemas estão mostrados nas Figuras 4.15 e 4.16 do capítulo 4. 


\subsubsection{TENSÃO NOMINAL ATUANTE $\left(v_{u}\right)$}

Baseado na Figura 7.14, tem-se a seguinte expressão para o cálculo de $\left(\mathrm{v}_{\mathrm{u}}\right)$ :

$\mathrm{v}_{\mathrm{u}}=\mathrm{v}_{\mathrm{u}, \max }=\mathrm{v}_{\mathrm{B}}=\frac{\mathrm{V}_{\mathrm{u}}}{\mathrm{A}_{\mathrm{c}}}+\frac{\gamma_{\mathrm{x}} \mathrm{M}_{\mathrm{x}} \mathrm{c}_{\mathrm{AB}}}{\mathrm{J}_{\mathrm{x}}}+\frac{\gamma_{\mathrm{y}} \mathrm{M}_{\mathrm{y}} \mathrm{c}_{\mathrm{CB}}}{\mathrm{J}_{\mathrm{y}}}$

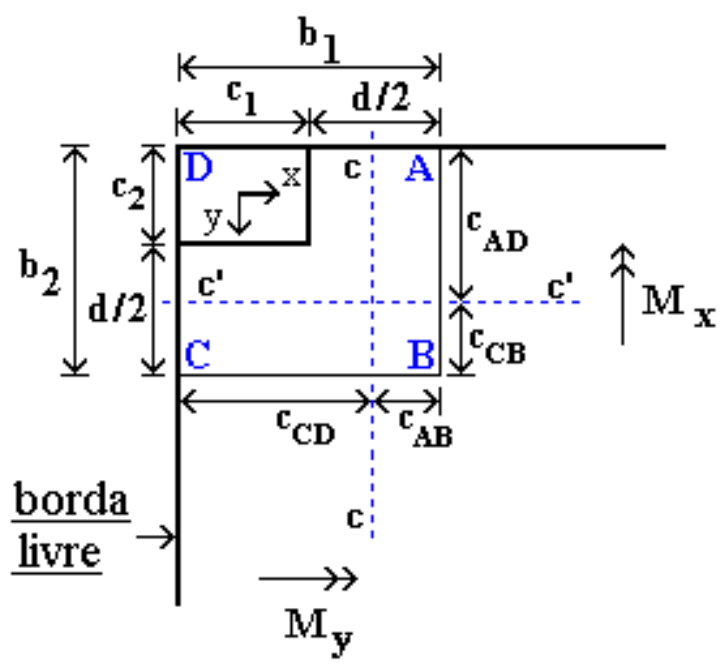

a) notação utilizada

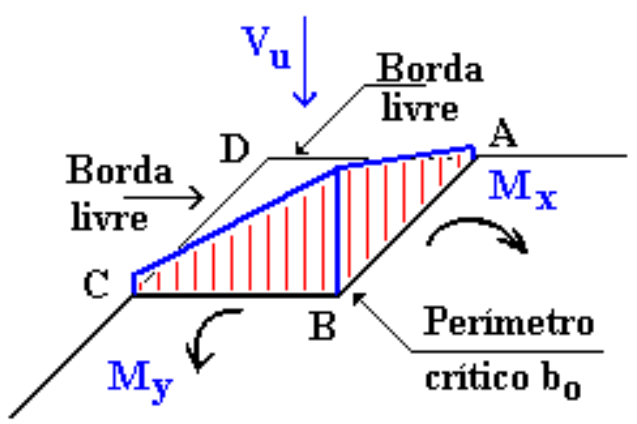

b) superposição de efeitos

Figura 7.14 - Notação

Portanto:

$\mathrm{c}_{1}=20 \mathrm{~cm} ; \quad \mathrm{c}_{2}=15 \mathrm{~cm} ; \quad \mathrm{b}_{1}=\mathrm{c}_{1}+\mathrm{d} / 2=24,25 \mathrm{~cm} ; \quad \mathrm{b}_{2}=\mathrm{c}_{2}+\mathrm{d} / 2=19,25 \mathrm{~cm} ;$

$\mathrm{c}_{\mathrm{CD}}=$ distância da borda livre (Face CD) até o eixo c-c, paralelo ao eixo y e que passa pelo centróide da seção crítica;

$\mathrm{c}_{\mathrm{CD}}=\frac{\mathrm{b}_{1}{ }^{2}+2 \mathrm{~b}_{1} \mathrm{~b}_{2}}{2\left(\mathrm{~b}_{1}+\mathrm{b}_{2}\right)}=17,49 \mathrm{~cm} ;$ 
$\mathrm{c}_{\mathrm{AB}}=$ distância entre o eixo c-c, paralelo ao eixo y e que passa pelo centróide da seção crítica até a Face $\mathrm{AB}$;

$\mathrm{c}_{\mathrm{AB}}=\frac{\mathrm{b}_{1}^{2}}{2\left(\mathrm{~b}_{1}+\mathrm{b}_{2}\right)}=6,76 \mathrm{~cm}$;

$\mathrm{c}_{\mathrm{AD}}=$ distância da borda livre (Face $\left.\mathrm{AD}\right)$, até o eixo $\mathrm{c}^{\prime}-\mathrm{c}^{\prime}$, paralelo ao eixo x e que passa pelo centróide da seção crítica;

$c_{A D}=\frac{b_{2}^{2}+2 b_{1} b_{2}}{2\left(b_{1}+b_{2}\right)}=14,99 \mathrm{~cm}$

$\mathrm{c}_{\mathrm{CB}}=$ distância entre o eixo $\mathrm{c}^{\prime}-\mathrm{c}^{\prime}$, paralelo ao eixo $\mathrm{x}$ e que passa pelo centróide da seção crítica, até a Face $\mathrm{CB}$;

$\mathrm{c}_{\mathrm{CB}}=\frac{\mathrm{b}_{2}^{2}}{2\left(\mathrm{~b}_{1}+\mathrm{b}_{2}\right)}=4,26 \mathrm{~cm}$;

$\mathrm{A}_{\mathrm{c}}=$ área da superfície crítica $=\mathrm{d}\left(\mathrm{b}_{1}+\mathrm{b}_{2}\right)=370 \mathrm{~cm}^{2}$;

$\gamma_{\mathrm{x}}=1-\frac{1}{1+(2 / 3) \sqrt{\mathrm{b}_{1} / \mathrm{b}_{2}}}=0,428$

$\mathrm{J}_{\mathrm{x}}=\frac{\mathrm{b}_{1}{ }^{3} \mathrm{~d}}{12}+\frac{\mathrm{b}_{1} \mathrm{~d}^{3}}{12}+\frac{\mathrm{b}_{1}{ }^{3} \mathrm{~b}_{2}{ }^{2} \mathrm{~d}}{4\left(\mathrm{~b}_{1}+\mathrm{b}_{2}\right)^{2}}+\frac{\mathrm{b}_{1}{ }^{4} \mathrm{~b}_{2} \mathrm{~d}}{4\left(\mathrm{~b}_{1}+\mathrm{b}_{2}\right)^{2}}=24752 \mathrm{~cm}^{4}$

$\gamma_{\mathrm{y}}=1-\frac{1}{1+(2 / 3) \sqrt{\mathrm{b}_{2} / \mathrm{b}_{1}}}=0,373$

$J_{y}=\frac{b_{2}{ }^{3} d}{12}+\frac{b_{2} d^{3}}{12}+\frac{b_{2}{ }^{3} b_{1}{ }^{2} d}{4\left(b_{1}+b_{2}\right)^{2}}+\frac{b_{2}{ }^{4} b_{1} d}{4\left(b_{1}+b_{2}\right)^{2}}=14488 \mathrm{~cm}^{4}$

Portanto, substituindo-se os valores na expressão (7.15) tem-se que:

$$
\mathrm{v}_{\mathrm{u}}=0,384 \mathrm{kN} / \mathrm{cm}^{2}=3,84 \mathrm{MPa}
$$




\subsubsection{TENSÃO NOMINAL RESISTENTE $\left(v_{n}\right)$}

Adota-se o menor valor dos obtidos através das expressões (7.2), (7.3) e (7.4), calculados a seguir:

a) expressão (7.2):

com $\beta_{\mathrm{c}}=1,333 ; \quad \mathrm{f}_{\mathrm{c}}{ }^{\prime}=25 \mathrm{MPa} ; \quad$ tem-se que: $\mathrm{v}_{\mathrm{c}}=2,07 \mathrm{MPa}$.

b) expressão (7.3):

com $\alpha_{\mathrm{S}}=20 ; \mathrm{b}_{\mathrm{O}}=\mathrm{b}_{1}+\mathrm{b}_{2}=43,5 \mathrm{~cm} ; \mathrm{f}_{\mathrm{c}}{ }^{\prime}=25 \mathrm{MPa} ;$ tem-se que: $\mathrm{v}_{\mathrm{c}}=2,45 \mathrm{MPa}$.

c) expressão (7.4): $\quad$ com $\mathrm{f}_{\mathrm{c}^{\prime}}=25 \mathrm{MPa}$, tem-se que: $\quad \mathrm{v}_{\mathrm{c}}=1,66 \mathrm{MPa}$.

$$
\text { Portanto: } \quad \mathrm{v}_{\mathrm{n}}=1,66 \mathrm{MPa} \text {. }
$$

\subsubsection{COMPARAÇÃO DAS TENSÕES}

Fazendo-se a comparação de $v_{\mathrm{u}} \operatorname{com} \phi \mathrm{v}_{\mathrm{n}}$, tem-se que:

$$
\mathrm{v}_{\mathrm{u}}=3,84 \mathrm{MPa}>\phi \mathrm{v}_{\mathrm{n}}=0,85 \times 1,66=1,41 \mathrm{MPa}
$$

Portanto, necessita-se aumentar a resistência da ligação.

\subsection{PILAR DE CANTO COM ARMADURA DE PUNÇ̃O}

Serão utilizados os dados referentes ao item anterior, complementados com dados referentes à armadura de punção utilizada. A disposição desta armadura está ilustrada na Figura 4.19 do capítulo 4. Para este exemplo, não foi considerada a recomendação do CEB/90 referente à armadura de punção adicional, ilustrada na Figura 4.19. Para este caso, os conectores "adicionais" foram considerados no cálculo. Deverão ser verificadas cada uma das duas seções consideradas críticas (a $\mathrm{d} / 2$ do pilar e a d/2 da região armada). 
- Tipo de armadura de punção: conectores tipo pino

- Bitola: $\phi 6,3 \mathrm{~mm}$ Aço: CA 50A Área do pino $\left(\mathrm{A}_{\mathrm{sy}}\right): 0,32 \mathrm{~cm}^{2}$

- $\mathrm{f}_{\mathrm{y}}=400 \mathrm{MPa}$ (valor máximo permitido pelo ACI 318/89)

\subsubsection{SEÇÃO CRÍTICA A d/2 DO PILAR}

a) Cálculo de $v_{\boldsymbol{u}}$ (já calculado no item 7.6.1): $\quad \mathrm{v}_{\mathrm{u}}=3,84 \mathrm{MPa}$.

\section{b) Cálculo de vn:}

$\mathrm{v}_{\mathrm{c}}=0,1661 \sqrt{\mathrm{f}_{\mathrm{c}}{ }^{\prime}}=0,831 \mathrm{MPa}$

$\mathrm{v}_{\mathrm{s}}=\frac{\mathrm{A}_{\mathrm{v}} \mathrm{f}_{\mathrm{y}}}{\mathrm{s} \mathrm{b}_{\mathrm{o}}}=0,407 \mathrm{kN} / \mathrm{cm}^{2}=4,07 \mathrm{MPa}$

$A_{V}=2,88 \mathrm{~cm}^{2} ; \quad s=6,5 \mathrm{~cm}>d / 2=4,25 \mathrm{~cm} ; \quad f_{y}=40 \mathrm{kN} / \mathrm{cm}^{2} ; \quad b_{0}=43,5 \mathrm{~cm}$.

$\mathrm{v}_{\mathrm{n}}=\mathrm{v}_{\mathrm{c}}+\mathrm{v}_{\mathrm{s}} \leq 0,4982 \sqrt{\mathrm{f}_{\mathrm{c}}{ }^{\prime}}$

Dessa forma:

$\mathrm{v}_{\mathrm{n}}=4,901 \mathrm{MPa}>2,491 \mathrm{MPa} \stackrel{\text { Portanto }}{\longrightarrow} \mathrm{v}_{\mathrm{n}}=2,491 \mathrm{MPa}$

Verificou-se que o espaçamento radial dos conectores não está de acordo com a recomendação do ACI 318/89. A princípio, o espaçamento deveria ser corrigido, mas visto tratar-se aqui apenas de um exemplo, será dado prosseguimento às verificações.

c) Comparação das tensões nominais atuante e resistente:

$\mathrm{v}_{\mathrm{u}}=3,84 \mathrm{MPa}>\phi \mathrm{v}_{\mathrm{n}}=0,85 \times 2,491=2,12 \mathrm{MPa}$ 
Portanto, nem mesmo com a presença da armadura de punção a laje passou na verificação. A princípio, não seria necessário realizar a próxima verificação; no entanto, a título de ilustração, ela será feita.

\subsubsection{SEÇÃo CRÍTICA A d/2 DA REGIÃO ARMADA}

O cálculo da nova tensão nominal atuante $\left(v_{u}{ }^{\prime}\right)$ foi feito de forma análoga à mostrada no item 7.3.2. Os novos perímetros U e U', utilizados no cálculo das parcelas da máxima tensão nominal atuante, relativas, respectivamente, à força cortante $\mathrm{V}_{\mathrm{u}}$ e aos momentos fletores atuantes $\mathrm{M}_{\mathrm{x}}$ e $\mathrm{M}_{\mathrm{y}}$, estão mostrados nas Figuras 7.15 e 7.16 .

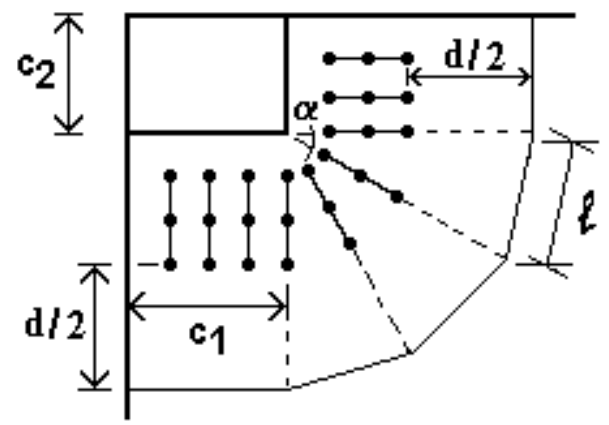

Figura 7.15 - Perímetro crítico U

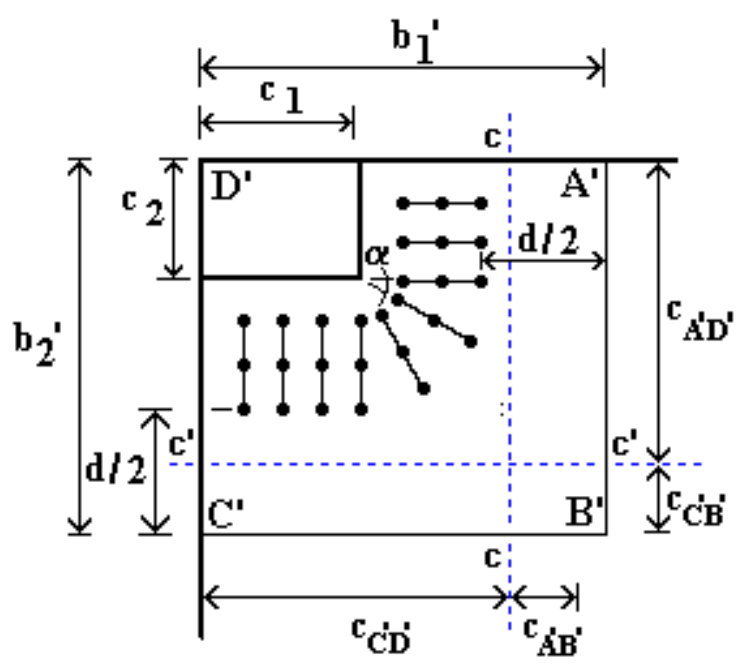

Figura 7.16 - Perímetro crítico U'

a) Cálculo da nova tensão nominal atuante $\left(v_{u}{ }^{\prime}\right)$

A expressão a ser utilizada deverá ser a seguinte:

$$
\mathrm{v}_{\mathrm{u}}{ }^{\prime}=\mathrm{v}_{\mathrm{u}, \max }^{\prime}=\mathrm{v}_{\mathrm{B}}^{\prime}=\frac{\mathrm{V}_{\mathrm{u}}}{\mathrm{A}_{\mathrm{c}}{ }^{\prime}}+\frac{\gamma_{\mathrm{x}}{ }^{\prime} \mathrm{M}_{\mathrm{x}} \mathrm{c}_{\mathrm{A}^{\prime} \mathrm{B}^{\prime}}}{\mathrm{J}_{\mathrm{x}}{ }^{\prime}}+\frac{\gamma_{\mathrm{y}}{ }^{\prime} \mathrm{M}_{\mathrm{y}} \mathrm{c}_{\mathrm{C}^{\prime} \mathrm{B}^{\prime}}}{\mathrm{J}_{\mathrm{y}}{ }^{\prime}}
$$


onde, com relação ao perímetro crítico U, tem-se que:

$$
\begin{aligned}
& \alpha=30^{\circ} ; \quad \mathrm{s}_{\mathrm{O}}=4 \mathrm{~cm} ; \quad \mathrm{A}=(\mathrm{d} \tan \beta) / 2=1,14 \mathrm{~cm} \text {; } \\
& \beta=\alpha / 2=15^{\circ} ; \quad \mathrm{s}=6,5 \mathrm{~cm}(>\mathrm{d} / 2) \quad \mathrm{B}=2 \operatorname{sen} \beta\left(\mathrm{s}_{\mathrm{O}}+2 \mathrm{~s}\right)=8,80 \mathrm{~cm} \text {; } \\
& \ell=\mathrm{B}+2 \mathrm{~A}=11,08 \mathrm{~cm} \\
& \mathrm{U}=\mathrm{c}_{1}+\mathrm{c}_{2}+3 \ell=68,24 \mathrm{~cm} \text {; } \\
& \mathrm{A}_{\mathrm{c}}{ }^{\prime}=\mathrm{Ud}=580 \mathrm{~cm}^{2}
\end{aligned}
$$

$$
\begin{aligned}
& \mathrm{b}_{1}^{\prime}=\mathrm{c}_{1}+\mathrm{s}_{\mathrm{o}}+2 \mathrm{~s}+\mathrm{d} / 2=41,25 \mathrm{~cm} ; \quad \mathrm{b}_{2}{ }^{\prime}=\mathrm{c}_{2}+\mathrm{s}_{\mathrm{o}}+2 \mathrm{~s}+\mathrm{d} / 2=36,25 \mathrm{~cm} \\
& c_{C^{\prime} D^{\prime}}=\frac{b_{1}^{\prime 2}+2 b_{1}{ }^{\prime} b_{2}^{\prime}}{2\left(b_{1}^{\prime}+b_{2}^{\prime}\right)}=30,27 \mathrm{~cm} ; \quad c_{A^{\prime} D^{\prime}}=\frac{b_{2}^{\prime 2}+2 b_{1}{ }^{\prime} b_{2}^{\prime}}{2\left(b_{1}{ }^{\prime}+b_{2}{ }^{\prime}\right)}=27,77 \mathrm{~cm} \\
& \begin{array}{l|l}
\mathrm{c}_{\mathrm{A}^{\prime} \mathrm{B}^{\prime}}=\frac{\mathrm{b}_{1}{ }^{\prime 2}}{2\left(\mathrm{~b}_{1}{ }^{\prime}+\mathrm{b}_{2}{ }^{\prime}\right)}=10,98 \mathrm{~cm} ; & \mathrm{c}_{\mathrm{C}^{\prime} \mathrm{B}^{\prime}}=\frac{\mathrm{b}_{2}{ }^{\prime 2}}{2\left(\mathrm{~b}_{1}{ }^{\prime}+\mathrm{b}_{2}{ }^{\prime}\right)}=8,48 \mathrm{~cm} ; \\
\gamma_{\mathrm{x}}{ }^{\prime}=1-\frac{1}{1+(2 / 3) \sqrt{\mathrm{b}_{1}{ }^{\prime} / \mathrm{b}_{2}{ }^{\prime}}}=0,416 ; & \gamma_{\mathrm{y}}{ }^{\prime}=1-\frac{1}{1+(2 / 3) \sqrt{\mathrm{b}_{2}{ }^{\prime} / \mathrm{b}_{1}{ }^{\prime}}}=0,385 ;
\end{array} \\
& \mathrm{J}_{\mathrm{x}}{ }^{\prime}=\frac{\mathrm{b}_{1}{ }^{3} \mathrm{~d}}{12}+\frac{\mathrm{b}_{1}{ }^{\prime} \mathrm{d}^{3}}{12}+\frac{\mathrm{b}_{1}{ }^{3} \mathrm{~b}_{2}{ }^{\prime 2} \mathrm{~d}}{4\left(\mathrm{~b}_{1}{ }^{\prime}+\mathrm{b}_{2}{ }^{\prime}\right)^{2}}+\frac{\mathrm{b}_{1}{ }^{\prime 4} \mathrm{~b}_{2}{ }^{\prime} \mathrm{d}}{4\left(\mathrm{~b}_{1}{ }^{\prime}+\mathrm{b}_{2}\right)^{2}}=121594 \mathrm{~cm}^{4} \\
& \mathrm{~J}_{\mathrm{y}}{ }^{\prime}=\frac{\mathrm{b}_{2}{ }^{3} \mathrm{~d}}{12}+\frac{\mathrm{b}_{2} \mathrm{~d}^{3}}{12}+\frac{\mathrm{b}_{2}{ }^{3} \mathrm{~b}_{1}{ }^{2} \mathrm{~d}}{4\left(\mathrm{~b}_{1}{ }^{\prime}+\mathrm{b}_{2}^{\prime}\right)^{2}}+\frac{\mathrm{b}_{2}{ }^{\prime 4} \mathrm{~b}_{1}{ }^{\prime d}}{4\left(\mathrm{~b}_{1}{ }^{\prime}+\mathrm{b}_{2}\right)^{2}}=89474 \mathrm{~cm}^{4}
\end{aligned}
$$

Portanto, substituindo-se os valores na expressão (7.16) tem-se que:

$$
\mathrm{v}_{\mathrm{u}}{ }^{\prime}=0,168 \mathrm{kN} / \mathrm{cm}^{2}=1,68 \mathrm{MPa}
$$




\section{b) Cálculo da tensão nominal resistente $\left(v_{n}\right)$}

Calculando-se o menor valor das tensões resistentes dadas pelas expressões (7.2), (7.3) e (7.4), tem-se que: $\quad v_{n}=1,66 \mathrm{MPa}$

Observa-se que para o cálculo do valor fornecido pela expressão (7.2), deve-se substituir o valor do perímetro crítico $b_{o}$, localizado a $d / 2$ do pilar, pelo valor do perímetro crítico definido a d/2 da região armada.

\section{c) Comparação das tensões}

Fazendo-se a comparação de $v_{\mathrm{u}}{ }^{\prime} \operatorname{com} \phi \mathrm{v}_{\mathrm{n}}$, tem-se que:

$$
\mathrm{v}_{\mathrm{u}^{\prime}}=1,68 \mathrm{MPa}>\phi \mathrm{v}_{\mathrm{n}}=0,85 \times 1,66=1,41 \mathrm{MPa}
$$

Portanto, esta ligação não passou em nenhuma das duas verificações feitas, nem para a região armada e nem para a região externa a ela.

\subsection{OBSERVAÇÕES GERAIS}

Ao contrário do EUROCODE N.2 e do CEB/90, o ACI 318/89 não menciona nenhuma armadura dobrada na região das bordas, destinada a combater esforços de torção.

Apesar do ACI 318/89 definir que o espaçamento radial entre os elementos da armadura de punção deva ser inferior a d/2, ao contrário do CEB/90, ele não apresenta nenhuma recomendação com relação ao afastamento circunferencial desses elementos. 
O ACI 318/89 permite que se eleve a resistência da ligação, devido à presença da armadura de punção em, no máximo, em $50 \%$ da resistência da ligação sem armadura de punção. Caso não houvesse esta limitação, nos exemplos vistos, tanto o pilar interno com armadura de punção como o pilar de borda com armadura de punção teriam passado em ambas as verificações, ao contrário do pilar de canto com armadura de punção, que não teria passado apenas na verificação da região além da transversalmente armada.

Por fim, o ACI 318/89 não fornece condições para que se calcule a influência do momento fletor na região crítica externa à armadura de punção, tendo sido usado, para os exemplos, a sugestão dada no item 7.1.2b.

Assim como no CEB/90, o ACI 318/89 menciona a necessidade de se detalhar bem a armadura de punção para lajes com espessura inferior a $25 \mathrm{~cm}$. 


\section{COMPARAÇ̃̃O COM RESULTADOS EXPERIMENTAIS}

Neste capítulo, serão comparados alguns resultados experimentais com os obtidos através das recomendações do texto base da NB-1/94, do CEB/90, do ACI 318/89 e do EUROCODE N.2 (1992). Os ensaios relativos aos valores experimentais utilizados serão sucintamente descritos.

Analogamente ao observado em ANDRADE; GOMES (1994a), utilizou-se a resistência dos materiais obtida diretamente de ensaios para se obter a carga concentrada correspondente à ruína da ligação, calculada de acordo com os critérios do texto base da NB-1/94, do CEB/90, do ACI318/89 e do EUROCODE N.2. Além disso, não foram utilizados os coeficientes recomendados pelos códigos para minorar a resistência do concreto e do aço. Desta forma, não se utilizou o coeficiente $\phi$, definido no item 9.3 do ACI 318/89. Já com relação ao EUROCODE N.2 e ao CEB/90, multiplicou-se o termo relativo à resistência do concreto por 1,5 e o termo relativo à resistência do aço por 1,15, definidos, respectivamente, nos seus ítens 1.6.2.4 e 2.3.3.2. Por fim, com base no item 10.5.2.1 do texto base da NB-1/94, as constantes utilizadas para multiplicar o valor da resistência do concreto e do aço foram admitidas iguais a 1,4 e 1,15, respectivamente. Desta forma, obteve-se uma resistência característica que teria a finalidade de garantir que apenas $5 \%$ das resistências observadas em ensaio fossem inferiores a ela.

Observa-se que foram respeitados os valores máximos dados pelos códigos, referentes à taxa de armadura de flexão e à tensão do aço a serem consideradas no cálculo dos valores das resistências. 
Por fim, tanto para o EUROCODE N.2, como para o ACI 318/89, existe uma limitação para o valor da resistência da ligação na região armada. Esta limitação permite que se eleve a resistência a, no máximo, 60\% e 50\%, respectivamente, da resistência de uma ligação correspondente, só que sem armadura de punção.

Visando facilitar a análise dos resultados, os ensaios foram separados em função da posição do pilar na ligação e das características a serem analisadas através do ensaio.

\subsection{ENSAIOS PARA PILARES DE CANTO}

\subsubsection{ENSAIO DE MARTINELLI (1974)}

O ensaio referente a este item está descrito em MARTINELLI (1974). A principal avaliação feita foi com relação à utilização de ganchos como armadura de punção (Figura 8.1a).

O carregamento foi realizado de tal forma que a excentricidade da força resultante aplicada passasse pelo plano bissetor da peça. Os ganchos foram distribuídos uniformemente pela região considerada crítica, localizada a $\mathrm{h} / \operatorname{tg} 30^{\circ} \mathrm{da}$ face do pilar, onde h é a espessura da laje (Figura 8.1b). A ancoragem dos ganchos foi feita através da face superior da armadura de flexão e do prolongamento desta armadura até a face inferior da laje, prolongamento este também realizado através de ganchos, conforme mostrado na Figura 8.1c.

Uma vez que esta distribuição de armadura não corresponde a uma distribuição radial e nem a uma distribuição em cruz, adaptou-se a ela uma distribuição "radial", a fim de que se possa aplicar as recomendações dadas conforme o texto base, o CEB/90 e o EUROCODE N.2. 


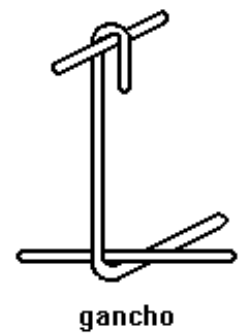

a) gancho

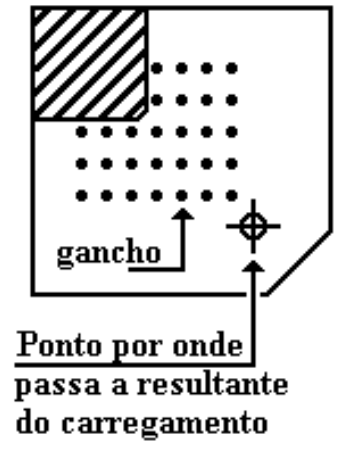

b) armadura e

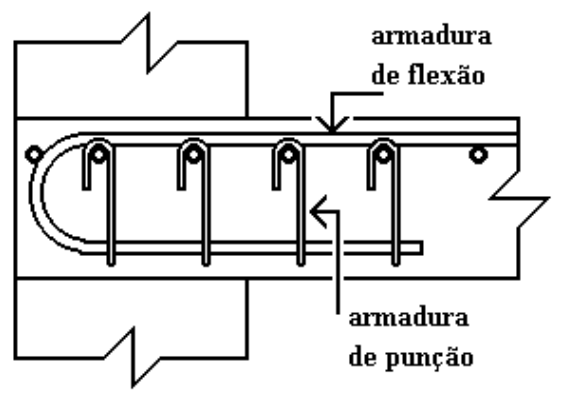

c) ancoragem

excentricidade

Figura 8.1 - Esquema do ensaio

Os valores comparados encontram-se nas Tabelas 8.1 e 8.2. Entre parênteses está definida a forma com que a ruína foi observada, tanto em relação ao ensaio, como em relação aos valores calculados através dos códigos. Na segunda coluna é dada a área total de armadura de punção utilizada.

TABELA 8.1 - MARTINELLI (1974) em valores absolutos

\begin{tabular}{c|c|c|c|c|c|c}
\hline \hline Modelo & $\begin{array}{c}\mathrm{A}_{\text {st }} \\
\left(\mathrm{cm}^{2}\right)\end{array}$ & $\begin{array}{c}\text { Ruína } \\
(\mathrm{kN})\end{array}$ & $\begin{array}{c}\text { NB-1/94 } \\
(\mathrm{kN})\end{array}$ & $\begin{array}{c}\text { CEB/90 } \\
(\mathrm{kN})\end{array}$ & $\begin{array}{c}\text { ACI 318/89 } \\
(\mathrm{kN})\end{array}$ & $\begin{array}{c}\text { EC - } 2 \\
(\mathrm{kN})\end{array}$ \\
\hline A1 & 0,00 & $64,32(\mathrm{pç})$ & $58,72(\mathrm{pc})$ & $76,74(\mathrm{pç})$ & $26,52(\mathrm{pç})$ & $54,20(\mathrm{pç)}$ \\
A3 & 8,80 & $72,51(\mathrm{flex})$ & $107,74(\mathrm{ext})$ & $118,23(\mathrm{ext})$ & $31,39(\mathrm{int})$ & $77,41(\mathrm{ext})$ \\
A4 & 17,60 & $68,88(\mathrm{flex})$ & $105,68(\mathrm{ext})$ & $115,97(\mathrm{ext})$ & 38,53 (int) & $74,76(\mathrm{ext})$ \\
\hline
\end{tabular}

Formas de ruína: pç - punção / flex - flexão / int ; ext - punção interna e externa à região armada.

Os modelos com armadura transversal romperam por flexão. 
TABELA 8.2 - MARTINELLI (1974) em valores relativos

\begin{tabular}{c|c|c|c|c|c}
\hline \hline Modelo & A & & & \\
& & $\frac{\mathrm{NB}-1 / 94}{\text { Ruína }}$ & $\frac{\mathrm{CEB} / 90}{\text { Ruína }}$ & $\frac{\mathrm{ACI} 318 / 89}{\text { Ruína }}$ & $\frac{\mathrm{EC}-2}{\text { Ruína }}$ \\
\hline A1 & 0,00 & 0,91 & 1,19 & 0,41 & 0,84 \\
$\mathrm{~A} 3$ & 8,80 & 1,49 & 1,63 & 0,43 & 1,07 \\
A4 & 17,60 & 1,53 & 1,68 & 0,56 & 1,09 \\
\hline
\end{tabular}

Os Gráficos 8.1 e 8.2 representam os valores absolutos mostrados na Tabela 8.1 e indicados através de pontos e de colunas, respectivamente.

Para o modelo sem armadura transversal, a ruína se deu por punção. O valor referente à carga de ruína fornecido pelo texto base foi o que mais se aproximou do resultado experimental, sendo ligeiramente inferior a ele. Já o CEB/90 não se mostrou um método muito seguro, uma vez que o valor obtido através de suas recomendações ficou cerca de $19 \%$ acima do valor de ruína observado no ensaio. A diferença entre o CEB/90 e o texto base é que enquanto o $\mathrm{CEB} / 90$ apenas considera uma distribuição uniforme de tensões nominais de cisalhamento, atuando em um perímetro crítico reduzido, o texto base, além disso, quantifica, de uma forma mais elaborada, a influência do momento fletor. O ACI 318/89 foi o método que apresentou os resultados mais conservadores. Uma das razões é que este método considera uma distribuição linear de tensões nominais de cisalhamento ao longo de segmentos do perímetro crítico que estejam na direção de atuação do momento fletor. Conforme relatado em PINTO (1993), esta distribuição não é adequada quando comparada com a distribuição de tensões de cisalhamento no regime elástico, fornecida por MAST (1970). Segundo PINTO (1993), a distribuição anti-simétrica adotada pelo texto base e pelo CEB/90, mostrada na Figura 19.3.3 do capítulo 3, é mais adequada. O EUROCODE N.2 apresenta uma forma bem simplificada de se levar em consideração a influência do momento fletor atuando na ligação. Ele considera um acréscimo fixo de 50\% no valor da tensão nominal atuante, distribuída uniformemente ao longo do perímetro crítico. Observa-se que, apesar de ser um método simplificado, o seu valor correspondente à ruína foi próximo do resultado observado no ensaio. 
Já para lajes com armadura transversal, a ruína se deu por flexão. Sendo assim, os valores dados pelos códigos deveriam estar acima dos valores experimentais. Observa-se que apenas o ACI 318/89 apresentou valores inferiores aos experimentais. Desta forma, a única conclusão que se pode tirar é que este método continua sendo o mais conservador, também para ligações com armadura de punção.

GRÁFICO 8.1 - ENSAIO DE MARTINELLI (1974): PONTOS (Pilares de canto)

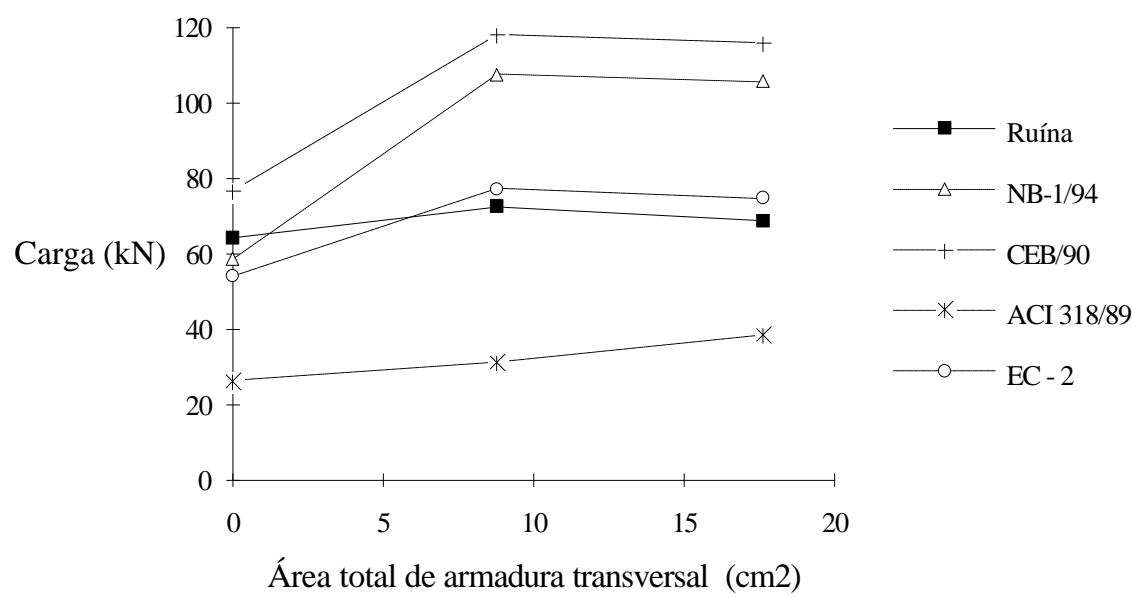

Os modelos com armadura transversal romperam por flexão.

GRÁFICO 8.2 - ENSAIO DE MARTINELLI (1974): COLUNAS (Pilares de canto)

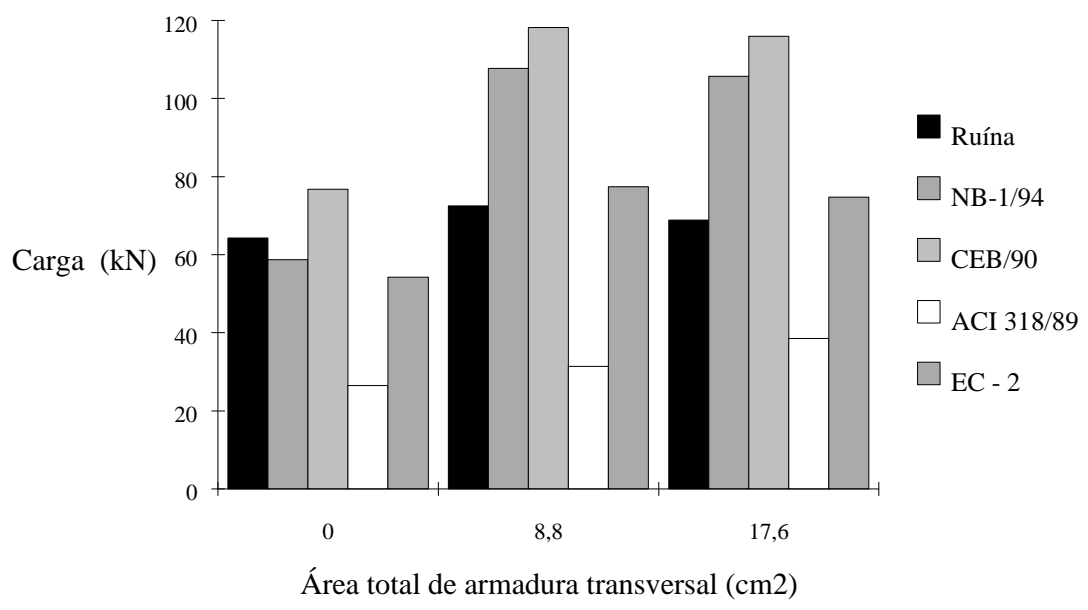

Os modelos com armadura transversal romperam por flexão. 


\subsubsection{ENSAIO DE STAMENKOVIC; CHAPMAN (1974)}

Neste ensaio, apoiaram-se as bordas livres da ligação e aplicou-se o carregamento diretamente através do pilar de canto. Desta forma, não se considerou a presença de momentos fletores aplicados diretamente à ligação. Com relação ao EUROCODE N.2 considerou-se o valor de $\beta$ como sendo unitário.

Fez-se necessária a adaptação dos valores de resistência do concreto obtidos através de corpos-de-prova cúbicos a valores de resistência correspondentes a corpos-de-prova cilíndricos. Portanto, considerou-se a resistência dos corpos-deprova cilíndricos como sendo 0,85 da resistência dada por corpos-de-prova cúbicos. Não foi utilizada armadura transversal. O modelo rompeu por punção. Os valores comparados encontram-se nas Tabelas 8.3 e 8.4.

TABELA 8.3 - STAMENKOVIC; CHAPMAN (1974) em valores absolutos

\begin{tabular}{c|c|c|c|c|c}
\hline \hline Modelo & Ruína $(\mathrm{kN})$ & NB-1/94 $(\mathrm{kN})$ & CEB/90 $(\mathrm{kN})$ & ACI 318/89 $(\mathrm{kN})$ & EC - 2 $(\mathrm{kN})$ \\
\hline V/C/1 & 27,13 & 30,46 & 30,12 & 33,66 & 26,81 \\
\hline \multicolumn{6}{c}{ O modelo rompeu por punção. } \\
\hline \hline
\end{tabular}

TABELA 8.4 - STAMENKOVIC; CHAPMAN (1974) em valores relativos

\begin{tabular}{c|c|c|c|c}
\hline \hline Modelo & $\frac{\text { NB }-1 / 94}{\text { Ruína }}$ & $\frac{\text { CEB } / 90}{\text { Ruína }}$ & $\frac{\text { ACI 318/89 }}{\text { Ruína }}$ & $\frac{\text { EC-2 }}{\text { Ruína }}$ \\
\hline V/C/1 & 1,12 & 1,11 & 1,24 & 0,99 \\
\hline \multicolumn{5}{c}{ O modelo rompeu por punção. } \\
\hline \hline
\end{tabular}

O Gráfico 8.3 representa a comparação feita na Tabela 8.3.

Para este caso, o texto base e o CEB/90 apresentam valores próximos, mas acima do valor de ruína observado experimentalmente, estando, portanto, ligeiramente contra a segurança. No entanto, talvez a adaptação dos valores de resistência do concreto possa ter influenciado este resultado. 
Em vista da não existência do momento fletor transmitido diretamente à ligação, surpreendentemente, o ACI 318/89 apresentou um valor muito acima do valor observado experimentalmente.

Já o EUROCODE N.2 foi o que apresentou o melhor resultado. No entanto, caso se tivesse utilizado o coeficiente $\beta$ igual a 1,5 , recomendado para pilares de canto, o valor de ruína, dado pelo EUROCODE N.2, representaria cerca de $66 \%$ do valor de ruína observado no ensaio, tornando-se, portanto, um método muito conservador, quando comparado aos demais códigos.

\section{GRÁFICO 8.3 - ENSAIO DE STAMENKOVIC; CHAPMAN (1974)}

(Pilar de canto)

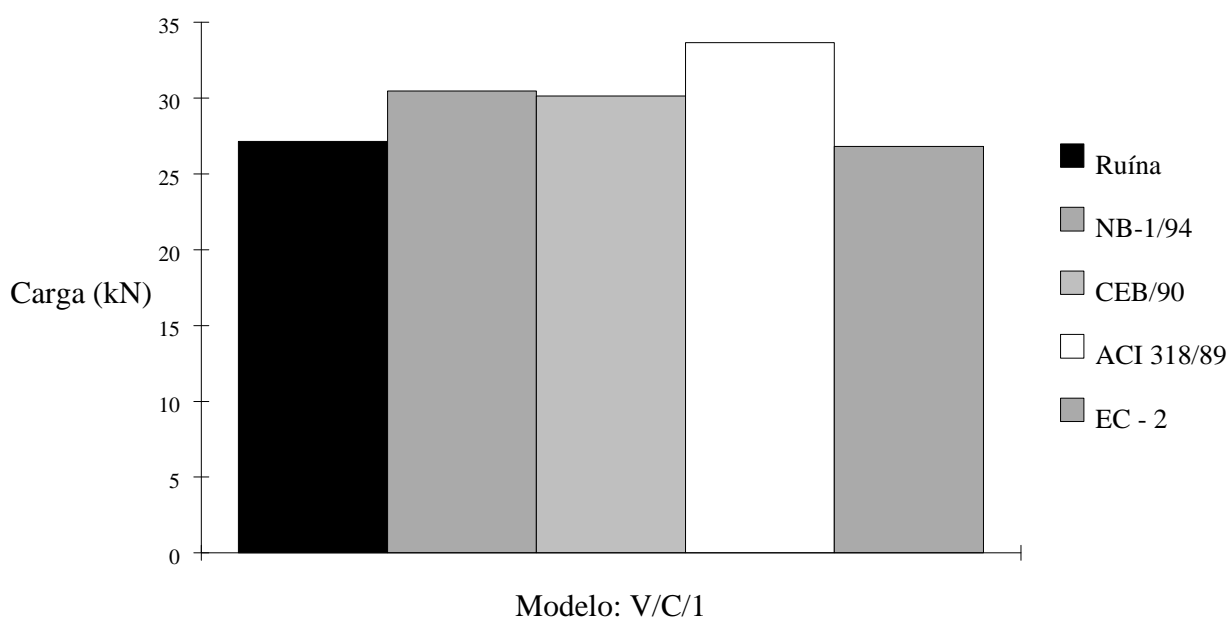

O modelo rompeu por punção.

\subsection{ENSAIOS PARA PILARES DE BORDA}

\subsubsection{ENSAIO DE TAKEYA (1981)}

Assim como em MARTINELLI (1974), a principal avaliação feita foi com relação à utilização de ganchos como armadura de punção. $\mathrm{O}$ carregamento foi 
aplicado de tal forma que a excentricidade da força resultante passasse pelo eixo de simetria da ligação (Figura 8.2).

Os ganchos e a forma de ancoragem já foram mostradas nas Figuras 8.1a e 8.1c, respectivamente. Os estribos foram distribuídos uniformemente pela região considerada crítica, a $\mathrm{h} / \operatorname{tg} 30^{\circ}$ da face do pilar, sendo h a espessura da laje.

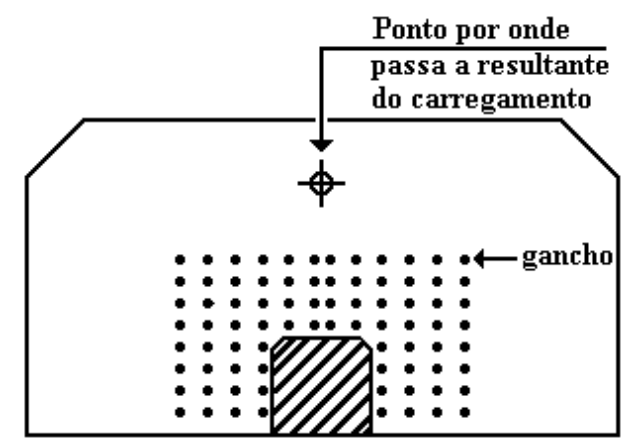

Figura 8.2 - Distribuição da armadura e excentricidade da força resultante

Os valores comparados encontram-se nas Tabelas 8.5 e 8.6. $\mathrm{Na}$ segunda coluna das tabelas é fornecida a área total de armadura de punção utilizada. Entre parênteses está definida a forma com que a ruína foi observada, tanto em relação ao ensaio, como em relação aos valores calculados através dos códigos.

TABELA 8.5 - TAKEYA (1981) em valores absolutos

\begin{tabular}{c|c|c|c|c|c|c}
\hline \hline Modelo & $\begin{array}{c}\mathrm{A}_{\text {st }} \\
\left(\mathrm{cm}^{2}\right)\end{array}$ & $\begin{array}{c}\text { Ruína } \\
(\mathrm{kN})\end{array}$ & $\begin{array}{c}\text { NB-1/94 } \\
(\mathrm{kN})\end{array}$ & $\begin{array}{c}\text { CEB/90 } \\
(\mathrm{kN})\end{array}$ & $\begin{array}{c}\text { ACI 318/89 } \\
(\mathrm{kN})\end{array}$ & $\begin{array}{c}\text { EC }-2 \\
(\mathrm{kN})\end{array}$ \\
\hline $\mathrm{T} 1$ & 0,00 & $124,16(\mathrm{pç})$ & $112,81(\mathrm{pç})$ & $157,85(\mathrm{pç})$ & $61,96(\mathrm{pç})$ & $98,29(\mathrm{pç})$ \\
$\mathrm{T} 2$ & 24,40 & $189,68(\mathrm{flex})$ & $176,54(\mathrm{ext})$ & $259,47(\mathrm{ext})$ & $93,22(\mathrm{int})$ & 158,11 (int) \\
$\mathrm{T} 3$ & 46,36 & $203,51(\mathrm{flex})$ & $173,31(\mathrm{ext})$ & $254,73(\mathrm{ext})$ & $90,68(\mathrm{int})$ & 152,39 (int) \\
\hline
\end{tabular}

Formas de ruína: pç - punção / flex - flexão / int ; ext - punção interna e externa à região armada Os modelos com armadura transversal romperam por flexão. 
TABELA 8.6 - TAKEYA (1981) em valores relativos

\begin{tabular}{c|c|c|c|c|c}
\hline \hline Modelo & $\begin{array}{c}\mathrm{A}_{\text {st }} \\
\left(\mathrm{cm}^{2}\right)\end{array}$ & $\frac{\mathrm{NB}-1 / 94}{\text { Ruína }}$ & $\frac{\mathrm{CEB} / 90}{\text { Ruína }}$ & $\frac{\text { ACI 318/89 }}{\text { Ruína }}$ & $\frac{\mathrm{EC}-2}{\text { Ruína }}$ \\
\hline $\mathrm{T} 1$ & 0,00 & 0,91 & 1,27 & 0,50 & 0,79 \\
$\mathrm{~T} 2$ & 24,40 & 0,93 & 1,37 & 0,49 & 0,83 \\
$\mathrm{~T} 3$ & 46,36 & 0,85 & 1,25 & 0,45 & 0,75 \\
\hline \hline
\end{tabular}

Os Gráficos 8.4 e 8.5 representam os valores absolutos mostrados na Tabela 8.5 através de pontos e de colunas, respectivamente.

O modelo sem armadura transversal rompeu por punção. Analogamente ao observado no item 8.1.1, o valor dado pelo texto base foi o que mais se aproximou do resultado experimental, enquanto que o CEB/90, novamente, se mostrou um método pouco seguro, uma vez que o valor dado segundo as suas recomendações ultrapassou cerca de $27 \%$ o resultado observado experimentalmente. O ACI 318/89 foi o método mais conservador. O EUROCODE N.2 apresentou um resultado ligeiramente inferior ao fornecido pelo texto base. Apesar de ser um método simplificado, que considera um acréscimo fixo de $40 \%$ no valor da tensão nominal de cisalhamento, distribuída uniformemente pelo perímetro crítico, em virtude da existência de um momento fletor aplicado à ligação, seu desempenho pode ser considerado satisfatório.

Já para elementos com armadura transversal, a ruína não ocorreu por punção e sim por flexão. Portanto era de se esperar que os valores fornecidos através dos códigos estivessem acima ou pelo menos próximos dos resultados experimentais. Observa-se que apenas o CEB/90 apresentou resultados superiores aos valores de ruína. O texto base apresentou resultados cerca de $11 \%$ inferiores aos valores experimentais. O EUROCODE N.2 apresentou, novamente, resultados ligeiramente inferiores aos do texto base. Por fim, o ACI 318/89 forneceu valores muito conservadores. 


\section{GRÁFICO 8.4 - ENSAIO DE TAKEYA (1981): EM PONTOS}

(Pilares de borda)

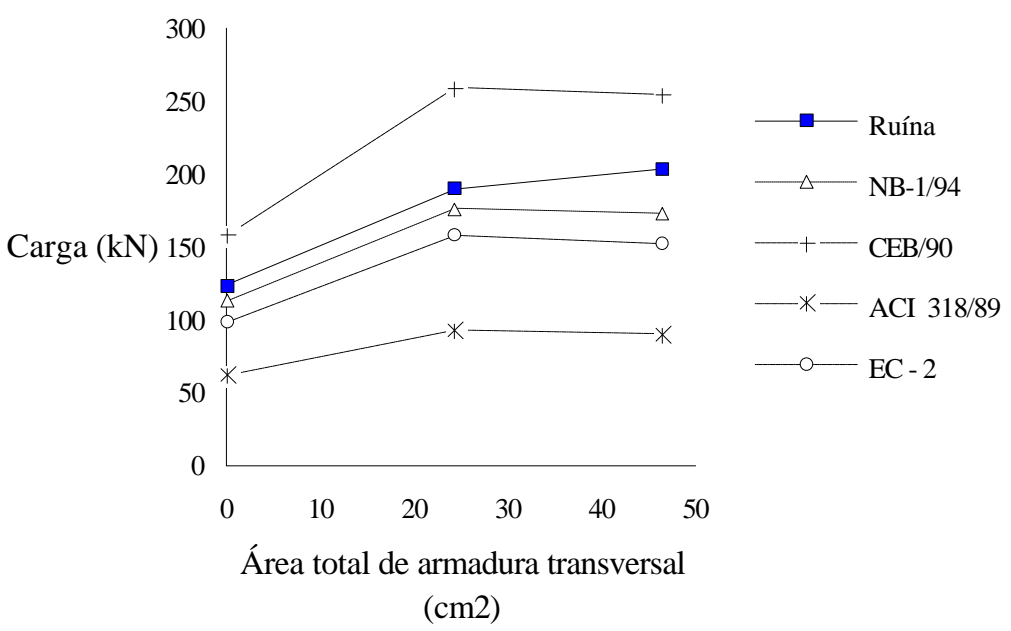

Os modelos com armadura transversal romperam por flexão.

GRÁFICO 8.5 - ENSAIO DE TAKEYA (1981): EM COLUNAS

(Pilares de borda)

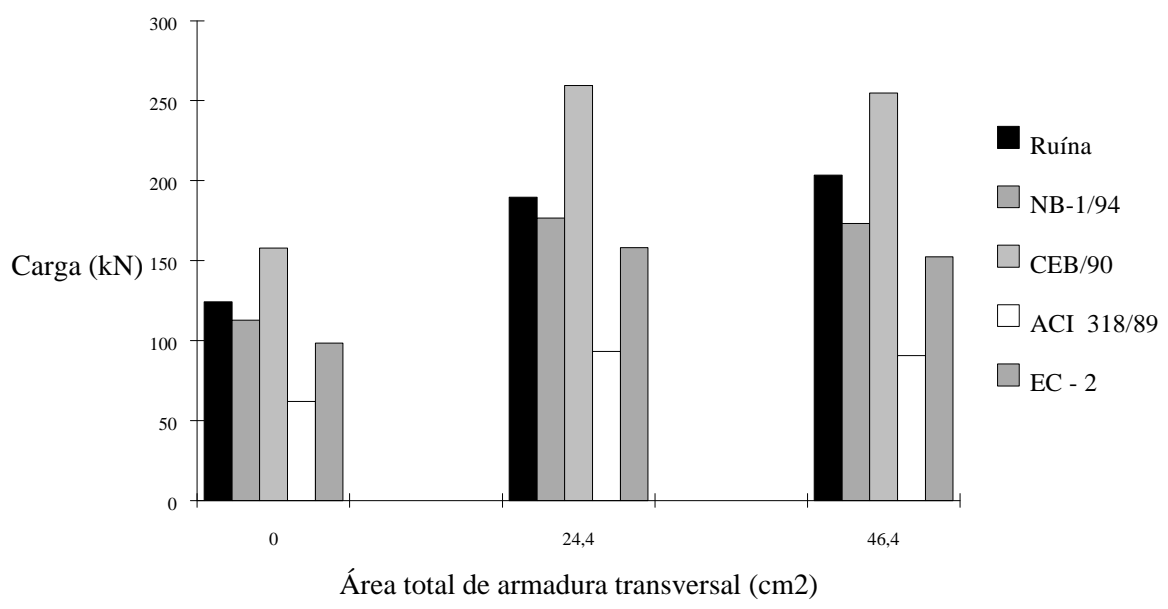

Os modelos com armadura transversal romperam por flexão.

\subsubsection{ENSAIO DE MODOTTE (1986)}

Este ensaio teve como objetivo principal avaliar a influência da posição da força resultante aplicada sobre uma laje transversalmente armada com estribos. 
A forma e a disposição desta armadura de punção é semelhante às mostradas nas Figuras 8.1a e 8.2, respectivamente. A forma de ancoragem desta armadura está ilustrada na Figura 8.1c, presente no item 8.2.1. Em um dos modelos, a resultante está localizada no plano diagonal do pilar (Figura 8.3); no outro, no plano paralelo à borda livre (Figura 8.4).

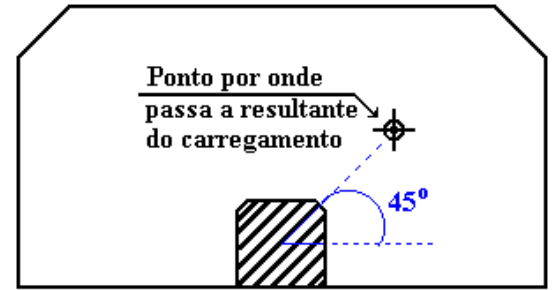

Figura 8.3 - Resultante no plano diagonal do pilar

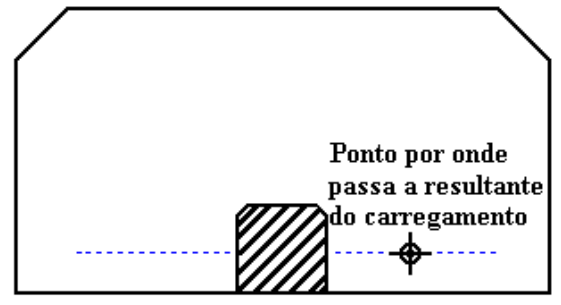

Figura 8.4 - Resultante no plano paralelo à borda livre

Em todos os ensaios, a ruína se deu por flexão. Desta forma, a princípio, não se pode comparar os valores de ruína com os valores dados pelos métodos; no entanto, para efeito de ilustração, os valores de ruína foram comparados entre si. Os valores comparados encontram-se nas Tabelas 8.7 e 8.8. Entre parênteses é definida a forma de ruína observada experimentalmente e a prevista pelos métodos.

O Gráfico 8.6 representa a comparação feita através da Tabela 8.7.

TABELA 8.7 - MODOTTE (1986) em valores absolutos

\begin{tabular}{|c|c|c|c|c|c|c|}
\hline Modelo & $\begin{array}{c}\text { Posição } \\
\text { da resultante }\end{array}$ & $\begin{array}{l}\text { Ruína } \\
(\mathrm{kN})\end{array}$ & $\begin{array}{c}\text { NB-1/94 } \\
(\mathrm{kN}) \\
\end{array}$ & $\begin{array}{c}\mathrm{CEB} / 90 \\
(\mathrm{kN}) \\
\end{array}$ & $\begin{array}{c}\text { ACI } 318 / 89 \\
(\mathrm{kN}) \\
\end{array}$ & $\begin{array}{c}\mathrm{EC}-2 \\
(\mathrm{kN}) \\
\end{array}$ \\
\hline EDL 23 & Plano diagonal & $\begin{array}{l}84,59 \\
\text { (flex) }\end{array}$ & $\begin{array}{c}153,35 \\
(p c ̧)\end{array}$ & $\begin{array}{c}162,55 \\
(\mathrm{ext})\end{array}$ & $\begin{array}{l}55,83 \\
\text { (int) }\end{array}$ & $\begin{array}{l}118,94 \\
\text { (int/ext) }\end{array}$ \\
\hline EDL 24 & $\begin{array}{c}\text { Plano paralelo à } \\
\text { borda livre }\end{array}$ & $\begin{array}{l}65,20 \\
(\text { flex }) \\
\end{array}$ & $\begin{array}{c}145,10 \\
(\mathrm{ext})\end{array}$ & $\begin{array}{c}143,50 \\
(\mathrm{ext})\end{array}$ & $\begin{array}{l}69,19 \\
\text { (int) } \\
\end{array}$ & $\begin{array}{l}143,92 \\
\text { (int/ext) }\end{array}$ \\
\hline
\end{tabular}

Formas de ruína: flex - flexão / int ; ext - punção interna e externa à região armada.

Os modelos romperam por flexão. 
TABELA 8.8 - MODOTTE (1986) em valores relativos

\begin{tabular}{c|c|c|c|c|c}
\hline \hline Modelo & $\begin{array}{c}\text { Posição } \\
\text { da força } \\
\text { resultante }\end{array}$ & $\frac{\mathrm{NB}-1 / 94}{\text { Ruína }}$ & $\frac{\mathrm{CEB} / 90}{\text { Ruína }}$ & $\frac{\mathrm{ACI} 318 / 89}{\text { Ruína }}$ & $\frac{\mathrm{EC}-2}{\text { Ruína }}$ \\
\hline $\begin{array}{c}\text { EDL } \\
23\end{array}$ & $\begin{array}{c}\text { No plano } \\
\text { diagonal }\end{array}$ & 1,81 & 1,92 & 0,66 & 1,41 \\
$\mathrm{EDL}$ & $\begin{array}{c}\text { Paralela à } \\
24\end{array}$ & 2,23 & 2,20 & 1,06 & 2,21 \\
\hline \hline
\end{tabular}

\section{GRÁFICO 8.6 - ENSAIO DE MODOTTE (1986)}

(Pilares de borda)

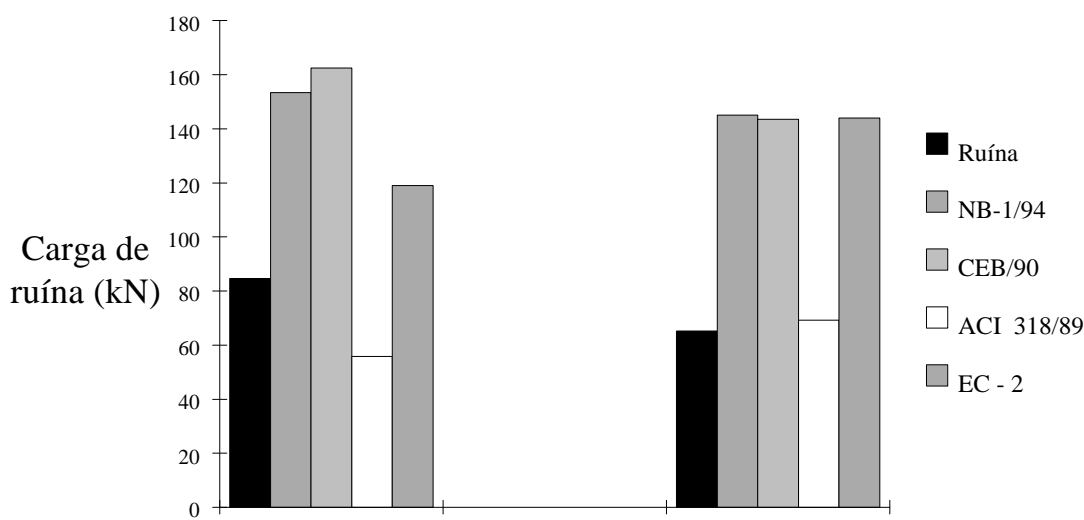

EDL 23

EDL 24

Os modelos romperam por flexão.

Uma vez que a ruína se deu por flexão, era de se esperar que os valores de ruína calculados segundo os métodos fossem superiores ao valor de ruína observado experimentalmente. Observando-se a Tabela 8.7, constata-se que apenas o ACI 318/89 apresentou um valor de ruína inferior ao observado experimentalmente (modelo EDL 23). Desta forma, pode-se tomar como indicação que este é o método mais conservador com relação aos outros apresentados. Quanto aos outros códigos, não se pode prever qual seja o mais eficiente, uma vez que a ruína não se deu por punção. 
Para o EDL 23, observou-se que a forma de ruína prevista pelo texto base foi diferente da prevista pelo CEB/90. Tal disparidade deve-se ao fato do CEB/90 limitar a tensão da armadura de punção em $300 \mathrm{MPa}$, enquanto que o texto base, para estribos, limita esta tensão em $250 \mathrm{MPa}$. Caso a limitação de $300 \mathrm{MPa}$ fosse a mesma para ambos os códigos, a forma de ruína prevista pelo texto base seria externa à região armada, atingindo cerca de $162,79 \mathrm{kN}$, valor este praticamente idêntico ao fornecido pelo CEB/90.

Já para o modelo EDL 24, tanto o texto base como o CEB/90 tratam o momento fletor paralelo à borda livre de uma maneira semelhante. Convém destacarse aqui que a semelhança deste tratamento apenas se dá devido ao fato do pilar ser quadrado. Sendo $\mathrm{c}_{1}$ e $\mathrm{c}_{2}$ os lados do pilar, perpendicular e paralelo à borda livre, respectivamente, enquanto o $\mathrm{CEB} / 90$ utiliza um coeficiente $\mathrm{K}$, dado em função de uma relação definida por $\mathrm{c}_{1} / 2 \mathrm{c}_{2}$, o texto base utiliza um coeficiente $\mathrm{K}_{2}$, análogo a $\mathrm{K}$, só que calculado em função da relação $c_{2} / 2 c_{1}$. Portanto, o fato que explicaria o valor superior do texto base em relação ao CEB/90, contrário ao observado em TAKEYA (1981), é que os coeficientes utilizados pelo texto base para calcular a resistência da ligação são ligeiramente superiores aos utilizados pelo CEB/90.

Apesar do EUROCODE N.2 ter apresentado resultados coerentes com relação aos dois modelos ensaiados, este código trata de forma muito simplificada a influência da direção em que o momento fletor atua, apresentando o mesmo coeficiente (igual a 1,4 para pilares de borda) para qualquer que seja a direção em que atue o momento fletor.

\subsubsection{ENSAIO DE STAMENKOVIC; CHAPMAN (1974)}

Ensaiou-se um pilar de borda de forma semelhante à mencionada no item 8.1.2, com a carga sendo aplicada diretamente à laje através do pilar. Desta forma, não se considerou a existência de momentos fletores que estivessem sendo aplicados diretamente à ligação. Portanto, com relação ao EUROCODE N.2, o valor de $\beta$ utilizado nos cálculos foi adotado como sendo unitário. O modelo rompeu por punção e os valores comparados encontram-se nas Tabelas 8.9 e 8.10. 
TABELA 8.9 - STAMENKOVIC; CHAPMAN (1974) em valores absolutos

\begin{tabular}{c|c|c|c|c|c}
\hline \hline Modelo & Ruína (kN) & NB-1/94 (kN) & CEB/90 (kN) & ACI 318/89 (kN) & EC - 2(kN) \\
\hline V/E/1 & 74,73 & 58,60 & 57,95 & 50,50 & 42,00 \\
\hline \multicolumn{6}{c}{ O modelo rompeu por punção. } \\
\hline \hline
\end{tabular}

TABELA 8.10 - STAMENKOVIC; CHAPMAN (1974) em valores relativos

\begin{tabular}{c|c|c|c|c}
\hline \hline Modelo & $\frac{\text { NB }-1 / 94}{\text { Ruína }}$ & $\frac{\text { CEB / 90 }}{\text { Ruína }}$ & $\frac{\text { ACI 318/89 }}{\text { Ruína }}$ & $\frac{\text { EC }-2}{\text { Ruína }}$ \\
\hline V/E/1 & 0,78 & 0,78 & 0,68 & 0,56 \\
\hline \hline
\end{tabular}

Observa-se que o CEB/90 e o texto base apresentaram resultados praticamente iguais. Em virtude da não ocorrência de momentos fletores, o ACI 318/89 deixou de ser o método mais conservador, ultrapassando o valor dado pelo EUROCODE N.2, mas ao contrário do observado no item 8.1.2, o valor dado segundo o ACI 318/89 não ultrapassou os valores fornecidos segundo o texto base e o CEB/90. Nenhum dos valores calculados segundo os métodos ultrapassou o valor de ruína observado experimentalmente. O Gráfico 8.7 ilustra a comparação feita através da Tabela 8.9 .

GRÁFICO 8.7 - ENSAIO DE STAMENKOVIC; CHAPMAN (1974)

(Pilar de borda)

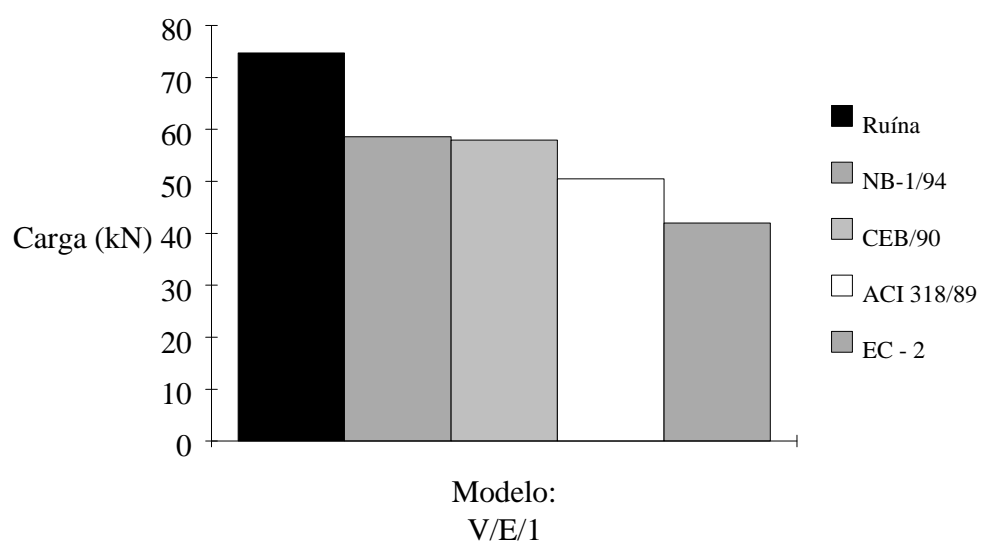

O modelo rompeu por punção. 


\subsubsection{ENSAIO DE LIBÓRIO (1985)}

Estes ensaios tiveram como objetivo principal avaliar a influência da variação na proporção entre os lados do pilar na resistência da ligação.

As proporções analisadas foram: 1:4, 1:3 e 1:2, onde o maior lado é sempre perpendicular à borda livre (Figura 8.5). A forma de carregamento dos modelos foi análoga à observada em TAKEYA (1981). Observou-se um acréscimo linear na carga de ruína à medida em que se aumentou a proporção entre os lados do pilar. Observa-se, ainda, que foram respeitadas as recomendações referentes ao EUROCODE N.2, com relação a pilares alongados. A ruína em todos os elementos se deu por punção.

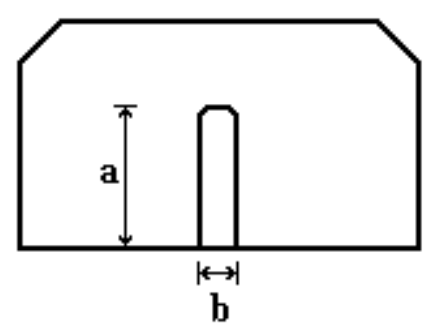

$a / b=4$

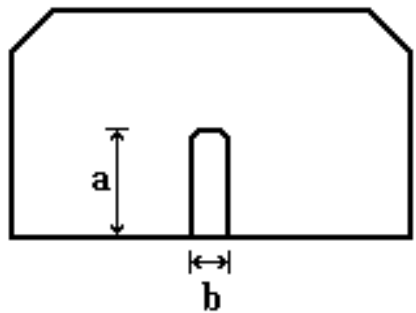

$\mathbf{a} / \mathbf{b}=\mathbf{3}$

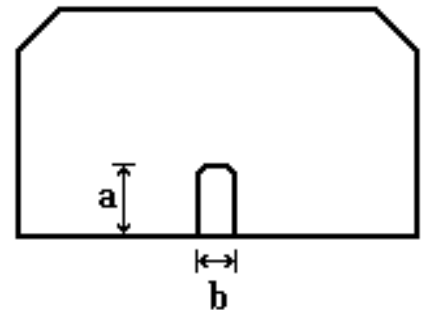

$\mathbf{a} / \mathbf{b}=2$

Figura 8.5 - Representação dos modelos

Os valores comparados encontram-se nas Tabelas 8.11 e 8.12 .

TABELA 8.11 - LIBÓRIO (1985) em valores absolutos

\begin{tabular}{c|c|c|c|c|c|c}
\hline \hline Modelo & Relação & Ruína & NB-1/94 & CEB/90 & ACI 318/89 \\
& $\mathrm{a} / \mathrm{b}$ & $(\mathrm{kN})$ & $(\mathrm{kN})$ & $(\mathrm{kN})$ & EC - 2 (kN) \\
& 4 & 89,23 & 72,86 & 87,40 & 31,69 & 36,27 \\
EDL 29 & 3 & 74,50 & 55,16 & 82,79 & 26,81 & 32,40 \\
EDL 30 & 2 & 56,23 & 46,09 & 82,63 & 21,27 & 46,83 \\
EDL 31 & Os modelos romperam por punção. \\
\hline \hline
\end{tabular}


TABELA 8.12 - LIBÓRIO (1985) em valores relativos

\begin{tabular}{c|c|c|c|c|c}
\hline \hline Modelo & $\begin{array}{c}\text { Relação } \\
\text { a/b }\end{array}$ & $\frac{\text { NB-1/94 }}{\text { Ruína }}$ & $\frac{\text { CEB / 90 }}{\text { Ruína }}$ & $\frac{\text { ACI 318 / 89 }}{\text { Ruína }}$ & $\frac{\text { EC-2 }}{\text { Ruína }}$ \\
\hline EDL 29 & 4 & 0,82 & 0,98 & 0,36 & 0,41 \\
EDL 30 & 3 & 0,74 & 1,11 & 0,36 & 0,43 \\
EDL 31 & 2 & 0,82 & 1,47 & 0,38 & 0,83 \\
\hline \hline
\end{tabular}

Os Gráficos 8.8 e 8.9 ilustram a comparação feita através da Tabela 8.11 , respectivamente, por pontos e por colunas.

\section{GRÁFICO 8.8 - ENSAIO DE LIBÓRIO (1985): EM PONTOS}

(Pilares de borda)

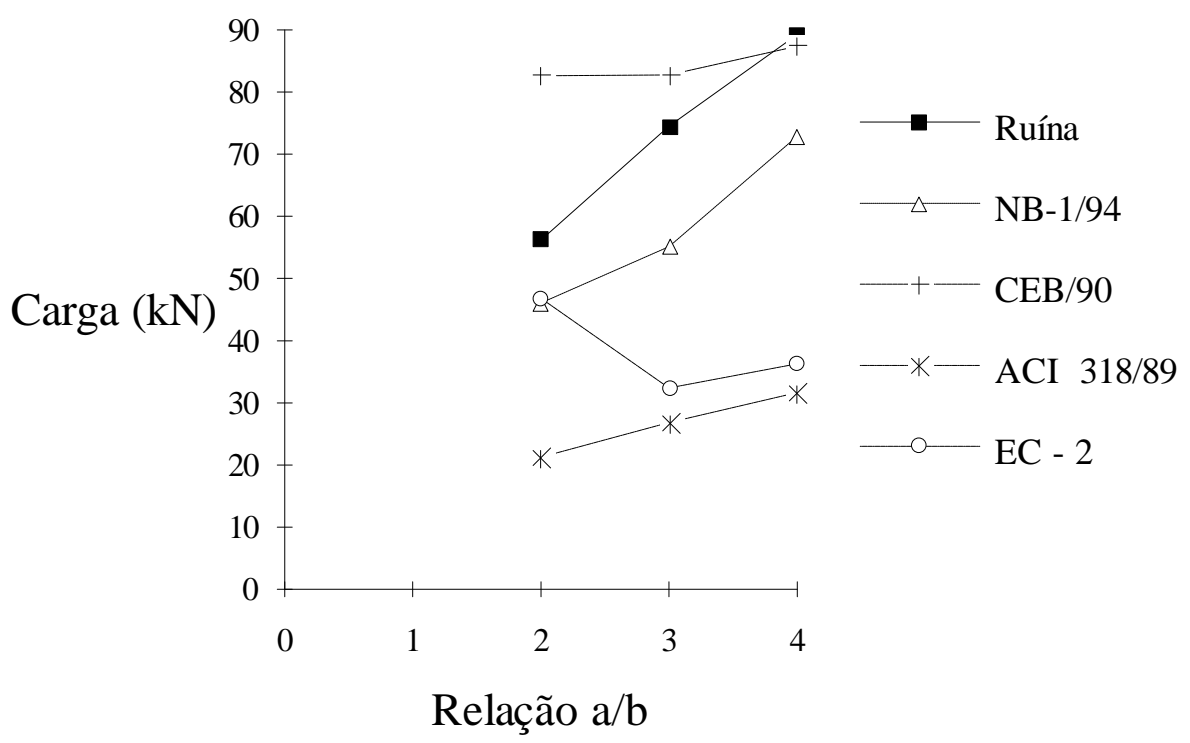

Os modelos romperam por punção. 


\section{GRÁFICO 8.9 - ENSAIO DE LIBÓRIO (1985): EM COLUNAS}

(Pilares de borda)

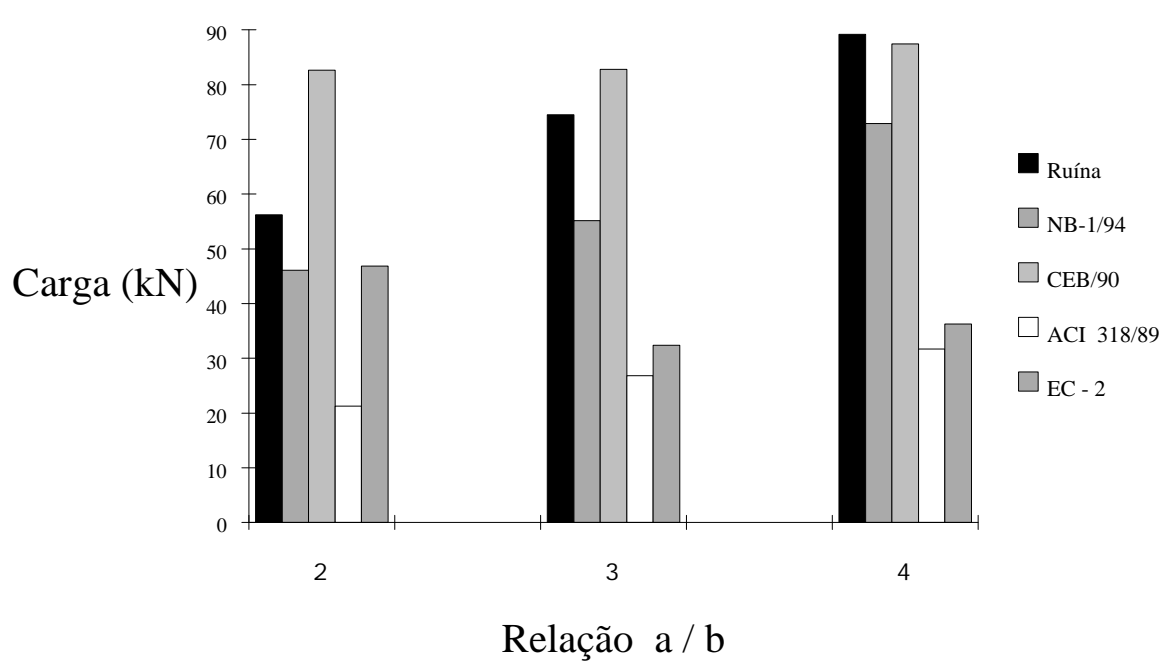

Os modelos romperam por punção.

Conforme já visto anteriormente, para relações a/b inferiores a 4 , o $\mathrm{CEB} / 90$ fornece valores que ultrapassam substancialmente os valores experimentais. O texto base foi o que apresentou os melhores resultados, mantendo a proporção entre seus resultados e os resultados experimentais. Observa-se que quanto maior a relação a/b, menor é a diferença entre o CEB/90 e o texto base. Isto se explica porque, pelas características do ensaio, quanto maior a relação $a / b$, menor era a excentricidade da força resultante gerada pelo carregamento e, conseqüentemente, menor a influência do momento fletor perpendicular à borda livre.

O ACI 318/89 foi o método que forneceu os resultados mais conservadores, uma vez que ele adota uma distribuição linear das tensões ao longo do perímetro crítico.

O EUROCODE N.2 apresentou um bom resultado para a relação a/b igual a 2, chegando praticamente a coincidir com o texto base. Porém, em virtude de suas recomendações para pilares alongados serem mais conservadoras, os valores fornecidos por este método acabaram se aproximando dos fornecidos pelo ACI 318/89 para relações a/b superiores a 2. 


\subsection{ENSAIOS PARA PILARES INTERNOS}

\subsubsection{ENSAIO DE GOMES et al. (1994)}

Este ensaio está descrito em GOMES et al. (1994). O carregamento foi aplicado concentricamente e foram utilizados conectores tipo pino como armadura de punção, distribuídos radialmente em relação ao pilar (Figura 8.6). A principal característica aqui avaliada foi a presença da armadura de punção em ligações sem a transferência de momentos fletores da laje para o pilar. Os modelos ensaiados romperam por punção, sendo que, para a laje com armadura de punção, a ruína ocorreu além da região transversalmente armada.

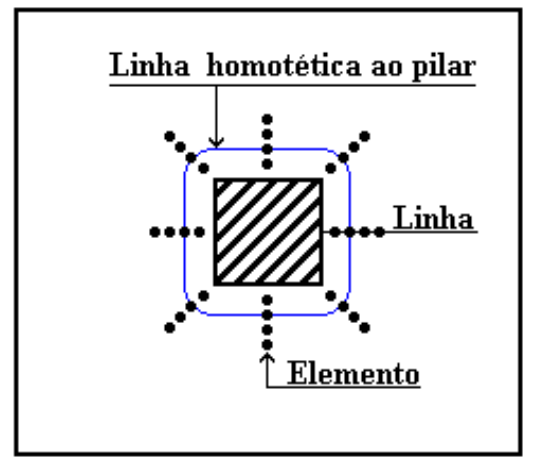

a) Distribuição radial

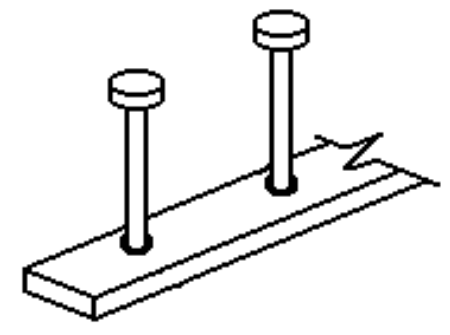

b) Conectores tipo pino

Figura 8.6 - Distribuição e tipo dos conectores

Os valores comparados encontram-se nas Tabelas 8.13 e 8.14 .

TABELA 8.13 - GOMES et al. (1994) em valores absolutos

\begin{tabular}{c|c|c|c|c|c|c}
\hline \hline Modelo & $\begin{array}{c}\mathrm{A}_{\mathrm{St}} \\
\left(\mathrm{cm}^{2}\right)\end{array}$ & $\begin{array}{c}\text { Ruína } \\
(\mathrm{kN})\end{array}$ & $\begin{array}{c}\text { NB-1/94 } \\
(\mathrm{kN})\end{array}$ & $\begin{array}{c}\text { CEB/90 } \\
(\mathrm{kN})\end{array}$ & $\begin{array}{c}\text { ACI 318/89 } \\
(\mathrm{kN})\end{array}$ & $\begin{array}{c}\text { EC - } 2 \\
(\mathrm{kN})\end{array}$ \\
\hline L-12 & 0,00 & $650,00(\mathrm{pç})$ & $632,43(\mathrm{pç})$ & $625,51(\mathrm{pç})$ & $474,86(\mathrm{pç})$ & $467,45(\mathrm{pç})$ \\
L-16 & 25,60 & $1140,00(\mathrm{ext})$ & $960,42(\mathrm{ext})$ & $949,87(\mathrm{ext})$ & $650,99(\mathrm{int})$ & $682,55($ int $)$ \\
\hline
\end{tabular}

Formas de ruína: pç - punção / int ; ext - punção interna e externa à região armada.

Os modelos romperam por punção. 
TABELA 8.14 - GOMES et al. (1994) em valores relativos

\begin{tabular}{c|c|c|c|c|c}
\hline \hline Modelo & $\begin{array}{c}\mathrm{A}_{\text {St }} \\
\left(\mathrm{cm}^{2}\right)\end{array}$ & $\frac{\mathrm{NB}-1 / 94}{\text { Ruína }}$ & $\frac{\mathrm{CEB} / 90}{\text { Ruína }}$ & $\frac{\text { ACI 318/89 }}{\text { Ruína }}$ & $\frac{\mathrm{EC}-2}{\text { Ruína }}$ \\
\hline L-12 & 0,00 & 0,97 & 0,96 & 0,73 & 0,72 \\
L-16 & 25,60 & 0,84 & 0,83 & 0,57 & 0,60 \\
\hline
\end{tabular}

Os Gráficos 8.10 e 8.11 representam os valores absolutos mostrados na Tabela 8.13, através de pontos e de colunas, respectivamente.

Para lajes sem armadura de punção, devido ao fato de não haver transferência de momentos fletores da laje ao pilar, os métodos se dividiram, basicamente, em duas classes: os mais próximos e os mais distantes dos resultados experimentais. Na classe dos mais distantes, estão o EUROCODE N.2 e o ACI 318/89, atingindo cerca de 72,5\%, em média, do valor de ruína observado em ensaio. Já os métodos mais próximos, que incluem o CEB/90 e o texto base da NB1/94, se aproximaram bastante dos valores de ruína observados em ensaio, atingindo cerca de $97,5 \%$, em média, do valor de ruína observado em ensaio. Observa-se através dos gráficos que estes métodos praticamente coincidem.

Para lajes com armadura de punção, observou-se esta mesma divisão em classes, sendo que, os valores fornecidos pelo texto base e pelo CEB/90 se distanciaram um pouco dos valores experimentais, atingindo cerca de 87,5\%, em média, dos valores de ruína observados em ensaio. Devido ao fato do ACI 318/89 e do EUROCODE N.2 limitarem o valor do acréscimo de resistência proporcionado pela presença da armadura de punção na região armada, seus valores se distanciaram mais ainda dos resultados experimentais. Além disso, a forma de ruína prevista por eles não coincidiu com a forma de ruína ocorrida no ensaio. Caso essa limitação não fosse adotada, a carga de ruína dada pelo EUROCODE N.2 atingiria cerca de $71 \%$ da carga de ruína observada em ensaio, ocorrendo esta na região além da armadura de punção. No entanto, para o ACI, a ruína ainda ocorreria na região armada, atingindo cerca de $73 \%$ do valor observado experimentalmente. 
GRÁFICO 8.10 - ENSAIO DE GOMES et al. (1994): EM PONTOS (Pilares internos)

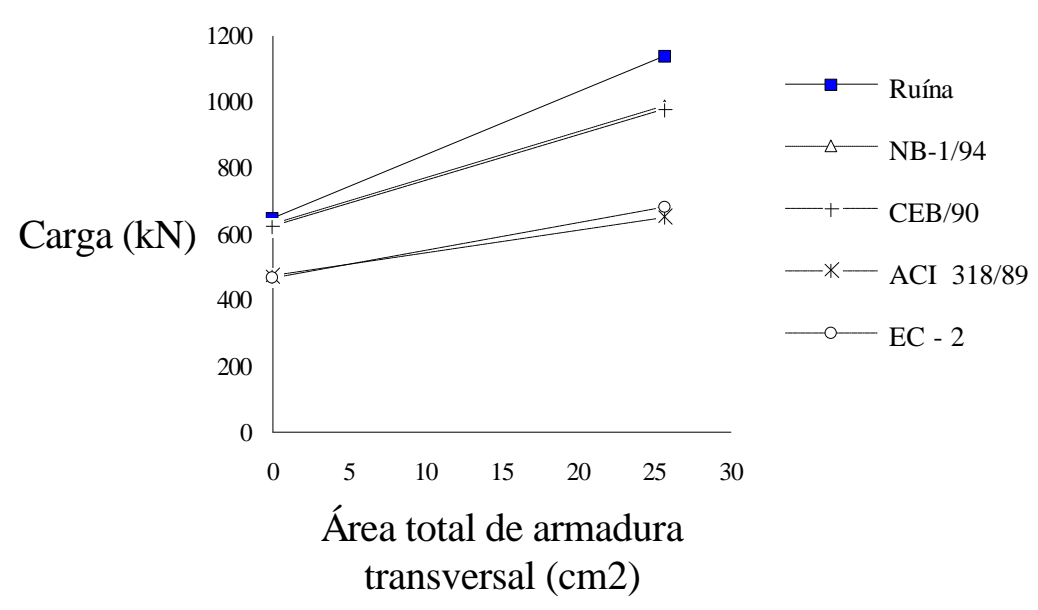

Os modelos romperam por punção.

GRÁFICO 8.11 - ENSAIO DE GOMES et al. (1994): EM COLUNAS (Pilares internos)

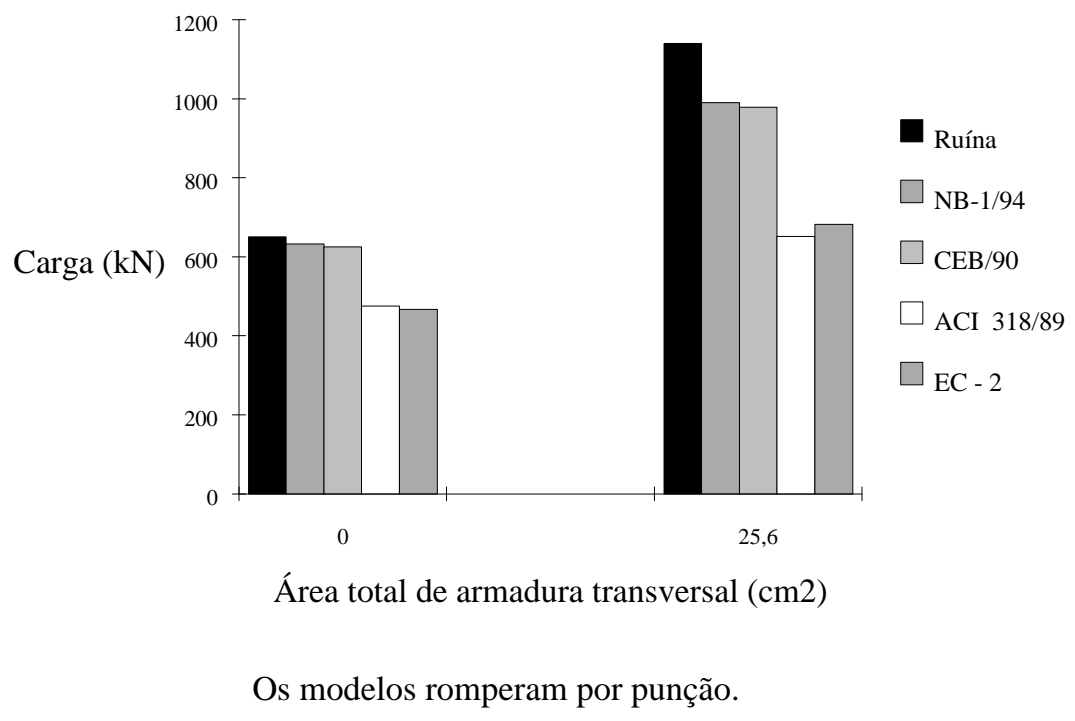

\subsubsection{ENSAIO DE STAMENKOVIC; CHAPMAN (1974)}

Ensaiaram-se pilares internos com forma quadrada e retangular, com carregamento concêntrico e sem armadura de punção. Todos os modelos romperam por punção. Os valores comparados encontram-se nas Tabelas 8.15 e 8.16. 
TABELA 8.15 - STAMENKOVIC; CHAPMAN (1974) em valores absolutos

\begin{tabular}{c|c|c|c|c|c|c}
\hline \hline Modelo & $\begin{array}{c}\text { Seção do pilar } \\
\left(\mathrm{cm}^{2}\right)\end{array}$ & $\begin{array}{c}\text { Ruína } \\
(\mathrm{kN})\end{array}$ & $\begin{array}{c}\mathrm{NB}-1 / 94 \\
(\mathrm{kN})\end{array}$ & $\begin{array}{c}\mathrm{CEB} / 9 \\
0\end{array}$ & $\begin{array}{c}\text { ACI 318/89 } \\
(\mathrm{kN})\end{array}$ & $\begin{array}{c}\text { EC - } 2 \\
(\mathrm{kN})\end{array}$ \\
\hline $\mathrm{V} / \mathrm{kN} / 2$ & $12,7 \times 12,7$ & 117,43 & 113,32 & 112,07 & 71,28 & 63,01 \\
$\mathrm{~V} / \mathrm{Ir} / 1$ & $15,24 \times 7,62$ & 108,54 & 107,45 & 106,29 & 65,33 & 61,81 \\
\hline
\end{tabular}

TABELA 8.16 - STAMENKOVIC; CHAPMAN (1974) em valores relativos

\begin{tabular}{c|c|c|c|c|c}
\hline \hline Modelo & Seção do pilar $\left(\mathrm{cm}^{2}\right)$ & $\frac{\mathrm{NB}-1 / 94}{\text { Ruína }}$ & $\frac{\text { CEB / 90 }}{\text { Ruína }}$ & $\frac{\text { ACI 318/89 }}{\text { Ruína }}$ & $\frac{\text { EC-2 }}{\text { Ruína }}$ \\
\hline V/I/2 & $12,7 \times 12,7$ & 0,97 & 0,95 & 0,61 & 0,54 \\
V/Ir/1 & $15,24 \times 7,62$ & 0,99 & 0,98 & 0,60 & 0,57 \\
\hline
\end{tabular}

Os modelos romperam por punção.

A comparação feita através da Tabela 8.15 é representada, a seguir, pelo Gráfico 8.12.

\section{GRÁFICO 8.12 - ENSAIO DE STAMENKOVIC, CHAPMAN (1974) \\ (Pilares internos)}

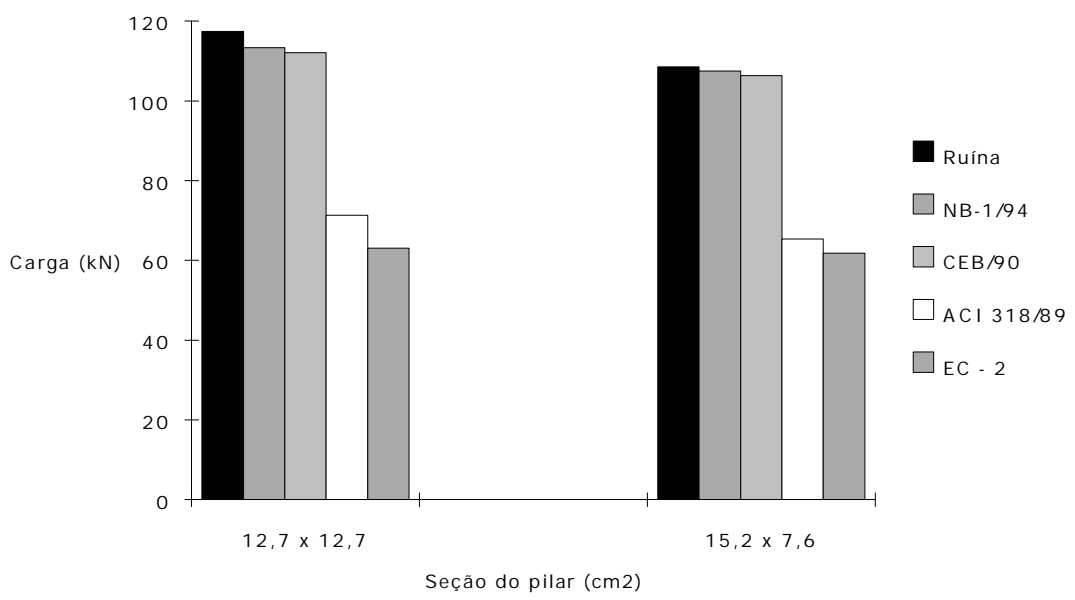

Os modelos romperam por punção. 
O comportamento dos modelos observados neste ensaio é, basicamente, o mesmo que o observado em GOMES et al. (1994). Destaca-se apenas que o texto base e o CEB/90 apresentaram excelentes resultados.

\subsubsection{ENSAIO DE GOMES (1991)}

Neste trabalho, analisa-se a resistência à punção em lajes com armadura de punção. Foram ensaiadas ligações com pilares internos submetidos a carregamentos concêntricos. Foram utilizados segmentos de um perfil metálico tipo "I" como armadura de punção (Figura 2.19). Foi adaptada a resistência do concreto, fornecida através de corpos-de-prova cúbicos para seu valor correspondente a corposde-prova cilíndricos. Os modelos romperam por punção.

As principais variáveis foram: área, número e disposição da armadura de punção (radial e em cruz). Os valores comparados encontram-se nas Tabelas 8.17 e 8.18. A quantidade de armadura dada na segunda coluna da Tabela 8.17 é a quantidade de armadura disposta por cada linha homotética ao pilar. Na terceira coluna, o termo n quantifica o número de linhas homotéticas ao pilar e que passam pela armadura transversal. Na quarta coluna está apresentada a forma com que a armadura foi distribuída.

TABELA 8.17 - GOMES (1991) em valores absolutos

\begin{tabular}{|c|c|c|c|c|c|c|c|c|}
\hline Laje & $\begin{array}{c}\mathrm{A}_{\mathrm{st}} / \mathrm{cam} . \\
\left(\mathrm{cm}^{2}\right)\end{array}$ & $\mathrm{n}$ & Disp. & $\begin{array}{l}\text { Ruína } \\
\text { (kN) }\end{array}$ & $\begin{array}{c}\text { NB-1/94 } \\
(\mathrm{kN})\end{array}$ & $\begin{array}{c}\text { CEB/90 } \\
(\mathrm{kN})\end{array}$ & $\begin{array}{c}\text { ACI } 318 / 89 \\
(\mathrm{kN})\end{array}$ & $\begin{array}{c}\mathrm{EC}-2 \\
(\mathrm{kN})\end{array}$ \\
\hline 01 & 0,00 & - & - & $560(\mathrm{pç})$ & 637 (pç) & $630(\mathrm{pç})$ & 490 (pç) & $494(\mathrm{pç})$ \\
\hline 02 & 2,26 & 2 & cruz $^{*}$ & 693 (int) & 664 (int) & 648 (int) & 388 (int) & 597 (ext) \\
\hline 03 & 3,01 & 2 & $\mathrm{cruz}^{*}$ & 773 (int /ext) & 773 (int/ext) & 765 (int/ext) & 477 (int) & 686 (ext) \\
\hline 04 & 4,02 & 3 & cruz & 853 (ext) & $839(\mathrm{ext})$ & $830(\mathrm{ext})$ & 539 (int) & 676 (int) \\
\hline 05 & 6,28 & 4 & cruz & 853 (ext) & 862 (ext) & 853 (ext) & 683 (int) & 711 (int) \\
\hline 06 & 6,28 & 4 & radial & 1040 (ext) & $1003(\mathrm{ext})$ & 992 (ext) & 708 (int) & 752 (int) \\
\hline 07 & 9,05 & 5 & radial* & 1120 (ext) & 1076 (ext) & 1064 (ext) & 674 (int) & 697 (int) \\
\hline 08 & 9,05 & 6 & radial* & 1200 (ext) & 1186 (ext) & 1173 (ext) & 678 (int) & 704 (int) \\
\hline 10 & 2,26 & 5 & radial* & 800 (int) & 673 (int) & 657 (int) & 394 (int) & 686 (int) \\
\hline 11 & 3,01 & 5 & radial* & 907 (int) & 744 (int) & 727 (int) & 449 (int) & 675 (int) \\
\hline
\end{tabular}


Observações:

•Formas de ruína: pç - punção / int ; ext - punção interna e externa à região armada.

-Número de elementos dispostos em cada linha homotética ao pilar: 8 .

-Cruz*: como a distância circunferencial entre os conectores mais externos é inferior a 2d, calculou-se como sendo uma distribuição radial adaptada.

-Radial*: apesar da distância circunferencial ser superior a 2d, a disposição adotada para o cálculo foi a radial.

-Os modelos romperam por punção.

A laje 09 não estava com a distribuição da armadura de punção em um padrão adequado para que se calculasse segundo as recomendações dos códigos.

TABELA 8.18 - GOMES (1991) em valores relativos

\begin{tabular}{c|c|c|c|c|c|c|c}
\hline \hline & & & & & & & \\
Laje & Ast/cam. & $\mathrm{n}$ & Disp. & NB-1/94 & CEB/90 & ACI 318/89 & EC - 2 \\
\hline \hline 1 & 0,00 & - & - & 1,14 & 1,13 & 0,88 & 0,88 \\
2 & 2,26 & 2 & cruz* $^{*}$ & 0,96 & 0,94 & 0,56 & 0,86 \\
3 & 3,01 & 2 & cruz* $^{*}$ & 1,00 & 0,99 & 0,62 & 0,89 \\
4 & 4,02 & 3 & cruz & 0,98 & 0,97 & 0,63 & 0,79 \\
5 & 6,28 & 4 & cruz & 1,01 & 1,00 & 0,80 & 0,83 \\
6 & 6,28 & 4 & radial & 0,96 & 0,95 & 0,68 & 0,72 \\
7 & 9,05 & 5 & radial* & 0,96 & 0,95 & 0,60 & 0,62 \\
8 & 9,05 & 6 & radial* & 0,99 & 0,98 & 0,57 & 0,59 \\
10 & 2,26 & 5 & radial* & 0,84 & 0,82 & 0,49 & 0,86 \\
11 & 3,01 & 5 & radial* & 0,82 & 0,80 & 0,50 & 0,74 \\
\hline
\end{tabular}

Os Gráficos 8.13 e 8.14 representam, em pontos e em colunas, respectivamente, a comparação feita para os modelos com armadura de punção disposta em cruz. Já os Gráficos 8.15 e 8.16 representam, em pontos e em colunas, respectivamente, a comparação feita para modelos com armadura de punção disposta radialmente. 


\section{GRÁFICO 8.13 - ENSAIO DE GOMES (1991): EM PONTOS}

(Pilares internos - armadura disposta em cruz)

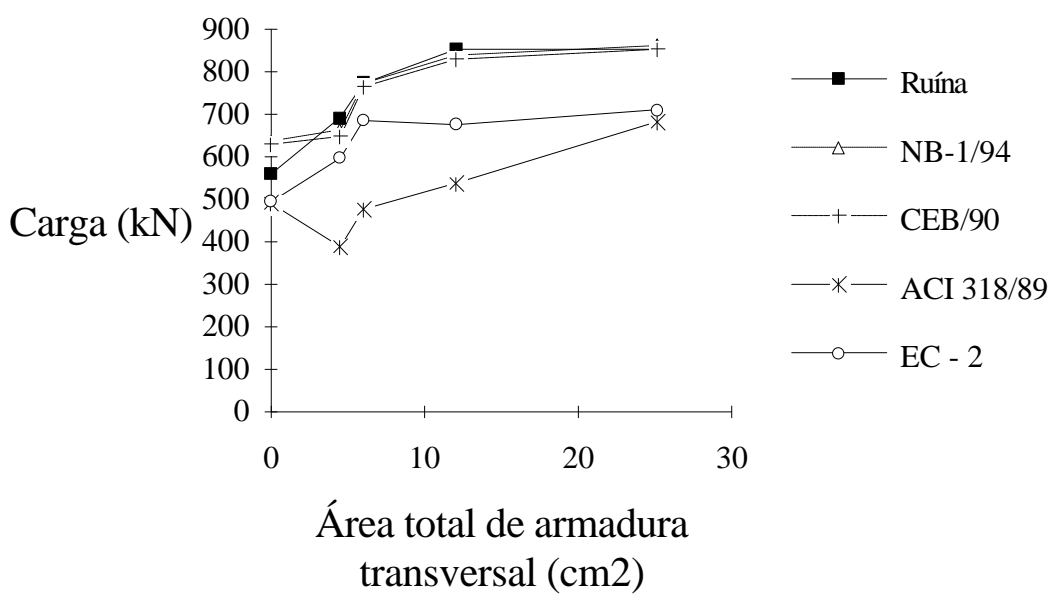

Os modelos romperam por punção.

\section{GRÁFICO 8.14 - ENSAIO DE GOMES (1991): EM COLUNAS}

(Pilares internos - armadura disposta em cruz)

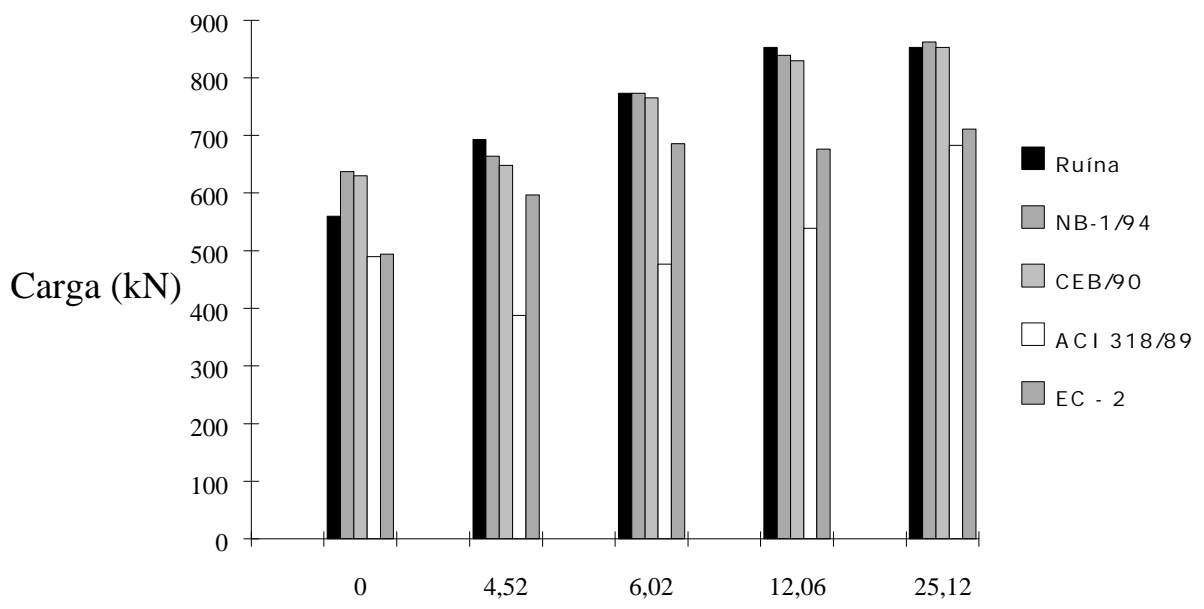

Área total de armadura transversal $(\mathrm{cm} 2)$

Os modelos romperam por punção. 
GRÁFICO 8.15 - ENSAIO DE GOMES (1991): EM PONTOS

(Pilares internos - armadura disposta radialmente)

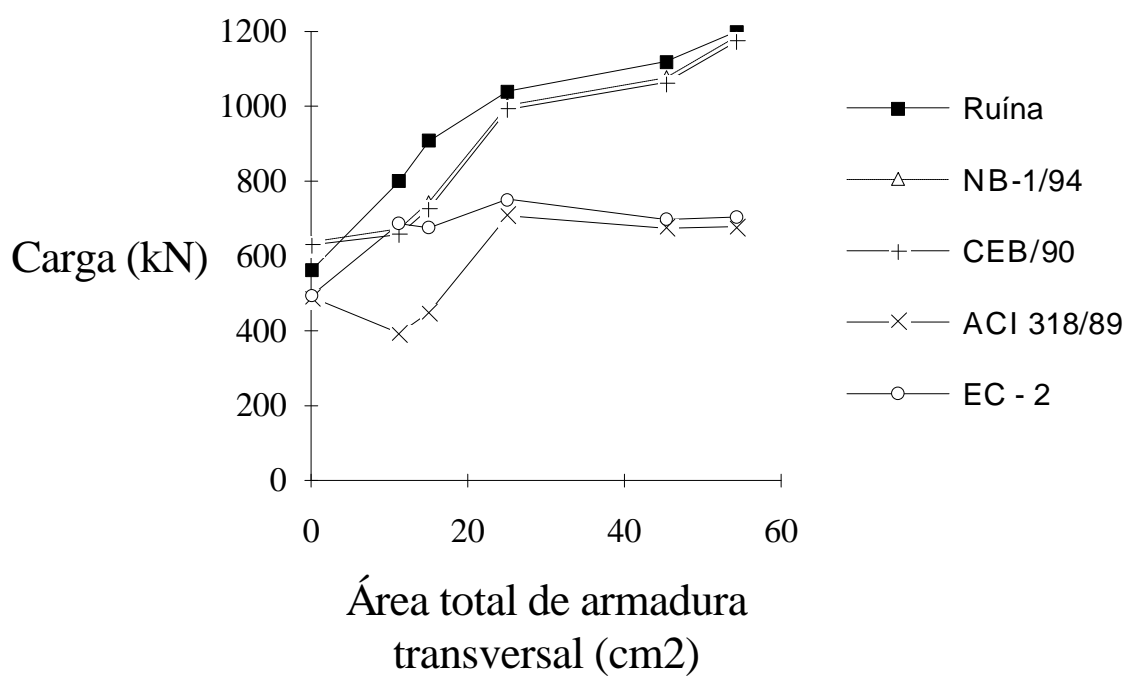

Os modelos romperam por punção.

GRÁFICO 8.16 - ENSAIO DE GOMES (1991): EM COLUNAS (Pilares internos - armadura disposta radialmente)

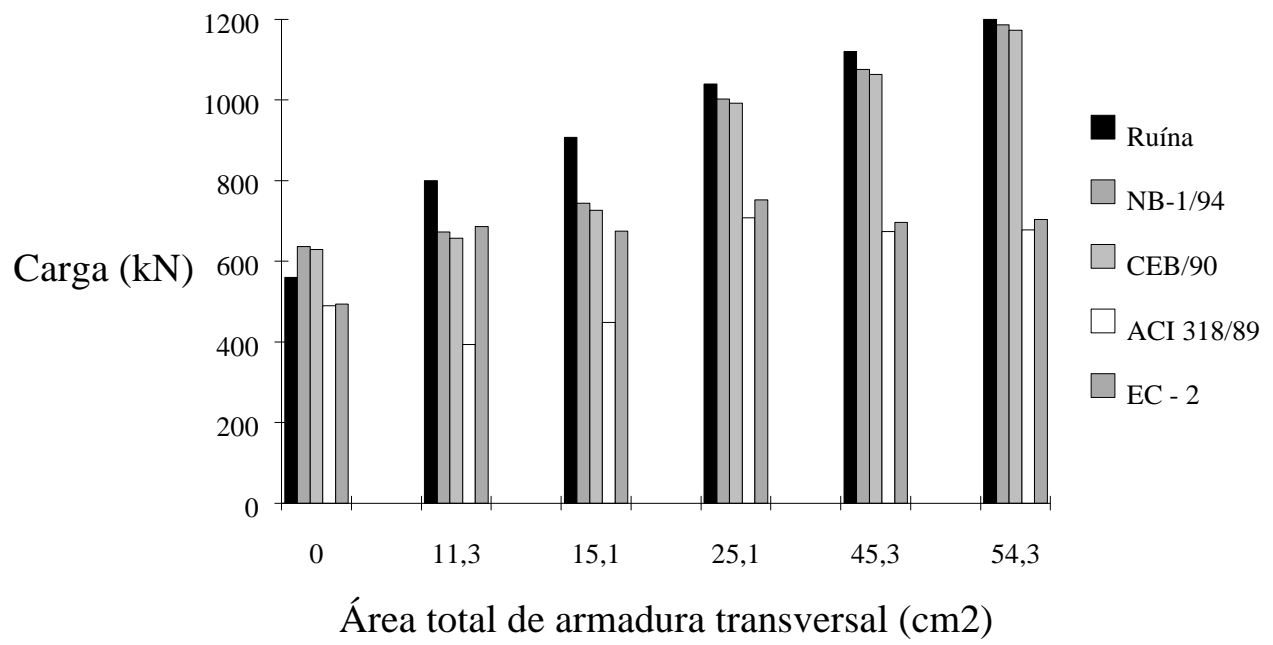

Os modelos romperam por punção. 
O comportamento observado para elementos sem armadura de punção foi semelhante ao observado em GOMES (1994), sendo que, para este modelo, os valores dados segundo o texto base e o CEB/90 ultrapassaram um pouco os resultados experimentais. No entanto, analogamente ao visto no item 8.1.2, talvez a adaptação dos valores de resistência do concreto possa ter influenciado esse resultado.

Para os modelos com armadura de punção, o texto base e o CEB/90 forneceram excelentes aproximações, prevendo com exatidão a forma com que se daria a ruína.

Já o EUROCODE N.2, apesar de fornecer resultados razoáveis, não apresentou coerência entre a forma de ruína prevista e a ocorrida. Quanto ao ACI 318/89, com a exceção do ensaio referente ao modelo sem armadura de punção, no qual o seu valor se aproximou do fornecido pelo EUROCODE N.2, ele foi o critério mais conservador, além de também não fornecer com exatidão a forma com que se daria a ruína.

Ainda com relação ao ACI 318/89, observa-se, nos Gráficos 8.13 e 8.15, que com a inclusão de uma pequena quantidade de armadura transversal, ao contrário do código fornecer um valor de resistência superior ao da laje sem armadura de punção, ele forneceu um valor menor. Isto pode ser explicado pelo seguinte fato: com a inclusão da armadura transversal, o ACI 318/89 diminui o valor da resistência do concreto, com relação a uma laje sem armadura de punção. Sendo assim, para elementos com baixas taxas de armadura transversal, este fato provoca uma diminuição na resistência da ligação, conforme observado nos Gráficos 8.13 e 8.15. Já para taxas de armadura maiores, o acréscimo de resistência proporcionado pela presença dessa armadura acaba por corrigir esta distorção. 


\section{CONCLUSÕES}

A utilização de lajes-cogumelo apresenta numerosas vantagens, sendo que este sistema estrutural pode se associar a outros, de forma a minimizar o efeito de suas desvantagens. Um exemplo disto é a sua associação com vigas de borda. Esta associação melhora, de forma significativa, o comportamento estrutural do edifício como, por exemplo, com relação aos aspectos de deformabilidade e de estabilidade global.

A punção em lajes é uma ruína do tipo frágil. No entanto, ensaios experimentais têm mostrado que a utilização de armaduras de punção, além de elevar a resistência da ligação, pode lhe fornecer certa ductilidade. São diversos os tipos de armadura que podem ser utilizados. A maior dificuldade na sua utilização é que elas não devem interferir na eficiência das armaduras principais dos pilares e das lajes. Além disto, deve-se garantir a ancoragem desta armadura de punção. Atualmente, a utilização de conectores tipo pino, ou mesmo de segmentos de perfis metálicos tipo "I", vem obtendo bons resultados, uma vez que esta armadura é provida de chapas de ancoragem nas suas extremidades, que garantem os requisitos mencionados anteriormente. Um outro tipo de reforço digno de ser mencionado, mas que não foi abordado por este trabalho, é a utilização de fibras, que seriam misturadas ao concreto. Apesar de resultados indicarem que a eficiência das fibras não é tão grande quanto à dos estribos, o seu tempo de preparo e de execução é bem menor que o tempo relativo aos estribos.

Neste trabalho foi analisado apenas um tipo de modelo de cálculo - o método da superfície de controle -, que, apesar de ser apenas um método empírico, é a base de diversos códigos e normas. 
No entanto, outros modelos definidos como racionais, em virtude de se basearem nos modelos constitutivos do concreto e do aço, vêm sendo desenvolvidos, como, por exemplo, o de SHEHATA (1985) e o de GOMES (1991). Uma das sugestões para a continuação desta pesquisa seria a comparação de alguns desses métodos com resultados experimentais e de normas.

Serão apresentadas, a seguir, algumas considerações sobre o texto base da NB-1/94 e a comparação de resultados experimentais com os relativos aos códigos analisados neste trabalho.

\section{$9.1 \quad T E X T O$ BASE DA NB-1/94}

O texto base, assim como o CEB/90, não menciona uma situação de cálculo caracterizada por pilares internos submetidos à atuação de momentos fletores atuando em duas direções diferentes.

O texto base define uma constante que é dada em função de uma relação $c_{2} / 2 c_{1}$, enquanto que o $\mathrm{CEB} / 90$ define uma constante análoga, só que dada em função de uma relação $c_{1} / 2 c_{2}$, sendo $c_{1}$ e $c_{2}$ os lados do pilar, perpendicular e paralelo à borda livre, respectivamente. Esta constante é utilizada na obtenção da tensão atuante de cálculo, relativa a um pilar de borda submetido à transferência de um momento fletor paralelo à borda livre. Observa-se que o texto base parece estar mais coerente com os resultados experimentais, uma vez que, quanto maior a dimensão de um pilar na direção da excentricidade do carregamento, maior a parcela do momento fletor a ser transmitida à ligação. Portanto, uma vez que o momento está atuando paralelamente à borda livre, quanto maior a relação $c_{2} / 2 c_{1}$, maior deveria ser o valor da parcela do momento fletor a ser transmitida ao pilar.

Neste trabalho são sugeridas expressões que visam facilitar e agilizar a aplicação do texto base, como, por exemplo, as expressões relativas ao cálculo de $\mathrm{W}_{\mathrm{P}}$ para pilares circulares internos, $\mathrm{W}_{\mathrm{P} 2}$ para pilares de borda e, por fim, e* e $\mathrm{W}_{\mathrm{P} 1}$, tanto para pilares de borda como para pilares de canto. Além disso, foi desenvolvida também uma expressão para calcular o perímetro crítico externo à região armada, referente a um pilar interno, com a disposição da armadura transversal em cruz. 
São feitas as seguintes observações com relação ao perímetro crítico externo à região armada:

- estudos preliminares têm mostrado que, para uma distribuição radial em relação ao centro do pilar (Figura 19.3.9, presente no capítulo 3), a substituição do perímetro composto por segmentos retos, por um perímetro definido através de uma circunferência circunscrita ao perímetro anteriormente mencionado, é adequada para se desenvolverem expressões de forma a se facilitar o cálculo da verificação da ligação, apesar de tal substituição apresentar uma pequena diferença contra a segurança;

- já para uma disposição radial em relação ao canto do pilar (Figuras 4.4, 4.10 e 4.19), sugere-se um novo perímetro crítico análogo ao mostrado na Figura 19.3.1, presente no capítulo 3 , só que posicionado a $2 \mathrm{~d}$ além da região armada.

O fato de que, para pilares de canto e de borda, apenas uma parte do perímetro crítico deva ser computado no cálculo, talvez traga alguns incovenientes na formulação das expressões a serem desenvolvidas.

Para o perímetro crítico externo à região armada e referente a uma disposição em cruz, seria interessante que se desenvolvessem os parâmetros $\mathrm{W}_{\mathrm{P}}$, $\mathrm{W}_{\mathrm{P} 1}, \mathrm{~W}_{\mathrm{P} 2}$ e $\mathrm{e}^{*}$ para as ligações com pilares internos, de borda e de canto.

O texto base ainda não fornece condições para que se verifique a região adjacente ao pilar. Neste caso, sugere-se que se utilizem as recomendações fornecidas pelo $\mathrm{CEB} / 90$.

Observou-se que algumas recomendações do CEB/90 e do EUROCODE N.2 não estão presentes no texto base. Como exemplo, tem-se que na ausência de resultados experimentais expressivos, deve-se evitar o uso de $\mathrm{f}_{\text {ck }}$ superior a $50 \mathrm{MPa}$. Além disso, O CEB/90 e o EUROCODE N.2 recomendam a utilização de uma armadura mostrada na Figura 5.6, a ser posicionada ao longo da borda livre, cuja finalidade é a de combater os esforços de torção. Por fim, o CEB/90 destaca ainda, a necessidade de cuidados referentes ao detalhamento da armadura de punção em lajes com espessura inferior a $25 \mathrm{~cm}$. 
É importante frisar que o texto base da NB-1/94 ainda não está aprovado, mas em fase de apreciação pelo meio técnico. As recomendações oficiais ainda são as dadas pela NBR 6118/82, com relação aos métodos de cálculo a serem adotados e às dimensões mínimas de pilares e de lajes.

Com relação aos exemplos calculados neste trabalho, observa-se que a utilização da armadura de punção elevou substancialmente a resistência da ligação.

Por fim, observa-se que para pilares próximos à borda livre, ainda não se têm recomendações específicas segundo o texto base.

\subsection{COMPARAÇÃO COM VALORES EXPERIMENTAIS}

Com relação à comparação entre os códigos e alguns resultados experimentais, dados no capítulo 8, deve-se frisar que as conclusões ora apresentadas devem ser encaradas apenas como indicações do comportamento dos códigos entre si, frente a algumas características analisadas nos ensaios.

O texto base, de um modo geral, foi o método mais adequado para as ligações aqui analisadas, fornecendo resultados relativamente seguros.

O CEB/90, para ligações com pilares de canto e de borda sem armadura de punção, com relação entre os lados (maior/menor) inferior a dois e submetidas a um momento fletor perpendicular à borda livre, forneceu valores acima dos observados experimentalmente, estando, desta forma, contra a segurança. Para pilares alongados, o resultado fornecido por este código se aproximou dos valores observados experimentalmente. Com relação a ligações com pilares internos, que possuam armadura de punção e sem a atuação de momentos fletores, tanto o CEB/90 como o texto base apresentaram excelentes resultados quando comparados com os valores experimentais, prevendo, com exatidão, a forma com que a ruína se daria, externa ou interna à região armada. 
O ACI 318/89 foi, no geral, o método mais cauteloso, à exceção de ligações de borda e de canto, sem armadura de punção e sem transferência de momento fletor para a ligação; para o caso de pilares de canto, seus valores chegaram a ultrapassar não só os valores fornecidos pelos outros códigos, mas também o valor observado experimentalmente.

Por fim, o EUROCODE N.2, apesar de ser um método relativamente simplificado, em algumas situações, apresentou resultados bem próximos aos do texto base, sendo, na maioria das vezes, ligeiramente inferior a ele. Para o caso de pilares de borda, submetidos a um momento fletor perpendicular à borda livre, sem armadura de punção e com relação entre lados (maior/menor) superior a dois, seus valores diminuíram significativamente em relação aos do texto base, em virtude de suas recomendações específicas para pilares alongados. Já para pilares internos, submetidos a carregamentos concêntricos e com baixas taxas de armadura de punção, seu comportamento tendeu a acompanhar os valores de ruína. No entanto, observa-se que a forma prevista pelo método, para lajes armadas em cruz, não coincidiu com a observada experimentalmente. Já para taxas de armadura maiores, em virtude da limitação do acréscimo de resistência proporcionado pela presença da armadura de punção, seus valores se distanciaram dos observados experimentalmente.

Resumindo, conclui-se que os resultados fornecidos pelo texto base, frente às características definidas nos ensaios analisados, podem ser considerados satisfatórios. Em alguns casos, como por exemplo, no ensaio de pilares de borda com relação entre lados (lado maior / lado menor) inferior a dois, os resultados fornecidos pelo texto base foram melhores que os fornecidos pelo CEB/90. Já para pilares internos, submetidos a carregamentos concêntricos, tanto com como sem armadura de punção, os resultados fornecidos pelo texto base foram semelhantes aos fornecidos pelo CEB/90.

Por fim, sugere-se ainda como prosseguimento desta pesquisa, a análise de ligações laje-pilar que possuam capitéis ou "drop panels". 


\section{BIBLIOGRAFIA}

ACI COMMITEE 318 (1989) Building code requirements for reinforced concrete (ACI 318-89) and Commentary ACI 318R-89. Detroit, American Concrete Institute.

ANDRADE, M.A.S.; GOMES, R.B. (1994a) Uma comparação dos métodos de cálculo para puncionamento em lajes cogumelo de concreto armado. In: REIBRAC, 36., Porto Alegre. Anais. v.2, p.605-618.

ANDRADE, M.A.S.; GOMES, R.B. (1994b) Furos na punção. Revista IBRACON, n.10, p.26-29.

ASSOCIAÇÃO BRASILEIRA DE NORMAS TÉCNICAS (1982) NBR 6118 Projeto e execução de obras de concreto armado. Rio de Janeiro. 76p.

ASSOCIAÇÃO BRASILEIRA DE NORMAS TÉCNICAS (1994) NB-1/94 Texto base para revisão.

BARR, B.; NOOR, M.R.M. (1985) The toughness index of steel fiber reinforced concrete. ACI Journal, v.82, n.5, p.622-629.

BASTOS, R.G. (1977) Ruína de lajes de concreto armado com efeito de membrana e redução gradativa da armadura. São Carlos. Dissertação (mestrado) - Escola de Engenharia de São Carlos, Universidade de São Paulo.

BEER, F.P.; JOHNSTON Jr., E.R. (1980) Mecânica vetorial para engenheiros. 3.ed. São Paulo, McGraw-Hill. v.1.

BRAESTRUP, M.W.; REGAN, P.E. (1985) Punching shear in reinforced concrete: a state of the art report. CEB Bulletin d'information, n.168.

BRANCO, A.F.V.C. (1989) Contribuição para o projeto de lajes-cogumelo. São Carlos. Dissertação (mestrado) - Escola de Engenharia de São Carlos, Universidade de São Paulo.

BRANCO, A.F.V.C.; PINHEIRO, L.M. (1991) Lajes-cogumelo: considerações gerais e subsídios para pré-dimensionamento. In: JORNADAS SULAMERICANAS DE ENGENHARIA ESTRUTURAL, 25., Porto Alegre. Anais. v.2, p.109-120.

BREBBIA, C.A. (1985) The boundary element method in engineering practice. In: BREBBIA, C.A., ed. Boundary element research. Southampton, CML. 
BROCHIE, J.F. (1980) Some australian research on flat plate structures. ACI Journal, v.77, n.1, p.3-11.

CALDERARO, R.C.B. (1983) Análise tridimensional de punção em lajes lisas de concreto armado. Rio de Janeiro. Dissertação (mestrado) - Pontifícia Universidade Católica.

CEB-FIP (1978) Systemé international de réglementation technique unifiée des structures code modele CEB-FIP pour les structures en béton, v.2. CEB Bulletin d'information, n.124/125-F.

CEB-FIP Model Code 1990, Final draft. CEB Bulletin d'information, n.204.

CORLEY, W.G.; HAWKINS, N.M. (1968) Shearhead reinforcement for slabs. ACI Journal, v.65, n.10, p.811-824.

DILGER, W.H.; $\quad$ GHALI, A.; LANGOHR, P.H. (1976) Special shear reinforcement for concrete flat plates. ACI Journal, v.73, n.3, p.141-146.

DILGER, W.H.; ELMASRI, M.Z.; GHALI, A. (1978) Flat plates with special shear reinforcement subjected to static dynamic moment transfer. ACI Journal, v.75, n.10, p.543-549.

EL DEBS, M.K. (1992) Estruturas pré-moldadas de concreto. São Carlos, EESCUSP. (notas de aula)

ELSTNER, R.C.; HOGNESTAD, E. (1956) Shearing strength of reinforced concrete slabs. ACI Journal, v.28, n.1, p.29-57.

ENCOL (1994) Critérios e parâmetros de projetos estruturais de edificações. (apostila)

ENCOL (1994) Diretrizes para projetos em lajes planas nervuradas. (apostila)

EUROCODE $\mathrm{N}^{\mathrm{O}}$ 2. (1992) Design of concrete structures, Revised final draft. Eurocode 2 Editorial Group. (versão em espanhol)

FIGUEIREDO F $\mathrm{F}^{\mathrm{O}}$, J.R. (1981) Estudo experimental da ruína de ligações laje-pilar em casos característicos de cantos de lajes-cogumelo. São Carlos. Dissertação (mestrado) - Escola de Engenharia de São Carlos, Universidade de São Paulo.

FIGUEIREDO F ${ }^{0}$, J.R. (1989) Sistemas estruturais de lajes sem vigas: subsídios para o projeto e execução. São Carlos. Tese (doutorado) - Escola de Engenharia de São Carlos, Universidade de São Paulo. 
FIGUEIREDO F , J.R. (1991) Métodos de verificação à punção nas lajes sem vigas: comparações com resultados experimentais. In: JORNADAS SULAMERICANAS DE ENGENHARIA ESTRUTURAL, 25., Porto Alegre. Anais. v.2, p.61-72.

FIGUEIREDO Fo , J.R.; ASSUMPÇÃO, J.F.P. (1991) Comparação de custos entre estruturas convencionais e em lajes sem vigas de edificios de concreto armado. In: JORNADAS SUL-AMERICANAS DE ENGENHARIA ESTRUTURAL, 25., Porto Alegre. Anais. v.2, p.73-84.

FIGUEIREDO F ${ }^{\mathrm{O}}$, J.R.; EL DEBS, M.K. (1990) Deslocamentos transversais nos sistemas estruturais de lajes sem vigas de concreto armado. In: SIMPÓSIO EPUSP SOBRE ESTRUTURAS DE CONCRETO, 2., São Paulo. Anais. v.2, p.515-534.

FLING, R.S. (1989) Designing for economy. Concrete Construction, p.97-101.

FUSCO, P.B. (1985) Investigação experimental sobre o cisalhamento em lajes de concreto armado. Boletim Técnico BT/PEF 8505, EPUSP.

GHALI, A.; ELMASRI, M.Z.; DILGER, W.H. (1976) Punching of flat plates under static and dynamic horizontal forces. ACI Journal, v.73, n.10, p.566-572.

GOMES, R.B. (1991) Punching resistance of reinforced concrete flat slabs with shear reinforcement. London. $\mathrm{PhD}$ Thesis, The Polytechnic of Central London.

GOMES, R.B. (1994) Resistência à punção de lajes cogumelo de concreto armado com furos e armadura de cisalhamento. Furnas Centrais Elétricas S.A., Relatório DCT.T.1.141.93-R0.

GOMES, R.B. et al. (1993a) Um método de cálculo da armadura de cisalhamento usada no combate à punção em lajes cogumelo de concreto armado. In: JORNADAS SUDAMERICANAS DE INGENIERIA ESTRUCTURAL, 26., Montevidéo. Anais. v.2, p.153-164.

GOMES, R.B. et al. (1993b) Utilização de perfis I de vigas metálicas como armadura de cisalhamento no combate à punção de lajes cogumelo de concreto armado. In: JORNADAS SUDAMERICANAS DE INGENIERIA ESTRUCTURAL, 26., Montevidéo. Anais. v.2, p.165-176.

GOMES, R.B. et al. (1994) Punção em lajes cogumelo de concreto armado com furos. In: REIBRAC, 36., Porto Alegre. Anais. v.2, p. 883-896.

GONÇALVES, R.M. (1986) Estudo experimental da ruína de ligações laje-pilar em bordas de lajes-cogumelo com reforço transversal constituído de perfis metálicos. São Carlos. Dissertação (mestrado) - Escola de Engenharia de São Carlos, Universidade de São Paulo. 
GUIMARÃES, R.L.; MELO, G.S. (1994) Cálculo de armadura contra colapso progressivo em lajes cogumelo. In: REIBRAC, 36., Porto Alegre. Anais. v.2, p.673-683.

HALL, A.S.; RANGAN, B.V. (1983) Moments in edge panels of flat plate floors. Journal of Structural Engineering, ASCE, v.109, n.11, p.2638-2650.

HANAI, J.B. et al. (1985) Estudo comparativo de sistemas estruturais para construção de unidades básicas de saúde do programa metropolitano de saúde de São Paulo. São Carlos, UFSCar. (Relatório Técnico - UFSCAR).

HOGNESTAD, E. (1953) Shearing strength of reinforced column footings. ACI Journal, v.50, n.3, p.189-208.

JIRSA, J.O.; SOZEN, M.A.; SIESS, C.P. (1966) Test of a flat slab reinforced with welded wire fabric. Journal of Structural Division, ASCE, v.92, n.3, p.199224.

LAIER, J.E.; BARREIRO, J.C. (1982) Complementos de resistência dos materiais. São Carlos, EESC.

LEONHARDT, F.; MÖNIG, E. (1978) Construções de concreto: casos especiais de dimensionamento de estruturas de concreto armado. Rio de Janeiro, Interciência. v.2.

LIBÓRIO, J.B.L. (1985) Estudo experimental da ruína de ligações laje-pilar em bordas com pilares de seção retangular. São Carlos. Dissertação (mestrado) Escola de Engenharia de São Carlos, Universidade de São Paulo.

LONG, A. E. (1975) A two-phase approach to the prediction of the punching strength of slabs. ACI Journal, v.72, n.2, p.37-45.

MARTINELLI, D.A. (1974) Sobre a ruína das ligações laje-pilar nos cantos de lajes-cogumelo. São Carlos, EESC.

MARTINELLI, D.A. et al. (1983) Resultados experimentais sobre a ruína das ligações laje-pilar em cantos e bordas de lajes-cogumelo. São Carlos, EESC.

MAST, P.E. (1970) Stresses in flat plates near columns. ACI Journal, v.67, n.10, p.761-768.

MELO, G.S. (1994) Proposição de ítem de norma com referência ao cálculo de armadura contra colapso progressivo em lajes cogumelo. In: REIBRAC, 36. Porto Alegre. Anais. v.2, p.725-734.

MELO, G.S.S.A.; REGAN, P.E. (1991a) Estudo experimental da resistência póspuncionamento das ligações laje-pilar em lajes lisas (parte I - lajes). In: 
JORNADAS SUL-AMERICANAS DE ENGENHARIA ESTRUTURAL, 25. Porto Alegre. Anais. v.3, p.319-330.

MELO, G.S.S.A.; REGAN, P.E. (1991b) Estudo experimental da resistência póspuncionamento das ligações laje-pilar em lajes lisas (parte II - ensaios complementares). In: JORNADAS SUL-AMERICANAS DE ENGENHARIA ESTRUTURAL, 25., Porto Alegre. Anais. v.3, p.331-342.

MELO, G.S.S.A.; REGAN, P.E. (1993) Uma proposição para a determinação da resistência pós-puncionamento de ligações laje-pilar lisas. In: JORNADAS SUDAMERICANAS DE INGENIERIA ESTRUCTURAL, 26., Montevidéo. Anais. v.3, p.255-265.

MITCHELL, D.; COOK, W.D. (1984) Preventing progressive colapse of slab structures. Journal of Structural Engineering, v.110, n.7, p.1513-1532.

MOE, J. (1961) Shearing strength of reinforced concrete slabs and footings under concentrated loads. Bulletin D47. Portland Cement Association.

MODOTTE, W.P. (1986) Estudo experimental da ruína de ligações laje-pilar em bordas de lajes-cogumelo com carregamento assimétrico. São Carlos. Dissertação (mestrado) - Escola de Engenharia de São Carlos, Universidade de São Paulo.

MONTANARI, I. (1979) Concreto protendido. São Carlos, EESC.

MOKHTAR, A.S.; GHALI, A.; DILGER, W. (1985) Stud shear reinforcement for flat concrete plates. ACI Journal, v.82, n.5, p.676-683.

NEVILLE, G.B. (1983) Simplified design: reinforced concrete buildings of moderate size and height. Skokie, Portland Cement Association.

NYLANDER, H. (1964) Punching of reinforced concrete slabs. CEB Bulletin d'information, n.44, p.159-183.

PARK, R.; ISLAM, S. (1976) Strength of slab-column connections with shear and unbalanced flexure. Journal of the Structural Division, ASCE, 102, ST9, p.18791901 apud LIBÓRIO, J. B. L. (1985)

PINHEIRO, L.M. (1993) Concreto armado: tabelas e ábacos. São Carlos, EESCUSP.

PINTO, R.C.A. (1993) Punção assimétrica de lajes. Rio de Janeiro. Dissertação (mestrado) - COPPE/UFRJ.

REGAN, P.E. (1984) The dependence of punching resistance upon the geometry of the failure surface. Magazine of Concrete Research, v.36, n.126, p.3-8. 
REGAN, P.E. (1985) Shear combs, reinforcement against punching. The Structural Engineer, v.63B, n.4, p.76-84.

RICHART, F. E. (1948) Reinforced concrete wall and column footings. ACI Journal, v.45, n.2, p.97-127; n.3, p.237-260.

RODRIGUES, P.F.N.; SORIANO, H.L. (1991) Larguras efetivas de lajes sem vigamentos em prédios lateralmente carregados. In: JORNADAS SULAMERICANAS DE ENGENHARIA ESTRUTURAL, 25., Porto Alegre. Anais. v.2, p.97-108.

SEIBLE, F.; GHALI, A.; DILGER, W.H. (1980) Preassembled shear reinforcing units for flat plates. ACI Journal, v.77, n.1, p.28-35.

SHEHATA, I.A.E.M. (1985) Theory of punching in concrete slabs. PhD Thesis, The Polytechnic of Central London.

SHEHATA, I.A.E.M. (1990) Simplified model for estimating the punching resistance of reinforced concrete slabs. Materials and Structures, n.23, p.364 371.

SHEHATA, I.A.E.M. (1991) Shear in slabs. In: COLLOQUIUM ON THE CEBFIP MODEL CODE 90, Rio de Janeiro. Anais. p.159-170.

SHEHATA, I.A.E.M.; REGAN, P.E. (1990) Punching in r. c. slabs. Journal of Structural Engineering. v.115, n.7, p.1726 - 1740.

SOUZA, V.C.M.; CUNHA, A.J.P. (1994) Lajes em concreto armado $e$ protendido. Niterói, Eduff.

STAMENKOVIK, A.; CHAPMAN, J.C. (1974) Local strength at column heads in flat slabs subjected to a combined vertical and horizontal loading. Proceedings of The Institution of Civil Engineers, v.57, n.2.

STUCCHI, F.R.; KNAPP, L.M. (1993) Punção em lajes. In: SIMPÓSIO EPUSP SOBRE ESTRUTURAS DE CONCRETO, 3., São Paulo. Anais. p.209-232.

SWAMY, R.N.; ALI, S.A.R. (1982) Punching shear behavior of reinforced slabcolumn connections made with steel fiber concrete. ACI Journal, v.79, n.4, p.392-406.

TAKEYA, T. (1981) Estudo experimental da ruína de ligações laje-pilar em bordas de lajes-cogumelo. São Carlos. Dissertação (mestrado) - Escola de Engenharia de São Carlos, Universidade de São Paulo.

TAKEYA, T. et al. (1985) Recomendações para o projeto e a execução da estrutura em lajes cogumelo pertencentes às UBS do plano metropolitano de saúde. São Carlos, EESC. (Relatório Técnico SET-EESC-USP). 
UNIVERSIDADE DE SÃO PAULO. Escola de Engenharia de São Carlos. Serviço de Biblioteca (1993). Diretrizes para elaboração de dissertações e teses na EESC-USP. São Carlos. 56p.

VAN DER VOET, A.F.; DILGER, W.H.; GHALI, A. (1982) Concrete flat plates with well-anchored shear reinforcement elements. Canadian Journal of Civil Engineering, v.9, n.1, p.107-114.

YITZHAKI, D. (1966) Punching strength of reinforced concrete slabs. ACI Journal, v.63, n.5, p.527-540. 